
$\times$ 


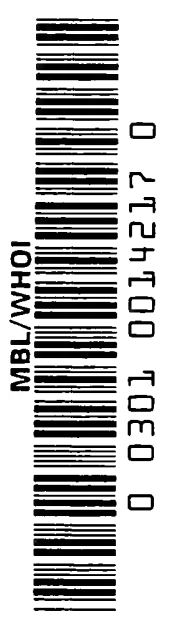





\section{PLANT ANATOMY}

STEVENS 



\section{PLANT ANATOMY}

FROM THE

STANDPOINT OF THE INEVEL.OPMENT

- AND FUNCTIONS OF THE TISSUES

AND

HANDBOOK OF MICRO-TECHNIC

$B Y^{\prime}$

WILLIAM CHASE STEVENS

PROFESSOR OF BOTANY IN THE UNIVERSITY OF KANSAS

SECOND EDITION, REVISED AND ENLARGED

WITH 152 ILLUSTRATIONS

PHILADELPHIA

P. BLAKISTON'S SON \& CO.

2012 WALNUT STREET

1911 
Copyright, i()to, By P. Blakiston's Son \& Co.

2488

printed by

The laple Press

lirk. $P_{i z}$. 


\section{PREFACE TO THE SECOND EDITION}

In getting ready the second edition it became erident that a chapter on reproduction should be added. Because of its promise in helping to solve the problem of evolution and its great importance for plant and animal breeding the subject of reproduction and heredity has come to the forefront of biological research; and especially under the great light that has shone from Mendel's laws has eager investigation been directed toward the details of cell beharior in reproduction.

It cannot yet be said that these investigations have arrived at undisputed achievement, but their results, however tentative, are so suggestive of important possibilities as to justify their survey in a text-book for students in colleges and agricultural schools.

Necessarily that part of the chapter on reproduction dealing with an interpretation of observed nuclear behavior that has frequently been suggested in current literature is a fit subject for critical examination and debate, and as such it will serve its purpose of marking a present-day view arising from a contemplation of observed facts of structure and behavior.

The theory of pangenes and unit characters may or may not stand as our knowledge advances, but it is serving the purpose in biology to-day that the atomic theory has so long and honorably fulfilled in chemistry.

Of great aid to me in the preparation of Chapter XIII have been Coulter and Chamberlain's Morphology of Angiosperms, Mottier's Fecundation in Plants, Mendel's Principles of Heredity, by II. Bateson, Strasburger's Die Stofflichen Grundlagen der Vererbung, Lotsy's Vorlesungen über Deszendenztheorien, de Vries's Die Mutationstheorie, Species and Varieties, and 
Plant Breeding, Bailey's Plant Breeding, and the Proceedings of the American Breeders' Association.

It is a pleasure to me to express my thanks here to Dr. McClung and Dr. Billings for suggested improvements in Chapter XIII, to Mr. Peace for improved processes in microtechnic, and to Miss Eugenie Sterling for the drawings in Chapter XIII.

W. C. Stevens.

UNIVERSITY OF KaNSAS.

October, IOIO. 


\section{PREFACE TO THE FIRST EDITION}

To one interested in biology the study of plant anatomy affords a rich and alluring field, since it reveals how plants, under conditions the most exacting, have met and solved the problems of their existence by achieving the power and habit of cell differentiation and cell association into tissues adapted to carry on the different physiological functions; and when the study of plant anatomy is directed to reveal the process of cell differentiation and the steps by which the mature tissues are made fit for their functions, the student cannot fail to see at once its high biological significance.

The ontogeny and physiology of the tissues is in fact so illuminating to their mature form and structure that the student of anatomy works to a distinct disadrantage if he is not constantly reverting for enlightenment to questions of origin and function; and whaterer motire may incite him to the study of plant anatomy, whether it be purely intellectual curiosity, or the recognition of the necessity of a knowledge of plant anatomy to the scientific pursuit of pharmacognosy or agriculture, he will find the outcome more worthy of his efforts if he has sought out the physiological and ecological interpretation of his anatomical findings. It is not nature's way to erolve cells and tissues at random, with no problems to be solved by their evolution. The tissues are not an aimless expression of the power of variability. Rather they represent the means of the triumph of living organisms over the conditions and forces which make up their environment.

This book attempts to point out in a brief and elementary way how plants arrive at this achievement by the evolution of the different physiological tissue systems from a primitive, undifferentiated embryonic tissue, and how the tissue systems 
are adapted by their character and relation to each other to carry out the plant's regetative functions. It seeks to answer in some measure fuestions about what kind of organisms plants are; how they wrest their living from the inorganic world; and how they are equipped to make satisfactory terms with their environment.

At the close of each chapter are given directions for obserrations that will afford a good foundation for critical discussion. In carrying out the work as there outlined the student will become familiar with the most important practices in microtechnic, and he will at the same time get training in independent work that will prove a significant part in his education. Chapters dealing in sufficient detail with microtechnic and microchemistry are given to help the student to pursue the subject beyond the limits of this book, and to undertake practical work in pharmacognosy and pure food and drug investigations.

In the illustrations much use has been made throughout the book of generalized diagrams. I have found these very helpful in my teaching, and I offer them here in the hope that they may prove suggestive to sudents in correlating and interpreting the details of the isolated sections with which the histologist has to deal, and of service in throwing light on the operation of the physiological functions.

I must make acknowledgment of especial indebtedness for substance and point of view to Strasburger's Botanisches Practicum, and Leitungsbahnen. Haberlandt's Physiologische Pflanzenanatomie, Pfeffer's Physiology of Plants, Zimmermann's Microtechnic. Czapek's Biochemie der Pflanzen, Meyer's Grundlagen und Methoden für die Mikroscopische Untersuchung von Pflanzenpulvern, Chamberlain's Methods in Plant Histology. and Winton's Microscopy of Tegetable Foods. The Bausch and Lomb Optical Company have kindly supplied the cuts for Figs. 1 27, 133,1,35 and 136; and the Spencer Lens Company the cul for Fig. I 3 I.

I am indebted to Miss Eugenie Sterling for preparing the drawings for most of the illustrations, and to Mrs. Marguerite 
Wise Sutton for some of the drawings. Mr. Alban Stewart prepared the camera lucida drawings of tissues of Aricennia, Psidium and Mangrove, from materials collected by him in the Galapogos Islands. Mr. L. M. Peace made the photomicrographs appearing here, prepared many of the sections from which the drawings were made, and gave me many valuable suggestions for the chapters on microtechnic.

My thanks are due my colleagues, Dr. M. A. Barber, Dr. C. E. McClung, Dr. F. H. Billings, and Prof. Chas. M. Sterling for reading and critizing different parts of the book, and to Ada Pugh Stevens for reading all of the proof sheets.

II. C. Stevens.

CNIVERSTY UF KANSAS. 



\section{CONTENTS}

\section{CHAPTER I}

The Plant C'ell

PAGE

The Protoplast.-Plasma Membrane or Ectoplasm.-Cieneral Cytoplasm.-The Nucleus.-The Plastids.-Cell-division.-Cell Differentiation.- - Sizes of Cells.-The Cellwall.-The Chemical and Physical Nature and Physiological Powers of the I'rotoplast.-1llustrative Stuclies.

\section{CH.AP'TER II}

\section{Differentiation of the Tissues}

General Survey.-The Primordial Meristem.-The Protoderm.--The Procambium.- The Ground Meristem.The Primary Permanent Tissues.-Illustrative Studies.

\section{CHAPTER III}

\section{SECONIARY INCREASE IN THICKNESS}

Dicotyledons and Gymnosperms.-Growth of the Vascular Bundles.- Increase in the Cortex.-Monocotyledons.Unusual Growth in Thickness. - Illustrative Studies . . +6-60

\section{CHAPTER IV}

Protection from Injurifs and Loss of Water

The Epidermis. - The Epidermis as a Protective Tissue.The Epidermis as a Waterproof Covering.-The Radial 
and Inner Walls of the Epidermis.-The Cell Contents of the Ep,idermis.-Outgrowths and Excretions of the Epidermis.-The Multiple Epidermis.-The Cork.Cork as a Protective Tissue.-Cork as a Waterproof Covering.-Use of Cork in Healing Wounds.--Other Means of Protection.-Illustrative Studies

\section{('HAPTER V}

\section{'The Plant Sigeleton}

The Making of the Skeleton.--The Tissues of the Skeleton.The Collenchyma.-The Bast Fibers.-The Wood Fibers.-The Stone Cells.-Topography of the Skeleton. - Illustrative Studies

\section{CHAP'TER II}

\section{The Absorption of Water and Minerals}

Roots in the Soil.- The Root Hairs.-Method of Intake of Water and Solutes.-Effect of Temperature of Soil, and Character and Amount of Solutes upon Absorption.Absorption of Water and Solutes by Aerophytes. Illustrative Studies:

\section{CHAP'TER VII}

\section{Traxpport of Water and Soll Solutes}

The Need of a Transporting System.--Tissues Devoted to the Transport of Water.-The Tracheal Tulses.course of Tracheal Tulses through the Stem.-The Tracheids.-Relation of the Tracheal Tissues to the Medullary Rays and Wood Parenchyma.-The Ring of Annual Growth.-Relation of Rings of Growth to Growth in Length.- Relation of Annual Rings to the Leaves.-Distribution of Water and Solutes throughout the Leaf.-The Power Concerned in the Ascent of 
Water.-Path of Water Ascent.-Influence of Environment on the Water Conducting Tissues.-Illustrative Studies

\section{CHAPTER V'III}

Intake and Distribution of Gases

Oxygen and Carbon Dioxide Necessary to Plants.-The Stomata.-The Relation of Stomata to the Environment.-The Lenticels.-The Intercellular Spaces.Diosmosis of Gases into and from Living Cells.-Motive Power in the Distribution of Cases throughout Plants.Illustrative Studies . . . . . . . . . . I $23-137$

\section{CHAP'TER IX}

\section{Construction of the J'Lant's Food}

The Source and Lses of Food.-Food Building Apparatus.The Chloroplasts.-The Sun's Energy.-The Palisade Cell the Chief Photosynthetic Unit.-Relation of Leaf as a Whole to Photosynthesis.-Conditions Affecting Photosynthesis.-Photosynthesis in the Lower Plants.Sinthesis of Food without Light.-Illustrative Studies . $138-156$

\section{CHAPTER I}

Transport of Foons throvghout the Plants

Need of Circulatory Tissues.-Eridence that the Phloem Carries the Food.-Evidence that the Tracheal Tissues Assist the Phloem in the Upward Transmission of Food. - Relation of Phloem Elements to Other Tissues.The Course of Food Distribution.-Annual Additions to the Food-conducting Tissues.-Relation of One Year's I'hloem Elements to those of the Next.Character of Food while in Transport.-The Propelling Power in Food Transport.-Illustrative Studies. I57-1 74 


\section{CHAPTER XI}

\section{STORAGE OF FOOD AND IVATER}

Need of Food Storage. - The Kinds of Stored Food.-The

Process of Storage.-Location and Extent of Food Storage Tissues.-Fluctuations in the Solubility and Insolubility of Stored Food.-Digestion of Stored Food. -Assimilation of Food.-Relation of Stored Food to Energy Supply.-The Storage of Water-Characteristics of Water Storage Tissues.-Illustrative Studies. . I75-ig8

\section{CHAPTER XII}

\section{SECRETION AND EXCRETION}

Nature of Secretions and Excretions.-Secreting Cells and Glands in General.-Laticiferous Vessels or Milk Tubes. - Tamin Cells.-Special Enzyme-secreting Cells.Secretion and Excretion of Minerals. - The Process of Secretion.-The Exretion of Liquiul IVater.-Illustrative Studies

\section{CHAPTER XIII}

\section{REPRODUCTION}

Development of Fern Sporangium.-Division of spore Grandmother Cells.-Germination of the Spores.Fertilization of the E.gr. - Interpretation of the Processes of Nuclear Division.-Two Generations in the Lifecycle.-Spore Formation in Spermatophytes.-Formation of the Microspores.-Details of Nuclear Division.Formation of the Negaspores.-Details in Division of Megaspore Grandmother Cell-Ciermination of the Megaspore.-Fertilization and Germination of the Egg. -The Triple-fusion Nucleus.-Behavior of Pedigree Hylrids.--Interpretation of Mendel's Results.-Paternal and Maternal Chromosomes. - Bearers of Hereditary 
Characters.- Theory of Pangeneic Interchange.-

Necessity of Pedigree Cultures.-Mosaic Character of Offspring of Hybrids.-Mendel's Laws.-Practical Applications.-Exceptions to the Rules.-Significance of Sexuality.-Illustrative Studies . . . . . . . 213-250

\section{CHAP'TER XIY}

The Preparation of Sections

Cutting Sections Free-hand.-Cutting Sections with a Microtome.-Care of the Section Knife.-Cytological Methods -The Fixing Process.-The Hardening Process.The Process of Imbedding in Paraffin.-Sectioning Material Imbedded in Paraffin.-Mounting Paraffin Sections.-Staining the Sections.-Imbedding in Celloidin.-Staining Celloidin Sections.-Making Permanent Mounts in Glycerine or Glycerine Jelly . . . . $251-270$

\section{CHAPTER NY \\ The Use of The Microscope}

Adjusting the Microscope.-Drawing to Scale from the Microscope.-Use of the Polariscope.-The Use of Reagents on Microscopic Preparations $271-287$

\section{CHAPTER XVI}

Reagents and Processes $285-329$

\section{CHAP'TER XVII}

Microchemistry of Plant Products. $3,30-367$

\section{CHAPTER XVIII}

Detection of Adulterations in Foods anil Drugs . . 368-374 



\section{PLANT ANATOMY}

\section{CHAPTER I}

THE PLANT CELL

The plant body is composed of structural units termed cells. These are minute boxes often barely visible and usually entirely indistinguishable to the naked eye. The walls of the boxes are composed of cellulose, wood, or cork, or a substance allied to cork called cutin. As a rule, the walls are without apparent perforations. The term cell has also come to include the living body which is always present in young cells and very frequently in old ones.

The discovery that the plant body is composed of the cell units was made by Robert Hooke, who, about r66o, with a compound microscope improved by himself, saw the cellular structure of cork. The cells of cork have the appearance of the cells of honeycomb, and this similarity led to his use of the word "cell" for the structural units of the cork, and ultimately to the extension of the usage to plants in general. The term is not an unfortunate one for cells considered merely as boxes; but its application to the living parts inclosed within the cell-walls, or to the living part where no wall is present is inapt. The term protoplast (Gr. protos, first, and plastos, formed, the thing first formed) is now in general use to designate the living part of the cell as a morphological unit; and the term protoplasm or plasma is applied to the substance composing the protoplast, just as a brick would be a morphological unit of a brick house, and burnt clay the substance composing it. Following the general usage the word cell will here be applied to the box and its living content 
taken collectively, or to the box alone when the living parts have disappeared, and the word protoplast will be used to designate the living part alone.

The box or cell-wall is manufactured by the protoplast for its own stability and protection, and the protoplast must, therefore, exist before the wall which encloses it. Since the protoplast is the living structural and physiological unit of the plant body, and since everything that the plant performs is really the work of its individual protoplasts, it necessarily follows that a satisfactory comprehension of plant anatomy and physiology is impossible without a knowledge of the nature of the protoplast itself.

The Protoplast.-If we study under high magnification sections of an onion root tip that has been fixed, imbedded, sectioned, and put up in permanent, stained mounts as directed in the chapter on The Preparation of Sections, we shall find near the root apex young cells that have not yet secreted their entire cell-walls, and we shall often find some degree of plasmolysis or shrinkage of the protoplasts away from their cell-walls so that their contour can precisely be made out. Fig. I, A, shows us such a protoplast. In the root all of the parts here shown were living, excepting possibly the nucleolus $b$. The cytoplasm $c$ constitutes the bulk of the protoplast; the nucleus $a$ is imbedded in the cytoplasm; the plasma membrane $d$ is a specialized outer portion of the cytoplasm; the plastids $e$ are relatively very minute parts of the protoplast, but have a special work to do, as will be learned later on. In older cells farther back from the root tip we find that the protoplasts have secreted a wall, as shown in Fig. I, $B$.

Comparing $A$ and $B$ of Fig. I, we see that in the younger protoplast the cytoplasm looks something like a sponge with very fine meshes, while in the older protoplast the cytoplasm does not so completely fill out the space inclosed by the plasmatic membrane, some of the meshes having widened into relatively large rifts. It seems that as the protoplast grows older the cytoplasm does not keep pace with the general increase in 
size and its network in consequence becomes broken in places, allowing the small meshes to coalesce into larger ones known as vacuoles. Both the meshes and the vacuoles are filled with cell-sap. 'The cell-sap is largely water containing in solution salts that have come up from the soil, and food substances together with various other compounds manufactured within the plant.

After this general view of the several parts of the protoplast we are ready to examine into the character and uses of each more thoroughly. In doing this let us not lose sight of the fact that the protoplasts taken collectively constitute the living body of the plant and whatever the plant does as a living organism is accomplished by them. 'They put to use various forces of the external world; they compound the plant's food and a multitude of other products, which are of various uses to plants themselves as well as to man; they make the cell-wall framework of the plant; they multiply and increase in size so that the plant as a whole is made to grow; they differentiate the various tissues, each suited to perform a particular service; they are sentient to gravity and light, moisture and temperature, and to the general state of the whole organism of which each protoplast forms a part, and they are capable of responding to these things in a definite and useful way. With this knowledge we might anticipate, and it is not surprising to find that each protoplast is a complex thing with visibly distinct parts, and that each part has its own physiological significance. We shall now take up the parts of the protoplast in the following order: plasma membrane, general cytoplasm, nucleus, plastids.

Plasma Membrane or Ectoplasm.-At the exterior of every protoplast is a very thin, hyaline membrane, which, as has been said, is morphologically a part of the cytoplasm, for when, a protoplast is torn or cut in two a membrane is produced from the cytoplasm over the wounded surface. This membrane is known as the plasma membrane or ectoplasm (Fig. I, $A, d$ ). It is approximately $.0003 \mathrm{~mm}$. thick, or about $\frac{1}{ \pm 0}$ of the thickness of this page. After the cell-wall has been formed it is very difficult to distinguish the plasma membrane because of its extreme thin- 
ness and close contact with the wall; but the greater part of this difficulty ranishes when the protoplast is made to shrink away from the wall. This we can do to advantage with the epidermal

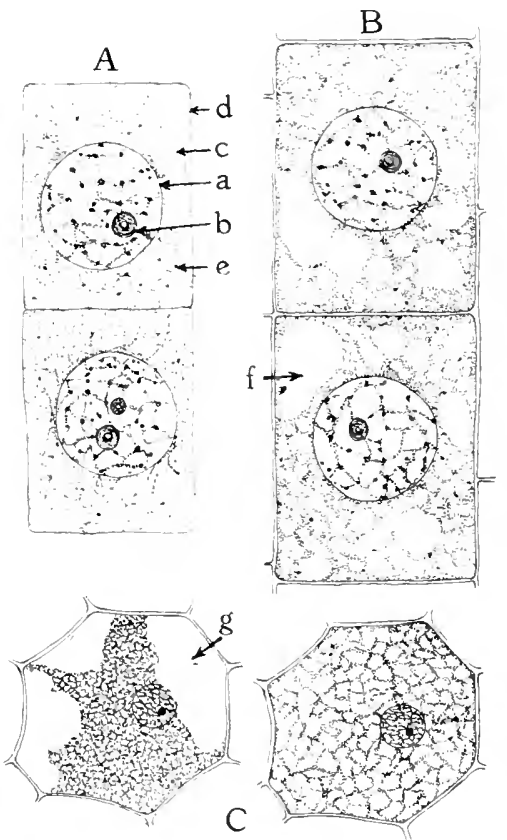

FIG. I.-A, embryonic cells from onion root tip; $d$, plasmatic membrane; $c$, cytoplasm; $a$, nuclear membrane enclosing the thread-like nuclear reticulun; $b$, nucleolus; $e$, plasticls (black lots scattered about). $B$, older cells farther back from the root tip. The cytoplasm is becuming racuolate; $f$. vacuole. $C$, a cell from the epidermis of the condition on the right, and flasmolyzed by a salt solution on the left; $g$, siace left by the recedence of the cytoplasm from the wall; the plasma membrane can now be seen as a lelicate membrane bounling the shruntien protoplast. All highly magnified midrib of Tradescantia zebrina, in its natural

cells of 'Tradescantia zebrina containing a colored cell-sap. ITe strip a bit of epidermis from the under side of a midrib of a leaf and mount it under a coverglass in a drop of water. Tre bring some of the colored cells under the objective and run a 5 per cent. $\mathrm{NaCl}$ solution under the coverglass. The salt solution draws water out of the cells by osmosis and the protoplast soon shrinks away from the walls because it is elastic and had been stretched by the water within the cell. We can now make out the thin plasma membrane at the surface of the shrunken protoplast (Figr. I, C). If we replace the salt solution under the coverglass with fresh water the protoplast quickly swells up and presses against the cell-wall all around as before.

In this experiment we can see that while the plasma membrane allows the water to be drawn from the protoplast by the salt solution it does not permit the coloring mater or the osmotic substances in solution in the cell-sap) to escape, for the color does not at all diminish in the protoplast as it shrinks, and the 
protoplast could not again swell up on the replacement of the salt solution by water if its osmotic substances had been lost. This guardianship of the exchange of materials between the the cells or between the cells and the external world is one of the well-recognized functions of the plasma membrane. Since the plasma membrane lies at the surface of the protoplast it must receive and transmit to the other parts the stimuli that come from without. Until the cell-wall is built the plasma membrane doubtless affords some rigidity and protection to the parts within; and when the time for the building of the cellwall arrives it seems that the plasma membrane constructs it by the chemical transformation of its own substance into the substance of the wall.

General Cytoplasm.-The cytoplasm is the living matrix in which the nucleus and plastids are imbedded. In very young cells it fills out all of the space not occupied by the nucleus and plastids (Fig. I, A), but in old cells it becomes a very thin film, hardly greater than $.0006 \mathrm{~mm}$. in thickness lining the cell-wall. In cells that have been killed, fixed and stained in the usual ways (see chapter on The Preparation of Sections) the cytoplasm has a spongy or netted appearance (Fig. I, A).

It is uncertain whether the cytoplasm is really sponge-like with irregular and intercommunicating canals or alveolar with each cavity a closed sac. Whaterer the exact character of the cavities may be, they are filled with cell-sap or, in many instances, with insoluble reserve food, such as starch, proteids, and oils, and excretions, such as crystals of calcium oxalate.

As has been stated, as the cell grows older some of the carities in the cytoplasm enlarge and coalesce, and are then known as vacuoles. A plasma membrane is formed about the vacuoles similar to the exterior plasma membrane already described. and it exercises a selective function over the passage of materials to and from the vacuole just as does the exterior membrane to and from the protoplast as a whole. The spongy, or alveolar, condition of the cytoplasm persists until the division of the nucleus preparatory to cell division sets in, when a 
part becomes thread-like and seems to assist in the translocation of the chromosomes (the definite parts into which the nuclear substance becomes segmented during nuclear and cell division) to the opposite pole of the cell; this process may, therefore, be classed as one of the functions of the cytoplasm (see Fig. 3).

Throughout the life of the cell the cytoplasm has many things to do of a chemical nature, but it is very improbable that it often works independently of the nucleus. Where storage of proteids and oils is taking place, we find them stowed away in the meshes of the cytoplasm, and this is good circumstantial evidence that the cytoplasm has manufactured them where we find them. This is particularly true of the insoluble proteids. The cytoplasm probably secretes the ferments by means of which the stored materials are digested when they are wanted for food. Many other of the ceaseless activities of the cell are doubtless accomplished with its assistance.

The Nucleus. - In young cells the nucleus is spherical in form and lies at the center imbedded in the cytoplasm and occupies from .5 to .8 the diameter of the cell. It consists of the nuclear membrane, nuclear reticulum and nuclear sap, and usually contains one or more nucleoli (Fig. $\mathbf{1}, A, b$ ). The nuclear membrane appears to be really a part of the cytoplasm, similar to the plasmatic membranes lining the exterior of the cell and of the vacuoles. The reticulum is the essential living part of the nucleus. The nuclear sap appears to be a fluid which furnishes to the reticulum water and food and in other ways serves it; while the nucleolus seems to be reserve food of a peculiar kind needed to help in the processes of nuclear and cell division.

The nucleus is often spoken of as the center of life of the cell. While the statement is rague, it conveys a meaning not entirely misleading. Some of the facts at the foundation of this conception are these: (a) When a protoplast is segmented into two parts by plasmolysis or other artificial means the part containing the nucleus has the power to construct a wall about itself, while the enucleated part has not. Although the plasmatic membrane is the immediate agent in the construction of 
the wall, it cannot do its work without the influence of the nucleus. (b) We have good reasons for the belief that the nucleus is the cause of oxidation in the living cell, and, without it, the tearing down and building up processes of the cell that depend upon oxidations cannot go on. (c) After the nucleus has been removed the remainder of the protoplast soon dies. While, on these grounds, the nucleus may be spoken of as the center of life of the cell, the fact must not be left obscured that a nucleus dissociated from the rest of the protoplast cannot long maintain its existence, and the coöperation of the other parts is necessary to the success of the functions of the nucleus.

The nucleus is also frequently spoken of as the bearer of the inheritable characters and qualities. This, too, is not without foundation, and if true the nucleus stands forth as the architect and master of the form, character, and activities of the cell and entire plant body. The grounds for the assumption are: (a) In the embryonic cells of the growing apex or cambium the nucleus is relatively large, having an average diameter 0.6 that of the entire cell. These cells are to undergo profound changes in size, form, and general character as the differentiation of tissues proceeds, and why should the nucleus be allotted so much space within the cells unless it plays a dominant part in the hereditary differentiations that are to follow? The evidence here is enough to raise the question, but it does not go far toward solving it. (b) During nuclear and cell division the nuclear reticulum, which is the essential part of the nucleus, divides into many pieces with great precision, and these pieces are equally distributed between the nuclei of the two resulting cells. What but the vehicle of hereditary transmission should require such exactness of distribution? Here again the facts afford us hardly more than the suggestion of the question. (c) In fertilization, when the sperm cell from the pollen grain is fusing with the egg cell within the ovule, the sperm cell consists almost entirely of nucleus, and the egg cell is relatively rich in cytoplasm; yet the offspring may partake as much of the peculiarities of the male as of the female parent. 'The inference 
is that, since the male contributed little more than a nucleus and the female a relatively large amount of cytoplasm in addition to the nucleus, it must be that to the nucleus have been given the inheritable qualities to transmit from generation to generation; for if the cytoplasm bears these qualities equally with the nucleus the impress of the female might be expected to preponderate in the offspring. (d) In the nuclear and cell divisions resulting in the production of pollen spores and embryo-sac spores the number of chromosomes (see Fig. 3) in each nucleus is reduced one-half. The sperm cell and egg cell arising from the germination of pollen spore and embryo-sac spore each contain the reduced number of chromosomes, but when they fuse in the act of fertilization the original number is restored in the fertilized egg and so continues throughout the body of the resulting offspring until pollen spores and embryo-sac spores are again produced by it with the reduced number. What the significance of this halving and doubling may be is told in Chapter XIII, where it is seen unmistakably to relate to the transmission and coöperation of paternal and maternal characters. Since the chromosomes are segments of the nuclear reticulum, the phenomenon here described may be classed as a part of the evidence that the nucleus is the bearer of the inheritable qualities. (e) A new line of evidence is at present being opened up in the study of reproduction. and especially in the reproduction of hybrids where the segregation and recombination of parental characters is in harmony with the behavior of the chromosomes during these processes, as told in detail in Chapter XIII.

The Plastids.--The plastids are distinct and usually relatively small parts of the protoplast. They vary in size from barely discernible points with the highest magnifications to discs and bands that traverse the entire length of the cell. In form they may be orbicular, ellipsoidal, disc, or ribband shaped. They are classed under three names according to their color: the leucoplasts are colorless; the chloroplasts contain the green coloring matter chlorophyll; the chromoplasts are yellow, orange. or red. They are, however, really the same thing under different 
guises and performing different functions, for the leucoplasts may become chloroplasts and the chloroplasts chromoplasts. This fact is well made out in the tomato, for instance, where the rery young pistil in the bud contains no other plastids than the leucoplasts and is colorless in consequence; later when the corolla drops away and the pistil emerges into the light the leucoplasts produce chlorophyll and the young fruit is green; but when the fruit begins to ripen the chlorophyll is gradually replaced by red and orange coloring matters, and the chloroplasts become
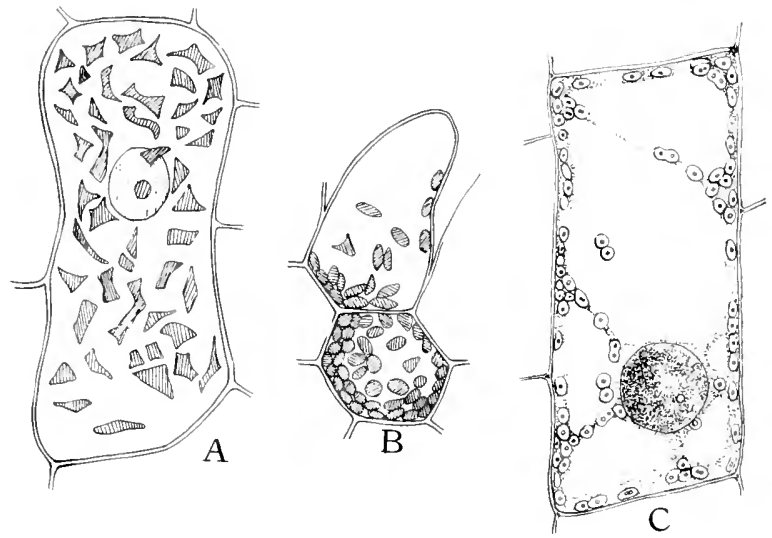

FIG. 2,- A, cell from the epidermis of the upper sile of the caly of Tropeolum maius with crystalline chromoplasts; B, cells from the petal of Lupinus luteus with yellow chromoplasts; $C$, cell showing numerous chloroplasts scattered through the cytonlasm. (A, atter Strasburger; B. after Frank.)

chromoplasts. The leucoplasts are therefore the progenitors of the other plastids, but they have their own functions to perform as leucoplasts: they take carbohydrates out of solution in the cell-sap and store these within themselves in the form of insoluble starch grains. This is well seen in those cells and tissues, as in the potato and the endosperm of seeds, where reserve food is stored away. The chloroplasts secrete two coloring matters known as chlorophyll-green and carotin or chlorophyllyellow. The chloroplasts employ these pigments in arresting the sun's energy, by means of which they make the food of the plant. 
In Chapter II the chloroplasts will be more fully discussed in connection with the photosynthetic system. 'The chromoplasts impart red, orange, and yellow colors to flowers and fruits, where, within the chromoplast body, the reds occur as crystalline carotin and the yellows as amorphous xanthin. These may be found separately or together in the same chromoplast. The presence of both produces an orange color (Fig. 2). The reddish and bluish pigments occurring in solution in the cellsap are known as anthocyanin, and it does not appear that the chromoplasts are necessary to their production.

Cell Division.-In the growing apices of root and shoot and in the cambium cell division may go on indefinitely. The process of cell division begins in the nucleus and terminates by the formation of a dividing cell-wall, as will be seen in Fig. 3, where the different stages may be followed. The nuclear reticulum (in a) becomes transformed into a thick winding thread (in $b$ ), which in successfully stained sections is seen to consist of colored discs or granules termed chromatin, imbedded in a colorless matrix called linin. The thread splits longitudinally throughout its length (in c), and then breaks into rod-shaped pieces, each of which consists of two longitudinal halves arising from the longitudinal division of the thread (in d). These rods are known as chromosomes, and their number varics with the species. Next the nuclear wall disappears and threads arise in the cytoplasm and converge to a point at two opposite poles, forming what is known as the nuclear spindle (in $e$ ). Some of the threads extend uninterruptedly from pole to pole, while others become fastened to the chromosomes. The chromosomes in some unknown way line up in an equatorial plane half-way between the poles, and then one-half of cach chromosome is drawn to one pole and the remaining half to the other when they form at each pole a nuclear thread $(e, f$, and $g)$. This spins itself out into a nuclear reticulum around which a nuclear membrane is soon organized (in $h$ and $i$ ). The connecting fibers extending between the poles bulge out at the equator more and more and new ones eridently are formed 
until the whole equatorial zone is traversed by them (in $g$ and $h$ ). The fibers thicken in the equatorial area and the thickenings fuse together, forming a closed membrane known as the coll-plate (progressive stages in $g, h$, and $i$ ). This is a plasmatic mem-

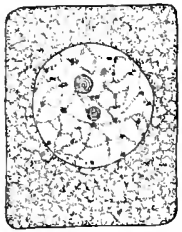

a
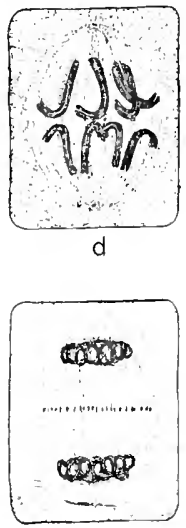

g

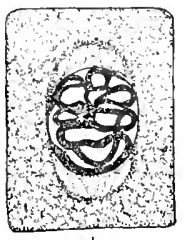

b
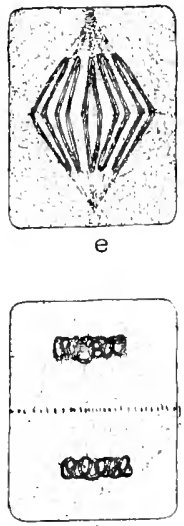

h
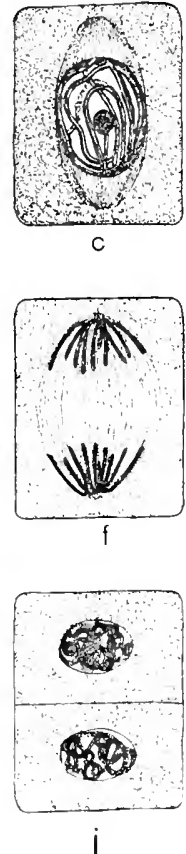

FIG. 3.- Semi-diagrammatic representation of nuclear and cell division. $a$, resting cell ready to begin division; $b$, the nuclear reticulum is assuming the form of a thickened threarl, and the cytoplasm at opposite poles is becoming threatlike to form the spindle fibers; $c$, the nuelear threat has divided longitudinally through the middle, and the spindle fibers have become more definite; $d$, the nuclear membrane and the nucleolus have disappeared, and the nuclear thread has become segmented into chromusomes which are assembling at the equator of the cell. All of the phases of division thus far are called prophases. $\epsilon$, the metaphase, where the longitudinal halves of the chromosomes are being drawn apart preparatory to their journey toward the opposite poles; $f$, the anaphase, or movement of the chromosomes toward the poles, is about completed, connecting fibers extend from pole to pole; $g$, telophase whcre the chromosomes have begun to spin out in the form of a nuclear reticulum. The connecting fibers have begun to thicken in the equatorial plane; $h$, the connecting fibers have spread out and come into contact with the wall of the mother cell in the equatorial plane, and the thickening of the fibers throughout this plane has made a complete cell plate within which the dividing wall will be produced; $i$, a nuclear membrane has been formed about each daughter nucleus, and the dividing cell wall is completed. The two daughter cells are now reacly to grow to the size of the parent cell in $a$, when the daughter nuclei will appear as does the nucleus there. All highly magnified. 
brane which organizes in its median plane a cell-wall dividing the mother cell into two. The fibers disappear, the cytoplasm becomes reticulate throughout, and the daughter nuclei increase rapidly in size.

About the time when the nuclear membrane disappears the nucleolus, as a rule, also vanishes from sight and cannot again

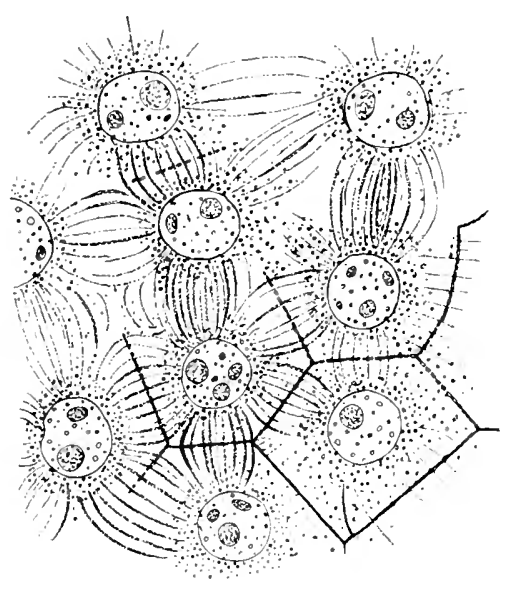

FIs. 4.-Formation of endosperm in the embryo-sac of Agrimonia Eupatorium. Cellwalls are being formed between the nuclei. (After Strasburger.) be found until the completion of the daughter nuclei. 'This has led to the conclusion that the nucleolus is not a living part of the protoplast, but is simply a form of reserve food needed at the time of nuclear and cell division. It does not, however, behave uniformly in all subjects and its exact nature is still a subject of debate.

In the nascent endosperm of seeds the division wall between daughter cells may not be formed until the nuclei have many times divided. Finally, when the embryo-sac containing the endosperm has completed its growth, new connecting fibers spring up in the cytoplasm between the nuclei, and cell-walls are laid down in the usual way (Fig. 4).

In the formation of spores in the Ascomycetes nuclear division takes place in the usual way, but the method of formation of the wall about the spores is unique. Here nuclear division continues within the mother cell until the number of nuclei equals the number of spores to be produced, when, at the close of the last nuclear division fibrillar radiations from the polar ends bend back about the daughter nuclei, and finally by their fusion form a complete plasma sac enclosing, together with the nucleus, a part of the cytoplasm of the mother cell 
(see Fig. 5). All of the spores thus produced lic unconnected within the mother cell. This is known as free cell formation.

In Spirogyra and other cases among the Thallophytes the dividing cell-wall is produced by a gradual ingrowth from the wall of the mother cell between the two daughter nuclei which
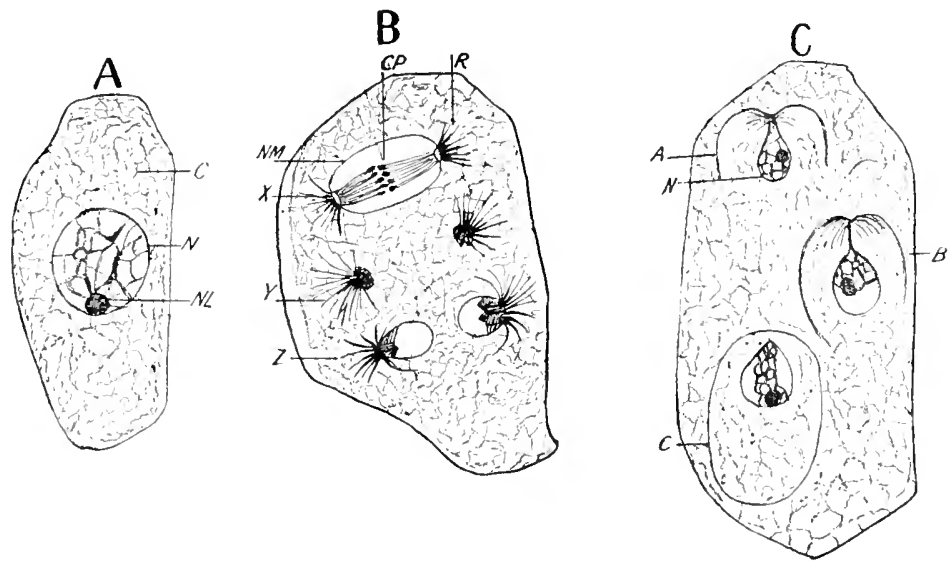

FIG. 5.-Free cell formation of spores in the ascus of Erysiphe communis. A, asctis with single nucleus; $C$, cytoplasm; $N$, nucleus; $N L$, nucleolus; $B$, successive stages in nuclear division within the ascus; at $\mathrm{I}$, early anaphase, nuclear membrane, $N M$, still persisting; $R$, kinoplasmic radiations from the poles; at $I^{*}$, telophase, new nuclear membran not yet formed; $Z$, a later stage where the nuclear membranes demark the daughter nuclei: $C, A, B$ and $C$, are successively later stages than $Z$ in $B$. At $A$ some of the kinoplasmic radiations are bending downward about the nucleus $N$; at $B$ the nuclews is nearly encloser: and at $C$ entirely enclosed by the raliations, which now form a complete nembrane cutting off a portion of the cytoplasm of the ascus, and thus forming a complete cell. (Arranged atter drawings by Harper. $B$ and $C$ are diagrammatic. For the sake of sinplicity of description, various stages of nuclear division are shown in a single ascus, although at any given time only one stage would actually be present.)

have previously been formed. This process of wall formation reminds one of gradual closing in from all sides of an iris diaphragm.

In yeasts and some other fungi cell division is preceded by budding. The mother cell puts forth an outgrowth like itself in general form; the nucleus divides and one of the daughter nuclei enters the bud; and a division wall is then formed separating the bud from the parent cell (Fig. 6). 
The kind of nuclear division above described is called indirect, mitotic, or karyokinetic division. Another method, called direct or amitotic division, is where the nucleus simply constricts itself
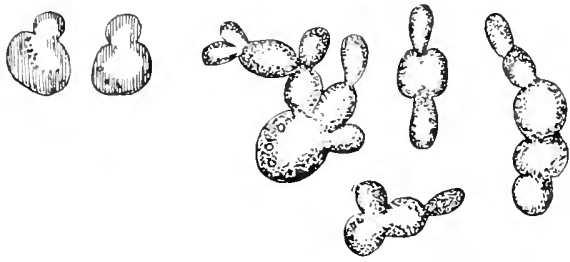

FIG. 6.-Various stages of cell multiplication by budding of Saccharomyces cerevisiæ. (After Reess.)

cambium do not long remain in size, form, and other characteristics just as they are when first produced. In cross sections of the growing point of Aristolochia, for example (Fig. 8), the cells are essentially all alike; but a little farther down the stem we find zones and groups of tissues which are readily distinguished from each other because the cells composing them differ in size, form, thickness of walls, etc. These cells and tissues have all arisen by changes in cells that were produced by cell division at the growing point. It appears that these cells, influenced by stimuli and impelled by impulses mysterious to us, set to doing different things: some doing little more than enlarging. uniformly; some enlarging and thickening and chemically changing their walls; others greatly elongating and becoming fibers and tubes. It is this power of the living cells to become different things that has made possible division of labor in the plant body, with the consequent successful occupation of all sorts of habitats and the commanding size of our trees and shrubs.

Sizes of Cells.--After its formation by cell division the cell grows to its adult size which varies within not very wide limits in each tissue. An average size of cells, not much elongated, 
like wood and bast fibers, is approximately $.03 \mathrm{~mm}$., or about one-fourth the thickness of one of these pages. Several reasons can be suggested for this habitually small size: (a) The plant is made stronger thereby. The cell-walls 'must be, on the whole, extremely thin to permit an easy interchange of materials, and the smaller the cells the stronger they will be with a given thickness of wall. The smaller the cells the greater the number of walls in a given volume of tissue, so that the whole tissue is made stronger. (b) Each cell is a chemical laboratory, each nucleus a center of oxidations, so that the more there are of these the greater the activity of the whole body. (c) The smaller the cells the greater the amount of protoplastic surface exposed for the osmotic interchange of materials between contiguous cells and between cells and intercellular spaces. (d) The smaller the cells the greater the number of nuclei to send forth hereditary stimuli which must dominate every part of the body. All of these problems are of great moment to the well-being of plants, and the minute size of the cells is one of the factors in their solution.

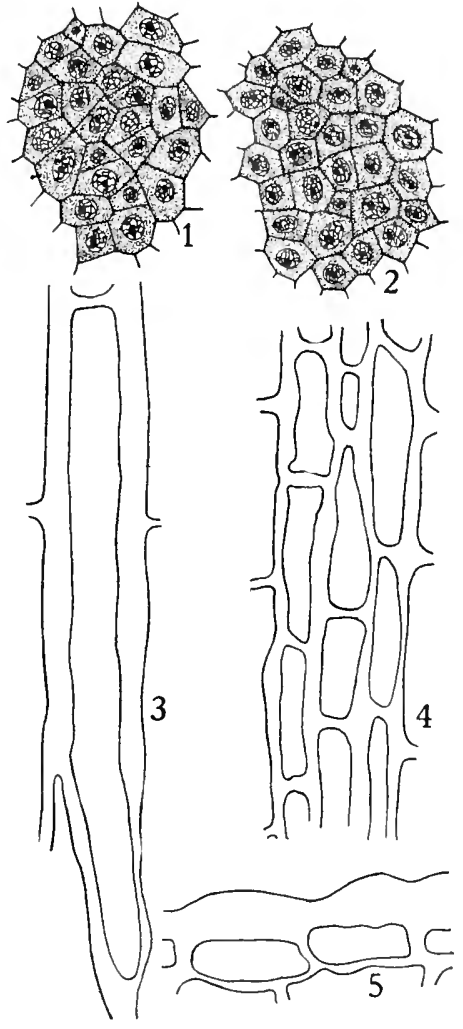

FIG.8.-r, cells from a cross section, and 2 , from a longitudinal section, through the primordial meristem of the growing apex of Aristolochia sipho; the cells are essentially alike from both points of view. 3,4 and 5 show cells from some of the different tissues which the primordial meristem produces. Note the different shapes and thicknesses of walls. 3 is from the sclerenchyma ring; 4, from the collenchyma, and 5 , from the epidermis. All magnified to the same scale.

The Cell-wall.- The cell-wall is the skeleton of the protoplast, preserving its form and protecting it from danger; it also 
gives rigidity and strength to, and preserves the form of, the whole plant body. When first formed the wall is usually cellulose $n\left(\mathrm{C}_{6} \mathrm{H}_{10} \mathrm{O}_{5}\right)$; we know, however, that we are including under this name a group of closely allied substances which yield different products on chemical decomposition.

The wall may remain cellulose throughout the existence of the plant, or it may become modified in different tissues to meet special requirements. Thus, in the bast and wood fibers. the walls become lignified; and in the epidermis and cork they are cutinized and suberized. It is not known precisely what the chemical nature of these modifications is, but lignification scems to increase the hardness, strength, and elasticity without decreasing the permeability of the walls; while cutinization and suberization involve infiltration with waxes, so that the walls are made more or less impermeable to water and gases, as happens to paper when infiltrated with melted paraffin. Sometimes the wall undergoes a mucilaginous modification by which, if the modification is extensive, it swells enormously on coming in contact with water. Walls of this kind occur at the surface of many seeds, such as flax and mustard, where they are useful in gluing the seeds to the substratum; and they are frequently found in desert plants, where they are useful in imbibing and holding stores of water.

The cell-wall when first formed is relatively very thin, and its growth in thickness and extent is accomplished by the addition of new particles within it (growth by intussusception) and at its surface (growth by apposition). On account of the unequal swelling of the cell-walls in water in its different dimensions. and its behavior like a crystal in polarized light, Nägeli has conceived the hypothesis that it is composed of aggregations in crystalline form of minute parts or molecules to which he has given the name micelle. He conceives that the micellite are separated by films of water which become thicker on the swelling and thinner on the drying up of the wall. This hypothesis still explains better than any other the optical properties of the cellwall and the phenomena of imbibition. 


\section{The Chemical and Physical Nature and Physiological} Powers of the Protoplast.-The exact chemical constitution of the protoplast is not known. The evidence thus far at hand goes to show that it is chiefly a complex of proteids of very large molecules where the elements carbon, hydrogen, oxygen, and nitrogen are always present, and frequently sulphur, and. in the nucleus, phosphorus. Water is always associated with the protoplast and is necessary to its life. Other substances than the proteids and water are sometimes, and may be always, present. On account of its complex nature the plasma or substance of the protoplast is easily broken down into simpler substances, setting free large amounts of energy; and correspondingly large amounts are required for its growth and repair.

In consistency the protoplast is apparently semi-fluid. We get this conception from the rotation and circulation of the cytoplasm in Nitella, stamen hairs of Tradescantia, Myxomycete plasmodia, etc. Here the cytoplasm simulates a fluid in its streaming movements, while it preserves its form sharply demarked from the surrounding cell-sap. The plasmodium of Myxomycetes consists of a mass of cytoplasm with many embedded nuclei, and no cell-walls are present; so that its consistency, which is about that of thin batter, may be taken as an indication of the consistency of protoplasts in general. The nucleus and plastids seem to be firmer and less fluid than the general cytoplasm, but their mobility is shown by the apparent ease with which they change their form; as when chloroplasts round themselves up or flatten out with varying intensities of light, and nuclei of tapetal cells flatten themselves and creep into very narrow rifts between groups of developing spores (Fig. 9).

The things which the protoplast is capable of doing as a physiological unit have partly been told in the foregoing, and will be further brought out in succeeding chapters. By way of convenient oversight these activities will now be grouped and classified:

(a) Absorption.-Water, and solids and gases in solution, are drawn through the plasma membranes into the meshes of the 
cytoplasm, vacuoles, and nuclear cavity. The powers of osmosis and diffusion are at work here, essentially as we find them in artificial cells and through artificial and lifeless membranes; but the chemical work done by the living protoplast makes and keeps up the conditions necessary to osmosis and diffusion, and the plasma membranes modify, and to a certain extent regulate, the osmotic and diffusion exchange of materials into and from the body of the protoplast.

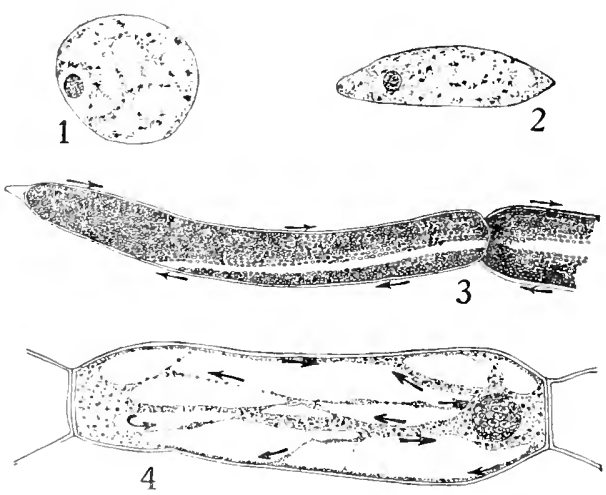

FIG. 9.-I and 2, nuclei from the tapetal plasmodium of the sporangium of Botrychium Virginianum, 1 , in the usual form, and 2, flattened while entering a crevice between sporegroups; 3 , cell from Nitella showing rotation of the cytoplasm as indicated by the arrows; 4, cell from stamen-hair of Tradescantia, showing circulation of the cytoplasm as indicated by the arrows.

(b) Construction.-.-The protoplast builds complex substances from simpler ones, as when sugar, starch, oil, and proteid foods are built from carbon dioxide, water, and salts of nitrogen and sulphur; and when the foods are assimilated to the substance of the protoplast itself.

(c) Destruction.--In respiration the protoplast breaks down a part of its own substance, and probably also reserve foods, into simpler compounds; and the self-destruction of the protoplast appears to take place in the production of secretions, such as cell-wall and digestive ferments.

(d) Excretion.-Frequently substances that are of no use are excluded from the protoplast by inclosure in an insoluble form 
in vacuoles, or deposited in the cell-walls, or thrown into intercellular spaces; or useful substances, such as enzymes, and acids for making intractable substances soluble, and nectar for alluring insects, may be expelled at the surface. This isolation by the protoplast of substances from the sphere of its operations is called excretion.

(e) Contraction and Expansion.-When the protoplasts are not hemmed in by a cell-wall, as in Euglena, the plasmodium of Myxomycetes, and zoospores (Fig. Io), they are found to be capable of alternate contraction and expansion, resulting in marked change of form in Euglena and plasmodia, and in the thrashing back and forth of the cilia of swarm spores; and the circulation and rotation of the cytoplasm spoken of above is probably caused by contraction and expansion in its different parts. The power of contraction and expansion is usually comprehended in the term contractility.
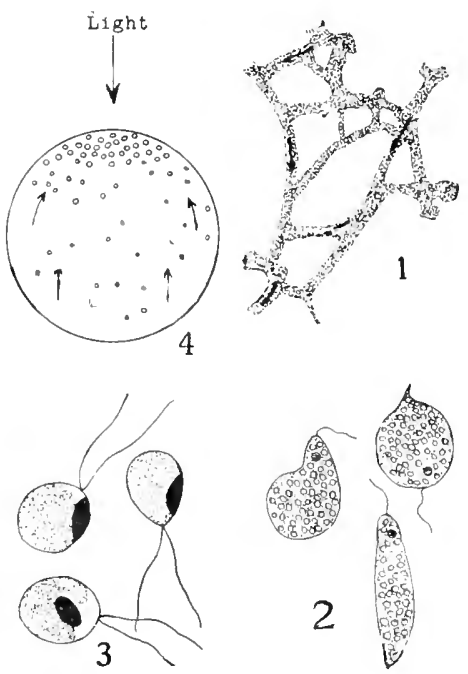

FIG. ro,-I, a bit of plasmodium of a Myxomycete, arrows showing direction of movement of the cytoplasm; 2, Euglena viridis in different stages of contractility; 3. ciliated swarm-spores of Ulothrix zonata; 4 , diagram indicating movement of swarm-spores of Ulothrix toward the source of light.

(f) Perception and Response.- The protoplast is capable of perceiving external stimuli and responding to them in a definite way. Thus, when the swarm-spores of Ulothrix are mounted in a drop of water for examination with the microscope they are found to swim to the side of the drop next the window, but if direct sunlight is allowed to fall upon them they recede to the opposite side. It is clear that they perceive the light and behave as they do on account of its varying intensity; and it appears that they not only perceive the light, but also the direction from which it is coming. The inclining of house plants toward the window is another 
example of this kind. When certain kinds of bacteria are mounted in a drop of water under a coverglass they are found to assemble about the edge of the coverglass to get oxygen; in which case the stimulus is of a chemical nature; and in fertilization the finding of the egg by the sperm cell seems to be due to the perception of a chemical substance excreted by the egg. The growth of roots toward the center of the earth and of shoots away from it is due to a perception of the direction of the gravity pull. Many other instances could be given for stimuli of different natures; but the few here cited will do to show the fact of perception and response by the protoplasts. This power of the protoplasts is called irritability.

(g) Growth.-When protoplasts are permanently increasing in size and assuming their permanent forms they are growing. Examples of this are seen where cells at a growing apex or in the cambium region are increasing in size and taking on the forms characteristic of the different tissues which they are to compose. Of course the size and form of the whole plant body are due to the growth activity of its individual protoplasts.

(h) Reproduction. - We have already seen that the protoplast is able to reproduce its kind by self-division, where the behavior of the nucleus indicates that the process is one of considerable complexity.

\section{Illustrative Studies}

1. Cut free-hand sections (see page 25I) of bottle cork from the three points of view illustrated in Fig. I23, and mount them for study in a drop of dilute glycerine (half glycerine and half water). Draw three or four cells from each point of riew. If the microscope is equipped with a micrometer eyepiece-and it should be for the work of this book-draw to scale as explained on page 278 . In drawing cell groups outline the cell cavities. leaving a space between adjoining cells to represent the thickness of the cells, as shown in Fig. I, $B$.

2. Study longitudinal sections of onion root tip prepared as directed under Cytological Methods on page 257. Or if 
this cannot be done study cross sections of onion root tips that have been prepared by fixing the tips in chrom-acetic fixative (page 260) and cutting the sections free-hand while the tips are enclosed in elder pith (page $25 \mathrm{I}$ ), and finally staining in safranin and mounting in dilute glycerine (page 326).

To secure the onion root tips boil a disk of carpet paper to moisten it and kill possible fungal parasites, lay it on glass or tile, place a few onions with basal ends on the moistened paper, and cover with a bell-jar. When the roots are about $3 \mathrm{~mm}$. long cut them off and place them in Flemming's fixative (page 258). Proceed as directed under Cytological Methods until the sections are stained in safranin-gentian riolet-orange, or in iron-hæmatoxylin (page 264), and mounted in balsam.

Find all the parts of the cells as described in the chapter. Draw younger and older cells to scale, using Fig. I as a model for line-work and stippling. By means of the eyepiece micrometer determine in millimeters the diameters of the cells, nuclei, and cell-walls. The plastids are so small here that they cannot be identified with certainty. If the sections show nuclear and cell division, as they should if the sections have been properly prepared, find the different stages illustrated in Fig. 3 and draw them to scale.

3. Mount a fresh moss leaf in a drop of water and study the chloroplasts with a high power. Draw to scale a single cell with its contained chloroplasts. Measure the chloroplasts. Possibly some of them will be found dividing by constriction. With a colored pencil tint the drawing of the chloroplasts green .

4. Make free-hand sections of the ray florets of Zinnias of different colors while holding the florets in elder pith (page 25I). Mount the sections in dilute glycerine and study them quickly before the pigments that are in solution in the cellsap have time to escape. Find the yellow and orange chromoplasts in some sections and colored cell-sap in others, and sometimes a combination of both in the same section. Draw a few cells in each case and use colored pencils to express the colors.

5. Crush out between coverglass and slide a very small bit 
of the pulp of a tomato or of climbing bitter-sweet berries, using the juice of the fruit as a mounting medium. Draw and measure chromoplasts of different forms and colors. Tint the drawings as near the natural colors as possible.

6. To see in a comprehensive way that cell-walls may be of different kinds mount thin cross sections of old stem of Aristolochia (Fig. 24), or of some other woody stem, in different reagents for differentiating cell-walls. Examine a section first in water to note the natural colors of the walls. Filter away the water and add a drop of chloroiodide of zinc. After a while the cell-walls of some of the tissues will be colored yellow and others purple. The purple walls are cellulose and the yellow are lignified, suberized or cutinized.

Mount another section in aniline sulphate and only the lignified walls will be colored yellow while the others will be left unstained. Mount a third section in phloroglucin and the lignified walls will be colored pink while all others will be unchanged. Finally sections left for several hours in a tincture of alcannin will have the cutinized and suberized wall alone stained pink. See under these reagents in Chapter XVI.

7. Mount a bit of Nitella in a drop of water and study the flow of the cytoplasm. With a micrometer eyepiece and a metronome to tick off seconds determine the rate of flow per second.

Remove a filament from a young bud of Tradescantia Virginica and mount it in a drop of water. Study the circulation of the cytoplasm in one of the cells of a hair growing from the filament. How does it differ from Nitella as to the manner and rate of flow? Draw a cell, using Fig. 9 as a pattern for line-work and stipplingr.

8. Mount in water some of the mealy green scum sometimes found at the surface of stagnant ponds. If it is found composed of motile green bodies with a red eyespot, these individuals are Euglena viridis. Note the beating back and forth of the colorless flagellum at the eyespot end, and show by drawings the different forms which a single Euglena is found to assume within a short time. 
9. Make a culture of yeast as follows: Pare, slice thin, and boil a good-sized potato in a pint of water. After boiling till it is soft mash it fine and add to this potato broth a tablespoonful of sugar. Pour a little of the broth into a test-tube (I) for future use and after the remainder cools dissolve in it a piece of yeast cake and set the culture in a warm place. After four or five hours when the culture is beady with bubbles, indicating that the yeast is rapidly multiplying, remove a drop and mount it under a coverglass, having first placed a hair in the drop to prevent the breaking up of the yeast colonies by the pressure of the coverglass. Study with a high power and draw a yeast colony showing different stages of budding. It would be interesting to note the development of the colonies from single individuals, and this can be done in a hanging drop culture. Pour some of the culture into a test-tube (2) and shake it vigorously to break up the colonies. Clean a coverglass thoroughly in soap and water, rinse it and rub it with a cloth dipped in alcohol. Place a drop of broth from test-tube (I) at the middle of the coverglass and dip the point of a needle first into the test-tube (2) and then into the drop to inoculate it with yeast. Now invert the coverglass over a hollow slide obtainable of the dealers, having run a thin film of vaseline around the border of the hollow for sealing the coverglass. Bring a yeast plant into focus with the high power and set the microscope in a warm place. Examine the culture at intervals of half an hour or so.

Instead of a hollow-ground slide a culture cell may be made by spinning a ring of melted paraffin on an ordinary slide. 


\section{CHAPTER II}

\section{DIFFERENTIATION OF THE TISSUES}

\section{General Surver}

A tissue is a group of united cells that are essentially alike, have had a common origin, and are prepared to perform a common function: thus, the outermost layer of cells, or epidermis. of an apple; the groups of bast and wood fibers, the assemblage of cells forming the pith, are tissues. At the growing apex of a stem there is but one tissue (Fig. I I), for the cells are essentially all alike. This is known as the primordial meristem.

On comparing cross and longitudinal sections at successive planes below the apex we find that the primordial meristem soon becomes changed into three distinct parts: the protoderm at the exterior, the procambium strands, and the fundamental or ground meristem (Fig. II). These three regions or tissues are to undergo further differentiations, and are known as primary meristems. In still older portions of the stem, lower down, we find that the protoderm has changed into a definite outer skin or cpidermis; the procambium has become transformed into three parts, now collectively termed a íascular bundle, an outer part called the phloem, an inner, called the rylem. and a part between these two termed the cambium; and the ground meristem is seen to have become differentiated into four main parts, namely, primary cortex, pericycle, primary medullary rays, and medulla or pith (Figs. I and If). These dirisions are suggested by distinct landmarks; thus, the inner limit of the primary cortex is a zone of cells, known as the endodermis or starch sheath. which is usually characterized by an ałundant starch content; the pericycle extends from this to the outer border of the vascular bundles; the primary medul 


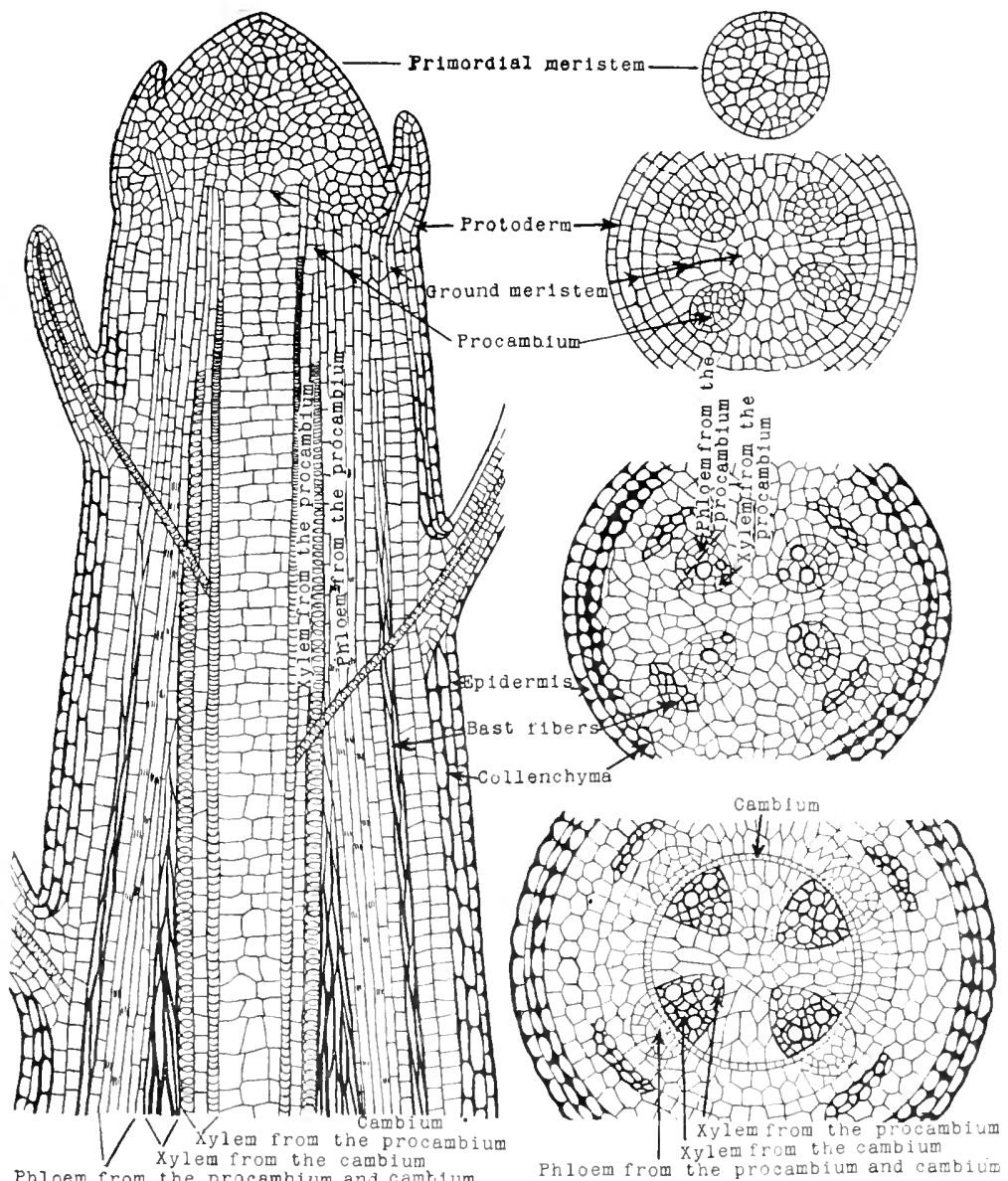

Phloem from the procambium and camtium

FIG. II.-Diagram showing the evolution of tissues from the frimordial meristem lown to the beginning of cambial activity. In the longitudinal diagram. at the bottom the intial $\mathrm{C}$ of the word cambium stands directly beneath this tissue which is radially but one cell in thickness.

lary rays lie between the bundles, and are limited externally by the plane touching the outer borders of the phloem strands, and internally by the plane bounding the inner borders of the xylem strands; while the medulla or pith is all of the tissue surrounded by the bundles. Everything within the starch sheath is called the stele. 
The character of the different tissues and their origin and progress of development will now be considered.

The Primordial Meristem.--The primordial meristem occurs at the growing apices, and from it all parts of the plant, directly or indirectly, take their origin. The cells composing it are nearly isodiametric, are essentially all alike, and are characterized by their relatively small size, relatively large nuclei, dense cytoplasm, absence of vacuoles, absence of insoluble foods, such as starch and oil, very thin cellulose walls, and power of repeated division. They are of course very tender, having little strength and rigidity excepting that due to turgidity; and having in and of themselves no protection against loss of water, they need to be protected when growing in the air, by the older tissues of scales, etc. The primordial meristem is continually carried forward by the enlargement of the cells beneath it that have been formed by its own cell division; just as a man, standing on a stone wall which he is building, is carried upward with each successive course of stone. The cells and tissues are thus successively older as they recede from the apex. Some quality in the heredity of the daughter cells of the primordial meristem causes them soon to become differentiated into the three primary meristems called the protoderm, procambium, and ground meristem (Fig. II).

The Protoderm.-This is the outermost layer of cells close to, and in some instances even surrounding the apex, which, after a period of cell division, is to become the epidermis. In most cases its cell divisions give rise to radial walls only. Radial walls run parallel with a line extending from center to circumference; so that it increases in superficial expanse as the tissues within enlarge; but in some instances it divides tangentially (that is, at right angles with the radius) and thus gires rise to a multiple epidermis of several cell layers. Usually the cells of the protoderm differ in form from those of the ground meristem bordering it within, but this is not always the case.

The Procambium. - In dicotyledonous stems the procambium occurs as isolated strands disposed in the form of an. 
interrupted ring where later the vascular bundles appear. In cross sections the procambium cells are much smaller than those of the surrounding ground meristem; and in longitudinal sections they are seen to be elongated, and more or less pointed at the ends (Fig. II). In the evolution of a procambium strand from the primordial meristem groups of vertical rows of cells of the latter divide repeatedly by vertical walls, producing the small cells so plainly made out in cross sections; these cells then elongate, as seen in longitudinal sections (Fig. II). They are then ready to differentiate into the different elements of the vascular bundles, and sometimes into bast fibers, as will later be shown.

In the stems of Monocotyledons the procambium strands are scattered promiscuously instead of being disposed in a ring (Fig. 27), as in Dicotyledons; and in roots the procambium occurs as a single central strand.

The Ground Meristem.-This has been derived from the primordial meristem by cross, as well as vertical, divisions of its cells. It is distinguished from the procambium by not being particularly elongated in any dimension, and from both procambium and protoderm by the relative largeness of its cells and the presence oftentimes of intercellular spaces.

The cells of the primordial meristem retain the power of division throughout the life of the plant, but those of the primary meristems, namely, protoderm, procambium, and ground meristem, after a time cease to divide, excepting the cambium cells from the procambium, as will later be shown; and they then form what is known as the primary permanent tissues, the protoderm giving rise to the epidermis, the procambium forming the primary vascular bundles, and the ground meristem differentiating into the primary cortex, pericycle, primary medullary rays, and pith, as already stated.

While these permanent tissues are characterized by the cessation of cell dirision, yet in large groups of dicotyledonous plants the cells of the primary cortex habitually give rise by cell division to a zone of cork cambium or phellogen from which the cork is 
derived; and cells of the medullary rays in like manner produce cambium cells (interfascicular cambium) which, joining with the cambium of the vascular bundles (fascicular cambium) complete the cambium ring. The interfascicular cambium and the cork cambium are classed as secondary meristem. The details of their origin and their relation to the other tissues will appear under the discussion of secondary increase in thickness.

The Primary Permanent Tissues.-The tissues formed by the transition of the primary meristems into the permanent state where cell division ceases are known as the primary permanent tissues in contradistinction to those that are the product of cambium cells, which are called secondary permanent tissues.

Beginning at the outside, the primary permanent tissues in dicotyledons are grouped on anatomical and topographical grounds into the following main divisions: Epidermis, primary cortex, pericycle, phloem part of the vascular bundle, xylem part of the rascular bundle, medullary ray, pith (Fig. I4). In Monocotyledons the order is the same until the pericycle is passed, and then follow the rascular bundles, with phloem facing outward and xylem inward, scattered through the ground tissue, where, in consequence, medullary rays and pith are not distinguishable (Fig. 28). The tissue groups in dicotyledons will now be taken up in the order named.

Epidermis.-As the protoderm cells are becoming transformed into the epidermis they enlarge more or less, varying a great deal in this respect in different plants and habitats, and in different parts of the same plant; and they assume a diversity of forms, from isodiametric to much elongated, and from regular polyhedra to forms of sinous contour (Fig. I2); and they may even grow out from the surface in the form of scales and hairs.

While the changes in size and form are going on, the outer wall is, as a rule, thickening and becoming chemically altered, particularly in parts exposed to the air. The most important chemical change is due to the addition and infiltration of a waxy substance called cutin which makes the outer wall water- 
proof. 'This occurs in its greatest purity as a thin film at the outer surface known as the cuticle. In some instances scales and rods of wax are deposited at the surface and cause the socalled bloom, as on the plum, grape, stems of some grasses, etc.. where they are easily rubbed off on account of their delicacy. In sections under the microscope the wax, cuticle, and cutinized parts of the wall are readily distinguishable by their yellow color when treated with chloro. iodide of zinc, while the cellulose portions of the wall assume at the same time a purplish color.

The thickening and cutinization of the outer wall makes of the epidermis an excellent protective tissue against loss of water, parasitic fungi, and, to a certain extent, mechanical injury. How quickly, for example, an apple will begin to dry up and decay when its epidermis is pared away.

The cells of the epidermis remain living so long as they
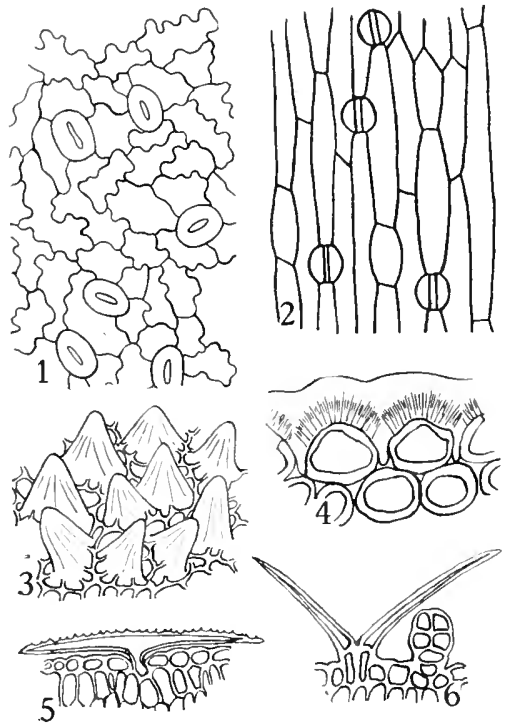

FIcr, I 2,- I, epidermis of oak leaf; 2, epilermis of Iris leaf, both viewed from the surface; 3 , group of cells from petal of Viola tricolor; 1 , two epidermal cells in cross section showing thickened outer wall differentiated into three layers, namely, an outer cuticle. cutinized layer (shaded), and an inner cellulose Jayer; 5 and 6 , epidermal outgrow ths in the form of scales anil hairs. (3 after Strasburger, 4 after Sachs, and 5 after de Bary.) are not cut off from the water supply by the formation of cork tissue. Their protoplasts exist as a very thin and hardly distinguishable film lining the walls. In rare instances, particularly in the Monocotyledons, the epidermal cells contain chloroplasts; and sometimes, as in fruits and foliage plants, a colored cellsap; but in most cases they are colorless and permit the unimpeded entrance of light. While they live the epidermal cells 
are filled with cell-sap, largely water, and serve in many cases as an effective storehouse for water. This function is carried to its fullest development where a multiple epidermis is produced by the tangential division of the protoderm, as in the rubber leaf (Fig. I3).

In herbaceous plants, and in leaves generally and fleshy fruits the epidermis remains, but in the perennial parts of plants that

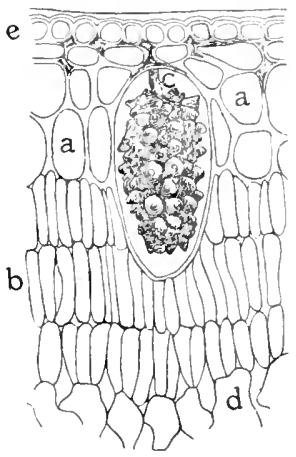

FIG. I 3.-Cross section of a portion of leaf of Ficus elastica showing the multiple epidermis from $\epsilon$ to a inclusive; $c$, cystolith; $b$, palisade parenchyma; $d$, spongy parenchyma. (After Sachs.) increase in size from year to year, such as the stems and roots of trees and shrubs, and in many underground parts that endure but for a season, such as the Irish potato, cork is after a time produced beneath the epidermis and this dies and sloughs away.

Primary Cortex.-All of the ground meristem lying exterior to the procambium strands (which, it will be remembered later become the primary vascular bundles) produces permanent tissues that are divisible into two zones by a layer of cells, more or less continuous, known as the starch sheath or cndodermis. The outer of these zones, which includes the starch sheath, is known as the primary cortex (Fig. I4). (The term primary cortex must not be confused with cortex as used in pharmacognosy, where cortex, employed synonymously with bark, is often applied to all of the tissues collectively which lie exterior to the cambium ring.) The primary cortex does not as a rule consist of a single tissue, but of two or more, so that in describing its evolution from the ground meristem the possible tissues composing it must be considered separately.

Beginning at its exterior just beneath the epidermis we commonly find a tissue whose walls are thickened at the angles where three or four cells join. This tissue is called the collcnchyma (Fig. I4). It is 'one of the first of the primary tissues to come to maturity, and its chief function, in virtue of its thickened 


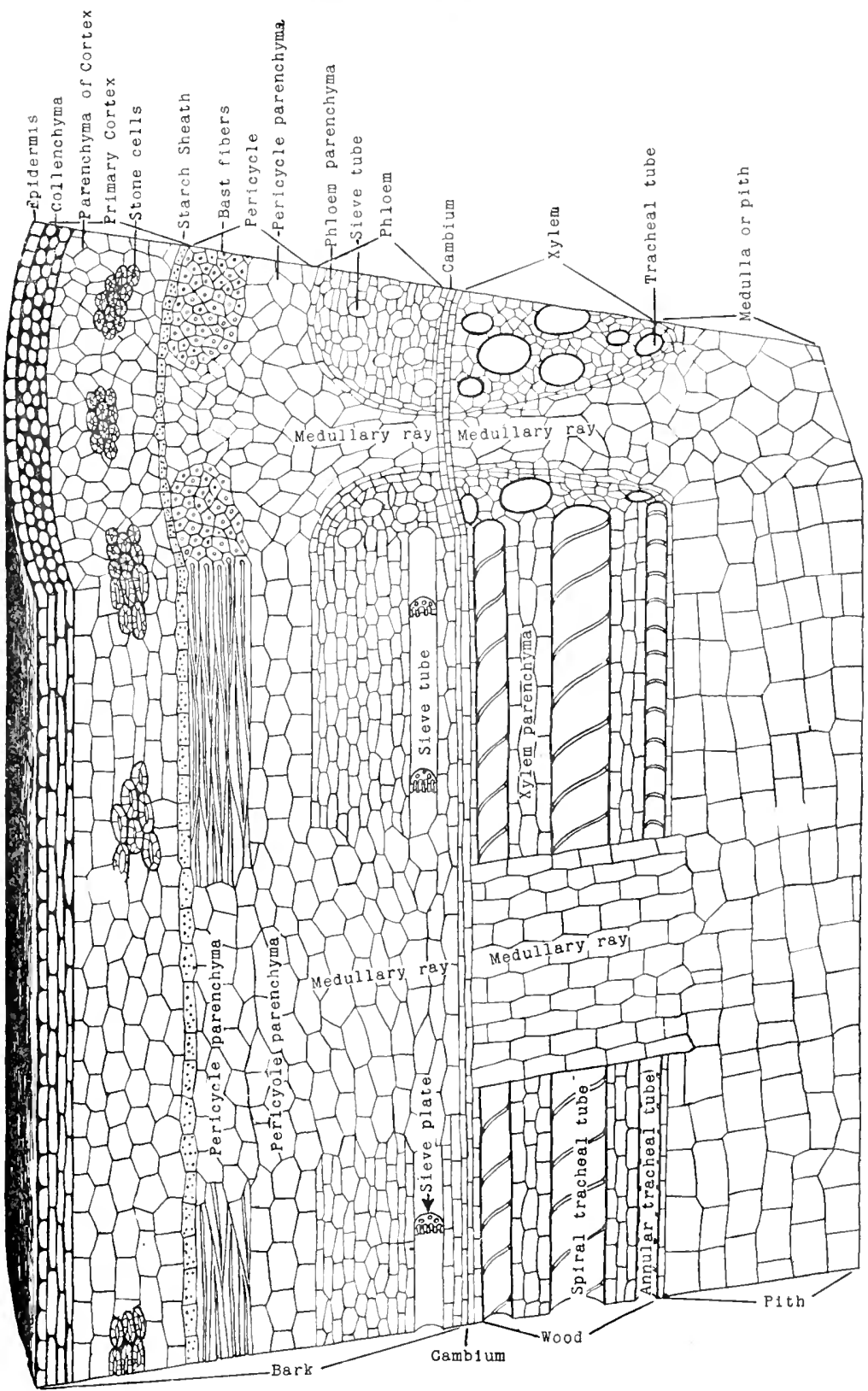

FIG. I 4.-Diagram to show the topography and character of the tissues that are evolved from the primary meristems. Cambial activity has not yet begun. 
walls, is to give strength at a time when the bast and wood fibers have not yet made their appearance or arrived at sufficient maturity to be effective. It may occur as a continuous zone or in separate strands. In producing the collenchyma the ground meristem cells divide transversely and vertically, the daughter cells enlarge and elongate vertically; the walls gradually thicken at the angles, but the cellulose composing them does not appear to become essentially altered or replaced. The collenchyma cells usually contain chloroplasts, and they remain living until cut off from the general circulation by cork cells in the formation of borke (see page 55), as frequently happens in woody plants.

Thin-zwalled Parenchyma lies next to the collenchyma internally: and as a rule constitutes most of the primary cortex. It has been evolved from the ground meristem by transverse and vertical division of the cells of the latter, and the growth of these cells about equally in all dimensions, or with a slight excess of elongation in the vertical or radial direction (Fig. If). The cell-walls of this tissue remain thin, and their original cellulose is practically unchanged. The cells frequently contain chloroplasts and remain alive unless involved in the formation of borke, as stated for collenchyma. In virtue of its chloroplasts this tissue, as well as the collenchyma, is able to manufacture food, and it is much used also in the slow conduction and storage of foods that have come to it from the leares.

Short Sclerenchyma Cells or Stone Cells are frequently found. singly or in groups, distributed amongst the thin-walled parenchyma (Fig. I4). These, as a rule, are transformed thin-walled parenchyma cells whose walls have become greatly thickened and more or less lignified. The tubular and often branched pits characteristic of the walls of these cells are thin places left as the thickening of the walls progresses. These cells soon die after the completion of their walls and seem chiefly to be used in giving strength and protection.

Long Sclerenthyma Cells or Bast Fibers sometimes occur in the primary cortex or in the pericycle (Fig. If). They take their 
origin from strands similar in appearance to procambium strands that have arisen from vertical division of the cells of the ground meristem or protoderm. In the latter instance they would be classified with the epidermis from the standpoint of their origin;

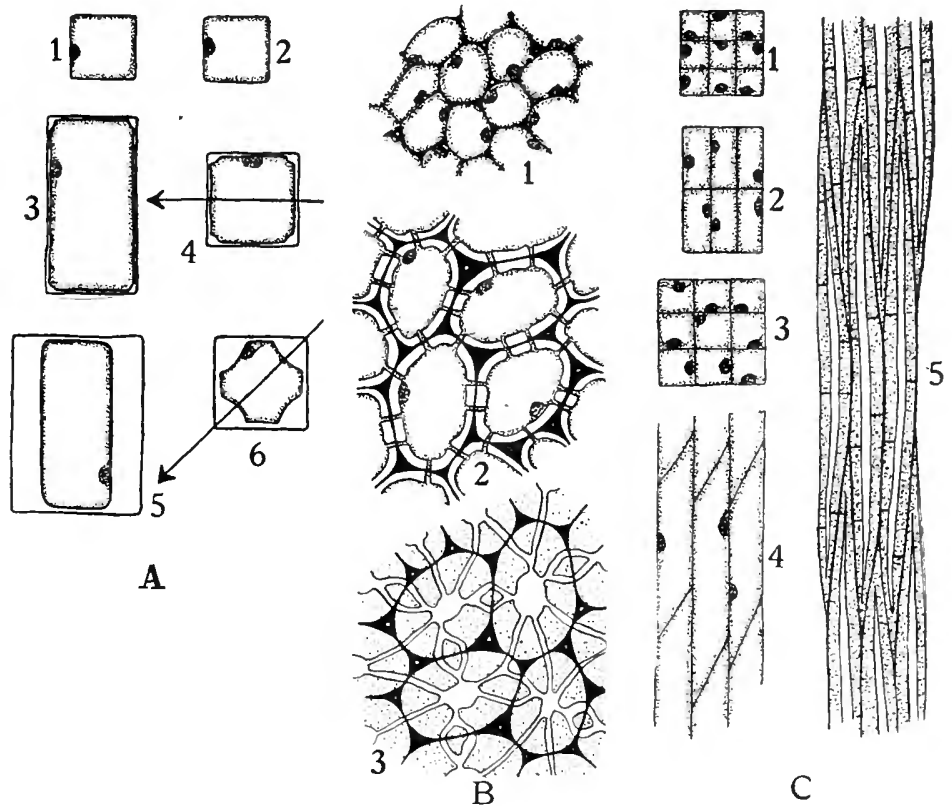

Fik. 15,--Diagram showing stages in the development of collenchyma. stone cells, and bast fibers. A, collenchyma; 1 and 2 , cross and longitudinal section of a collenchyma cell in its primary meristem condition; 3 and 4 . longitudinal anil cross-sections of the same cell at a later stage, the walls in 4 have commenced to thicken at the angles; 5 and $6,10 n g i$. tudinal and cross-sections of a mature cell. The arrows indicate the planes through which the longitudinal sections were cut. The stippling inside the walls indicates the rrotoplasts. $B$, stone cells; 1 , in the primary meristem condition; 2 , the cells have enlarged and the walls have begun to thicken and become pitted; 3 , the walls are completed. The primary wall is black, cellulose additions white, and the lignified walls in 3 are stippled. Notice that the protoplasts have disappeared in 3 , and the pits in some instances are branchea; $C$, bast fibers; 1 and 2, cross and longitudinal sections of primary meristem cells that are to become bast fibers; 3 and 4 , the same at a later stage; 5 . longitudinal section of completed bast fibers. In 5 the stippling of the wall indicates lignification. Note that the walls have become pitted and the protoplasts have disappeared from the fibers.

but on account of their position they will here be included twith the primary cortex. In their procambium-like state the bast fibers are thin- and cellulose-walled and rertically elongated; proceed- 
ing toward maturity the procambium-like cells enlarge, and principally in the rertical direction, so that the ends shove past each other and become pointed; the walls thicken and become lignified as a rule (Fig. I5), and the protoplasts finally disappear, leaving the fibers dead. This is the mode of origin of bast filers wherever they occur.

The bast fibers seem to serve chiefly, if not solely, for giving strength, for which purpose they are fitted, whether they occur in

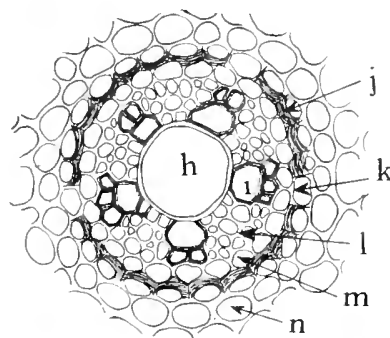

Fic. if.-Portion of a cruss. section of a root of Allium ascalonicum. $h$, large central tracheal tubc; $i$, xylem, and $l$, phloem frortion of the vascular bunule; $n$, cortex cells; $j$, endodermis with thin-walled cell at $k$ to admit passage of materials; $m$, pericycle or pericambium. (After Haberlandt.) the primary cortex or in the pericycle, by their vertical elongation, thick and lignified walls, and dove-tailing or interlacement of the ends. In roots the primary cortex usually consists of thinwalled parenchyma alone (Fig. I6).

The innermost layer of the primary cortex is the starch sheath or endodermis (Fig. I4). This in stems is, as its name implies, unusually rich in its starch content, and other than this, in stems, it oftentimes has no striking characteristics. In recent years good evidence has been brought forward. notably by Haberlandt, to show that the starch grains in this tissue act like the otoliths in the ear, and by falling always to the lower side of the cell as the position of the part to which it belongs is shifted, they furnish by their impact the stimulus for perceiring the direction of the gravity pull.

In other instances, and particularly in roots, the endodermal cells become differentiated from the rest of the primary cortex by elongating somewhat in the rertical direction, suberizing their radial walls, and by partially or completely thickening their walls (Fig. I6).

The intercellular spaces that can be found in other tissues of the primary cortex are lacking in the endodermis. These characteristics have led to the conception that the endodermis possessing 
them is intended to reduce permeability between primary cortex and stele; and this conception is strengthened by the occurrence, in such an endodermis, of thin-walled cells just in front of the xylem portion of roots where water absorbed from the soil has need of access to the water tubes (Fig. I6). In old portions of roots it often happens that the outer parts of the primary cortex slough away, leaving the endodermis to protect the stele.

The Pericycle.-The pericycle lies between the starch sheath or endodermis and the outer rim of the phloem part of the vascular bundles (Fig. If). In stems we commonly find it composed of two kinds of tissues, thin-walled parenchyma and bast fibers, the origin of which from the ground meristem is as stated for the corresponding tissues in the primary cortex. The bast fibers

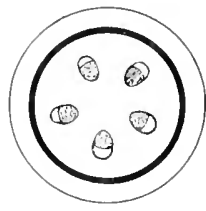

A

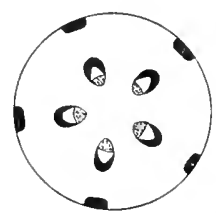

B

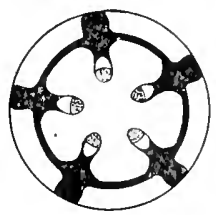

C

FIG. I 7.-Diagram to show different plans in the distribution of bast fibers. A, bast a continuous cylinder in the pericycle; $B$, isolated strands of bast in the cortex and in the pericycle in front of each vascular bundle: $C$, a combination of $A$ ani $B$. (After (ireen.)

may form a continuous zone all around the stem, or they may occur as isolated groups, either associated with, and seemingly a part of the phloem of the bundles, or dissociated from the phloem (Fig. I 7). In the stems of most dicotyledonous plants the bast fibers are restricted to the pericycle. They serve, of course, for giving strength; and unless, or until, the cambium later adds a substantial amount of wood fibers or fiber tracheids they remain the chief reliance in this respect.

The thin-walled parenchyma cells of the pericycle, like those of the primary cortex, often contain chloroplasts, and they serve for the slow conduction and storage of reserve foods, particularly of the non-nitrogenous class.

In roots the pericycle occurs usually as a single layer of 
thin-walled cells (Fig. I6), and its chief significance here is that from the division of its cells the lateral roots take their origin.

The Primary Vascular Bundle.-The typical vascular bundle of dicotyledonous stems consists, as already stated, of three parts, an outer or phloem, an inner or xylem, and a median or cambium. These, in primary bundles, are all the product of the differentiation of the procambium, and the progress of their evolution will now be followed.

A typical phloem consists of three elements, the siev'e tubes, the companion cells, and the sieve or phloem parenchyma (Fig. I4). A sieve tube consists of a vertical row of cells each of which is vertically elongated and separated from its neighbor above and below by a thickened partition wall that is perforated by many openings. These partition walls somewhat resemble a sieve and have therefore suggested the name for the tube (Fig. I4).

In the evolution of a sieve tube a vertical row of procambium cells divides longitudinally, producing a double vertical row of cells. The cells of one row enlarge transversely and rertically; their transverse or end walls thicken, leaving thin places or pits, which finally become complete openings from one cell cavity to another by absorption of the wall at the bottom of the pits, and the rertical row of cells in this way becomes a continuous tube (Fig. I 8 .)

The vertical walls of the sieve tubes are usually comparatively thin, but they are sometimes markedly thickened. The cells in the row companion to the sieve tubes, known as the companion cells, enlarge in all dimensions somewhat, but remain much smaller than the cells of the sieve tubes. The cells of the sieve tubes remain alive, at least throughout the first year of their formation. but they strangely lose their nuclei. This is an anomaly, for cells that have been deprived of their nuclei artificially soon die. It is thought in this instance that the nuclei of the companion cells extend their influence to those of the sieve tubes and so keep up there the oxidative and other processes that depend upon nuclear activity. The walls of both sieve tubes and companion cells remain cellulose. 
The contents of the sieve tubes are found to be rich in proteids, amido-acids, and soluble carbohydrates, and minute starch grains may sometimes be present in abundance. Even proteids that are in solution do not pass readily through cell-walls, and in the sieve tubes the perforations allow them to pass in an unobstructed stream from one cell or sieve tube member to the other. That the sieve tubes are for the vertical flow of proteids and allied substances is shown by direct observation under the microscope while using suitable reagents for the demonstration of proteids; and further by girdling and constriction experiments described in Chapter X.

The sieve parenchyma cells in differentiating from the procambium elongate vertically more or less and increase in their cross diameters (Fig. I8), but they do not become, as a rule, so large in any dimension as the cells of the sieve tubes. Their walls remain cellulose and commonly thicken but little. They appear to serve chiefly in the translocation of carbohydrates and as storage places

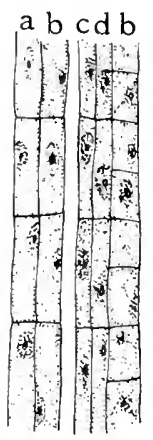

A

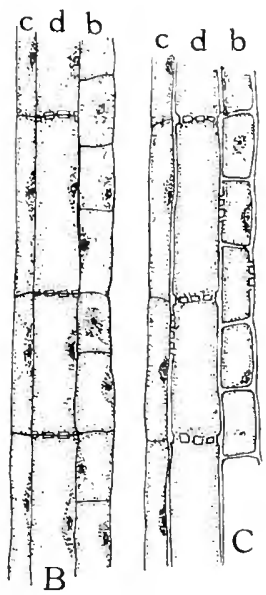

FIr; I8.-Stages in the development of sieve tubes, compranion cells, and phloem frarenchyma. $A, a$ and $b$. two rows of procambial cells; in $c$ and $d, a$ has divided longitudinally ande is to become companion cells; $d$, a sieve tube, and $b$, phloem paren chyma; $B, c$, companion cells, and $d$. a beginning sieve tube from $c$ and $d$, respectively in $A$. The cross-twalls in $d$ are pitted; $b$, phloem frarenchyma grown larger than in $A ; C$, the same as $B$ with the pits in the cross-walls of the sieve tubes become pertorations. and the nuclei gone from the cells composing the tube. for proteids which they are in position to take from the sieve tubes when a surplus is at hand, and they assist in delivering over to the medullary rays materials from the sieve tubes to be stored by the rays or transported inward for storage in the cells of the wood or xylem parenchyma.

The sieve tubes, companion cells, and sieve parenchyma cells seem to remain alive and functional throughout the first year of 
their origin, and in some instances certainly for several years, but it may be stated as a rule that they soon become crushed by the pressure of surrounding tissues, and their effectiveness is thereby reduced, and after a time altogether destroyed (Fig. 24).

The three kinds of cells taking part in the formation of the phloem as described above do not always occur together; in Monocotyledons, for example, the parenchymatous elements are absent, and in Gymnosperms and Pteridophytes the companion cells are lacking.

The primary xylem (namely, that portion of the xylem that has differentiated from the procambium and exclusive of that which is added later by the cambium) may consist of three classes of elements, the tracheal or water tubes, tracheids, xylem parenchyma, and wood fibers. 'These elements do not, however, commonly all occur together. The wood fibers are usually absent, and tracheids are not common in the primary xylem of Angiosperms; while in Gymnosperms true tracheal tubes do not occur, with few exceptions.

A tracheal tube is produced by the absorption of the end or transverse walls in a vertical row of cells, and at the same time the enlargement in all dimensions of the cells composing the tube, and the subsequent unequal thickening, and lignification of the vertical walls. The thick places in the walls are for strengthening the tube, while the thin places are for the easy passage in and out of water and materials in solution. In the tubes first formed the thick places are in the form of rings or a spiral coil. To realize the use of these, imagine barrel hoops or a flexible spiral coil of wood sewed inside a loag to make it stand open. This type of tracheal tube is differentiated from the procambium not far from the growing apex in internodes that have not yet ceased elongating, and it will be seen that the corresponding growth in length which these tubes must undergo will be but little resisted by the kind of thickenings which their walls possess. In older internodes where elongation has nearly or quite ceased stronger tracheal tubes are laid down having thin places of more restricted area in the form of pits or elongated meshes. 
While a tracheal tube consists of a chain of fused cells a tracheid is a single cell only with thin places in its walls in the form of pits with overhanging border for greater strength. These are known as bordered pits (Fig. I9). Or the thickenings may be of the spiral and reticulate types. In becoming a tracheid the procambium cell elongates and tapers at the end to a greater or less degree, thickens its wall unequally, and finally lignifies its wall (Fig. I9).

The tracheal tubes are primarily for carrying water from roots to and throughout the leaves; and the tracheids have the same function. but they may assume the character of wood fibers and be depended on for strength as well as for conducting water, as in the case of pine wood.

The cells of the xylem parenchyma are, as a rule, relatively thin-walled, and the walls are sometimes, and in woody plants commonly, lignified, and they may or may not be pitted. To form the xylem parenchyma the procambium cells divide transversely, and the young parenchyma cells enlarge in all dimensions, becoming more or less elongated vertically, with end walls at right angles to the vertical or, as a rule, only slightly inclined (Fig. I9). They differ from the tracheids by their less elongation, blunter ends, commonly thinner walls and unbordered pits. The proportion of xylem parenchyma to the other elements of the primary xylem varies greatly in different examples, from occupying the bulk of the xylem to entire absence. Its function is to store rescrve water and foods, and possibly to assist in lifting the water to the lcaves.

The wood fibers are characterized by being much elongated and taper-pointed at the ends, and by thick and lignified walls and small unbortered pits. The steps in the evolution of a wood fiber from a procambium cell are evident. 'The cell elongates, and in doing this the ends of contiguous cells shove past each other; the walls gradually thicken, and finally become more or less completely lignified. The wood fibers are chiefly to give strength, and they are assisted in this by their interlacing and dove-tailing together, as well by their thick and lignified walls. 
The cells composing the tracheal tubes soon die, so that the tube is not long alive after it comes to maturity. The wood fibers may live but one or only a few years, while the tracheids in respect of length of life seem to vary between the tracheal tubes

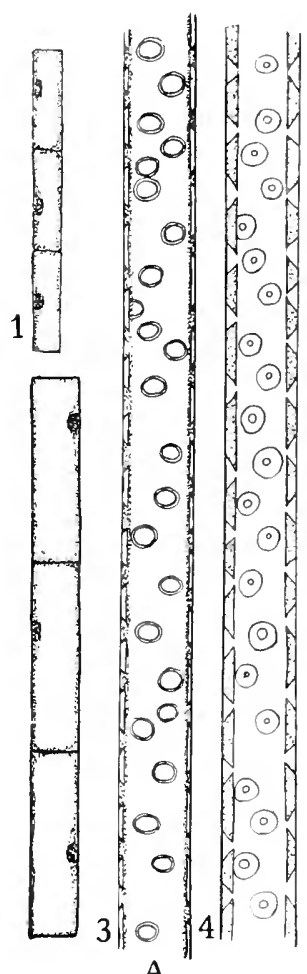

A

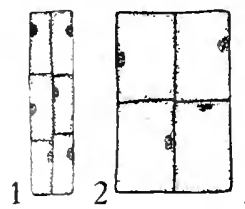

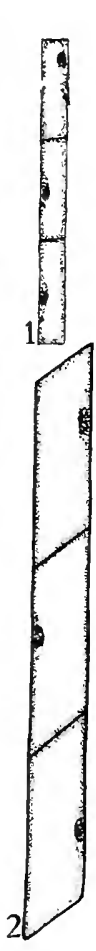

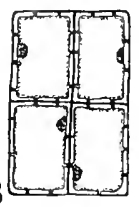

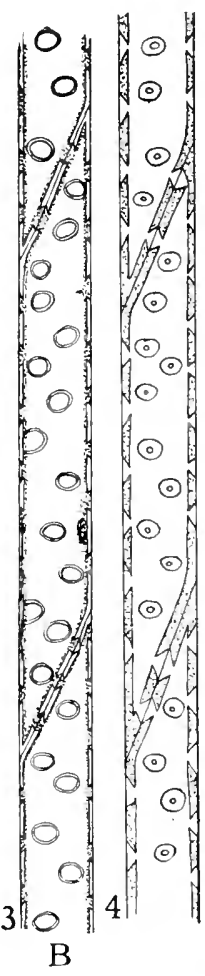
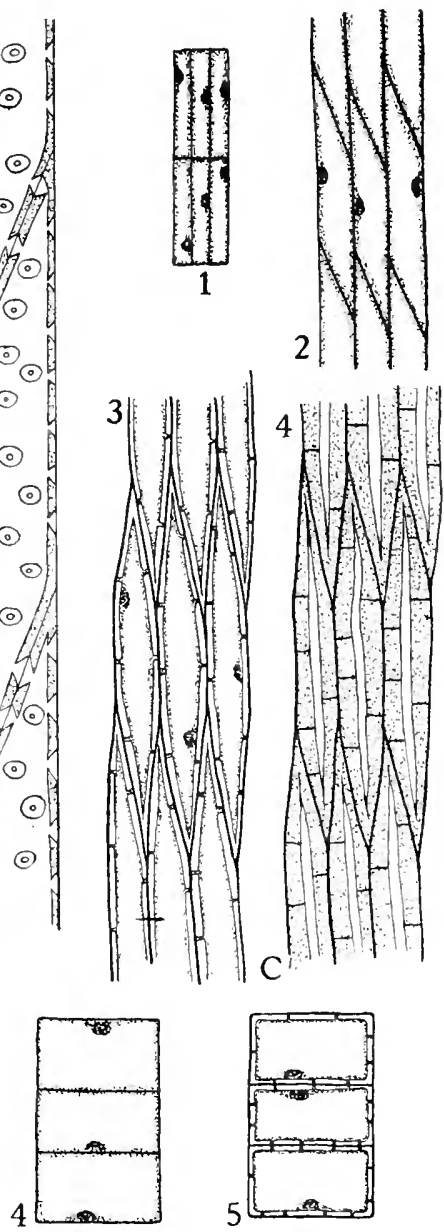

$\mathrm{D}$

Fit. ry.-Stages in the development of the elements of the xylem. A, progressive steps in the development of a tracheal tube. I, row of procambial or cambial cells that are to take part in the formation of a tube; 2, the same at a later stage enlarged in all dimensions; 3 , the cells in 2 have grown larger, their cross-walls have been dissolved out, and the wall has become thickened and pitted; 4 , the walls in 3 have become more thickened, 
and the wood fibers. The parenchyma cells are, as a rule, the longest lived of all xylem elements. They have been found still carrying on the vital function of starch storage in rings of growth nearly a century old.

After the elements of the primary xylem and phloem have been completed it is found that a layer of undifferentiated procambium cells remains between them in Dicotyledons, while in Monocotyledons and Pteridophytes the whole of the procambium enters into the composition of phloem and xylem. The layer of undifferentiated cells in Dicotyledons is known as the cambium, and its most important characteristic is that it retains the power of cell division for a longer or shorter time, even indefinitely in the case of woody perennials.

The divisions of the cambium cells may take place transversely, or vertically in radial and tangential planes; but the tangential vertical division is by far the most frecpuent and gives rise to cells known as the tissue mother cells, which by one or more cell divisions produce other cells that differentiate into the elements of the xylem on the one hand and those of the phloem on the other. These new additions to the primary vascular bundle constitute the secondary xylem and phloem.

The medulla or pith is formed by transverse and vertical divisions of the ground meristem, and the subsequent enlargement in all dimensions of the daughter cells. The pith cells are not apt to be much elongated in any one dimension, and their walls, as a rule, remain relatively thin and unchanged

the pits have an overhanging borler, the walls have become lignified as indicated by the stippling, and finally the protoplasts have disappeared, and the tube is mature and dead: $B$, stages in the formation of tracheids from procambial or cambial cells. The steps are the same as in $A$, excepting that the cross-walls remain and become pitterl. $C$, steps in the development of wood fibers from cambial cells; 1 , cambial cells; 2 , the same grown larger in all dimensions with cells shoving past each other as they elongate; 3 , a later stage with cells longer and more pointed and walls becoming thickened and pitted; 4 . complete wood fibers with walls more thickened than in the previous stage and lignified. as shown by the stippling. The protoplasts in this last stage have disappeared and the fibers are dead. $D$, steps in the formation of wood parenchyma from cambial or procambial cells. I, group of cambial or procambial cells; 2, the same enlarged in all dimensions; 3 , the same with walls thickened and pitted; 4 and 5 show the same stages as 2 and 3 , but here the cells have enlarged radially or tangentially more than they have vertically. The walls of these cells are apt to become lignified, but the cells are longer lived than the woorl fibers. 
from their orginal cellulose composition; but they are sometimes decidedly thickened and lignified. They are short lived; in woody plants the surrounding bundles crowd in and crush them, and in herbaceous plants they often break down and leave a hollow space; in other cases still they may persist for a long time as dead elements. The pith cells are for some time of use in the storage and slow conduction of water and sometimes they are employed in the storage of food, even after they are several years old, but they are evidently not commonly depended on long for any essential function.

The ground meristem lying between the vascular bundles undergoes cell division vertically and transversely and the cells thus formed enlarge and frequently become elongated in the

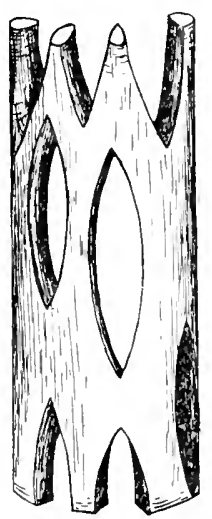

FIG. 20,-Diagram showing how the vascular bundles anastomose around the medullary rays. The gaps represent the rays. radial direction. In this way the primary medullary rays are formed. The medullary rays have two distinct functions: they carry water and substances in solution radially, inward and outward as needed, and they store water and reserve foods. Since the primary rays extend usually only a few millimeters vertically they are not suited for transporting materials in that direction. A study of crosssections needs to be supplemented by an examination of vertical tangential sections to make the extent of the medullary rays clear. In these vertical sections it is seen that the primary vascular bundles do not maintain an independent and isolated course through the stem, but anastomose with each other across the upper and lower borders of the rays, as seen in Fig. 20.

In the foregoing a type of vascular bundle has been chosen known as the collateral type; where one phloem strand stands radially in front of the xylem strand. While this is the prevailing type, there are others that must not be passed unnoticed here. It sometimes happens that a second phloem strand stands 
radially within, or on the pith side of the xylem, forming what is known as the bicollateral bundle; in other instances the phlocm surrounds the xylem, or vice versa, making a concentric bundle; while in roots it is the rule that the phloem and xylem of the primary bundle are in strands alternating with each other,
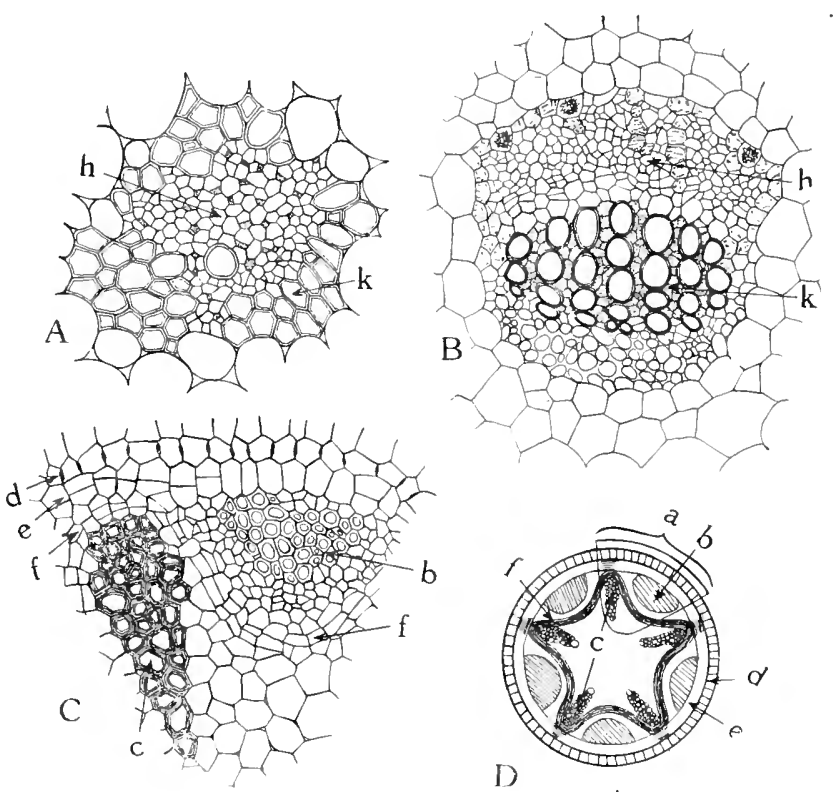

Fig. 2x.-Different types of vascular bundles. A, the concentric type, with xylem, $k$, surrounding the phloem, $h$. $B$, the collateral type, with phloem, $h$, standing in front of the xylem, $k . \quad C$, a portion of the radial type, shown complete in $D$, where the fart outlined at $a$, corresponds to $C$. Corresponding parts are lettered the same in both figures: $c$, xylem; $b$, phloem; $f$, cambium ring; $c$, pericycle; $d$, cndodermis. $C$ and $D$ are from the tap root of Vicia faba. (After Haberlandt.)

neither standing radially in front of the other, thus making what is called a radial bundle. (See Fig. 2 r for these types.)

In leaves the primordial meristem becomes differentiated into protoderm, ground meristem and procambium strands; and, just as in stems, the protoderm gives rise to the epidermis, the procambium strands to the vascular bundles which make up the greater part of the veins, and the ground meristem to 
the mesophyll cells, which correspond to the primary cortex of stems. Near the bases of leaves, below where the vascular bundles have become split up to form the smaller veins, there is often a sheath of cells surrounding the bundles which corresponds to the parenchyma cells of the pericycle of stems.

Where the rascular bundles first enter the leaves they have essentially the same constitution as in stems, with the exception of a functional cambium, but they become smaller as they proceed and ramify throughout the leaf and have correspondingly fewer parts. The rule is that the sieve tubes gradually give place to elongated but otherwise undifferentiated parenchyma cells; and in the ultimate ramifications only spirally and reticularly thickened tracheids are left to represent the bundle, and these are surrounded by a sheath of parenchyma cells belonging to the mesophyll or primary cortex, and known as the parenchyma sheath. It is the function of these mesophyll cells to collect and carry toward the base of the leaf the foods manufactured by the rest of the mesophyll (see Fig. 90).

\section{Illustrative Studies}

I. Prepare cross and longitudinal sections of the growing apex of stems of Aristolochia sipho by imbedding the material in paraffin and making permanent stained mounts as described under Cytological Methods in Chapter XIV. Use erythrosin and iodine green for the stains or safranin and hæmatoxylin.

Prepare in the same way sections from several successive internodes back from the apex. The object is to follow the progressive development of the tissues from the primordial condition at the apex down to where the primary permanent tissues appear. Find all of the tissues described in the chapter.

Draw a few cells from each tissue, using the eyepiece scale (page 279) to get all details to scale. Determine the actual sizes of the cells and thicknesses of the walls.

The erythrosin and iodine green will stain cellulose walls pink, and lignificd and cutinized walls green, and in this way 
it can be determined how far back from the apex the original cellulose walls first become modified for specific purposes.

Notice where the first elements of the vascular bundle appear in the procambium and how in older segments of stem these have become longitudinally stretched.

2. Make cross and longitudinal sections of Aristolochia stem where the stem is older than where the sections in the above studies were taken, but where the cambium has not yet begun to add to the thickness of the stem. The stem in this region will probably be too hard for the paraffin process and the sections may be cut free-hand or on a sliding microtome as described on page 262. Double stain the sections in erythrosin and iodine green and make permanent mounts in balsam (page 263). Note the changes which each tissue has undergone since the earlier stages and make drawings to scale to show these changes. Think over carefully what you have seen and embody your results in your permanent note-book.

If it is thought best not to make the permanent mounts as above suggested the sections can be examined in chloroiodide of zinc (page 292) in which cellulose walls will be blue and all others yellow. One objection to this reagent is that it swells the walls more or less. In its place aniline sulphate might be used (page $28_{7}$ ) and then the lignified walls would be yellow and all others would be uncolored. Cutinized walls could then be demonstrated by learing sections for several hours in alcanna tincture (page 285) when these walls would be pink.

3. Note the functions that in this chapter are attributed to each tissue, and see in what ways the tissues are adapted to them. Enter your observations in your permanent note-book.

4. Make a cross section of a leaf through one of the lateral veins and identify there the epidermis and the vascular bundle of the rein. The rest of the tissues belong to the fundamental or ground tissue, called in the leaf the mesophyll. Since the leaf is to be studied in detail in another place it will suffice here to enter in the note-book a simple diagrammatic drawing showing the relative positions and amounts of these different tissues. 


\section{CHAPTER III}

\section{SECONIUAR INCREASE IN THICKNESS}

\section{DICOTYLEDONS AND GYMNOSPERMS}

If we follow the history of any particular region of stem or root we find that its growth in thickness up to the time when its growth in length ceases is due to the enlargement of the cells that arise from the division of the cells of the primordial and primary meristems. In other words, increase in thickness is at first due to the enlargement of the cells of the epidermis, primary cortex, pericycle, phloem, xylem, medullary ray, pith. Such increase, known as primary increase in thickness, soon ceases, and subsequent growth in thickness is due to the differentiation of additional tissues following the production of new cells by the division of the cambium, or cork cambium in the bark.

Growth of the Vascular Bundles.-It will be remembered from the preceding chapter that the cambium ring is composed of two parts: the fascicular cambium consisting of procambium cells lying between the phloem and xylem which remain practically unchanged in form and retain their power of division, and the interfascicular cambium which is formed by the tangential division of primary medullary ray cells that lie in a line connecting the fascicular cambium of contiguous bundles. The cambium cells begin active cell division immediately following the differentiation of the primary tissues told about in the last chapter, and by the differentiation of these new cells the fascicular cambium adds tissues to the xylem toward the inside, and to the phloem toward the outside, and the interfascicular cambium makes additions in like manner to the primary medullary rays.

It is found on comparing the rate of growth of phloem and xylem that the latter increases much more rapidly than the 


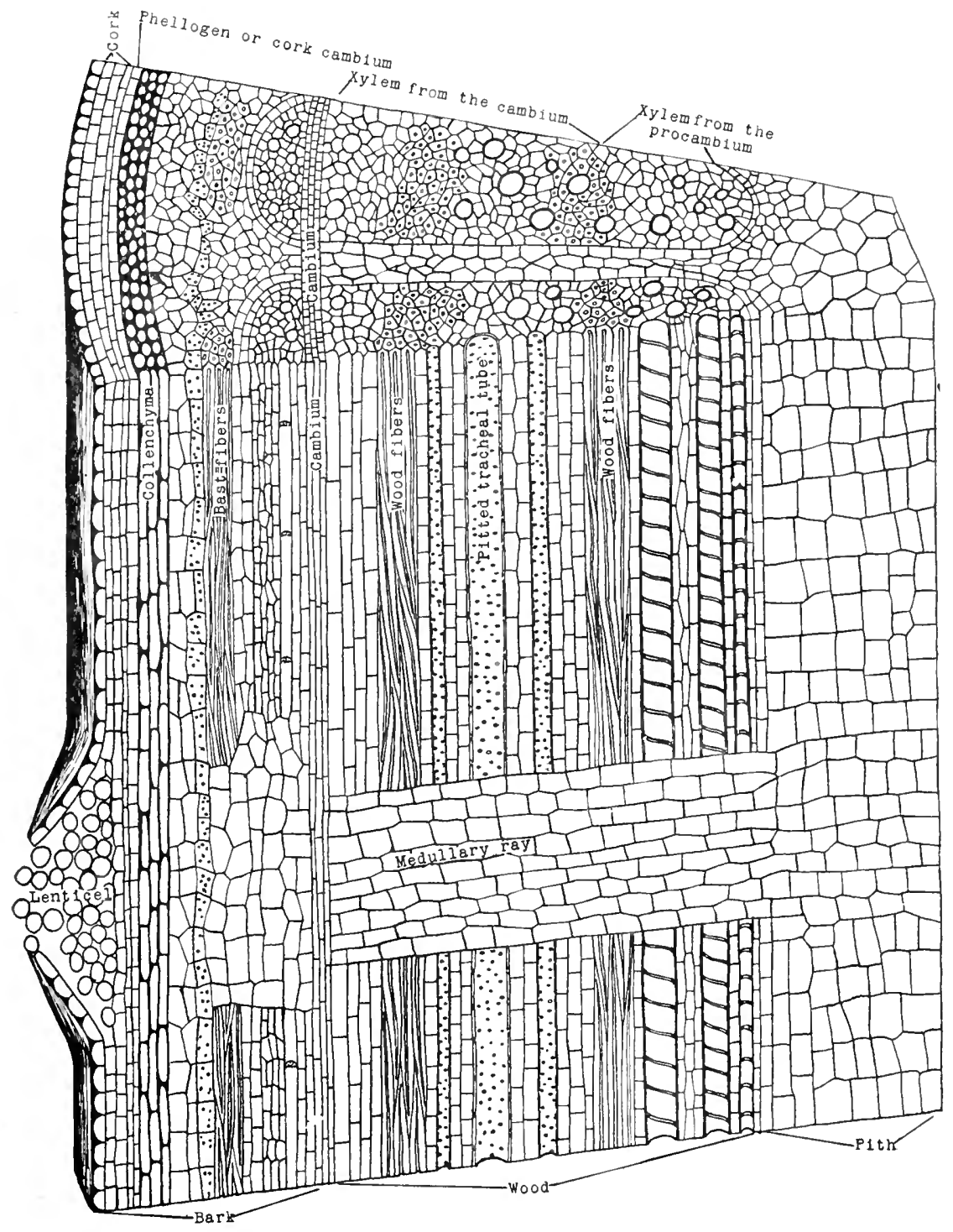

FIG. 22.-Diagram showing additions to the primary tissues through the activity of the cambium and phellogen or cork cambium. Compare this with Fig. I. In this diagram stone cells have been omitted. 
former. This is due to the fact that when a cambium cell divides, by the formation of a tangential wall, which it usually does, the daughter cell facing the xylem much more frequently differentiates into the permanent condition than the one facing the phloem, the latter continuing as a cambium cell; but sometimes the daughter cell facing the phloem grows to be one of the phloem elements, while the one facing the xylem remains in the cambium condition.

The kinds of tissues which the cambium adds to the xylem vary in different plants. In many Gymnosperms wood paren-

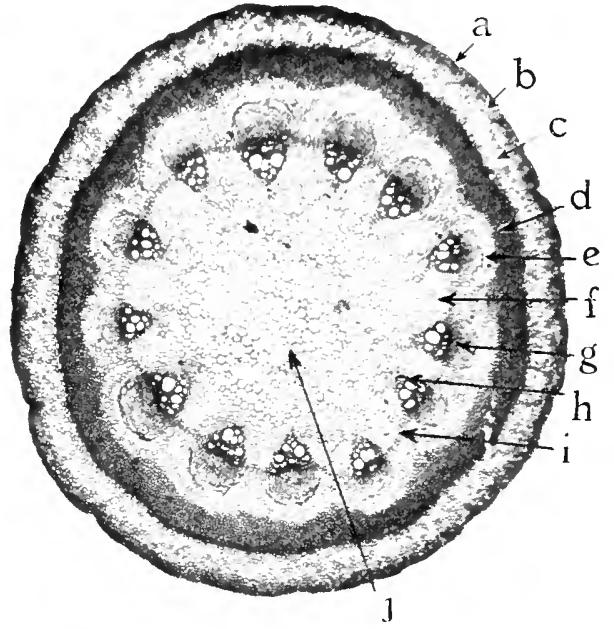

FIrr, 23.-Photomicrograph of cross section of stem of Aristolochia sipho, where cambial activity is just beginning. $a$, epidermis; $b$, collenchyma; $c$, thin-walled parenchyma of the cortex, the innermost cell layer of which is the starch sheath or endodermis; $d$, sclerenchyma ring of the pericycle; $\varepsilon$, thin-walled parenchyma of the pericycle; $f$, primary medullary ray; $g$, phloem; $h$ xylem; $i$, interfascicular cambium; $j$, melulla or pith. $\times 20$. chyma cells are formed, but, except in a single genus, neither tracheal tubes nor wood fibers, their place being usurped by tracheids which perform alike the strengthening and water-conducting functions. In Angiosperms are produced tracheal tubes of the pitted type, tracheids, and transitional forms between these two. xylem parenchyma and wood fibers, and transitional forms between these also (Fig. 22). On the phloem side the cambium adds sieve tubes, and, varying with the kind of plant, companion cells or phloem parenchyma, or both of these, and, in many instances bast fibers.

While, by its tangential divisions, the cambium is thus adding to the radial diameters of the phloem and xylem, it is also, but at a slower rate, increasing their tangential diameters by its 
radial divisions; so that in cross sections the vascular bundle has the form of a wedge with its apex pointing toward the center (Figs. 22, 23 and 24). As this wedge broadens new or secondary medullary rays are from time to time begun by the fascicular cambium (Fig. 24). These rays average less than half a millimeter in vertical extent, although in a few instances they run Ioo to 200 millimeters from node to node; and in their tangential diameter they are seldom more than five hundredths of a millimeter, while radially they keep pace in growth with the phloem and xylem, and so always extend from the place of their origin in the xylem out between the phloem strands. The stimulus to form more medullary rays seems to come from the need of more radial highways as the diameter of stem and root and absorbing surfaces of new roots and food-building tissues of new leaves increase. The details of this will be discussed in Chapters VII and X. The daughter cells of the fascicular cambium, in becoming secondary medullary ray cells, enlarge chiefly in their radial and tangential diameters, becoming elongated radially, as a rule, in the xylem, but often vertically in the phloem.

While the vascular bundle is thus enlarging and secondary medullary rays are being laid down, the interfascicular cambium is adding new cells to the primary medullary rays and thus causing them to keep pace in radial growth with the vascular bundles. Not infrequently, however, the interfascicular cambium forms new vascular bundles which, in cross section, appear to cut the primary ray into narrow strips.

In the xylem portion of both primary and secondary medullary rays the tangential walls remain relatively thin or become pitted, and the radial walls are thin or pitted where they come into contact with tracheal tubes, tracheids, or xylem parenchyma; while the transverse walls are apt to be much thickened and lignified. In the phloem portion of the rays the walls remain thin and unlignified.

Fig. 24 shows that the cambium adds much more to the xylem than it does to the phloem. The growth of the xylem 
continues, as a rule, to the middle or end of August, but the growth of the phloem continues after this even until frost.

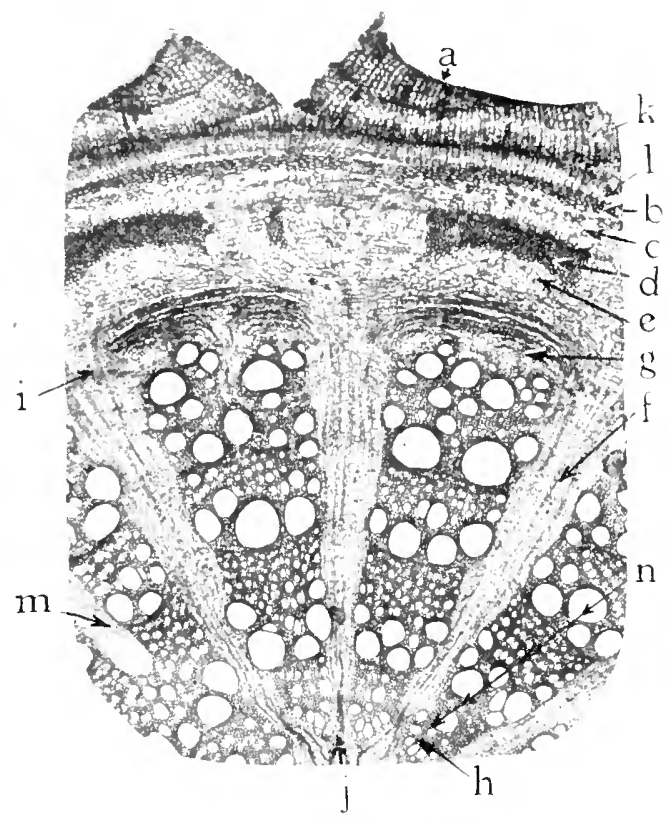

Fit. 24-Portion of cross section of four-year-olid stem of Aristolochia sipho, as shown by the rings of growth in the wood. The letters are the same as in Fig. 23, but new tissues have been added by the activity of the cam bium; and a corh cambium has arisen from the outermost collenchyma cells and given rise to cork. The new tissues are: $l$, cork cambium; $k$, cork; $g$, secondary phloem from the cambium, and just outside this is older crushed phloem; $n$, secondary xylem proluced by the cambium; $m$, secondary medullary ray made by the cambium (notice that this does not extend to the pith). Half of the pith is shown. Notice how it has been crushed almost out of existence. Compare Figs. 23 and 24 , tissue for tissue, to find out what changes the primary tissues undergo with age, and to what extent new tissues are added. Photomicrograph $\times 20$.

phloem may vary in like degree; bast fibers may or may not occur; and so with the companion cells and phloem parenchyma.

One of the most wonderful things about plants is that the daughter cells of the cambium may become such various things. How is it that a daughter cell facing outward is directed to
'The kinds and relative amounts of the tissues in secondary xylem and phloem vary a great deal in different families, genera, and species; and this fact is often very uscful to the anatomist and pharmacognosist in characterizing and identifying materials. parenchyma may vary from abundance to entire absence; tracheids may prevail or be lacking; tracheal tubes may vary greatly in size and number, or in their contact with one another or complete isolation; wood fibers may be present or absent, numerous or infrequent. The character of the Thus, the xylem 
take part in the formation of a siere tube, while one facing inward undergoes quite other transformations to form a tracheal tube? And how can the daughter cells facing inward become any one of the xylem elements, apparently quite at will? They all have the same parentage, and probably the same potentialities, but behave differently, possibly because they are responding to stimuli of different natures. It may be that these stimuli arise in present need or necessity; but the response is modified by the peculiar potentialities of the particular species. Thus, the daughter cells of the cambium in the oak, feeling the need of more water-transporting tissues, would transform themselves into tracheal tubes, while in the pine, under like circumstances, tracheids with large cavities would be formed. The so-called ring of growth throws some light on this question and will now be considered.

In the stems and roots of trees and shrubs it is found that the addition made to the xylem during each growing season consists of two more or less well-defined parts, namely, an early growth, in which the tracheal tubes are relatively more abundant and possess larger cavities (Fig. 24), or where, as in conifers, the tracheids have relatively large cavities and thin walls; and a late growth, in which the tracheal tubes are relatively fewer and smaller, and the tracheids have smaller cavities and thicker walls (Fig. 52). In the early growth the water conduction elements may be said to preponderate, and in the late growth the strengthening elements; and this is as it should be, for the plant first feels the need of water in the spring, and later the need of greater strength. The first manifestation of growth in the spring is the unfolding of the leaves, and in Dicotyledons and Gymnosperms there are more of these than appeared the previous year, for the crown of branches grows larger every year; and even if the old tracheal tubes or tracheids were in direct communication with the new leaves they would not suffice. But the old water channels in the stem do not extend into this year's leaves and new ones must be formed which will be continuous with those in the leares (see Fig. 25). Later, when most 
or all of the leaves have been formed, and tracheal tubes communicating with these have been laid down in the stem, the

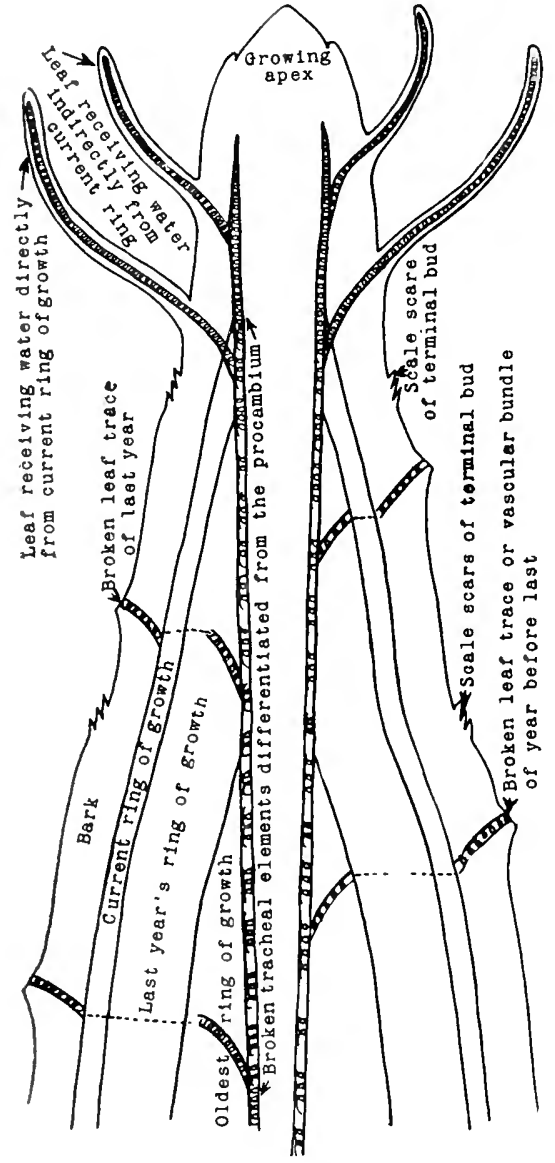

FIs. 25,-Diagram showing the relation $\mathrm{ct}$ this year's leaves to the wood of the current year. cambium can derote itself more exclusively to the production of strengthening tissues, the need for which has been caused by the increased size and weight of the crown. The two different regions of a ring of annual growth are, therefore, seen to be an anatomical expression of varying physiological needs.

Sometimes it happens that trees are stripped of their leaves by insects, and later become rehabilitated by the growth of buds that would under normal conditions, have lain dormant until the succeeding spring. It is then found that the new crop of leaves stimulates the production of a new ring of growth in the stem, much as would have happened the following spring if things had been left to their wonted course.

In those tropical regions where there is no pronounced dry season and the leaves do not all fall off at once, but just a few at a time with gradual renewal, there is no ring of growth formed; but where in the tropics a decided dry period provides plants with too little water, the leaves drop off just as they do outside 
the tropics on the approach of winter, and when these plants again clothe themselves with leaves a ring of growth is formed as already described. Such facts as these strengthen the conception that the formation of the ring of growth is at first stimulated by the demand for water on the part of the leaves.

Secondary increase in thickness in roots does not differ essentially from that of stems, and the slight difference that occurs is due to the peculiar arrangement of the phloem and xylem in the root bundle. It will be remembered that the phloem and xylem strands in roots stand side by side and not in radial line as in stems. (Compare diagrams in Fig. 2I.) When secondary increase in thickness begins, the cambium flanking the phloem on the inside or toward the center lays down xylem elements, so that, with the already existing phloem, a collateral bundle, such as is typical in stems, is produced. At the same time the cambium in front of the original or primary xylem commonly forms a medullary ray (Fig. 26), but it sometimes makes phloem elements and thus completes a collateral bundle here also. The cambium then continues to add new phloem and new xylem in both cases, and secondary medullary rays as the dimensions of the xylem and phloem wedges increase, and the root soon comes to look quite like a stem, the discernible difference being 
where the landmarks of the primary xylem and phloem can still be made out.

The purpose of the radial arrangement of the primary xylem and phloem of roots appears to be to allow the water absorbed by the root hairs to pass into the xylem highways without first traversing the food highways in the phloem. The changes brought about by secondary thickening would not interfere with this purpose because they occur in older parts of the root where the root hairs have already dicd away.

Increase in the Cortex. - The growth of the vascular bundles subjects the primary cortex to a good deal of tangential tension and its thin-walled parenchyma cells commonly undergo enough increase by radial division to keep from breaking apart, but increase in thickness of the primary cortex takes place in woody perennials and in the underground parts of herbaceous perennials by the formation and continued activity of a zone of cork cambium or phellogen. This takes its origin in the tangential division of the epidermis or in a similar division of the cells immediately beneath the epidermis (compare Figs. 23 and 24). When the origin is in the epidermis the inner cell cut off by the tangential wall takes part in the formation of the cork cambium, while the outer cell enlarges and remains epidermal. If the origin is in the cell layer just beneath the epidermis, it is the outer row of daughter cells that becomes cork cambium. 'The formation of the cork cambium commonly takes place before the end of the first year's growth, and by frequent tangential as well as radial divisions it soon gives rise to layers of cork cells toward the outside, and frequently to thin-walled parenchyma cells toward the inside, called the phelloderm. These new tissues, including the cork cambium which forms them, are termed the periderm. Since the walls of the cork cells are suberized and in uninterrupted union, the passage of water and gases is prevented. The epidermis being thus shut off from the water supply from within soon dies and gradually sloughs away; but provision is made for the aeration of the tissues lying within the cork zone by the production of a loose mass of cells which inter- 
rupts the cork layer and allows the air to enter through its intercellular spaces (Fig. 22). This aerating tissue is known as a lenticel. It commonly arises beneath a stoma by the division of phellogen cells lying at the same depth as those that form the cork, and as it increases in size the stoma above it is crowded outward and a rent is made in the epidermis.

In woody plants, as a rule, the cork soon comes to take the place of the epidermis, as can be seen by the roughening of the surface where the epidermis has disappeared. 'The phellogen first formed near the surface does not remain active indefinitely and a new one is formed deeper in, which, after a time of cork building, is replaced by a still deeper one, and so on. Sometimes phellogen layers are formed as deep in as the tissues of the pericycle, and even within the secondary phloem, and large masses of tissues called borke, thus cut off from the water supply by cork which the phellogen builds, die, dry up, and fall off. This is well seen in the shell-bark hickory, sycamore, grape vine, and birch. Frequently the borke clings with great tenacity and is furrowed by many clefts as it is stretched beyond its strength by the increase in diameter of the stem, as seen in the oak, hackberry, and elm. After a time it may come about, as the borke falls away, that all of the original primary cortex is gone and its place is taken by cork, phellogen, and phelloderm; or, to use the collective term, by the periderm; and, as has been said, even the pericycle and old phloem tissues may be thus replaced.

The periderm and additions to the phloem by the cambium are collectively called the secondary cortex. It will be seen from the foregoing that the word cortex has three different applications: First there is the primary cortex, extending from the epidermis to the pericycle; then there is the secondary cortex as just defined; and finally cortex without qualifying adjective is applied to all of the tissues outside the cambium ring and is synonymous with bark. Borke is a Germna word meaning bark or rind. As frequently used by the German botanists, it has not the same application as our bark, which includes every- 
thing outside the cambium, but designates those tissues which are cut off by the deep-lying cork layers as told above.

In roots the phellogen takes its origin from the pericycle, so that the whole of the primary cortex is shut off from the interior water supply as soon as cork is formed and soon thereafter dies. It is, therefore, the periderm that constitutes most of the bark of old roots.

\section{Monocotyledons}

Monocotyledons have no cambium ring and additions to the rascular bundles cannot take place as in Dicotyledons. The absence of a cambium ring is due to the fact that the procam-

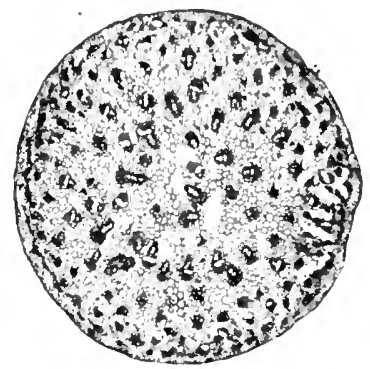

Fic, 27-Photomicrograph of cross section of very young cornstalk, where the procambium strands have just gone over into vascular bundles. For comparison with Fig. 28. bium strands differentiate entirely into the permanent tissues of xylem and phloem, learing none of their cells in the meristematic condition (Fig. 28). Increase in thickness in most monocotyledons takes place simply by the enlargement of the cells of the permanent tissues that are formed from the primary meristems near the growing apex, and this enlargement, as a rule, soon ceases (compare Figs. 27 and 28); but in palms it continues for a long time in the ground tissue, including the sclerenchyma sheath around the vascular bundles, until the diameter of the stem has been doubled or trebled. This method of enlargement does not increase the number of the vascular bundles, nor the capacity of the food and water highways of those already existing, and the size of the crown of leaves which would evaporate the water and supply the food cannot be permitted to increase indefinitely from year to year, as in the case of Dicotyledons, where the conducting highways are added to each year by the cambium. In palms, for instance, the old leaves are shed about as fast as new ones are formed. 
Another method of growth in thickness is found in the arborescent Liliacex, represented by the genera Dracena, Yucca, and Aloë. Here, either close to the growing apex, or remote from it in the region of the permanent tissues, a secondary meristem is formed by the tangential division of the cells of the pericycle, which adds new cells both inward and outward. A part of the cells added toward the inside become differentiated into new vascular bundles (Fig. 29), and a part into new ground meristem; while those, much less in number, formed toward the outside constitute a secondary cortex. In this way growth in thickness goes on from year to year, and has been known to produce in Dracæena a stem diameter of fifteen feet. In this instance, however, the tree was estimated to be six thousand years old.

Unusual Growth in Thickness.--Variations from the usual modes of secondary thickening take place in several families of Dicotyledons (Apocynacer, Sapindacex, Bignoniacere, Chenopodiacee, Amarantacex, Phytolaccaceæ, Papilionacex, Nyctaginacere, and, under the Gymnosperms, the Cycadacex and species of Gnetum. A type of frequent occurrence is where the cambium ring soon ceases its activity and a new ring of secondary cambium is formed by tangential division of cells of the pericycle, and after this has laid down a zone of rascular bundles surrounding those first formed it becomes inactive and a new cambium ring giving risc to a new zone of bundles is 
formed outside of it, and so on (Fig. $30, C^{*}$ ). A peculiar type is found in the climbing Serjanias of the family Sapindaceæ where the stem is traversed rertically by several ridges, which in cross section look like lobes, each containing a circle of vascular bundles surrounding a pith; and the center of the stem is occu-

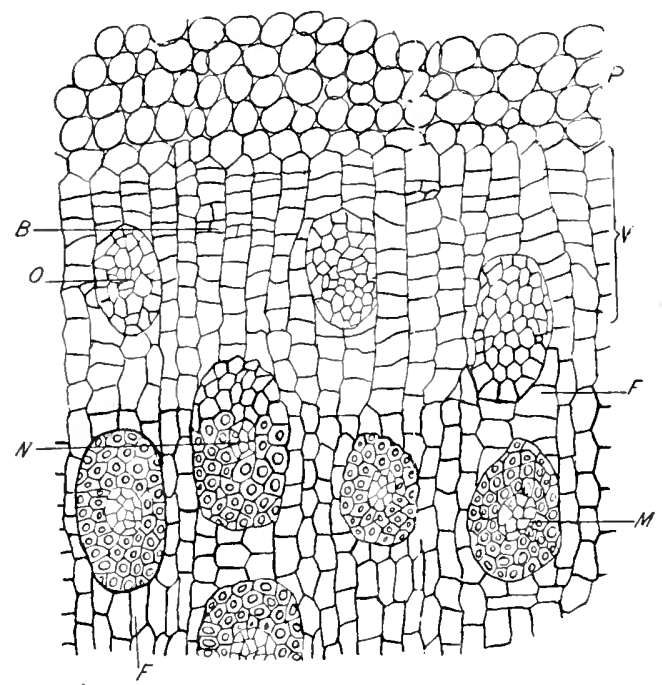

FIG. 29.-Portion of a cross section through the stem of Dracena marginata. $P$, parenchyma of cortex. $\quad \mathrm{V}$, meristematic zone of the pericycle by the activity of which the stem increases in diameter, with the aldition of new vascular bundies. $M$, mature vascular bundle. $N$, nearly mature vascular bundle. $O$, newly formed procambium strand from which a vascular bundle is to arise. $B$, beginning of a procambium strand by the division of cells in the meristematic zone. $F$, parenchyma of the fundamental tissue. (After Haberlandit.)

pied by a circle of vascular bundles in the usual way. The stem is ridged when first formed from the primordial meristem, and the primary bundles, following the contour of the stem are laid down in the form of a lobed circle, as seen in cross section. When the interfascicular cambium is formed it extends across the base of each lobe, cutting it off from the central or main part; and then it completes the circle of bundles in each lobe and also the central circle, so that each xylem or wood cylinder is entire and surrounded by a phloem cylinder. 
Some of the climbing Bignoniacere vary from the usual type by the cambium failing to form xylem here and there as secondary thickening progresses; so that the wood cylinder becomes more or less deeply cleft by the phloem (Fig. 30, $A$ ). In cxtreme instances the wood may become cut up into many isolated strands by the production of secondary meristems from cell division in the rood parenchyma, medullary rays and pith (Fig. 3o, B), and by ingrowth of cells of the pericycle; and the secondary meristems may add new tissues to these strands and even interpolate new strands among them.

The growth in thickness of fleshy roots, tubers, and rhizomes, does not, as a rule, differ in method from the normal type, but the cambium gives rise principally to wood parenchyma and medullary ray cells, or the cells of the primary cortex and pericycle multiply enormously and constitute most of the thickening; or, again, the secondary cortex may be chiefly involved, as in the root of Taraxacum officinale. A notable exception to the normal type is found in the root of the beet where successive secondary cambium rings are formed outside the first and by their activity bring about the thickening of the root.
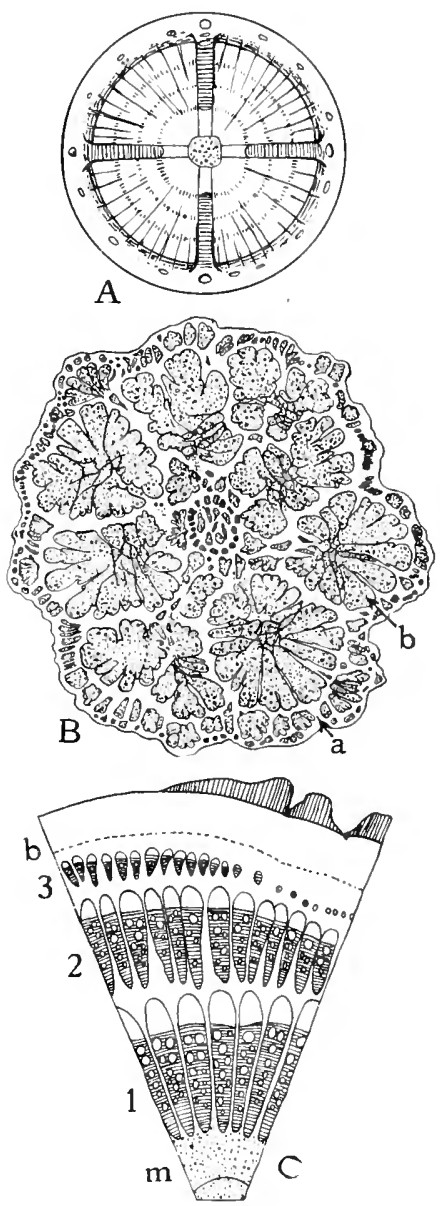

Frg. 30.-Diagrans showing some types of unusual growth in thickness. $A$, cross section through a four-year-old stem of Anisostichus capreolata; $B$, cross section of stem of species of Bauhinia; the xylem strands, $b$, are stiplled while the surrounding parenchyma and bark tissues are left white. $C$, portion of a cross section of stem of Gnetum scandens; 1,2 and 3 are successive rings of growth; $m$, is the pith; $b$, is a sclerenchyma ring. The xylem portions with the exception of the larger tracheal tubes are shaded, while the medullary rays, phloem and tissues intervening betwcen the rings of growth and the outer cortex tissues are left white. (A and $C$, after de Bary; $B$, after Schleirlen. 


\section{Illustrative Studies}

I. Make cross and longitudinal sections of a stem of Aristolochia that is several years old (Fig. 24). The sectioning will need to be done on a sliding microtome, and the sections should be stained with erythrosin and iodine green, or with safranin and hamatoxylin, and made into permanent mounts in balsam. Study with low and high powers and note the changes which each tissue has undergone since the last condition studied. What tissues have increased? decreased? been broken? crushed? Have new tissues appeared? Make drawings and diagrams to show the changes discovered.

2. Pay particular attention to the new medullary rays. What evidence can you find as to how they have originated? Assuming that the function of the rays is to carry water and food radially and to store them also, can you see special need of the new rays?

3. Find the primary xylem and phloem (page 36 ) of the rascular bundles. Have they been changed in position and condition since first they were formed from the procambium?

4. Study cross sections of cornstalk close to the growing apex and farther down where growth in diameter is well-marked. As the stem increases in diameter, do the vascular bundles enlarge? Does the number of cells in them increase? Does the number of vascular bundles increase? What changes take place in the ground tissue as stem enlargement progresses? Do you find cambium in the vascular bundles? Draw a vascular bundle on a large scale and show how it differs from a dicotyledonous bundle (of Aristolochia, for instance).

Good material for this study of corn can be obtained from stalks of field corn about two feet high. By stripping away the leaves and leaf sheaths the stem will be found extending about six inches up from the ground with nodes and internodes in all stages of derelopment. 


\section{CHAP'TER IV}

\section{PROTECTION FROM INJURIES AND LOSS OF IVATER}

The simplest unicellular plants cover themselves with a thin cellulose cell-wall. This is harder and tougher than the protoplast and preserves its form and protects it from injuries; but since it must be of a nature to allow the passage inward of water and solutes it cannot be efficient in keeping the protoplasts from drying up. It is found that if a cell-wall will allow water to pass in it will also let it out; and while the plasmatic membrane is able to retain osmotic substances in solution in the water of the cell-sap it is unable to prevent the loss of the water itself. The unicellular plants, or those consisting of a few cells only, have found that they can inhabit only wet and moist places, or else be able to exist for longer or shorter periods in a condition of extreme desiccation. As soon as plants in the course of their evolution increased in size and complexity and began to burrow in to the earth for its treasures of water and minerals, and, at the same time, to rise into the air and light, where they could appropriate other raw materials and the sun's energy, they found themselves exposed to danger of destruction from mechanical injuries and loss of water; and they found in working out the problem, which such plants have had to solve, of division of labor among different sets of cells composing the body, that it was necessary to assign one or more exterior tissues to the function of protection.

'Two tissues, the epidermis and the cork, have accordingly been evolved for the specific purpose of protection, and two others, the collenchyma and superficial sclerenchyma cells and fibers which belong to the skeleton of the plant, also give protection by reason of their hardness, toughness, and tensile strength. Without such safeguards large terrestrial plants standing ready at 
any time to make use of available materials and forces never could have been wrought out.

\section{The EpIderuis}

The Epidermis as a Protective Tissue.-The epidermis is the first, and often the only, protective tissue formed, and since it lies at the exterior it must bear the brunt of adverse conditions
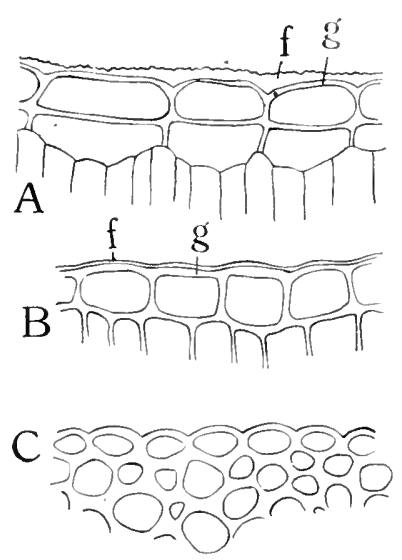

FIG. 3I,- 4, cross section through upper half of leaf of Pyrus Japonica, showing cutinized layer of the outer wall at $f$, and cellulose layer at $g$. $B$, the same for the leaf of Russian olive; the cutinized layer is thinner and the cellulose layer thicker than in the former instance, $C$, portion of cross section of subnerged stem of Nymphæa odorata, where there is no cutinizerl layer, and the cuticle is a hardly distinguishable film.

in the environment. It prepares itself for its task mainly by modifications of its outer wall, which it thickens and waterproofs according to the demands made upon it. The thickness of an average outer epidermal wall under normal conditions of moisture in the substratum and surrounding atmosphere is not far from $.0033 \mathrm{~mm}$., or about one thirty-sixth the thickness of this page; but as greater dryness in the environment imposes severer conditions, and where the epidermis persists through several years with incident wear and tear, we find the outer wall often increasing in thickness, even up to $.03 \mathrm{~mm}$., or one-fourth the thickness of this page, as in the case of the mistletoe (Fig. 3I). Measured by ordinary standards, the epidermal outer wall is in any case extremely thin and would seem poorly adapted to withstand any kind of mechanical attack; but it must be remembered that the epidermal cells are very minute, averaging about $.03 \mathrm{~mm}$. in tangential diameter, so that the radial walls serving as a foundation on which the outer wall rests, are that distance apart merely. Any stress upon the outer wall is, therefore, not borne by it alone, but by the radial walls also and the underlying tissues with which 
these are connected. Added to this the outer wall commonly curves outward, as it spans the space between the radial walls (Fig. If) and is thus made more resistant against stress from without. The part which the radial walls play as props for the outer wall will be better apprehended by an example. Assuming that the tangential diameter of the epidermal cells is $.03 \mathrm{~mm}$. and that the cells as seen from the surface are four-sided, then if any object I sq. mm. in cross section were pressing upon the epidermis there would be more than 2,000 radial walls immediately beneath and sustaining that portion of the outer wall upon which the pressure comes. Of course the smaller the object which is pressing upon the surface the better chance it has of piercing the outer wall. Since the point of an ordinary needle would cover not more than one-quarter of the surface of our arerage epidermal cell it could be placed so as to aroid the radial walls in piercing the surface. Experimenting on leaves grown under a verage conditions, it has been found that when using such a needle a pressure of $.55 \mathrm{gm}$. to $.8 \mathrm{gm}$. was necessary to break through the outer wall of the upper epidermis.

Incrustations and infiltrations of silica and calcium carbonate often contribute to the defense of the outer wall, and this to a very notable extent in Equisetum and many grasses where silica is very abundant.

The cutinization of the outer wall, which is primarily for waterproofing, increases the power to resist tearing, experiments having shown that the cutinized wall may be even ten times as strong in this respect as ordinary cellulose walls.

Turning from the anatomical and experimental details, we find nature giving a broad and convincing answer regarding the mechanical efficiency of the epidermis. Leaves, on the whole, outride the storms and vicissitudes of three seasons practically uninjured; and herbaceous plants run their course with nothing but the epidermis to cover them. In the whole group of fleshy fruits the epidermis has been found an adequate protection until the time of ripening; and in many woody plants, such as species of Acer, Rosa, Cornus, Acacia and Cinnamomum, the epidermis, 
continually renewing the outer wall as it wears away, remains as the sole outer covering for many years.

The epidermis is, however, not proof against all attacks that plants are subject to; insects seem to have little difficulty in gnawing through or piercing the outer wall, and many parasites excrete ferments that render it soluble, and storms sometimes overtax its strength. But such things are on the whole not sufficiently severe and widespread, at least in the course of a single growing season, to make a serious demand for reenforcement of the epidermis.

The Epidermis as a Waterproof Covering.- The chief value of the epidermis lies in the protection which it gives against a too rapid evaporation of water. All terrestrial plants of any size would lose water faster than they can absorb it, but for the protection which the epidermis affords. As stated in the previous chapter, the waterproofing of the epidermis lies in the cuticle and cutinized layer of the outer wall. The cutin which gives these their peculiar character is waxy in its nature, and when present in abundance it makes the wall practically impervious to water. The cuticle seems to be nearly pure cutin, while the cutinized layer appears to contain a certain percentage of unaltered cellulose. In many cases the cutinized layer is absent and then the outer wall consists of cellulose bounded externally by the water-proof cuticle. We adopt the scheme of plants when we pour paraffin over jelly to keep it from drying out and molding, and when we coat paper with paraffin for waterproofing purposes.

The efficiency of the epidermis in preventing loss of water is seen by comparing the amount of loss where the epidermis is removed in some cases and left intact in others. For instance, two apples were hung up in a dry atmosphere, one pared and the other uninjured, and after forty-eight hours the former had lost 33 per cent. of its original weight and the latter I per cent. An Aloë leaf, according to Heberlandt, had in twenty-four hours lost 15.6 times 'more water where the epidermis was removed than where it was left on. 
As might be expected, the amount of cutinization, as well as thickness of the outer wall, depends upon the severity of the demands made by the environment. In submerged water plants the outer wall is usually thin and little if at all cutinized, while parts rising above the surface of the water show greater thickness of wall and more cutinization. In land plants the waterproofing characters become more pronounced and reach their fullest development in desert regions, or in alpine and arctic regions, and bogs and salt marshes, where the water, although present in abundance, is difficult of absorption on account of its low temperature or the inimical nature of the substances dissolved in it. Plants of the same kind grown in dry and in moist atmos-
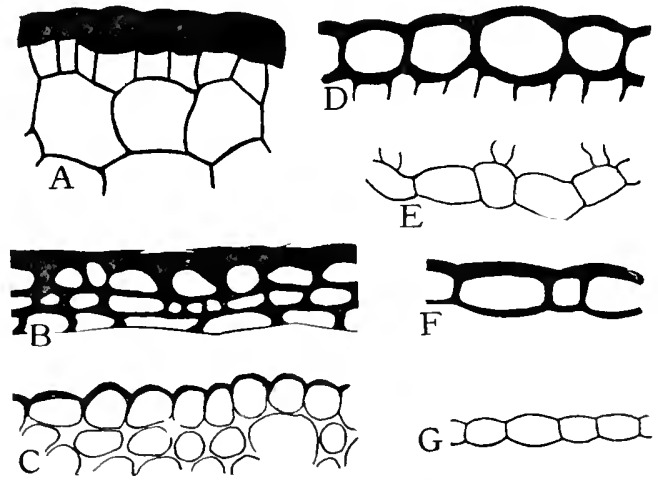

FIG. 32.-A, portion of cross section of leaf of Avicennia growing in salty soil; outer wall of epidermis very thick. $B$, cross section through skin of apple. $C$, cross section through upper half of petal of Japan quince. $D$, upper, and $\mathrm{E}$, lower epidermis of leaf of Hibiscus moscheutos. $F$, epidermis of leaf of Lactuca scariola in the sun; and $G$, in the shade.

spheres are apt to differ decidedly in their epidermal defenses; and even the different parts of the same plant or the same members of a plant are apt to differ in this respect according to the demands made upon them. Thus, the upper epidermis of a leaf has, as a rule, a thicker and more highly cutinized outer wall than the lower epidermis (Fig. 32), and the epidermis of the petals of a flower, which are to endure for so short a time, is insignifi- 
cant in its defensive characters in comparison with the epidermis of the fruit which is to last through a much longer period and endure greater hardships (Fig. 32).

The Radial and Inner Walls of the Epidermis.--The radial and inner walls are usually thinner than the outer. Cutinization sometimes extends for some distance into the radial walls, but it seldom involves the whole of the radial wall or any part of the inner wall. It has already been stated that the epidermis remains alive so long as it is not cut off from water by the formation of cork beneath it, and the relative thinness and non-cutinization of the radial and inner walls permit the inflow of water and the interchange of materials necessary to all living cells.

The Cell-contents of the Epidermis.-The cell cavity is usually quite clear and is evidently serving as a reservoir for surplus water. The protoplast lines the wall as a very thin film, and although so well exposed to the light it seldom contains chloroplasts excepting in the guard cells of the stomata, and in the case of some plants, particularly Monocotyledons, of shady habitats. Leucoplasts are frequenlty present, and in flowers and fruits they often become transformed into chromoplasts, and produce the yellow, orange, and some of the red colors. Not infrequently blue, violet, and some qualities of red pigments occur in solution in the sap of the epidermal cells of flowers and fruits, young leaves in the spring, the upper epidermis of some alpine and tropical plants where absorption of a part of the intense sunlight before it reaches the chlorophyll apparatus may be of use, and of the lower epidermis of some shade-loving plants where it may be of advantage in absorbing more of the sun's energy before it escapes at the lower surface. We assume that the pigments in fruits and flowers attract insects and other animals that may be of use in pollination and in dissemination of seeds. The use of pigment in the cell-sap of young leaves seems to be to protect the chlorophyll against the destructive chemical changes which are induced by strong light. In addition to pigments tannins not infrequently occur in the epidermal cells, where they may be of use in warding off attacks of animals and fungous parasites. 
Outgrowths and Excretions of the Epidermis.-Excretions of wax in the form of rods, scales, and grains often occur orer the epidermis of fruits, leaves, and tender stems (Fig. 33). These, as experiments show, materially assist the water-proofed outer wall in preventing loss of water.

Outgrowths of the epidermal cells in the form of hairs, both slender and spinous, and scales, are of frequent occurence. In forming these the epidermal cells may grow outward without undergoing cell division, or they may undergo cell division and give rise to multicellular protuberances. These are apt to vary in different species in size, form, complexity, and other characteristics (Fig. $33)$, and are very useful to the microscopist in detecting the source and purity of powdered foods and drugs. Although in many instances these structures appear to be mere caprices of growth without any function assigned to them, yet, in other cases, their use is very apparent. They are, indeed, employed in a wide range of service, being used as a protection against injury, to assist climbing plants in holding on to their support, in the scattering of fruits, in the re-
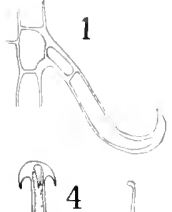

4

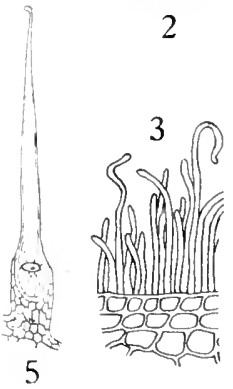

FIG. 33.-- Different forms of epidermal outgrowths. I, hooked hair from Phaseolus multiflorus; 2, climbing hair from stem of Humulus Lupulus; 3, rod-like wax coating from the stem of Saccharum officinarum; 4 , climbing hair of Loasa hispida; 5 , stinging hair of Urtica urens. (Fig. 3 after de Bary; the remainfer from Haberlandt.) duction of transpiration and the intensity of illumination, in the secretion of special substances; and in the absorption of water and other materials.

All of those hairs and scales that are more or less rigid and rough, sharp-pointed or barbed, offer difficulties to browsing animals that would tend to lessen their onslaughts. In the stinging hairs of the Urticas the device for protection has reached a high degree of efficiency (Fig. 33). Here the outer wall is silicified about the apex, and is so thin and brittle that it breaks 
on slight pressure and the jagged edges of the fracture prick through the skin, while a stinging fluid is injected into the wound by the pressure that breaks off the point, and doubtless also by the elasticity of the turgid cell. In Humulus Lupulus, Phaseolus multiflorus, and Loasa hispida we find excellent examples of hairs that act as hooks to assist plants in climbing (Fig. 33), while in the branched and interlaced hairs of Verbascum Thapsus and the stellate scales of species of Abutilon, Olea and Croton are efficient devices for reducing transpiration and reflecting a part of the sun's rays. The reduction of transpiration is brought about largely by the formation of dead air spaces between the interlaced hairs and beneath the scales.

Hairs that are used for absorption and the secretion of special materials will be discussed in the chapters on absorption and secretion.

The Multiple Epidermis.-Sometimes the outer layer of epidermal cells is underlaid by one or more layers similar to it in content. These cells may have arisen from a division of

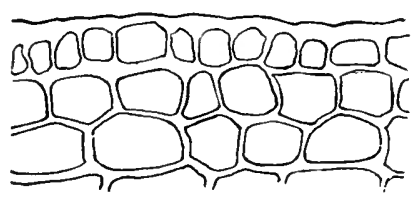

FIG. 34--Mlultiple epidermis of leaf of mangrove in cross section. This serves as a water reservoir, and the relatively thick walls of the inner cells reenforce the protective power of the outer layer. The mangrove grows in the salt soil of seacoasts. the protoderm, in which case they are morphologically or by descent epidermal, or they may have sprung from the ground meristem beneath the protoderm, and then they would be not strictly epidermal, although so classed by general usage. Whatever their origin, these cells, together with those of the outer layer, are collectively called the multiple epidermis (Fig. I3). The inner or accessory cell layers, as a rule, seem to serve almost exclusively as water reservoirs. In most cases their walls remain cellulose and thin and their cavities become relatively large. As in the outer layer, the protoplast is a thin film lining the walls, and the cell cavity is filled with a clear fluid, of course mostly water. Since these accessory layers are chiefly for holding water they should be discussed in the 
chapter on storage of reserve materials, but they also have a place here because they protect the chemically active cells beneath by filtering out some of the sun's heat and by supplying them with water when evaporation is reducing their turgidity too low for the normal performance of their functions. In some cases, however, the accessory layers have thick walls and relatively small cavities and assist the outer layer chiefly in protecting against mechanical injuries (Fig. 34).

\section{The Cork}

It is the rule in the peremnial parts of trees and shrubs that the epidermis is sooner or later replaced by the cork tissue (Fig. $24)$; in many instances the change beginning in the first year, and in others not until the lapse of many years. The cork then assumes the protecting and waterproofing functions of the displaced tissue.

By additions from the phellogen or cork cambium the cork tissue becomes several to many cell-layers thick. After the cork cells have attained their growth they die and their cellsap is replaced by air, a fact which accounts for the lightness of cork. The walls of the cork, as a rule, are thin and in some instances suberized through and through, while in others a middle lamella of cellulose is present. The suberization or waterproofing of the wall is accomplished by chemical changes in the original cellulose wall and by additions of suberin layers to this, or by the latter process alone. The suberin is quite similar to cutin in its chemical constitution and physical properties, and both are of the nature of wax.

Where the cork becomes only a few cell layers in thickness the cells are apt to be flattened so that the tangential diameters are broader than the radial, but where annual additions are made by the phellogen, the cells first formed are not so flattened and may be even larger in the radial diameter, and these are succeeded at the close of the season's growth by radially narrower cells, so that rings of growth appear in the cork as 
well as in the wood. This is seen in bottle cork as alternating light and dark bands.

Cork as a Protective Tissue.- The fact that the cork tissue is several cell-layers in thickness makes it better than the epidermis as a buffer against stresses from without; and since in perennial parts the phellogen may keep up its activity from year to year any injuries and losses to the cork are quickly repaired, and therefore the cork is, on the whole, better than the epidermis where chances of injury are multiplited by years.

The many suberized walls of the cork tissue interpose a series of barriers against the ingress of fungal parasites. The sweet and Irish potatoes afford examples of the effectiveness of cork in this respect. Here the cork is quite thin, averaging hàrdly more than six layers of cells in thickness, and yet the potatoes remain sound until the cork covering is broken through, when decay is apt to set in very quickly, because the omnipresent microscopic bacteria and spores of fungi can now get at the deeper and less resistant tissues.

Cork also affords protection from danger of another kind; air is a very poor conductor of heat, and each cork cell embraces a dead air space which prevents sudden interchanges of temperature. If the outside temperature suddenly falls its effect cannot at once be felt by the deeper tissues, and only little by little can the heat of the plant be dissipated through its cork jacket. Again, after the plant has once frozen, if the exterior temperature suddenly rises, the cork may prevent death that is so apt to result to the tissues from sudden thawing.

The Cork as a Waterproof Covering.-The walls of the cork cells are permeable with great difficulty to water and gases. Experiments with the Irish potato have shown that in 48 hours a potato with the cork covering removed lost sixty times as much water as an unpeeled one of equal weight. It was found by Wiesner that a film of cork two or three cells in thickness allowed no air to pass through it, even under a pressure of more than a third of an atmosphere continued for several weeks. This gives us an exact statement of a fact that everyone apprehends in 
general terms from our experience with cork stoppers, namely that - Huids in a state of vapor are practically unable to penetrate them.

Use of Cork in Healing Wounds. - In case of injury to stems and roots, as when the bark is gnawed or branches are broken off by storms or pruned away, the parenchyma cells of the cortex and pericycle in the region of the wound form secondary meristems by cell division, which build the various tissues of the bark until the wound is closect over and form a new cambium layer where that has been torm away, and a phellogen which generates an exterior covering of cork. When leaves ripen and fall away the cells at the surface of the wound become suberized and are in effect cork cells.

The relative dependence of the different parts of a plant on epidermis and cork is shown diagrammatically in Fig. 35. The fact that a waterproofed epidermis does not occur at the growing apex is indicated by a very thin line. As the epidermis becomes better developed on the successively older leaves and portions of stem and root the line is thickened. The evanescent flower does not demand as effective an epidermis as the leaves and stem, and this

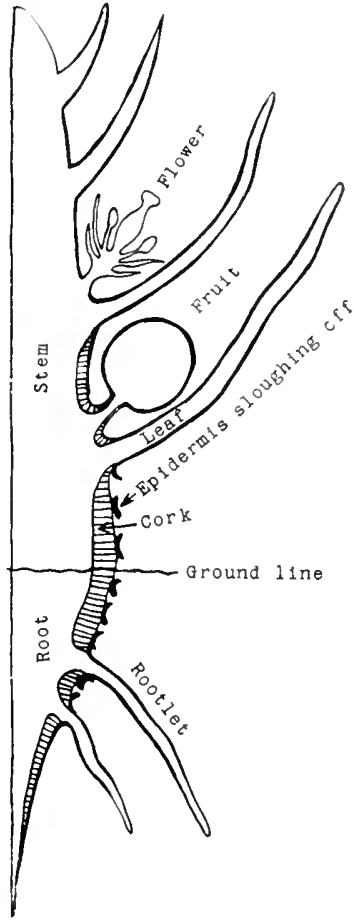

Fig. 35.-Diagram illustrating the relative develupnient of the protective tissues in different parts of a plant. Description in the text. is here indicated by its thin outline. The pistil persists, and as it develops into the fruit it perfects its epidermis as a waterproof covering, as indicated by the thick outline of the iruit in the diagram. Finally on the older portions of stem and root cork appears (the barred zone in the diagram) and gradually increases until it bursts the epidermis, and after a time takes its place altogether. 


\section{Other Means of Protection}

Since the epidermis and cork lie at the rery exterior they may be classed as preëminently protective tissues; but other tissues lying near the surface may be of a nature to give the cork and epidermis substantial assistance; and although the chief function of these may lie in another direction they cannot be passed unmentioned when the function of protection is being discussed. The collenchyma and sclerenchyma tissues belong in this class.

The origin and general character of the collenchyma has been told on page 30 . It forms a somewhat rigid foundation for the epidermis and cork of superficial origin. As stated on page 32 , the term sclerenchyma is applied to those cells of whatever form whose walls are on the whole uniformly thickened and commonly lignified. When short and stocky these are called stone cells, and when long and slender they are termed bast fibers. These not infrequently occur close to or just beneath the epidermis or periderm and help to keep these from caving in and breaking under the stress of a blow or pressure from without. In stone fruits, such as the walnut and peach, it is the stone cells forming the stone that affords the sole means of protection to the seed after the pulp or shell has been removed.

The borke ( $\mathrm{p} .55$ ), although a mass of dead tissues in process of elimination, is of no small use as a protective covering; indeed, the very fact that it is dead and dry and hard gives it its protective value. Good illustrations of this are found in the shellbark hickory, sycamore, and graperine.

\section{Illustrative Studies}

I. Enclose a bit of apple peeling in elder pith (page 25I) and cut free-hand sections. Mount some of the thinnest of these in a drop of dilute glycerine. Draw to scale a few of the epidermal cells. Measure the cell cavity and the thicknesses of the walls.

Note the color of the walls in dilute glycerine and mount 
other sections directly in chloroiodide of zinc. The walls that turn yellow in this are cutinized and those that turn blue are cellulose.

2. Select two similar apples and pare one. Weigh them both and hang them up by their stems. After forty-eight hours weigh them again and estimate the percentage of loss of water in each case.

3. Heat a glass slide quite hot and press the skin of an apple against it. Notice the waxen spot that is left on the glass.

4. Study cross sections of a marshmallow leaf, for instance, and measure the thickness of the outer wall of the upper and lower epidermis. Draw a few cells from each epidermis to scale.

5. Make note of what becomes of the epidermis in the stem of Aristolochia as the stem grows older, using the permanent mounts already prepared for the previous chapter.

6. Strip the epidermis from an Iris leaf or any other leaf from which the epidermis is readily removed and mount it in a drop of dilute glycerine. Count the number of radial walls (walls on edge in the preparation) in one or more squares of the eyepiece scale and estimate the number of these in a square millimeter.

7. Determine from cross sections of old and young Aristolochia stems where the cork in the old stems comes from. Measure an average cork cell and the thickness of its walls. Draw a few cells to scale.

Mount a cross section of old Aristochia stem in chloroiodide of zinc, and the walls of the cork cells should turn yellow. Measure the thickness of the entire cork layer.

8. Cut in elder pith sections from a bit of potato peeling that has been hardened by standing in 95 per cent. alcohol. Study sections in dilute glycerine and chloroiodide of zinc. Compare the cork cells found here with those in Aristolochia. Measure the thickness of the cork layer.

9. Select two potatoes of about equal size and pare one. Weigh them and hang them up for forty-eight hours; then weigh them again and estimate the percentage of loss of water in each case. Compare these figures with those from the apple. 
Does either tissue (cork or epidermis) seem to be more efficient than the other?

Io. Study cross-sections of leaves of mullein, Russian olive, Crotonopsis, or sections of other leaves having a dense coating of hairs and scales.

Make drawings to show how these trichomes (outgrowths from the epidermis) can help in reducing illumination and transpiration.

I I. Cut out a piece of the hollow stem of Equisetum, and, beginning with the inner surface, scrape away the tissues down to the silicious outer incrustation of the epidermis. Put this preparation into a strong chromic acid solution to macerate and separate the organic parts from the incrustation. Rinse the preparation and at the same time brush it with a soft brush. Mount the preparation in a drop of dilute glycerine and study it with low and high powers. Note how complete is the incrustation, and the details about the stomata. Make a drawing to show these things. 


\section{CHAPTER I}

\section{THE PIANT SKELETON}

The cell-wall of unicellular plants such as Pleurococcus and yeast is essentially an exoskeleton since it provides some degree of strength and rigidity, and this is true of the cell-walls in the higher plants; but where a plant on account of its size and exposure to the elements is in danger of breaking down or being crushed or torn it has been found necessary to set apart certain tissues as a skeleton for the plant body as a whole, and these tissues have been modified to become more effective as skeletons and at the same time less efficient for other functions. The need of a skeleton for the larger and more complex plants is at once apparent. The larger the plant the greater is its tendency to collapse on account of its own weight. Imagine a tree trying to attain its normal size with all of its tissues like elder pith or the pulp of an apple, or a toadstool presuming to become the size of a tree without making any tissues like bast or wood. The more branched a plant is the greater is its danger of becoming dismembered, and the greater is the need of the body being strong to support the branches, and of the branches being firmly knit to the body. The more differentiated the plant body becomes the greater is the danger attending dismemberment; and the greater also are the demands made on the environment; and the catastrophe is correspondingly more serious when any parts are torn away or thrown out of their normal positions. Hence it is that the higher plants have been under the necessity of building a skeleton of greater or less strength and hardness.

Ve find that for the purpose of a skeleton four tissues have been wrought out, whose origins have already been told in Chapter II, namely the collenchyma, the bast fiber tissue, the wood fiber tissue, and the stone cell or stereid tissue. 
The Making of the Skeleton.-The necessary strength and hardness of the skeleton is obtained by modifications of the cell-wall and changes in the forms of the cells. 'The ordinarily thin walls do not suffice to hold the plant body erect by their own strength, but when filled with cell sap until they are stretched they become rigid, like a toy rubber balloon when inflated with gas, and in that way hold the body firm and erect. Plants or parts of plants that depend upon this condition for strength soon wilt when they begin to lose water faster than they take it in.

The skeletal tissues make plants more or less independent of fluctuations in the water supply in maintaining the right form and position of the body. The modifications of the wall involve thickening of the originally thin wall, chemical alterations of the wall by changes in the old materials and depositions of new, and transformations in the physical condition of the wall, such as its hardness and elasticity. The changes in the form of the cells consist, as a rule, in their elongation parallel with the line of action of the main forces which they are to resist. While the cells are elongated their ends usually glide past each other and form spliced joints which greatly increase the strength of the tissue (Figs. I5 and I9).

\section{The Tissues of the Skeleton}

The Collenchyma.-This is the first skeletal tissue formed. It appears in stems a short distance below the growing apex where the bast and wood have as yet not begun to be formed, and it is therefore the only tissue thus far having a strengthening function chiefly. Its chief characteristic is that its walls are thickened at the angles where three or four cells join, and this thickening in extreme cases becomes so great as almost to close the cell cavity. While the angles are thickening a median strip of the wall is left thin, clearly in order to allow a flow of sap from cell to cell. The walls, as a rule, remain cellulose throughout (Figs. II and I4). 
Since the collenchyma is formed where growth in length of the stem is still taking place it must be capable of growing itself or of stretching and offering a moderate resistance only to the increase in size of the other tissues. For this reason it cannot be relied on as the mainstay very far down the stem where the stresses to be overcome are greater than in the region of the apex, and the bast fiber tissues are formed there to reenforce it (Fig. II). The elastic strength of the collenchyma is small compared with that of wood and bast fibers, and when the elongation of the stem is rapid it is continually stretched beyond its limit of elasticity. This is shown by the fact that such stems on wilting droop through several internodes dominated by the collenchyma. We may therefore look upon the collenchyma as a compromise between the need for strength and the need to elongate during the growth in length.

When growth in thickness sets in the collenchyma becomes stretched tangentially and may even be broken apart in many places (compare Figs. 23 and 24); but this is not apt to take place until the bast fibers or the wood fibers also are ready to reënforce it. Through all these vicissitudes of stretching and tearing the collenchyma remains alive, till the end of the season in annuals, and in perennials till the formation of a deep-lying cork tissue shuts it off from the supply of water and sap.

In a very subordinate way the collenchyma may be used for the slow conduction and temporary storage of materials, and since it sometimes contains chloroplasts it may take part in the manufacture of food (see Chapter IX).

The Bast Fibers.-As has been learned in Chapter II, the bast fiber tissue may occur in the primary cortex, pericycle, or secondary cortex. Where it occurs as a primary tissue in the primary cortex or pericycle it is formed below the apex where growth in length has ceased, following next to the collenchyma in time (Fig. I I). It may occur anywhere in the regions named, from immediately beneath the epidermis to a position in front of, and in contact with, the phloem portions of the vascular 
bundles. It may be in isolated longitudinal strands or in the form of an unbroken hollow cylinder (Fig. I7).

The walls of the bast fibers become much thickened, even in extreme cases to the entire closing of the cell carity. The length of the fibers varies within wide limits: in some cases they are no more than $1 \mathrm{~mm}$. long, while in flax they reach a length of to $\mathrm{mm}$. and in hemp $77 \mathrm{~mm}$. The average length is about $2 \mathrm{~mm}$. It will readily be seen by these figures how it is that the fibers of flax and hemp can be twisted into thread and woven into cloth, while those of most plants are much too short for the purpose. 'The length of the fibers has much to do with the strength of the bast tissue as a whole, for, as has already been said, as the nascent fibers elongate their ends glide by one another, and the length of the splice increases with the length of the fibers. As a rule the walls of the bast fibers become decidedly lignified, but all grades of condition occur from almost pure cellulose to complete lignification.

In those herbaceous plants whose cambium produces little or no wood fiber tissue the bast remains the chief dependence for strength; but where the wood is much represented as in the older parts of many annual stems and in all woody perennials, the significance of the bast as a strengthening tissue falls into the backgrouud. This fact is quickly appreciated by noticing how little in such cases the strength of the stem is diminished by stripping off the bark.

The bast fibers are employed not only to strengthen the stem as a whole, but also to protect and give stability to the delicate tissues of the primary and secondary phloem, as when the bast strands stand like a buttress before the primary phloem or, in the secondary phloem, are built by the cambium alternately with groups of siere tubes, companion, and parenchyma cells. In Monocotyledons a fibrous tissue similar to the bast of Dicotyledons surrounds each isolated vascular bundle more or less completely (Fig. 40).

The bast fibers are especially fitted for their mechanical function by their great elastic strength. (By elastic strength is 
meant the measure of the force required to stretch the fibers to the point beyond which they are unable to return to their original length.) In this respect they are quite equal to wrought iron, and in some instances they equal and even surpass steel. But they surpass both iron and steel in a respect of great importance to plants: they are able to stretch many times as much as the former before the limit of clasticity is reached. 'This quality enables plants to bend before the wind and spring back to their original positions when the stress is past.

When the bast fibers have reached their full development they die and their cell cavities become filled with water or air, but they continue none the less effective as skeletal tissues.

The lengths and frequency of occurrence of the bast fibers often afford good evidence in the detection of the purity of powdered drugs.

The Wood Fibers.--The wood fibers are those bast-like fibers that occur in the wood or xylem portions of stems and roots. In most cases they are the product of the cambium alone, and not of the procambium, and we therefore expect to find them in the secondary, but not in the primary xylem. While they are similar to the bast fibers in being elongated and tapering and haring thickened and lignified walls, they do not equal the bast in length. They are rarely as long as $1.5 \mathrm{~mm}$. and are known to be as short as $0.3 \mathrm{~mm}$. Since, as a rule, they are derived from the cambium only, they do not occur as close to the growing apex as do the bast fibers, but farther back where secondary increase in thickness has begun (Fig. I I).

The proportion of wood fibers to the other elements of the secondary xylem varies greatly in different species. In many woody Dicotyledons the wood fibers constitute the greater part of the secondary xylem or wood; but even in this class of plants cases occur where the other elements of the xylem greatly preponderate.

The specific grarity, hardness, elasticity, and strength of the wood depend upon many factors, not all of which are referable to the wood fibers themselves. The proportion of wood fibers 
and the thickness and physical character of their walls are all important factors in the quality of the wood; but the plan of distribution of the tracheal and thin-walled parenchyma elements causes the fibers to occur in larger or smaller groups in the different species, thus making the wood as a whole stronger or weaker in consequence.

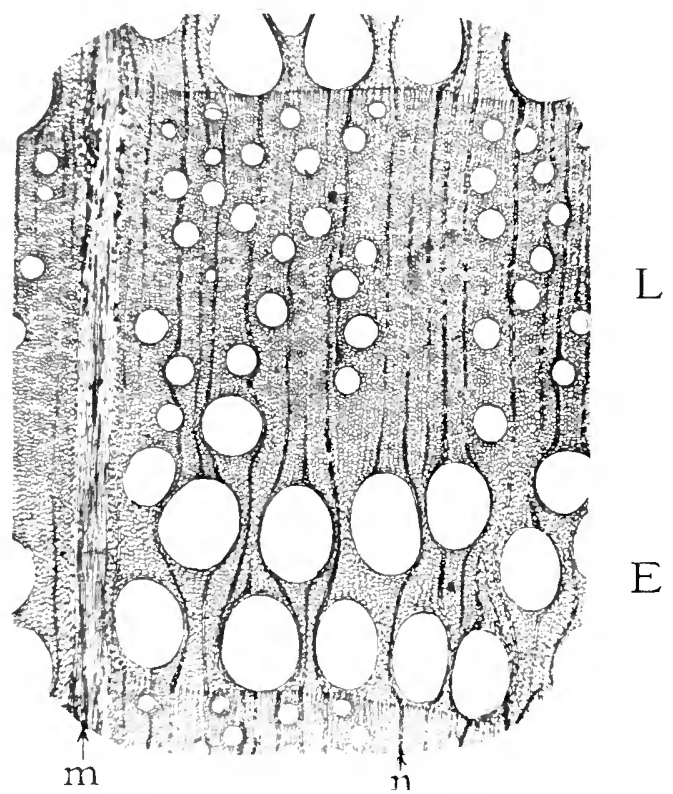

FrG. 36.-Photomicrograph of cross section of oak wood. $E$, early growth; $L$, late growth; $m$, larger medullary ray; $n$, smaller ray. $\times 25$.

In woody plants the wood fibers are, as a rule, relatively much more numerous in the late than in the early growths. This difference stands out sharply in such woods as the ash and the oak (Fig. 36) where the late growth is a dense, hard, and strong cylinder encasing the relatively weak and porous cylinder of the early growth. In some trees, like the yellow poplar of commerce, the wood fibers are relatively few throughout the entire year's growth, and the wood is relatively light, porous and weak in consequence (Fig. 37). Although the 
quality of the wood depends much upon its visible characters, such as the frequency of its wood fibers and the thickness of their walls, other invisible characters, such as the hardness, elasticity, and breaking strength of the walls are factors so important that whether a wood should be classed as hard or soft,

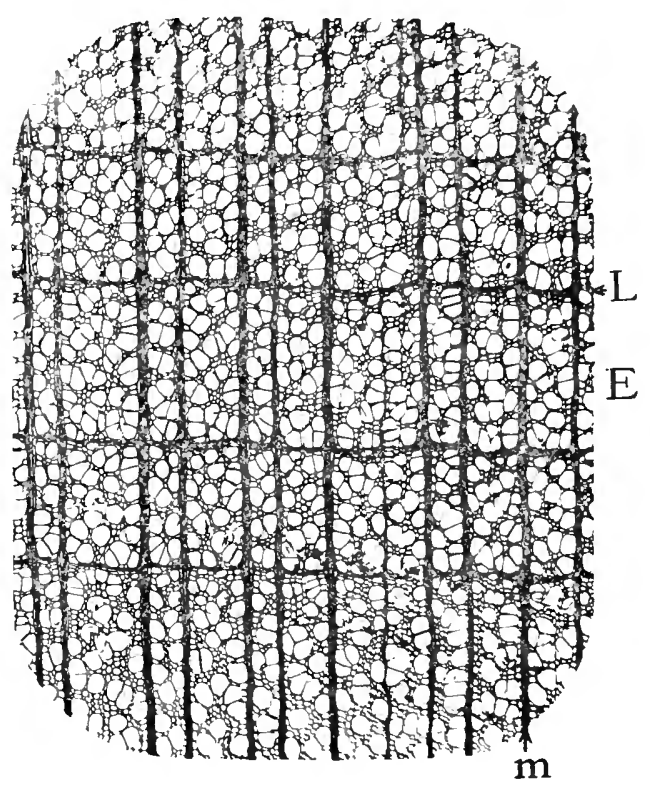

FIG. 37.-Cross section of yellow poplar wood. E, early; $L$, late growth; m, medullary ray. Photomicrograph. $\times 20$.

weak or strong, could not be determined by microscopic examination alone.

Sometimes the wood fibers are entirely lacking, as in Aristolochia sipho, where their place is taken by tracheids, and as in pine and other Gymnosperms where tracheids perform the double function of wood fibers and tracheal tubes.

The Stone Cells. - The stone cells are formed by the thickening and lignification of the walls of originally thin-walled parenchyma cells (Fig. I5). They may be found in the primary and secondary cortex, pericycle, medullary rays and pith, in the integuments of many seeds, and in the shells and stones 
of nuts and stone fruits. In the latter instances they may form continuous tissues, but in roots, stems and leares they occur in more or less isolated groups or even singly. They occur in many barks in sufficient numbers to make them notably strong and hard, as in hickory, and they sometimes reënforce the bast fiber tissues by forming firm unions between their separate strands, as in the oaks. They contribute to the tough and leathery character of some leares, as in Camellia and Olea, for example, where they occur scattered among the mesophyll cells, to which they, indeed, belong morphologically. Small groups of stone cells are found scattered throughout the pulp of such fruits as the pear and quince and they give to these their gritty character.

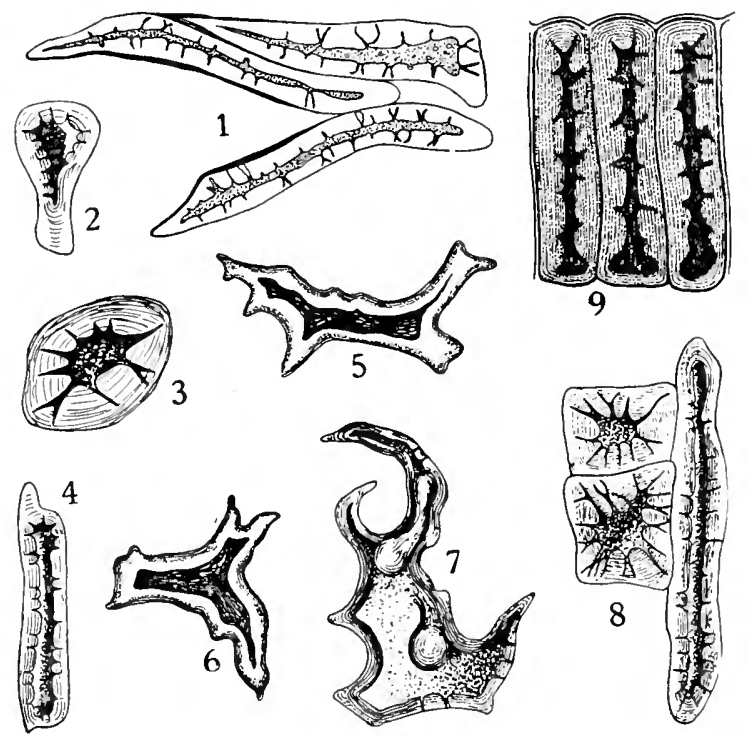

Fir, 38. - Stome cells from different sources. $\quad$, from coffee; 2,3 ancl 4, from stem of clove: 5 and 6 , from tea leaf; 7,8 and $y$, from powdered star-anise seed. (After lloeller.)

The uses of stone cells are apparent. In nuts and stone fruits they box up, against injury and loss, the embryo and other tender parts of the seed, and are in such cases of the nature of an exoskeleton such as a turtle has among animals. In barks, 
fruits, and leaves, where they occur in more or less isolated groups, they give hardness and toughness without being an impediment to increase in size.

The stone cells are frequent and important landmarks in the study of powdered drugs and condiments. Fig. 38 shows a variety of forms, enough to give a general conception of their visible characters.

Topography of the Skeleton.--Purely mechanical considerations cannot alone be taken into account by plants in the location of the skeletal tissues. The trunk of a tree, for instance, is something more than a strong column to bear the crown aloft: it is also a part of the body through which water and food must circulate and be stored; respiration, digestion, and assimilation must occur in it as in other members of the plant; and cell division and growth must take place there, and these functions are quite as important as that performed by the skeleton. Therefore the problem before plants in the building of their skeletons is to follow the best mechanical principles wherever this can be done without too great sacrifice of the other functions.

In Dicotyledons it is of the utmost importance that the parts of the skeleton be so placed that they do not obstruct secondary increase in thickness; while in Monocotyledons, where increase in thickness continues, as a rule, but for a brief period, this consideration is of much less importance.

In stems which have to bear the weight of the crown, and withstand the stretching and compressing stresses as they are swayed back and forth by the winds or other agents, the best position for the skeleton tissues from a purely mechanical standpoint is at the outside of all other tissues, in the form of a hollow cylinder; or, other things interfering, as near this form and position as possible. But in all of the higher land plants it is an absolute necessity to have a tissue at the exterior suited to prevent loss of water, or to keep the water from filling the intercellular air spaces in case of the higher water plants, and so the skeleton must give way to the epidermis and cork. Further, in Dicotyledons, a complete skeletal cylinder at or near the 
surface could not long be maintained without its breaking asunder due to the new tissues formed by the cambium, or, if too strong for this, without preventing increase in diameter. These conditions, however, we find are happily met. Next the epidermis is placed the collenchyma, in the form of a hollow cylinder or in separate strands. It is not too strong to resist growth in diameter; and, since it is chiefly for temporary service until the bast and wood fibers have been laid down, it can without detriment be broken apart or tangentially stretched as growth in diameter proceeds.

The bast fiber tissue is, as a rule, near to the surface, but in isolated strands, in order that increase in diameter and the flow of water and sap radially to and fro may not be too much interfered with. The strands of bast fibers that stand in front of and against the phloem serve the double function of skeleton for the stem as a whole and for the thin-walled phloem tissues in particular which they sustain as the bones do the weaker tissues of the vertebrate body. In Fig. I 7 different plans of collenchyma and bast fiber topography are shown.

The secondary xylem in many herbaceous and all woody Dicotyledons and Gymnosperms furnishes a skeleton that is especially adapted to secondary increase in thickness, since it is located inside the cambium ring and can be increased indefinitely without hindering the growth of other tissues or being itself subjected to stresses that tend to tear it asunder. It can therefore form the continuous cylinder that is so highly desirable in the plant skeleton.

In many herbaceous plants the xylem cylinder surrounds a relatively large pith, and so conforms in the measure that other functions will permit to the accepted principles of mechanical construction where economy of materials is desired; and in woody perennials the xylem that is first formed is placed outside a pith of greater or less dimensions, but secondary increase in thickness after a few years so far surpasses the original diameter of the stem that whether the xylem cylinder remains hollow or crowds in and crushes out the pith becomes a matter of no significance. 
In roots the xylem is placed closer to the center than in stems, and by crowding in very soon obliterates the pith and assumes the form of a solid rod. This difference of the wood skeleton in the stem and the root is related to the difference in the direction of the stresses which they have to overcome. In the stem it is the weight of the crown and the alternate stretching and compressing when swaying in the wind; while in roots it is the pulling force which the swaying stem exerts on the roots,

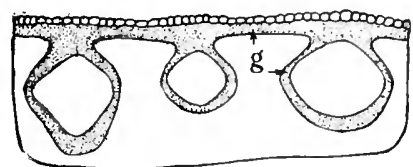

FIG. 39.-Camera-lucida outline of portion of cross section of cornstalk, showing at $g$ bast fiber zone beneath the epidermis and surrounding the outermost vascular bundles. and the compressing force with which the soil resists growth in thickness of the roots, and both of these stresses the solid wood cylinder of roots is well adapted to withstand.

In most monocotyledonous stems the problem of locating the skeletal tissues is simplified because no allowance needs to be made for secondary increase in the vascular bundles, and seldom for secondary increase in the stem as a whole, and this fact is taken advantage of by encasing, and so bracing and

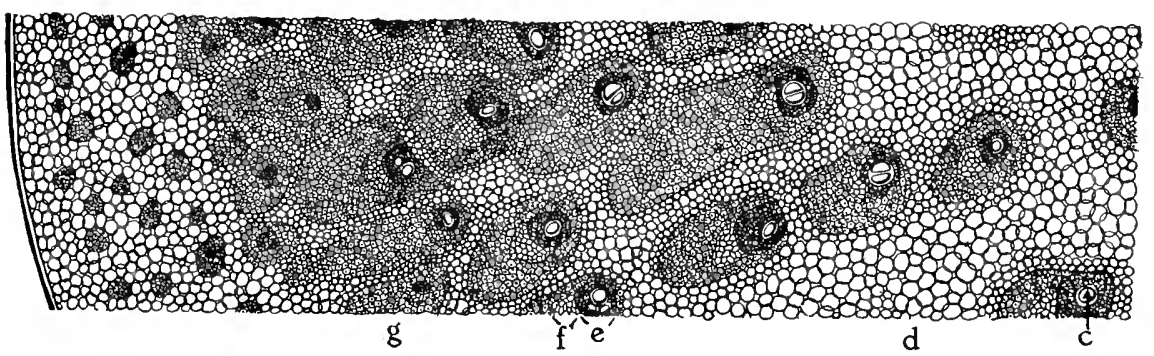

FIG. 40.-Cross section of a portion of palm stem. $e$, xylem; $f$, phloem portions of vascular bundle; $g$, sclerenchyma tissue about vascular bundle; $d$, fundamental or ground tissue; $c$, larger tracheal tubes in vascular bundle. (After Engler and Prantl.)

strengthening each vascular bundle in a sheath of sclerenchyma or bast fibers developed from the ground parenchyma tissues (Figs. 28 and 40).

In grasses and similar Monocotyledons many vascular bundles are massed close to the epidermis, each with its protecting 
and strengthening sclerenchyma cylinder, and all are bound together by thick-walled ground parenchyma, and bundles of subepidermal bast fibers flank the most exterior bundles (Fig. 39). These facts account for the hardness and strength of the

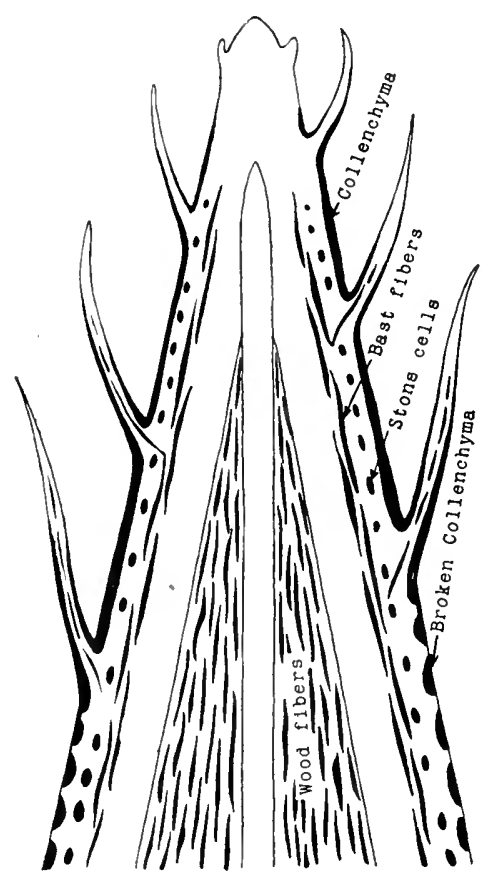

Fig. 41,-Diagram showing the progressive development of the skeletal tissues from the apex toward the base of the stem. exterior part of many grass stems, such as corn and bamboo.

In palm stems the skeleton consists of numerous strands of bast fibers in the peripheral ground tissue, and large masses of these fibers of extraordinary hardness and strength surrounding each vascular bundle wherever located (Fig. 40). There being no cambium, wood fibers are not produced as in the Dicotyledons, and the xylem part of the vascular bundle is occupied by tracheal tubes, tracheids, and xylem parenchyma.

In leaves the skeleton is in the form of bast fibers attending the main ramifications and anastomoses of the rascular bundles; and sometimes subepidermal bast strands occur at the edges of leaves or at other places without direct connection with the rascular bundles. Collenchyma is also sometimes employed to strengthen the leaf borders.

Fig. + I indicates diagrammatically the progress in the derelopment of a woody plant. At and near the growing apex there are no skeletal tissues. Some distance back from the apex the collenchyma appears, and further back bast fibers and stone cells reënforce the collenchyma. Finally, in older parts 
still the wood fibers make their appearance and the wood zone is continually broadened by the activity of the cambium as the stem grows older. This stretches and breaks the collenchyma, and it, as well as the bast, becomes gradually of less and less importance as the wood increases.

\section{Illetstrative Studies}

I. We have already seen collenchyma in both cross and longitudinal sections in the stem of Aristolochia; we can, however, find this tissue carried to a higher stage of development in the stem of sunflower, Zinnia, hemp, and many other herbaceous plants. Make cross sections from such a plant and mount them in dilute glycerine. Note the great thickening of the walls at the angles of the cells. The shapes of the cells, as outlined by the primary walls, before thickening began, can be seen. Draw a few cells to scale. Measure the thickness of the walls across the corners. Are not these thickenings really rertical rods? Study longitudinal sections to see how continuous these rods are.

2. In the stem of Aristolochia we found a sclerenchyma ring made of long cells with walls lignified and somewhat thickened. These are bast-like, but they are not typical bast fibers. Sunflower and species of AJutilon, flax and hemp will furnish good examples of fibers of various lengths.

Study cross sections of sunflower stem in aniline sulphate (page 287). The bast fibers will be yellow. Or when the fibers are clearly recognized they may be studied in dilute glycerine. Draw a few cells to scale. Measure the thickness of their walls. Macerate longitudinal sections in hydrochloric acid-alcohol and ammonia (see under Maceration in Chapter XVI) and tease out the fibers in a drop of dilute glycerine. Draw a few fibers to scale and measure their lengths.

Study cross sections of young and old stem segments of Abutilon Avicennæe mounted in aniline sulphate. Here the firstformed groups of bast fibers belong to the pericycle and later 
groups have descended from the cambium. Find the evidence for this. Draw a few cells from a mature group and others from a younger group where thickening of the cell-walls is not yet complete. Macerate longitudinal strips of the bark in hydrochloric acid-alcohol-ammonia, tease out some of the fibers in dilute glycerine, and draw one or more to scale. Measure the lengths of the fibers.

Study cross sections of flax in aniline sulphate. The sections are best made from small lengths of stem imbedded in celloidine or collodion (page 266). In your judgment what is the origin of the numerous groups of fibers found here. From the ground meristem of cortex? From the pericycle? From the cambium? The student should now be able to answer these questions from his own observations. Make a diagram showing the position and frequency of the groups.

Macerate strips of bark as told above for Abutilon, only here the strips should be 5 or $6 \mathrm{~cm}$. long. Tease out a single fiber and measure its length. Draw a portion of its length as seen under high magnification.

3. Study cross sections of seeds that have been soaked in water and imbedded in glycerine gum (see under this head in Chapter XVI). Draw some of the cells to scale. Note the character and frequency of pits in the walls. 'Treat some of the sections with phloroglucin (see under this head in Chapter XVI). Are the walls of the stone cells lignified?

Make thin sections of stone cell tissue from the stone of a peach and the shell of a cocoanut. This can be done by sawing as thin a section as possible with a hack saw, and then rubbing it to the requisite thinness between two water hones kept wet. This is a slow process and one is in danger of losing the section altogether toward the end of the operation; but sections obtained in this way are worth the labor. Another way to get sections that will do fairly well is to shave them off with a sharp knife. They will curl tightly when made in this way, but the thinnest may be selected and forcibly straightened out in a drop of water. If they break in doing this, nevertheless the small 
fragments will show what is wanted. Stain the sections in fuchsin or safranin, dehydrate them in alcohol, rinse them in xylene and mount them in balsam.

4. Study cross sections of pine wood in dilute glycerine. Note the absence of tracheal tubes and the presence of relatively large tracheids in the early growth and small ones in the late growth. Examine a longitudinal radial section and compare the tracheids of the early and late growths. Draw a few tracheids from the two regions from both points of view to show the relative sizes of the tracheids and wall thicknesses.

Macerate longitudinal sections in nitric aid and potassium chlorate (page $3 \mathrm{I}_{2}$ ) and tease out the tracheids in dilute glycerine. Draw to scale a tracheid from the early and the late growths.

Study in a similar manner wood of oak, walnut, and yellow poplar. In both the macerated and unmacerated longitudinal sections note the difference between wood fibers and fiber tracheids, both similar in form, but the former with plain pits in the walls and the latter with bordered pits (page I $_{7}$ ).

What does the microscopic examination show as the relative hardness and lightness and uniform grain of these woods?

In the longitudinal sections and macerations medullary rays and wood parenchyma will be met with, and these should be studied here enough to recognize their characters, although a detailed study of them will be undertaken in another chapter. 


\section{CHAPTER II}

\section{THE ABSORPTION OF WATER AND MINERALS}

All substances that penetrate into the body of the plant cell must be in solution, excepting in the case of low forms of plants destitute of cell-walls which are sometimes able to engulf solid particles. Simple unicellular and filamentous algxe can absorb water throughout their entire surface, but more complex plants from the liverworts and mosses upward to the seed plants. which have ventured to raise a part of their bodies above the substratum where the energy of the sunlight and materials of the atmosphere can be more freely appropriated, have found it necessary to put forth special absorbing organs into the substratum for the intake of water and minerals; and the larger, taller, and more branched the part above the substratum, the more extensive on the whole must be the absorbing parts beneath the substratum.

From the vascular cryptogams (ferns, lycopods, equisetums) up through the seed plants, roots are employed for anchorage, and for absorption and conduction to the stem, of water and soil solutes. In floating water plants and in many aerophytes (air plants) there are roots that serve for absorption and conduction only.

Roots in the Soil. - It is only the younger parts of soil roots, and particularly the root hairs growing near their apices, that are fit to carry on alssorption, the older parts having the walls of the cxterior cell more or less waterproofed. As will presently be seen, the root hairs are the solution of some difficult problems in the relation of plants to the soil. In order to penetrate the soil in a necessarily sinuous course and to get past obstructions in the best way the place of elongation in roots has been restricted to the rugion of the apex, so that this delicate, sensitive part might feel its way among the soil particles as it elongated, 
without being shoved and jammed forward as would be the case if elongation were kept up in the remoter parts.

Under average conditions the water in the soil exists as a thin film around each soil particle and holds in dilute solution (๑.০ I per cent. to 0.03 per cent.) some of the constituents of the particles that are necessary to plants. To get the water and solutes it is obriously necessary that many fine outgrowths from the root should reach out on all sides, and, pressing them-

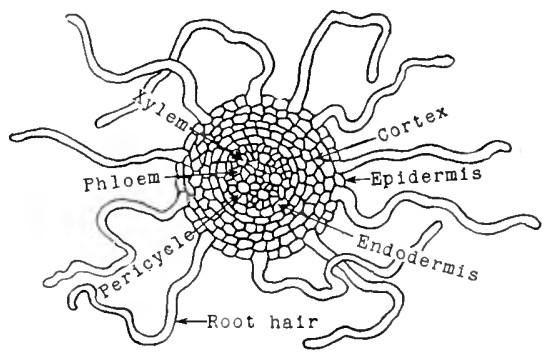

FIG. 42.-Cross section of a root in the region of the root hairs. selves against the soil particles, become immersed in the films of water.

The Root Hairs. - The root elongates close to its apex, and 2 or $3 \mathrm{~mm}$. back from this it ceases to grow in length, and some of the epidermal cells here grow out in the form of slender tubes known as root hairs (Fig. 42 ). So far as recorded measure-

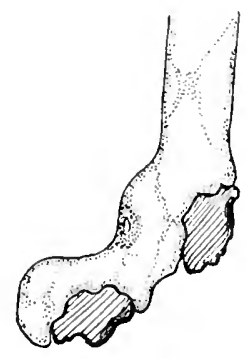

FIG. 43.-Apex of root hair flattened out over and imbedding soil particles. ments show these may become from a fraction of a millimeter to 8 millimeters in length.

Growing only at its point a root hair reaches out through the humid atmosphere of the soil interspaces until it strikes a solid particle, when it bends about this and flattens out over it to a certain extent (Fig. 43). At the place of contact the delicate cellulose wall of the hair becomes somewhat mucilaginous and is thus all the better able to cling on and imbibe water, and when it reaches a soil particle and becomes fastened to it this contact seems to act as a stimulus to stop its further growth in length. By means of the root hairs the roots are able not only to make close contact with soil and soil water, but they also increase their absorbing surface many times-from five to twelve times ac- 
cording to recorded estimates. So that if the hairs were stripped away the capacity for absorption would be correspondingly reduced. The effect of this we see when young plants are transplanted, for even when great care is taken not to break the roots wilting is apt to occur at first because the delicate root hairs have

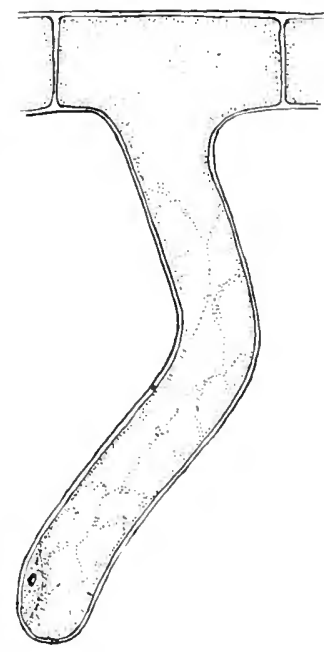

FIG. 44.-A single root hair on a large scale, showing that it is an outgrowth of an epidermal cell, and the fact that it possesses a living protoplast and large vacuole filled with cell-sap a n d traversed by cytoplasmic strands. The nucleus is near the apex of the hair. been torn off or have died away as a result of the shock of transplantation. Soon, however, new hairs are formed, water is again absorbed in plenty, and the plant picks up from its wilted condition.

The protoplast of the mature root hair is in the form of a very thin film lining the wall, and the cavity which it surrounds is filled with cell-sap containing sugars, acids, etc., in solution that afford osmotic conditions for the intake of soil water with considerable power (Fig. 44).

Any substances from the soil, either water or solutes, before mingling with the sap in the root hairs, must pass through the cellulose cell-wall, the external plasma membrane, the general cytoplasm, and the internal plasma membrane. The living plasmatic parts, however, taken altogether form a film so thin as to be discerned with difficulty even with high powers of the microscope. Not all substances in solution in the soil water are able to make this passage. Probably all of them can penetrate the cellulose wall, but to some the external plasma membrane presents an impassable barrier, and this membrane is then said to exercise a selective function. Similarly the plasma membranes, external and internal, keep the osmotic and nutrient substances of the cellsap from escaping. We must not, however, overlook the fact that substances that have penetrated the wall of the root hair 
but are unable to pass the plasma membrane may by travelling in the wall alone, enter the plant body and become distributed throughout its length without once having entered the living cells.

The selective action of the plasma membranes has never been satisfactorily accounted for on the basis of chemical and physical processes alone, although, presumably, this could be done if all the conditions were accurately understood. As soon as the protoplast dies the membranes lose their power of selection and the cell-sap readily escapes from the cell; and so it seems the membranes are able to do their work because they are living. When we are unable to give a chemical or physical explanation of a. physiological phenomenon of this sort we speak of it as due to a vital power, by which we mean that its seat is in the living protoplasm and its origin is shrouded in mystery. And the mystery in this instance is the more profound because the selective action varies in purposeful ways through the self-regulatory action of the protoplast, as will be brought out in subsequent chapters.

The root hairs excrete organic acids and carbon dioxide, and these go into solution in the soil water and have a solvent effect on some of the soil constituents.

The water and solutes (substances in solution in the water) absorbed by the root hairs pass into the adjoining cortex cells and thence across the root to the tracheal tubes and tracheids of the xylem where they begin their ascent into the stem. The relative positions of the primary xylem and phloem strands (Fig. 42) which make it possible for the water and solutes (now after their entrance into the plant called the crude sap) to reach the xylem without traversing the phloem is evidently a device to keep the crude sap and the elaborated sap (sap containing soluble food such as sugar in solution) distinct and apart. As will be seen in Chapter X the elaborated sap makes its way in the phloem longitudinally throughout the plant from the leaves to the roots.

The root hairs are very short lived and the older ones die away about as fast as the new appear. After the root hairs die the walls of the outer cortex cells become more or less suberized and 
by this are made stronger and better protected against parasites, but less able to take in water and solutes. Probably all of the cells of the root epidermis are, up to a certain age, capable of growing forth as root hairs, and only need the stimulus to do so, for we find that the number of root hairs varies with the character of the environment, more being formed where more are needed. For instance, when grown in a moist atmosphere, where only that water can be absorbed which the air holds, the hairs are very numerous and long, while in a moist soil where the hairs can become partly submerged in the water films about the soil particles shorter hairs in less number are formed; and where roots are grown in water fewer and shorter hairs grow forth or none at all.

Method of Intake of Water and Solutes.-The water and solutes enter the root hairs by osmosis and diffusion. The sap of the root hairs holds in solution osmotic substances such as sugar and acids which cause the inflow of the water, and since this is continually passed on to the conducting tissues the conditions causing its intake are more or less constant. The substances in solution in the soil water (the solutes) pass into the root hair by diffusion, and the speed of their onward movement through the membranes is by no means necessarily the same as the rate of the inflow of the water. If the intake of water is accelerated because increased evaporation from the leaves is creating larger demands for water, it does not follow that the entrance of solutes into the root hairs is hastened to the same extent. The morements of water and solutes are governed by different conditions. The solutes keep going in so long as there is less of them in a unit of volume inside the cell than outside; while the water continues to enter while there is a greater concentration of osmotic substances inside than outside. And the same thing is true in the interchange of water and solutes between different cells of the plant body, namely the water passes from the cell having less into the one having the greater concentration of solutes, while the solutes pass from the cell having greater into the one having the less concentration of solutes. Of course, 
however, inside a cell or water tube the water tends to sweep the solutes along in its currents.

It appears that so long as the osmotic conditions are good the water can pass freely into the plant and from cell to cell; but this is not true of all solutes, for the plasmatic membranes will not let all kinds pass, although many kinds are allowed to enter that are apparently of no use. As has been said it is not understood just how the membranes act in discriminating between the solutes; but the size of the molecules of the latter apparently is not always a decisive factor, for large molecules are known to enter when smaller ones are held back. The plasmatic membranes are, however, subject to change and may at one time allow a certain substance to pass and not at another.

Effect of Temperature of Soil, and Character and Amount of Solutes upon Absorption.-A warm soil is conducive to rapid absorption, while a cold soil hinders and may practically stop it; although a perceptible amount of absorption may in some cases still take place at or below $\circ^{\circ} \mathrm{C}$. The coldness of the soils of arctic and alpine regions acting in this way has a very great influence on the stunted growth and economical use of water of the plants native to these places.

If the soluble salts in the soil reach a concentration above .5 per cent. they hinder the flow of water into the plant either by their influence on osmosis or by a poisonous effect on the absorbing organs. Thus it comes about that plants along the strand or in salt marshes have reduced transpiring surfaces correlated with the slow intake of water, as seen in the Russian thistle and garden asparagus, both of which are native to the salty soil of seacoasts. Humic acid also, which is formed by the decay of regetation in boggy places, retards the absorption of water enough to call forth a reduction of the transpiring surfaces.

Absorption of Water and Solutes by Aerophytes.-The aerophytes, epiphytes, or air plants, send no roots into the soil, nor parasitic roots into the plants on which they have found lodgment; but they derive all of their supplies from the atmosphere, which contributes its moisture in the form of rain or dew, pro- 
rides carbon dioxide and oxygen just as it does for other green plants, and brings soil substances in the form of dust. These plants are not therefore living on the air alone, as their name might imply, but they have essentially the same raw materials

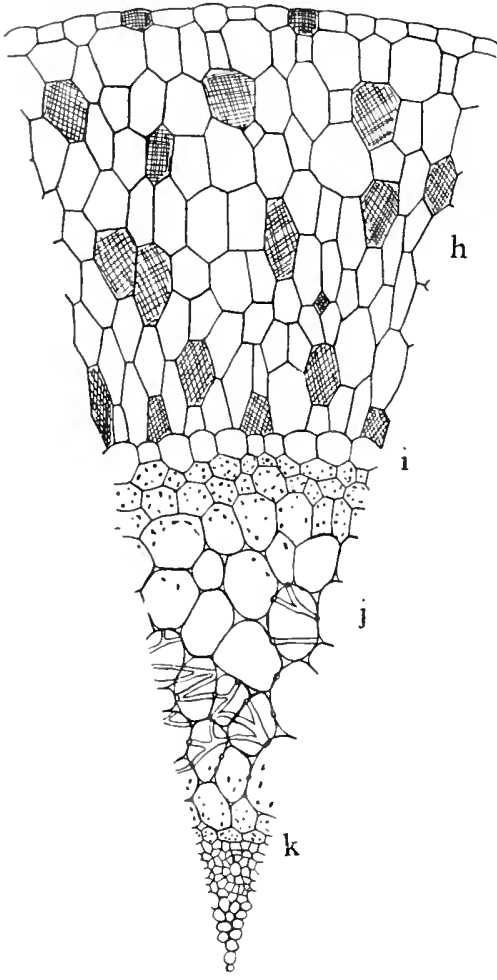

FIG. 45.-Portion of a cruss section through an aerial root of Stanhopea oculata. $h$, The velamen; $i$, exodermis; $j$, cortex; $k$, endodermis. (After Haberlandt.) for building their food as have plants rooted in the soil.

To illustrate the essential mode of their obtaining water and solutes two types of aerophytes will be discussed, namely, the type where true roots are sent forth into the air, and the type which, producing no roots, has its stems and leaves equipped for absorption. In the first instance, some tropical orchids, and other aerophytes lodging on the branches of trees, send forth roots into the air that have an external covering of dead tissue known as the ielamen (Fig. 45). The cells of this tissue have many very minute openings through their exterior and interior walls through which water passes when the root is wet with rain or dew. 'The relamen is formed by tangential division of the protoderm, beginning a short distance from the apex and giving rise to layers of cells varying from one to eighteen or more according to the species. The cell-walls of the velamen sometimes remain thin, but usually they are thickened, either uniformly, or in the form of a network or spiral bands. After the cells have reached maturity the protoplasts soon die, and 
the cell cavities become alternately filled with air and water as a dry interval is succeeded by a wet one. 'The necessary soil constituents are doubtless obtained from the dust which gathers on the roots or is washed down to them from the other parts or from overhanging branches of the tree on which the aerophyte is encamped; and from particles washed out of the atmosphere by the falling rain drops.

Separating the velamen from the rest of the root is a cell-layer known as the exodermis (Figr. 45) which is similar to the endodermis (page 43 ) of the ordinary roots in having the cell-walls more or less thickened and suberized, with the exception of cells at intervals whose thin

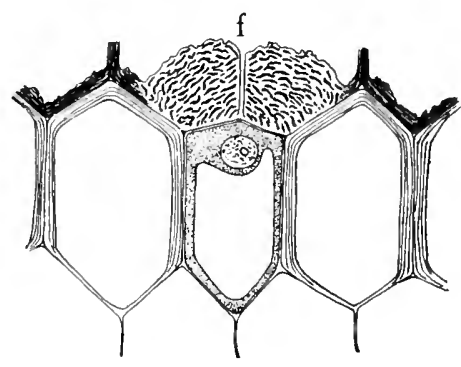

FIt; 40.- Showing at $f$ the felty body crvering the passage way through the exodermis of the aerial root of Sobralia macrantha. (After Ilaberlandt.) cellulose walls permit the passage of water and solutes which the relamen has gathered in. In some instances the outer wall of these passage cells is covered externally by a felty mass of interlaced fibrous outgrowths (Fig. 46). It has been conjectured that this is a device to condense moisture from the atmosphere when rain and dew are not keeping the relamen supplied; but conclusive evidence is lacking to show that the velamen has the power to condense water from the vapor state by this or any other device. In any event the felty covering may help to retard evaporation through the walls of the passage cells when the velamen is dry. When the velamen is wet the root is as if embedded in a saturated sponge, and when dry the velamen acts as a mulch to keep the rest of the root from drying.

Tillandsia usneoides, the hanging moss of the southern states, represents the second class of aerophytes where the roots do not develop, although their fundaments are present in the young seedlings. This plant hangs from trees of various kinds, but has no organic connection with them and derives no materials from them. The branches are wiry and the leares slender, 
and both are thickly beset with overlapping scales under which rain and dew gather and find entrance by osmosis into the cell cavities. Here the scales, like the velamen, serve both for the absorption of water and protection against its loss. The scales when dry are shrunken and lie close against the stem or leaf; but when wet their thicker outer wall swells and bulges outward,

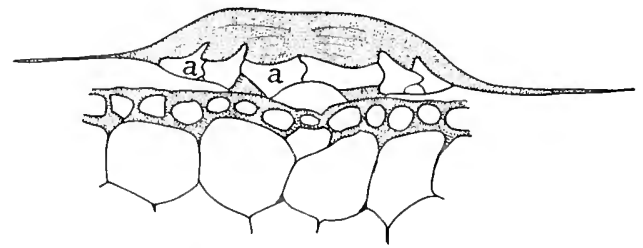

Fir. 4,-Cross section through a water-absorbing scale of Tillandsia usneoides; $a$, a, waterabsorbing cells partially filled with water. (After Schimper.)

water is drawn into the cell cavities, and by their turgidity the scales rise and make room for more water beneath them (Fig. +7 ). Practically the whole plant body is thus enabled to imbibe water, and solutes that have come in the form of dust.

Other Methods of Absorbing Water.-Some desert plants have devices for absorbing water into the leaves. Diplotaxis Harra, for example, a cruciferous plant of the Egyptian and Arabian deserts, has its foliage beset with stiff hairs which, acting as points for the radiation of heat, after sunset gather dew. The hair is practically waterproof excepting at its base, where the lew. running down from above, forms a film over the wall and is quickly alssorbed.

There are some interesting anatomical details in these hairs of Diplotaxis (Fig. +8). Cellulose additions to the wall fill the cell cavity down to the spreading base, where the cavity enlarges and is lined with an unusually thick protoplastic layer. The watl separating the hair from the body of the leaf has many pits through which the imbibed water can pass into a water reservoir tissue beneath, whence it is distributed directly to the mesophyll cells. The entire leaf is so thoroughly waterproofed that only 
the basal part of the hairs can be wetted. Nevertheless when a wilted leaf is submerged in water it soon regains its turgidity.

Practically the same device with modified details is repeated in various other desert plants whose roots do not go deep enough to draw water from the depths of the soil.

Although there are many devices for absorbing water and solutes under various environments, in one respect they are all alike: they are outgrowths that increase the absorbing surface manyfold and enable the plant to make effective demands on the source of supply.

\section{Illustrative Studies}

Soak a flower pot in water. Soak mustard seeds in water overnight. Dash these seeds against the inner surface of the moist pot where they will stick luecause of their

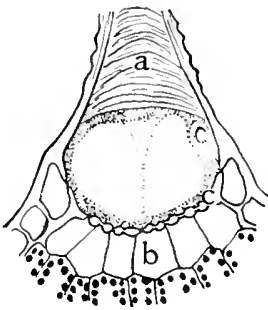

Fig. 48. - Water-absorbing hair of Diplotaxis Harra. $a$, secondary cellulose thickening of the cell-wall, filling the cell cavity nearly to base of hair; $b$, water-storage cells communicating by neans of pits with the cell-lumen of the hair. (After Haberlanidt.) mucilaginous surface. Invert the pot in a saucer of water and the seeds will germinate and furnish an abundance of root hairs. Cut off the roots and lay them in a dish of 5 per cent. $\mathrm{KOH}$ overnight to bleach and clear them up. Mount one of the cleared roots in a drop of the $\mathrm{KOH}$ solution under a coverglass and crush the root a little by gentle pressure on the coverglass. Study with low and high powers. Can you now make out that a root hair is an outgrowth of an epidermal cell? Measure the length and breadth of a hair and the thickness of its walls. Note the tracheal tubes near the center of the roat. Draw an entire root hair including the enlarged basal part. Study a cross section of a root put up in the form of a double-stained permanent mount as described in Chapter XV. Find the stumps of root hairs. Note the number and character of the cells which the water and solutes absorbed by the root hairs must traverse in going to the tracheal tubes. Draw a segment of the cross section to show all this. 
3. Make permanent double-stained mounts from paraffin material of Cuscuta parasitic on balsam or on any other host suitable to jaraffin sectioning. Study with low and high powers. Note whether the water and food-conducting tissues of the parasite are in organic union with the corresponding tissues of the host. Can you tell precisely where the tissues of the parasite leave off and those of the host begin? and if so, how can it be told? Show by a diagrammatic drawing the host and parasite, and on a larger scale draw a few cells of the phloem and xylem of the host and corresponding cells of the parasite joining these.

4. Study free-hand cross sections, or paraffin sections done into permanent mounts, of Tillandsia usneoides. Mount freehand sections in dilute glycerine. Make a drawing through a scale showing its relation to the tissues of the stem. 


\section{CHAP'TER VII}

TRANSPORT OF WATER AND SOIL SOLUTES

The Need of a Transporting System.-Unicellular plants living in water or in moist and shady places can absorb water and solutes throughout their entire surface, and in simple multicellular water plants consisting of a single row of cells or of an expanse of tissue only one cell in thickness, each cell is in position to absorls water and solutes for itself. But in bulkier plants the interior cells have to draw upon the exterior for their necessary materials. And where the distance to the remoter cells is great and loss of water through leaves and other aboveground parts is considerable a system for the conduction of water and solutes becomes imperative.

A tissue made up of short cells will not serve this conductive purpose, as is shown by the fact that a strip of pith or cortex with its lower end in water will soon begin to wither at a height of 5 to 15 centimeters even when protected from rapid loss of water; and experiments involving the extirpation of the pith and the removal of the bark show that the water tubes in a few thin vascular bundles can supply the water lost by transpiration through the leaves, while all of the tissues of the pith and bark combined fail to do this. 'These things show us how necessary has been the differentiation of a water-conducting system as plants in their evolution have aspired to greater and greater heights above the soil.

Tissues Devoted to the Transport of Water.-The tracheal tubes and tracheids have been shown to be the highways through which water and solutes that have entered from the soil make their way to the leaves. The origin and nature of these tissues have already been told in Chapters II and III, and we have now to consider their structural adaptations to the work they have to do. 
The Tracheal Tubes.- The tracheal tubes, or water tubes, are fitted for carrying water by being essentially continuous tubes from the finest branches of the roots up through the stem and into and throughout the leaves. In some instances cross walls have been found in them every 45 to 9 I centimeters apart. but the amount of resistance which these walls afford to the ascent of water must be extremely slight compared to that which would come from the 15,000 to 30,000 cross walls in a chain of ordinary cells reaching to the same height.

The average diameter of the tracheal tubes is approximately $.05 \mathrm{~mm}$. They average the smallest in submerged water plants where the need for them is not great, and the largest in tall-growing climbing or clambering plants where stems of small diameters have to carry relatively large amounts of water through long distances. In shrubs and trees the water tubes are larger in the early growth of spring and summer, when the new crop of leares is to be supplied with water, than in the later growth when the demand for a larger water-carrying capacity has been almost or quite satisfied.

It has been told in Chapter II that the walls of the tracheal tubes are thickened after various patterns, spirally and annularly (Fig. Ig) in those that are first formed by the procambium, and more extensively, leaving thin places in the form of circular or transversely elongated pits in those that are last formed by the procambium and later by the cambium (Fig. I9). The thickenings of the walls are needed to hold the tubes open against growth and turgor pressures from the surrounding tissues, pressures great enough to burst the bark even when this is reënforced by a continuous sclerenchyma ring, as in the case of Aristolochia (compare Figs. 23 and 2.4), and to crowd the wood in to the complete obliteration of the pith.

The thin places between the spiral and annular thickenings and in the pits are of course needful to allow water and solutes readily to pass out to supply the surrounding tissues as they need them, and to permit reserve food solutes to pass in when after a period of storage, in the wood parenchyma and medul- 
lary rays, they are needed above by unfolding buds and developing seeds and fruits.

The spiral and annular thickenings are such a nice adjustment to specific conditions that their significance, already mentioned in Chapter II, will admit of further discussion. Tubes of these kinds are the first permanent tissues to become differentiated from the procambium, and they will be found in stem cross sections not far from the growing apex and on the side of the procambium bordering the pith (Fig. I4). Already before other tissues of the vascular bundle make their appearance in the procambium strand these tubes have characteristically thickened and lignified their walls. In longitudinal sections they stand out sharply as channels for conduction of water into the meristematic region close to the growing apex. Where these tubes appear a good deal of stem elongation has yet to take place, and it will be seen at once that wall thickenings in the form of rings or spiral bands will allow the tubes to stretch without interposing much resistance to stem elongation. The pitted kinds of tubes which later appear are formed farther back from the apex where growth in length has ceased, and these are stronger and better adapted for long service than are the earlier sorts which finally become ruptured and ineffective.

Course of Tracheal Tubes Through the Stem. 'The' course of the tracheal tubes through the stem is best followed by tracing the course of the rascular bundles of which they form a part. Nearly all rascular bundles end in the leaves, and only rarely do they end in the stem without entering a leaf. Therefore there is no better way to trace the bundles than to begin in the leares and follow their course downward. Pro ceeding in this manner we find that the bundles or bundle, as the case may be, that descend into the stem from each leaf continue their downward course through one or more internodes, and then as a rule branch and fuse with bundles that have entered the stem from other and lower leaves (see Figs. 49 and 50). In this way the whole system of bundles in stems is made continuous, a 
system comparable in this respect to the anastomosing reins and arteries of the animal body.

It will be seen that if the leares on one side of a tree are made to transpire faster than those on the other because of greater

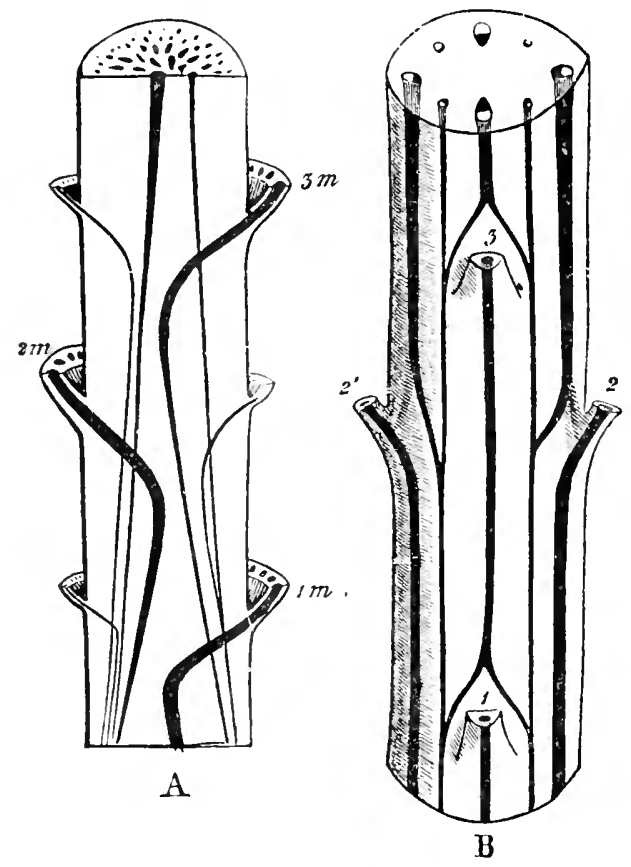

Fir 4. - A, diagram of course of vascular bunciles in a palm stem; $1 m, 2 m, 3 m$, bundles from the median portions of the leaves. $B$, diagram of vascular bundles in external view and in cross section of the stem of Cerastium. The leaves are shown cut off at $1,2,2$ ' anil 3. (Aiter Vines.) exposure to the sun or drying wind from that quarter they can draw upon the water in the whole circle of bundles in the trunk; or when one side of a stem is severely injured so as to interrupt the flow of water on that side, the leaves above the injured part can draw their water from the opposite side, which in turn can reëmburse itself from the injured side below the wound.

The vascular bundles that descend from a leaf into the stem constitute a leaf trace. 'The number of bumdles in each leaf trace varies commonly from one to three, but there may be more. The rule is that the whole ring of vascular bundles in Dicotyledons is composed of leaf traces, but, as was stated above, instances occur where bundles do not extend into the leaves, and these anomalously are in the pith or even in the cortex, and since they do not run out of the stem they are called cauline bundles, while the others that run into the leaves are called common bundles. 
The vascular bundles in most monocotyledonous stems are all leaf traces. It will be remembered that the leaves of these plants are parallelreined, and usually many bundles descend from a single leaf into the stem. These at first penetrate rather sharply toward the center, and then descending turn gradually outward and unite with bundles from other leaves. 'The larger bundles go farther toward the center than the weaker; and so it happens that the bundles in most Monocotyledons are not arranged in a concentric circle as in Dicotyledons, but are more or less promiscuously distributed, as seen in the stem cross section (Fig. 49). Monocotyledons with hollow stems vary from this plan in that the bundles keep closer to the periphery; and in the grass type of stem the bundles are united at the nodes by a plexus of anastomosing branches.

'Throughout all classes of stems it is a noteworthy fact that the leaf has one or more vascular bundles

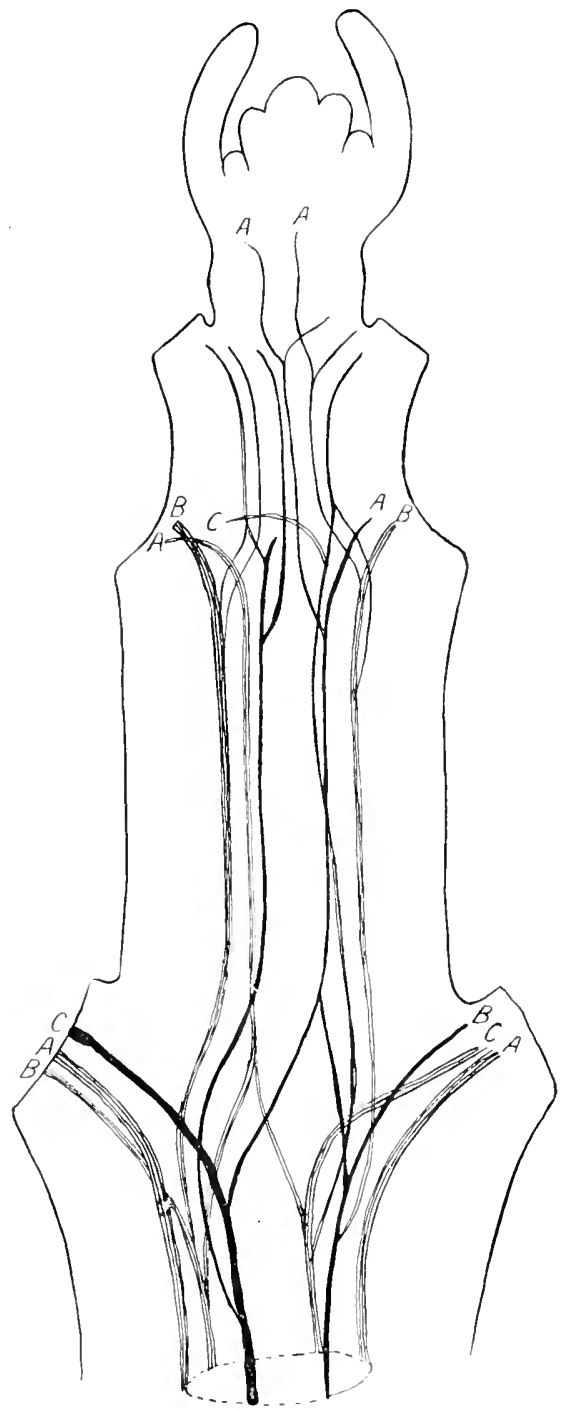

Fili. 50.-Diagram showing the course of the vascular bundles in a stem of Clematis viticella. llerlian bunlles from the leaves are marked $A$, lateral bundles $B$ and $C$. (After Nägeli.) 
descending into the stem to take on and conduct to it directly the water and solutes which it as a transpiring and photosynthesizing member demands.

The Tracheids. - The tracheids are elongated cells especially adapted to be water carriers by numerous thin places in the walls in the form of bordered pits or associated with spiral, annular, or reticulate thickenings (Fig. I9). Each tracheid is a single closed cell, and water and solutes flowing into and out of it find the thin places suited to their passage.

The length of the tracheids varies a good deal; from I to $2 \mathrm{~mm}$. is a common length, but they are often shorter, and they may become many times longer than this. It therefore appears that a water-conducting system composed of tracheids would offer more resistance to the flow of water than one made up chiefly of tracheal tubes, because of the less frequent cross walls in the latter case.

Tracheids commonly occur associated with the tracheal tubes. but they are sometimes lacking. They usually replace the tracheal tubes in the smaller ramifications of the reins of leares. and where tracheal tubes anastomose, as notably at the nodes of grasses, the connections are commonly made by tracheids; and freruently tracheal tubes in successive annual rings of growth communicate by means of tracheids.

Comparing the use of tracheal tubes and tracheids among the Monocotyledons and Dicotyledons it appears that the tracheal tubes are most in use for conduction through long distances, while for transport through short distances the tracheids are preferred.

In Pteridophytes tracheids occur more frequently than tracheal tubes, and in Conifers tracheids constitute the sole waterconducting tissue, excepting special water-conducting parenchyma in the medullary rays; and the nearest approach to tracheal tubes is found in the elongated, spirally-thickened tracheids, which as a product of the procambium alone, occur next the pith.

The wood of the pine, save the medullary rays, and a small amount of wool parenchyma devoted to the secretion of resin. 
is composed entirely of fiber-tracheids which serve perfectly well for the conduction of water, even to the tops of tall trees. It does not necessarily follow, however, that tracheids are as efficient in the transport of water as are tracheal tubes, for under like conditions the leaves of pine transpire very little water compared with the leares of ordinary dicotyledonous trees. The leares of the beech, for example, weight for weight, grive off ten times as much water as do those of the pine. The pine tree relies upon these fiber-tracheids for strength as well as for the conduction of water, and the success of the plan is shown by the fact that pines grow to be great trees and thrive in exposed situations where the stress of the winds and demands for water are heary. The essential details leading to the success of this plan appear to be these: First, as to water conduction, practically the whole of the early growth is devoted to this, and the late growth materially assists, and the xerophytic leaves keep transpiration down to a minimum. Second, as to strength, the thin places in the tracheids are reënforced by prominently overhanging borders, and the two weakest tissues
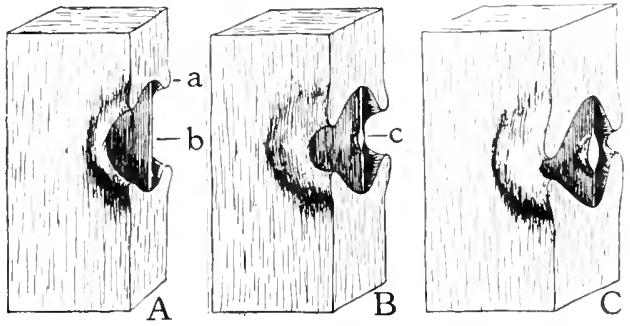

F1G. 5I.-Different stages in the development of a bordered pit. $b$, The original, thin, primary wall; $u$, the overhanging border formed as the wall thickened. $B, T$ Thickening of the wall has continued and extended the border; the primary wall has thickened at $c$. forming the torus. $C$, the borier and the torus are finished.

in wood, namely the wood parenchyma and the tracheal tulyes. are, respectively, almost and entirely lacking. Considered as strengthening elements the fiber-tracheids are in all essential respects like wood fibers. They are long and tapering cells, their ends interlace, their walls are thickened and lignified. 
But in one noteworthy detail they are very unlike wood fibers, namely, their walls have numerous and large bordered pits, and it is this that fits them for water highways (Fig. 5i).

The bordered pit is a thin area in the wall with an overhanging border. The thin place is clearly to facilitate the passage of water and solutes. and the border serves the double purpose

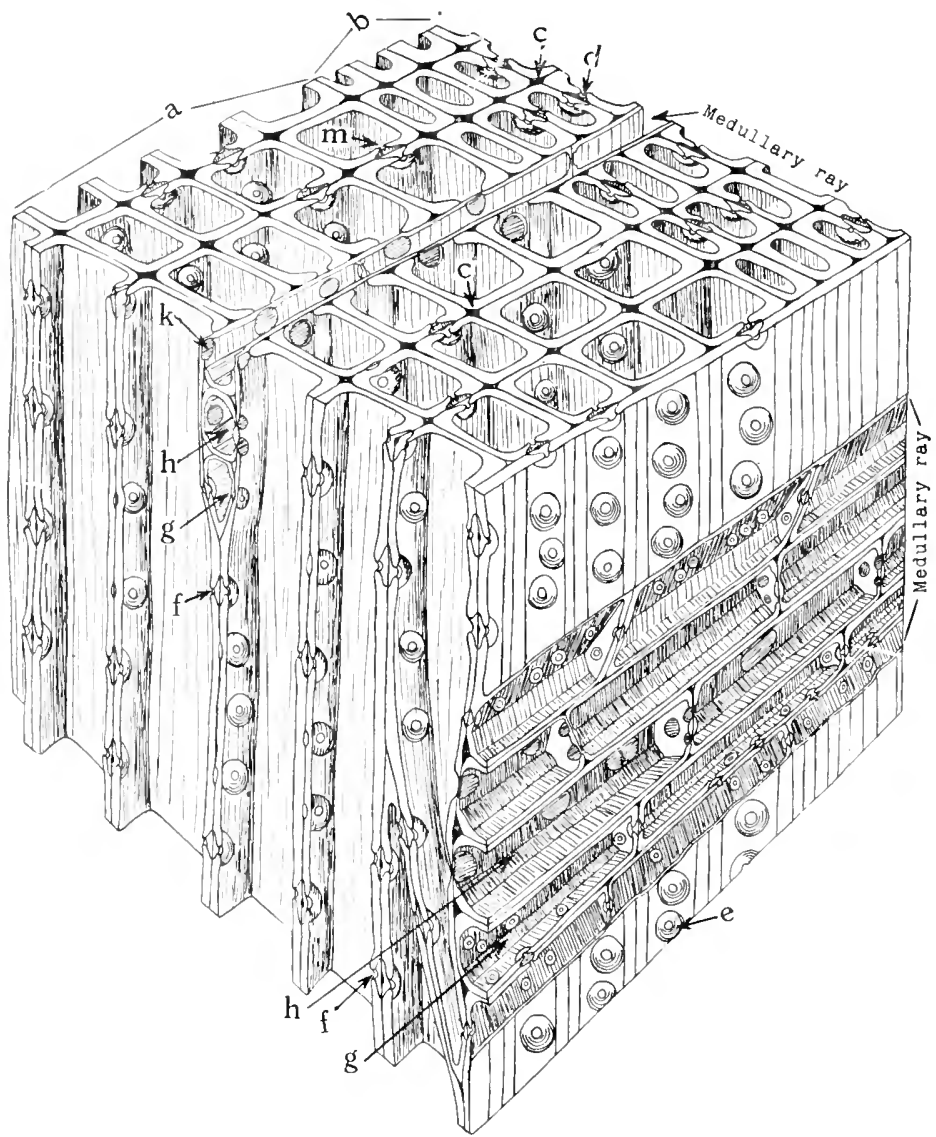

Fis. 52, - Diagrammatic relresentation of a blcck of pine wood highly magnifiel. $a$, Early growth; $b$, lategrowth; $c$, intercellular space; $d$, bordered pit in tangential wall of late grow th: $m, f$ and $\epsilon$, bordered pit in radial wall of early growth from different points of view: h. row of medulary cells for carrying food; $g$, row of medullary ray cells for carrying water; $k$. thin place in radial wall of ray cells that carry food. 
of strengthening the wall where it is weakened by the thin place, and of arresting and bracing the thin part when from unequal pressure at one side or the other it is in danger of bulging too far and bursting.

In the early growth of the annual ring of pine the bordered pits are almost exclusively in the radial walls, while in the late growth they occur for the most part in the tangential walls (Fig. 52). This difference seems to relate to certain physiological demands. If for any reason one side of the tree-the windward side, for instance-demands more water than the others, the water rising through the trunk can pass to that side through the pits in the

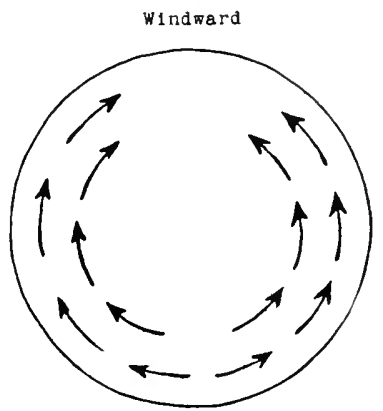

FIG. 53.-Diagram to show the tangential flow of water from the side where there is less demand to the side where the demand is greater. radial walls, as shown in the diagram (Fig. 53). And since the medullary rays extend individually but a fraction of a millimeter vertically the water can find its way around the stem without traversing them, as illustrated by Fig. 54. Again, when

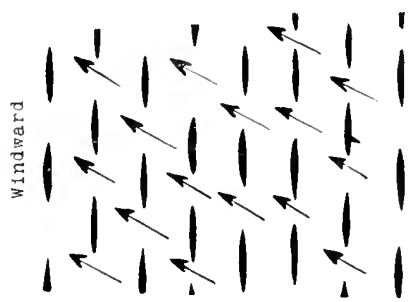

FIG. 54.-Diagram showing by the arrows how the water can flow tangentially around a plant without traversing the nedullary rays, which are indicated in black. the new crop of leaves is produced in the spring and the cambium commences the new ring of growth, beginning in the crown and progressing toward the roots, the bordered pits in the tangential walls of the late growths of the previous summer permit water to pass into the tracheids of the new growth as the latter progresses toward the roots and is not yet in position to draw directly upon the roots themselves (Fig. 55).

How the boardered pits assist in the flow of the water vertically, which without doubt is their chief function, is made clear by a study of longitudinal tangential sections where it 
is seen that the pits are plentiful in the slanting common wall between two vertically contiguous tracheids (Fig. 56).

Tangent1al Wall

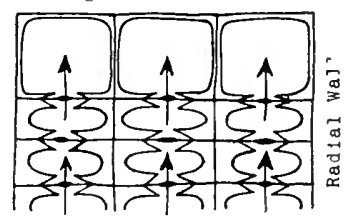

FIG. 55.-Diagram to show the radial flow of water in pine wood, from the tracheids of the late growth of one year into those of the early growth of the succeeding year.

Relation of the Tracheal Tissues to the Medullary Rays and Wood Parenchyma.--One of the functions of the medullary rays is to carry radially into the bark water which they have taken on from the tracheal tubes and tracheids. Their other most important function of transporting and storing food will be spoken of in later chapters. Wherever a medullary ray comes into contact with a tracheal tube or tracheid there are pits or thin areas in the common wall separating them through which water and solutes can the more easily pass. And the same condition exists where the wood parenchyma cells come into contact with the tracheal tubes and tracheids. The medullary rays and wood parenchyma are therefore in position to take up and store water, and to assist in its radial and tangential distribution.

It has not been demonstrated, and it is indeed doubtful, that the rays and wood parenchyma as living tissues assist materially the dead tracheal tissues in the vertical transmission of water. The undoubted use of their intimate relationship, aside from the radial and tangential distribution of water, will be told in subsequent chapters.

The Ring of Annual Growth.-The physiological significance of the ring of growth has already been told in the chapter on secondary increase in thickness. Recapitulating in a sentence: The large tracheal

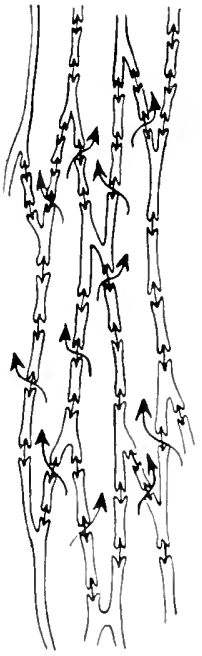

FIG. 50.-Diagram indicating by arrows how the water in the tracheicls of pine passes longitudinally from one tracheid to another. tubes and tracheids of the early growth provide for the increased demand for water, while the predominating wood fibers 
and smaller tracheids of the later growth are a response to the demand for greater strength. 'The ring of growth in its relation to the transport of water and solutes demands our attention in this chapter.

The large tracheal tubes and tracheids of the early growth are the most efficient in carrying the transpiration stream because of their relatively large diameters. That, however, the tracheal tissues of the late growth are useful in carrying water is shown by experiments with colored solutions, and by the numerous pits in their tangential walls which are evidently designed to deliver water to the early tracheal elements of the succeeding year. Furthermore, there is frequent communica tion of the late tracheal elements with the early elements of the following year by means of radial rows of tracheids; and at the close of the season's growth groups of small tracheal tubes are often produced which are to lie immediately against, or in close juxtaposition to, the large tracheal tubes of the succeeding year.

The number of years the tracheal elements remain active varies with different species. In trees like the oak, walnut, etc., whose wood is differentiated into sapwood and heartwood the heartwood has lost the power to conduct water through the filling of the tracheal tubes by ingrowths of the wood parenchyma into their cavities, and by the infiltration of the walls of the tissues in general with gums, resins, and coloring matters. On the other hand, in trees like the beech which produce no heartwood the water highways remain functional through many years. But always it is the wood of the current year that is the most active in water conduction, while the part played by the older rings of growth lessens with each succeeding year. In perennial monocotyledonous stems, as in the case of the palm, for example, where there is no annual increase in the size of the bundles, the same tracheal elements must retain their activity indefinitely. 
Relation of Rings of Growth to Growth in Length.When the terminal bud unfolds and adds another year's growth in length to the stem, it, together with the new shoots from

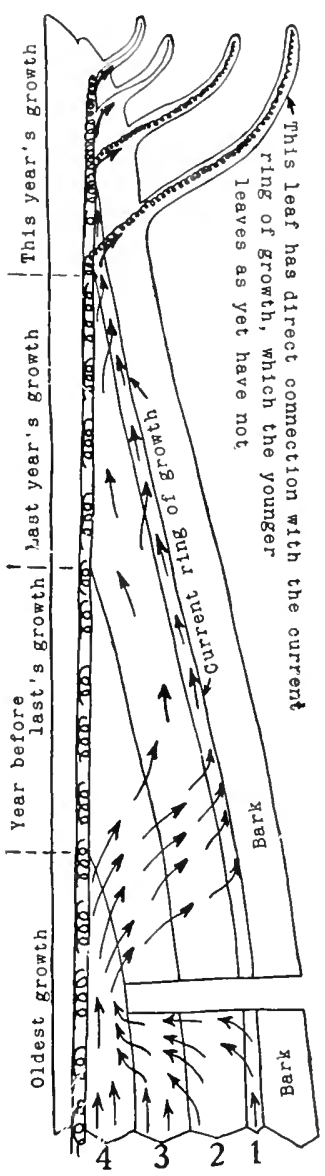

Fis. 57--Diagram show ing the relation of the watercarrying tissues of the leaves to those of the stem, and how the older rings of growth give up their water to the newer before this water can enter the leaves. The figures at the bottom indicate in years the age of the rings. lateral buds, produces the leaves of the current year. All of the leaves, it will be remembered, with the exception of perennial leaves such as those of the pine, are borne on these new shoots. We must now proceed to enquire what is the relation of the tracheal elements of the new segments of stem to those of the leaves and of the preceding years' growths.

While the internodes of the new shoot are still elongating and the cambium has not yet begun secondary increase in thickness, only the small and few spiral and annular tracheal tubes differentiated from the procambium are present in the new growth to take up and carry water from last year's segment of stem into the unfolding leares of the new shoot (Fig. 57). And it sometimes happens that the leaves are more than half grown before these first tracheal tubes are reënforced by others from the cambium. In this fact we have the evidence, since young leares are known to transpire water rapidly, that the spiral and annular tracheal elements first laid down are very efficient water conductors, through short distances at least. Soon, however, these earliest tracheal elements are reënforced by others laid down by the cambium, and on account of their weakness they break apart and go out of function (Fig. 57). 
The tracheal elements of the new shoot (new stem and leaves) have direct communication with the roots through the tracheal elements of the new ring of growth which the cambium adds along the whole stem. It often happens, however, that before the cambium has made this connection the leaves are already well along in their development and are drawing water through the channels of the older wood. How this is accomplished will be seen in Fig. 57. In this figure the spiral and annular tracheal elements are represented by a spiral line, the current ring of growth is the outermost zone with the ascending arrows and the older annular rings are between this and the pith. It will be seen that the first-formed tracheal elements (the spiral lines in the figure) from the leaf join with those of the current year's segment of stem. It will be seen also that the first-formed tracheal elements in last year's segment of stem, as well as of preceding years, have broken apart and presumably can be no longer functional. Before the cambium becomes active in the new shoot practically all of the water which the leaves get must be drawn through the small spiral and annular tubes of the new shoot from the tracheal elements of last year's growth. When the cambium begins its activity it forms new tracheal elements in the new shoot which unite with the tracheal tissues from the leaf and pursue a continuous course through the new ring of growth all the way down the stem and into the roots (Fig. 57).

Relation of Annual Rings to the Leaves. - A study of the diagram, Fig. 57, will show how the tracheal elements from the leaves have most extensive and direct connection with the tracheal elements formed by the cambium the current year, and therefore the great advantage to water-conduction which comes from the formation, first of all, of large tracheal clements in this new growth.

Experiments with eosin and other aniline dye solutions have shown that water rises throughout the sapwood, but most rapidly in the newest rings, and that if the latter are cut through the older rings are then employed to carry the water past the 
gap, above which the water is distributed to the newer rings again for farther transportation. See basal part of Fig. 57.

Distribution of Water and Solutes throughout the Leaf. -In one class of leares the vascular bundles entering the leaf
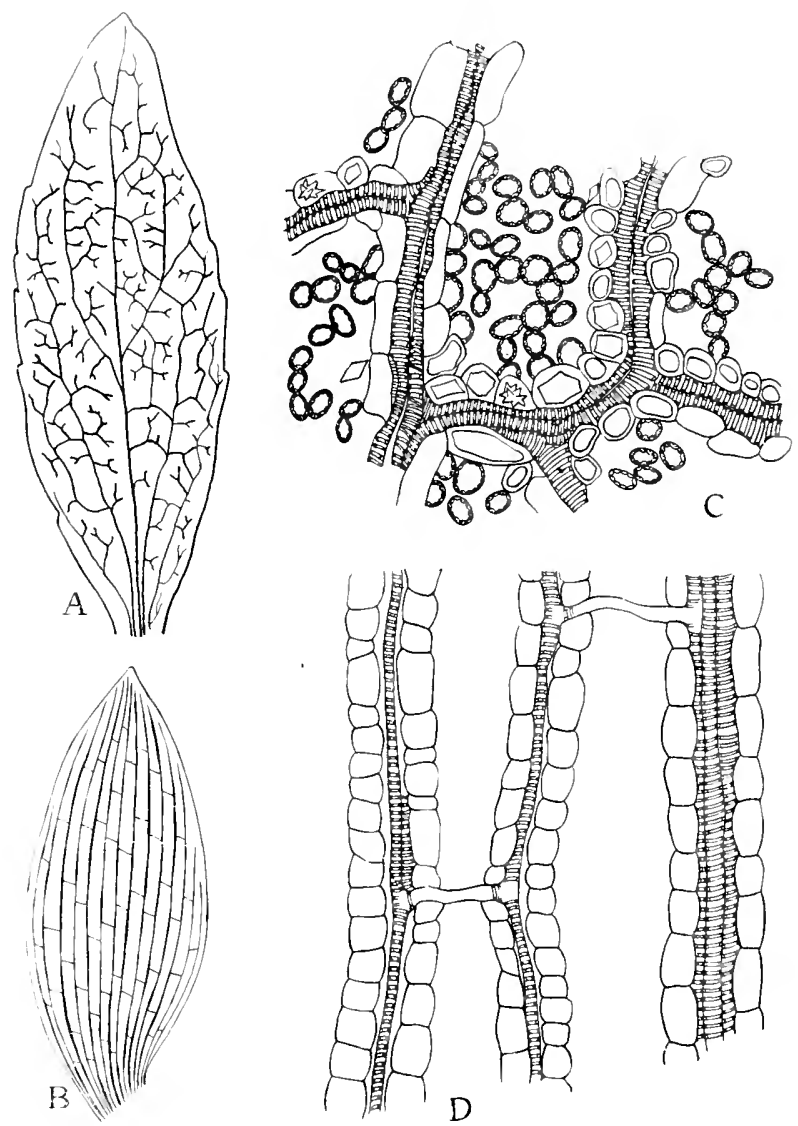

FiG. 5.5-Camera-lucilla drawing of a bleached leaf of a Dicotyledon, showing the course of the vascular hunlles, and how they end free in the mesophyll. $B$, the same for a leaf of a Monocotylerion, showing the anastonosis of the parallel veins by means of slender lateral branches; $C$, magnified cletail of $A ; D$, magnified detail of $B$.

are all wathered into the midrib, whence branches run into all parts of the blade. These are known as netted-reined leaves (Fig. 58. 4). In another class all of the bundles are not merged 
with the mid-rid, but some run an independent course from base to apex, as seen in grass leares. These leares are called parallel-reined (Fig. 58, B). In the netted-reined sort the reins divide and subdivide until the meshes are extremely small-in some leaves approximately $0.2 \mathrm{~mm}$. in diameter, and the ultimate branches end free in the mesophyll. In the parallelreined type the main veins running from base to apex are united by frequent cross branches (Fig. 58,D). Where the ultimate branches are $0.2 \mathrm{~mm}$. apart water from them needs to flow

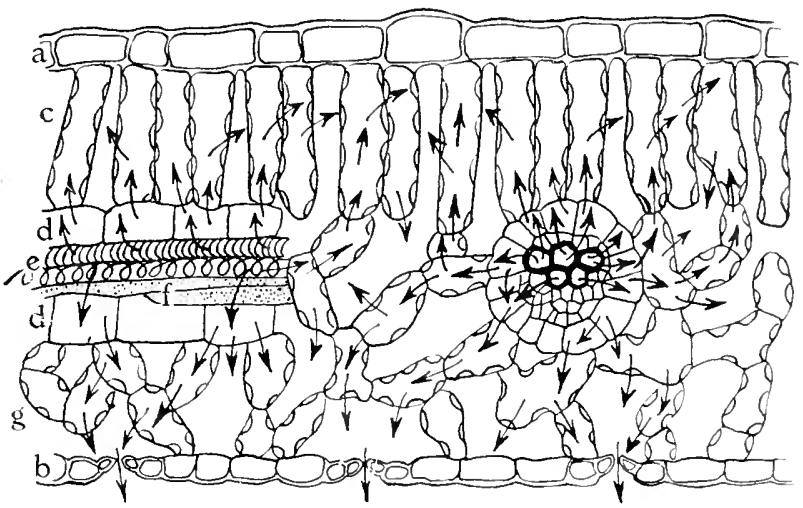

FIG. 59.- Semi-diagrammatic cross-section of a leaf showing by arrows how the water passes from the tracheal elements of a rein into the border parenchyma cells, and thence into the palisade and spongy parenchyma, from which it evaporates into the intercellular sfraces and passes from the leaf through the stomata. $a$, upper epidermis; $b$, lower evidermis; $c$, palisade parenchyma; $g$, spongy parenchyma; $d$, borler parenchyma; $e$, tracheal elements; and the stippled cells below $e$, the phloen cells.

laterally only o. I mm. to supply the mesophyll cells at the center of the mesh. Illustrations of this kind make clear the general fact that the provision for the distribution of water throughout the leat is very efficiently wrought out.

In the successively smaller branches of the bundles in leares we find the tracheal elements becoming ferver and smaller until the smallest ramifications may have but a single line of tracheids. The phloem elements also are successively reduced in the smaller and smaller branches; the sieve tubes give way to undivided 
mother cells of sieve tubes (see page $3^{6}$ ) and companion cells, and these finally are succeeded by border parenchyma cells merely. Thus it happens that at the ends of the ultimate branches the vascular bundles may be represented by a single tracheid merely since the border parenchyma is not morphologically a part of the rascular bundle.

Water is drawn by osmosis from the tracheids by the border parenchyma cells, and from these in the same way by the palisade and spongy parenchyma. From these tissues it is for the greater part evaporated into the intercellular spaces, and passes thence through the stomata into the external atmosphere (Fig. 59). In this way some plants give off in twenty-four hours of a hot summer day as much as ro c.c. of water for each square centimeter of leaf surface; but the average rate is much lower. A large birch tree has been found to give off from 300 to 400 kilograms of water in twenty-four hours.

Only a relatively small part of the water taken in to the palisade and spongy parenchyma cells is used in the manufacture of carbohydrates. (See page 147 .)

The Power Concerned in the Ascent of Water.--The force of osmosis in the root hairs and cortical cells of the young roots sets up the flow of water from the soil into the tracheal system; and this force communicated to the tracheal elements is at times sufficient to raise water many feet; but that it does not work fast enough to be the dominant force when transpiration is at its height is shown by the fact that at such times there is a negative pressure in the water highways, which may be taken as an indication that the effective power is in the form of a pull from above.

'The tracheal tubes and tracheids are small enough for capillarity to be a significant force in water ascent and in sustaining the weight of the water columns; and doubtless capillarity does play an important part. But it seems from the data now available that capillarity under the conditions existing in plants cannot lift the water fast enough, nor high enough to supply the taller trees. 
It seems that the palisade and spongy cells in the leares must be exercising a powerful osmotic pull on the water in the tracheal elements in the reins; and this pull communicated downward might explain the negative pressure in the vater highways when transpiration is rapidly going on.

Although the medullary rays and wood parenchyma are in direct contact with the tracheal elements and take water from them (Fig. 60), it is now very doubtful whether the living cells in the rays and wood parenchyma are essential factors in water ascent, for many liters of water have been drawn up through the trunk of a tree after the tissues in the trunk have been killed by poisonous solutions to the height of sixty feet. Again, when a branch with foliage is placed in a solution of indigo-carmine, a stain which does not at all enter living cells, the dye is found nevertheless to rise in the tracheal elements along with the water; and it may be inferred from this that the water holding the dye in solution has risen without being drawn into, and forced along by, living cells. Osmotic intake by

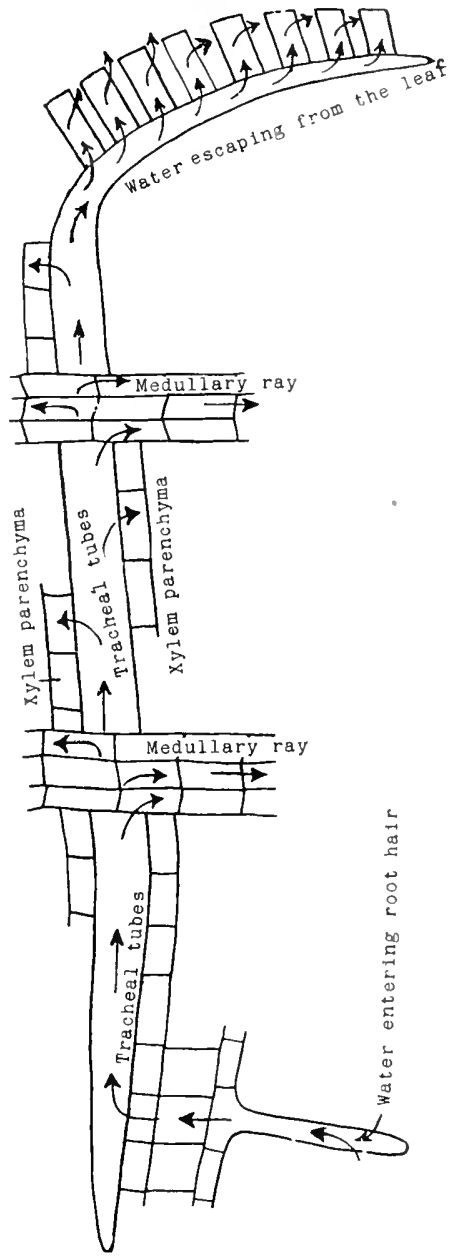

FIG, 60.-Diagram to show the path of the water as it rises to, and escalles from, the leaves. the roots, capillarity, osmotic suction by the mesophyll cells of the leaves, acting together, seem to be the chief forces concerned in water ascent. 
Path of Water Ascent.-The path of the ascent of water is clearly mapped out by placing a leafy stem in a weak solution of eosin or indigo-carmine. If the stem is then studied by means of longitudinal and cross-sections before the stain has had time to diffuse from the tissues through which it is rising into surrounding tissues, it will be found that only the tracheal tubes and tracheids are stained; and when the stain has risen into the leares it is the tracheids in the reins that first show its presence. Furthermore, if the cut end of a stem having foliage be dipped into melted gelatine or paraffin the tracheal tubes will be plugged up for some distance, so that the end of the stem can be trimmed to expose all the tissues without remoring the plugs from the tracheal elements. If the end of the stem is then submerged in water the leaves soon wither, while in a control experiment employing a similar branch with the tracheal elements left open the leares continue fresh and unwilted. These and other experiments leading to similar results leave no ground for doubt that the path of water ascent from the roots is through the carities of the tracheal tubes and tracheids.

\section{Influence of Environment on the Water-conducting} Tissues. - The amount of tissue deroted to the circulation of water depends upon the intensity of the demand for water to supply the loss by transpiration. In submerged water plants where transpiration does not take place the tracheal elements are hardly more than restigial. In water plants with foliage borne above the surface the water-conducting tissues are better dereloped, while in land plants these tissues spring into still greater prominence. 'The amplitude of water-conducting tissues reaches its climax in tall-growing climbing plants with slender stems and large crowns of foliage, where the distance to be traveled is far and the demand for water through transpiration large; and in those trces also, such as the willows and Liriodendron (yellow poplar of commerce) whose roots find abundant water in the moist soil of intervales and along streams. and whose foliage is lavish in transpiration (Fig. 6I). 


\section{Illustrative Studies}

T. Study longitudinal radial sections of old Aristolochia stems made into permanent mounts and double-stained in erythrosin and iodine green or in safranin and hrmatoxylin; or if fresh sections are used mount them in aniline sulphate. Note

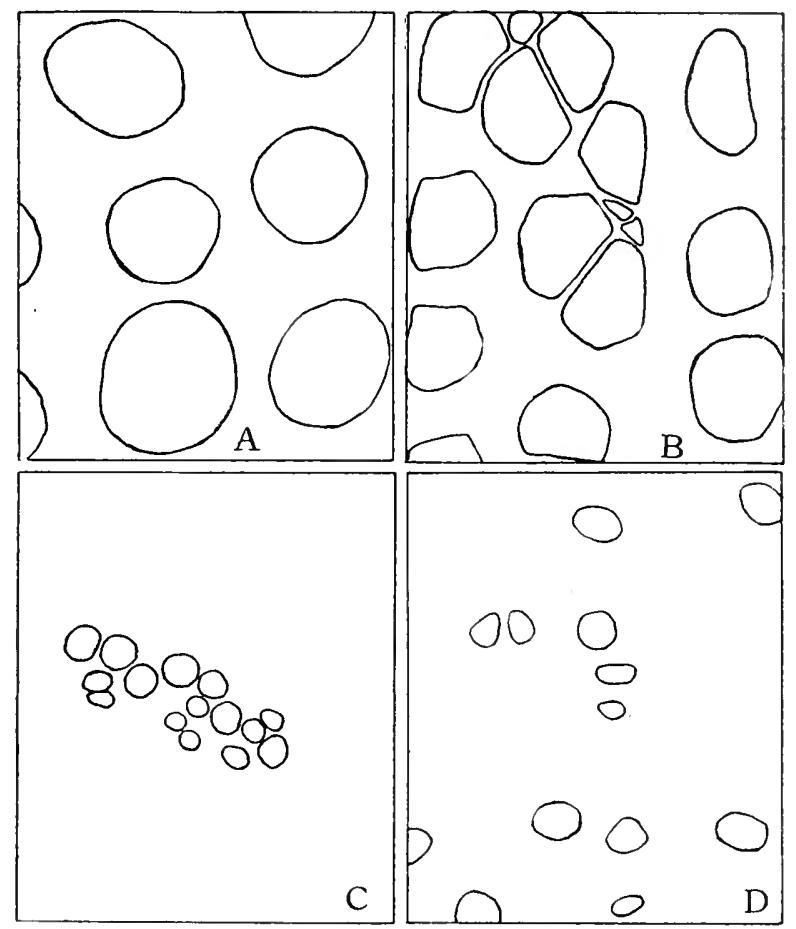

Fig. 61.-Camera-lucida trawings of equal areas of cross sections of stems of .4, hop; $B$, yellow poplar; $C$, water cress, and $D$, Psidium Galapageium which grows in a ferpetually dense fog. The first two stems have neer to carry relatively large quantities of water, and the last two relatively little. Only the tracheal tissues are here outlineti.

the spiral and annular tubes next to the pith that have been formed by the procambium, and the different pitted kinds that have been formed by the cambium farther out. Draw the different kinds and let the drawings of the tangential walls, namely, those that are on edge in the radial section, show clearly 
the thick and thin places in the walls - the thick places to keep the tuber from collapsing and the thin places to allow the inflow and outhlow of water and solutes.

2. Study cross and longitudinal radial and tangential sections of pine wood, double stained and permanently mounted. Study the cross section first and draw to scale a small portion at the juncture of the early growth of one ycar with the late growth of the preceding year where a medullary ray cuts through. Look sharply for any means of interchange of matcrials between early growth, late growth, and medullary rays. If the drawing is not made as exactly as possible, important details will be left out.

Now study the longitudinal radial section at the juncture of two rings of growth where a medullary ray runs across. Make a careful drawing to the same scale as that of the previous drawing. After studying the cross section the appearance of the radial section is surprising. What we now want to do is to discover in one section every thing we have found in the other. To do this it is necessary to recognize in the radial section both the tangential and radial walls of the tracheids. In the cross section these are casily recognized, since the radial walls run parallel with the medullary rays and the tangential walls are perpendicular to the rays. Notice that in the radial section the tangential walls are seen on edge and the radial walls are lying flat. Every thing seen in the radial section can be found in the cross section and vice versa but from different points of view and having a different appearance, and the same thing is true of the tangential section. Discover whatever means of communication there is between the tracheids laterally and longitudinally and between the ray cells and the tracheids and between the two rings of growth. Are the medullary ray cells all alike?

3. Study the longitudinal tangential section and discover from this point of view all details that have been found in the other two. Look for provision for the flow of materials in all directions. Draw to scale a small portion where a medul- 
lary rity and tracheids join. Determine the number of medullary rays in one sq. $\mathrm{mm}$. Discover whether every tracheid is touched once or more than once throughout its length by a ray.

4. Criticize Fig. 52, which is constructed from the three sections above studied.

5. Study cross and longitudinal radial and tangential sections of oak, and yellow poplar, double-stained and permanently mounted. Note by comparison of all sections what provision has been made for the interchange of materials between the tracheal tubes, tracheids, medullary rays, wood parenchyma and wood fibers.

In the tangential sections determine how many rays occur in one sq. $\mathrm{mm}$. and how many rays touch a tracheal tube for every $\mathrm{mm}$. of its ascent. The purpose of this is to find out how complete is the provision for taking up and distributing the water and solutes carried vertically by the tracheal tubes.

6. Compare for frequency and water-carrying capacity the tracheal elements in cross sections of stems of oak, hop and water lily. Make diagrams to illustrate what is found.

7. Study the tracheal tissues in leares. Clear a leaf by boiling it in alcohol, placing it in 5 per cent. hydrochloric acid for about ten hours or over night, and keeping it for a while in a saturated chloral hydrate solution. Mount the leaf in chloral hydrate. The leaf should now be perfectly clear. Study it with low and high powers. Make drawings of the endings of the tracheal tissues of the veins. Measure the distance apart of the ultimate branches of the veins. Determine by slow focusing from one surface to the other what position the tracheal tissues occupy in the leaf. We are in this way finding evidence of the efficiency of the tracheal elements in distributing water quickly to all cells of the leaf.

8. Select a plant having leaves with prominent veins. Cut some of the reins across clear through. Does the leaf above the cut wilt? Cut across more and more reins. How do you account for the results? 
9. To map out the course of water ascent in a very vivid way place a young shoot of balsam or Ricinus into a weak solution of eosin. If the plants have been crowded in the seed-bed so that the stems are spindling and colorless, all the better for this experiment. After a while in the balsam stems the stain can be seen from the outside ascending the vascular bundles, and later extending into all the fine ramifications of the reins. Cross and longitudinal sections of the stem now show that the tracheal elements alone are stained, and a leaf cleared in 5 per cent. hydrochloric acid followed by saturated chloral hydrate will show the tracheal elements stained. Of course if the stems have been left long in the eosin this will diffuse from the tracheal to the surrounding tissues. 


\section{CHAP'TER VIII}

\section{INTAKE AND DISTRIBUTION OF G.ASES}

\section{Oxygen and Carbon Dioxide Necessary to Plants.-All}

plants liberate energy stored in complex compounds, and all of the higher plants and most of the lower need the free oxygen of the atmosphere to do this fast enough for their normal functions. The union of free oxygen with the protoplasm and reserve foods whereby these substances are broken down, and in consequence cnergy is liberated within the cells, is the essential process of aërobic respiration, while in anaërobic respiration the breaking down process releases energy without the assistance of oxygen. 'This energy is used in keeping up the rital processes. Respiration, in other words, is the means of converting stored or potential energy into active or kinetic energy. 'This is the essential function of respiration without which plants could not live any more than animals could. Each living cell of the plant boty must respire for itself, for the energy liberated in one cell is not available in the next. Ife are led to conclude, indeed, that any part of the living protoplasm that is to benefit by the kinetic energy must take part in its liberation and be directly acted upon by the kinetic energy as it is being transformed from the potential condition. In a large plant body, therefore, consisting of masses of cells, there must be provision for access of oxygen to every cell, and for the elimination of carbon dioxide resulting from respiration. The oxygen absorbed by one cell may diffuse into one adjoining, and so on for a short distance; but the surest way of securing to each cell all of the oxygen that its greatest demands may require is to have it exposed for a part of its surface to an aircarrying intercellular space, a condition that is approximated by an elaborate system of intercellular spaces. 
The cutinized and suberized walls of epidermis and cork, which, as we have learned, in Chapter IV, are necessary to keep plants from drying up, also retard the inflow and outhlow of gases, and this fact has made necessary the passage ways through the epidermis and cork known as stomata and lenticels.

While every living cell in the plant body must have free oxygen for its respiration, all cells which make the food of the plant from carbon dioxide and water, namely the green cells, and particularly those in the leaves, must have carbon dioxide brought to them. There are times in the spring and summer, during rapid growth or the storage of reserve foods in seeds, tubers, etc., when carbon dioxide must be absorbed in large quantities. But this gas exists in the atmosphere in very dilute solution, namely, there are between three and four parts of it in 10,000 parts of atmosphere, and every facility must be offered for its entrance and distribution. Accordingly we find stomatal openings through the epidermis of leaves, and relatively large, continuous, open ways between the food manufacturing cells within the leaves.

Doubtless the need of the absorption and distribution of oxygen and carbon dioxide is the chief reason for the existence of an aerating system composed of openings and passage ways; but vapor of water is excreted into the same channels and through them is thrown off into the air. How much this is merely incident to the fact that the passage ways are there, and how much the well-being of the plant demands this excretion of water has not been definitely determined. There are times of great turgidity of the tissues when water filtrates into the intercellular spaces; but this water soon evaporates through the stomata and lenticels, leaving the spaces again open.

The intercellular spaces, then, serve three main purposes: They provide for the admission and distribution of oxygen used in respiration, and of carbon dioxide employed in food-making, and they furnish a way for the elimination of water vapor. Other kinds of intercellular spaces and other uses for them will be spoken of in Chapter XII. 
The Stomata. - The stomata are minute openings, invisible to the naked eye, through the epidermis. They may be found on any part of plants except the roots, and they occur in greatest numbers in the leaves, where they average Ioo to 300 per square millimeter; and sometimes, as in species of Olea and Brassica, they become as numerous as 600 to 700 per square millimeter.

A stoma is guarded by two guard cells (Fig. 62), which,

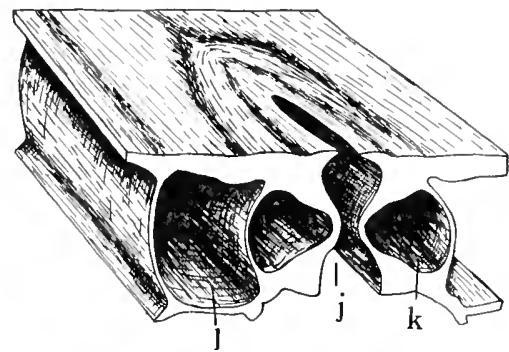

Fisi. 0.2. A typical stoma in cross section and surface view combined. $k$, guard cell; $j$, the gap or stoma between the guard cells; l. epilermal cell bordering a guard cell. as a rule, have the power automatically to open and close the stoma. The formation of a stoma comes about by the division
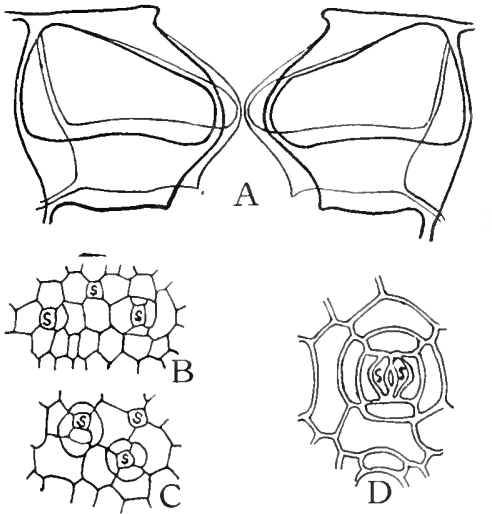

FIG. 63.-4, diagram showing relative position of the guarl cells in cross section in the open and closed positions; the heavier line indicates the open position. $B$ and $C$, early stages in the formation of stomata; at $s$, mother cells of guard cells are shown. $D, s, s$, two guard cells formed by the division of a mother cell. (After Sachs.) of a protodermal mother cell into two daughter cells and the dissolution of the middle lamella of the wall separating these, thus forming a crevice. which may be closed, or opened out by the action of the guard cells to a breadth of approximately .0o8 $\mathrm{mm}$., or about one-nineteenth the thickness of this page (Fig. 63). So minute are these clefts in the epidermis, even in their wideopen condition, that their value as entrance ways for carbon dioxide gas cannot be appreciated without experimental data. This, fortunately, is at hand. It has been found in purely physical experiments that this gas will diffuse at a faster rate through very minute open- 
ings in a membrane than through larger openings; and by having the minute openings frequent enough it is possible for it to pass through them as rapidly as if no membrane whatever were interposed. Physiological experiments show further that when the stomata are closed carbon dioxide does not enter the leaf rapidly enough for food-making. (See Chapter IX.)

A better conception of the frequency of the stomata will be gained by a comparison of $a$ and b, Fig. 6. $a$, which is a square of $5 \mathrm{~mm}$. on the side, contains roo dots. Imagine this figure reduced to the size of $b$, while retaining the same number of dots, and it will be conceived how small and numerous

FI G. 04.-Diagram indicating the frt quency of the stomata a. a square of $5 \mathrm{~mm}$. om the side containing 100 lots; these would have to be crowded into $h$. to approximate the average frequency of stomata in leaves. the stomata must be when there are Ioo of them in a square millimeter. Then conceive of 300 or eren 700 of them in the same area! In this way our idea of the size and frequency of the stomata becomes somewhat definite.

The chief use of the stomata is to allow carbon dioxide gas to enter by diffusion from its rery dilute solution in the atmosphere. Oxygen also enters through the stomata, but so far as this gas is concerned they seem to be unnecessary, for respiration in which oxygen is employed seems to go on perfectly well when the stomata are closed or artificially plugged with vaseline, etc. Respiration can still take place under such circumstances because there are 20 parts of oxygen in 100 parts of atmosphere, or about 500 times as much oxygen as carbon dioxide.

Assuming that the chief function of the stomata is to admit carbon dioxide for food-manufacture, it is evident that the conditions which most faror food construction should also induce the opening of the stomata; and this is found to be the case, for when the cells are turgid and the sun is shining-two conditions essential to the manufacture of food by the chloroplasts in the leaves-the stomata stand open, while in darkness and when turgidity is low in the leaves, they close. Their behavior under these conditions admits of a simple physical explanation: 'The 
guard cells contain chloroplasts (see Chapter IX), which manufacture sugar, etc., when the sun is shining. 'These products become dissolved in the cell sap and increase its osmotic pressure. Water is then drawn osmotically into the guard cells from the surrounding epidermal cells until the former become turgid and swollen, and in this condition the guard cells draw apart and leave a passage way between them into the interior of the leaf. This behavior is apparently due to the fact that the wall of the guard cell farthest from the opening is more extensible than the wall bordering the opening and bulges out farther when the turgidity of the cell increases. and drags the wall bordering the opening along with it (Fig. 63, A). This action is made clear by a simple experiment with rubber tubing. Two short pieces of tubing are connecter by a $\mathrm{Y}$-tube with a water faucet. The lower ends of the pieces of tubing have been plugged and fastened together, and the exterior side of each piece has been pared thin with a sharp knife or scissors. When the water pressure is turned on the thin outer sides bulge and the pieces of tubing draw apart as shown by the dotted lines in Fig. 65.

Under exposure to light there may be other influences on the action of the guard cells

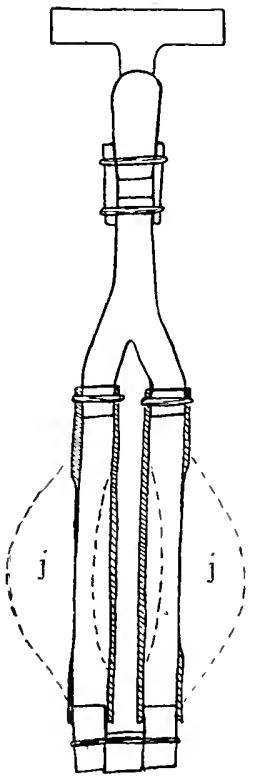

Fis. 65,-Diagram of apparatus showing how the guard cells draw apart; $j, j$, position of the rubber tubing when the water pressure is turned on than the increase in them of osmotic substances; but experiments have shown that the stomata do not, as a rule, open in an atmosphere devoid of carbon dioxide, and this points to photosynthesis (see page I fo) in the guard cells, yielding substances that increase the osmotic pressure, as the main factor in stomatal action. It must be stated, however, that experiments of this sort have given apparently contradictory results, for in some experiments with well-nourished plants in an atmosphere 
free from carbon dioxide the stomata have still been found to open on exposure to the light.

We have noted the necessity of stomata for the admission of carbon dioxide for food construction, and the fact that in most cases they are not needed to let in oxgyen for respiration. Are they a necessity in the elimination of water or transpiration? This process of course hastens the flow of water from roots to leares, and soil solutes are swept along in this current, and the intake of the solutes is consequently hastened. It seems possible that, in tall plants at least, the passage of solutes from the roots to the crown by diffusion alone would be too slow for the needs of nutrition, and the stomata are doubtless very useful in this. But it may also be true that while the stomata are standing open to let in carbon dioxide during the hours of daylight a great deal more water incidentally passes through them than is needed for the ascent of solutes. Indeed, when the water supply in the soil is running low its transpiration through the stomata becomes a real danger to the plant, and the ability to close the stomata when the guard cells lose their turgidity, as they would under such conditions, becomes a safeguard against harm and even death from drying up.

Even in bright sunlight the stomata will close when water evaporates through the guard cells faster than it can be taken in. The sensitiveness of the guard cells to variations in the water supply is shown when a plant with open stomata is taken from the moist air of a greenhouse to the dryer air out of doors; then the stomata close in spite of the fact that the plant may be in bright sunlight. Some plants, such as the willows and alders, are found to have lost the power of closing the stomata, and the lack of this check on the transpiration stream may be the reason for the restriction of these plants to habitats where the roots find a perennial supply of water along streams and in wet soil.

The stomata as a rule occur on both sides of leares, but with greater frequency on the lower side. There are instances, as in the rubber leaf, and some oaks, plums and apples, where the 
stomata are all on the lower side, and still fewer instances, as in the water-lily, where the stomata are practically all on the upper side. Where the leaves hang downward, like those of some poplars, or stand upright, as in the grasses, the number of stomata is about equal on both sides.

Often when the stomata occur on one side only they make up in frequency there for the lack on the other side. Thus, per square millimeter of surface, Nymphaa alba has 460 stomata on the upper side and none on the under; Pirus malus has none on the upper side and 246 on the lower; while Triticum sativum has 47 on the upper and $3^{2}$ on the lower side.

The Relation of Stomata to the Environment.-In desert regions and in places where plants at certain seasons are in danger of suffering from scarcity of water it has been found advantageous to plants to equip the stomatal apparatus with devices that retard evaporation while allowing the diffusion of gases into the leaf.
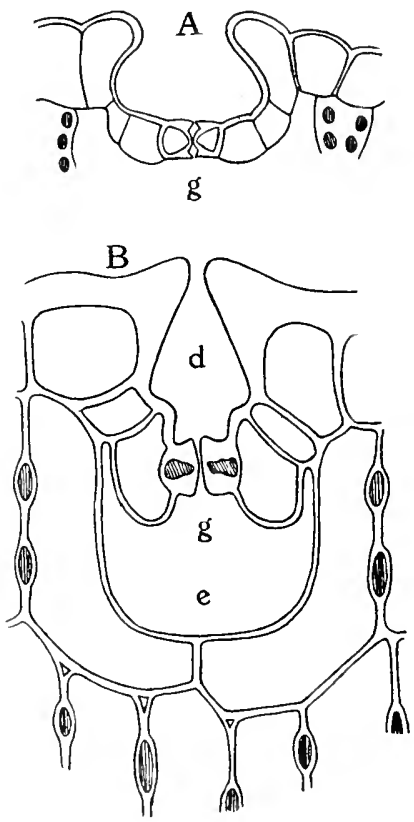

Fig. 66.- $A$, depressed stoma of the under side of a leaf of Amherstia nobilis. $B$, depressed stoma of Hakea suaveolens. $g$, strands beneath the guard cells; $d$, outer, and $\epsilon$ inner, cavities. (After Haberlandt.)

A common plan is to sink the stomata below the level of the general epidermis, so that each is at the bottom of a pit where the wind scannot sweep away at once the water vapor as fast as it is transpired. Sometimes the outer wall of the guard cells is elevated in the form of a crater, or an elevated border of wax may serve to maintain a quiet atmosphere just above the stoma. However the pit or crater is produced it is sometimes made more effective by outgrowths that partially roof it over, as in Fig. 66. 
The Lenticels. - In stems where the epidermis is being replaced by cork the phellogen or cork cambium (see page 54) instead of producing ordinary cork tissue immediately below the stomata forms loose layers of cells, through the intercellular spaces of which gases pass in and out (Fig. 22). These groups of loose cells are called lenticels. As the lenticels become larger by additions from the phellogen they press out and burst the epidermis and appear at the surface as rounded, elliptical or oblong excrescences.

The formation of lenticels outruns that of the cork tissue, so that when the cork has encased the stem and replaced the epidermis as a protective tissue the lenticels have taken the place of the stomata and have provided aeriferous channels from the exterior entirely through the periderm. (See page 55.)

The intercellular spaces of the lenticels are in direct communication with the main intercellular channels of the bark and rood. This is demonstrated by sealing one end of a cutoff stem, submerging the stem with the closed end downward, and forcing air into the upper end. Air bubbles then issue from the lenticels. And when a ring of bark is removed from the upper end so that the air pressure tube is connected with the wood only the bubbles issue as before, showing that the lenticels communicate with the intercellular spaces in the wood as well as with those of the bark. Plainly the lenticels are for the acration of the stem throughout its entire body.

The radial distribution of gases that enter through the lenticels is carried on through intercellular spaces running through the medullary rays, and from these the rertical distribution takes place largely through spaces between the cells of the xylem parenchyma (Fig. 67).

The main use of the lenticels is evidently for the interchange of gases in respiration, namely, for the intake of oxygen and the excretion of carbon dioxide, since they occur on stems where respiration must be going on continuously, but where the converse process of taking in carbon dioxide for food building is laking place to a rery subordinate degree, if at all. Incidentally 
some vapor of water passes out through the lenticels, but that they are needed for this seems improbable.

The Intercellular Spaces.-If there were no intercellular spaces threading the plant body in all directions the cells lying remote from the surface would have access to the gases of the atmosphere only as they came by slow diffusion in solution in the cell sap, and this would be inadequate for all cells that are actively living and working, such as those cells that construct and store, digest and otherwise transform food, and all cells that are passing through cell-division, growth and differentiation. And so air spaces are formed between cells throughout the whole plant body from tips of roots to tips of branches and from stomata or lenticels to the pith. The plant is, in fact, riddled with these fine spaces to such an extent that probably the cells farthest from them are distant not more than a few tenths of a millimeter.

The formation of the intercellular spaces begins in the meristematic tissues before the differentiation of the permanent tissues has begun; and this

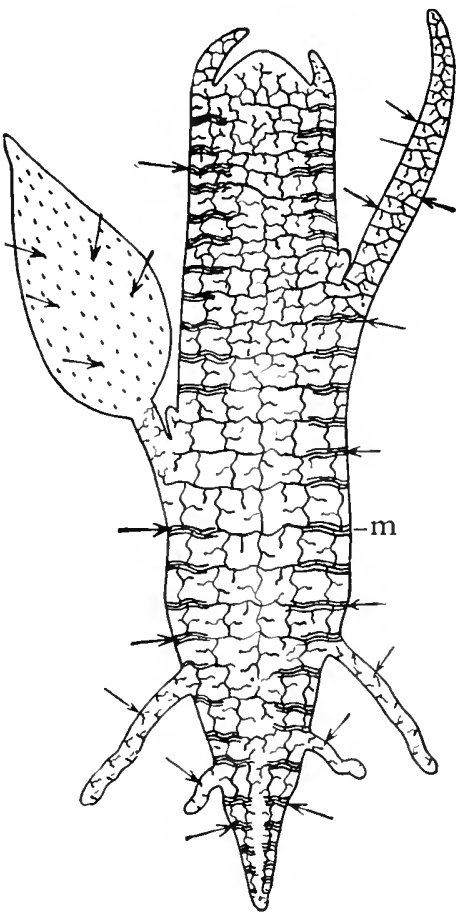

Fify, 67.-Diagram suggestive of the distribution of intercellular spaces throughout a plant. The heavy horizontal lines in stem and root indicate intercellular spaces in medullary rays. The arrows indicate the entrance of gases through the stomata of the leaves and stomata and lenticels of the stem, and anywhere over the roots, which are less water-proofed than the leaves and stems. Lenticels have been found where the lateral roots grow out from the main root. should be expected since the dividing and growing cells of the meristems respire rapidly and make relatively large demands for oxygen and the elimination of carbon dioxide. 
The intercellular spaces are made by the dissolution of the middle lamella of the cell-walls, particularly where three or four cells come together, and a subsequent growing apart of the cells at these places. Another mode of their formation occurs also where in some instances the spaces are of uncommon size, as in the hollow stems of grasses, thistles, Equisetums, etc. In cases of this kind the large central cavity is formed by the breaking down and disappearance of the interior fundamental tissue. The first method of intercellular space formation is called schizogenous and the last, lysigenous.

As a rule the intercellular spaces are larger in leares than in other parts of the plant body. The per cent. of the volume of leaves occupied by intercellular spaces is different in different plants, varying all the way from $7 \mathbf{1} .8$ per cent. in Pistia Texensis, a floating aquatic herb, to 3.5 per cent. in Begonia hydrocotylifolia, a succulent creeping herb native to Mexico.

A large volume of intercellular space in leaves is a response to the need of them to provide the photosynthesizing or foodconstructing cells (see page I43) with carbon dioxide. Where the habitat provides plenty of water the demand for large spaces in the leares can be satisfied without danger, as in Pistia; but where water is hard to obtain and too great transpiration might result from large intercellular spaces this provision for the circulation and storage of carbon dioxide must be sacrificed to a greater or less extent, as in the Begonia above mentioned, and in plants in general of desert and other xerophytic habitats.

In the stems and roots of plants growing under mesophytic or arerage conditions of moisture the intercellular spaces are very minute and can be made out only under close scrutiny when good sections are prepared and studied under great magnification. It seems from this that the large percentage of oxygen in the atmosphere cnables the gas to diffuse through the plant body fast enough without much space being given over to diffusion highways. The case is different, however, in water or marsh plants, that is, plants under hydrophytic conditions, where oxygren must be taken from its dilute solution in water, or must 
travel longitudinally through the length of the plant from its place of intake in floating or aerial leaves, or from its place of liberation by photosynthesis in the green parts. In these plants the intercellular spaces become relatively very large, as in $\mathrm{Ne}$ lumbo, Heteranthera, Juncus, etc. (Fig. 68.)

It seems that in mesophytic and xerophytic plants (mesophytes and xerophytes or plants at home under average conditions of water supply, and where water is scarce, respectively)
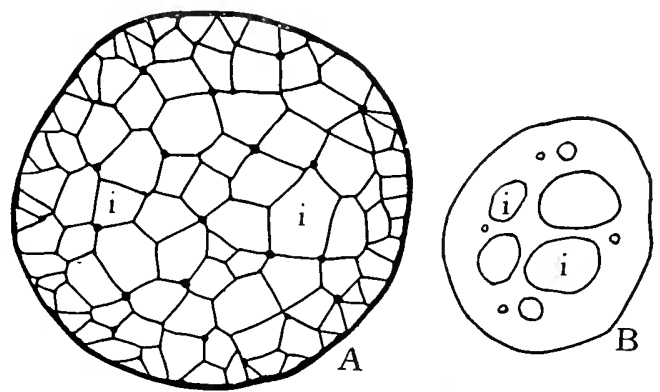

FIG, 68. - Low-power, camera-lucida drawings of $A$, cross section of stem of Juncus; and $B$, stem of Nymphæa, showing large intercellular spaces at $i$. In $A$ the black lines traversing the section are really chains of cells and thin-walled cells with relatively large intercellular spaces between them fill up $i$.

the intercellular spaces are so small that each part, root, stem, and leaves must take in air more or less independently of the others - the stem cannot supply the root with air, neither can the root or the leaves supply the stem, although seedlings of Pisum and Vicia are known to be exceptions to this rule. If the soil in which mesophytes or xerophytes are growing be inundated, so that the stems and leaves are not submerged, the roots cannot get air and the plants die. The same thing may happen when earth is filled in around trees to a depth of several feet.

Diosmosis of Gases into and from Living Cells.-The wall of every living cell is infiltrated with water, and a very thin film of water covers its free surface. Therefore the gases in the intercellular spaces must, before entering the cell, go into solution in this water, and in this condition diosmose through 
the cell-wall. Likewise gases that are to be given off from the cells must in solution diosmose through the cell-wall and break away from the superficial film of water into the intercellular space or outer air. The dry walls of dead cells are much less permeable to gases than those of the living ones soaked with water.

\section{Motive Power in the Distribution of Gases throughout} Plants.-Gases pass by diffusion in and out through the stomata and lenticels, and throughout the intercellular spaces. By this process the atmosphere does not move as a whole but each component gas mores independently in obedience to the laws of diffusion according to which the movement is from the place of greater concentration of a particular gas to that of less concentration. So that if carbon dioxide is being used in photosynthesis by any tissue, or oxygen is being employed in respiration, more of these gases will flow to that tissue by diffusion. Or if respiration is pouring carbon dioxide into the intercellular spaces, or photosynthesis is loading them with oxygen, these gases will flow toward the exterior and pour out through stomata and lenticels. Interchange of gases in this way is constant so long as their concentration inside and outside the plant body is different. In the day time there would be a flow of oxygen from the photosynthetic tissues toward the other parts that are breathing, as well as toward the exterior, and a flow of carbon dioxide toward the photosynthetic tissues from those that are giving it off in respiration, as well as from the exterior. In parts of plants destitute of chloroplasts, and hence incapable of photosynthesis, there would be no evolution of oxygen, but on the contrary there would be a continual production of carbon dioxide by respiration, and this gas would flow thence toward the photosynthetic tissues and toward the exterior. When darkness falls no part can longer photosynthesize while all parts continue to respire, and therefore a flow of oxygen more exclusively from the exterior to all parts sets in, and the return flow of carbon dioxide becomes more exclusively toward the exterior, since the photosynthetic tissues can no longer make use of it. 
Thus the flow of gases by diffusion throughout the plant body while in necessary obedience to physical laws is yet in direct accordance with physiological demands.

Movements of the atmosphere en masse throughout the plant body are accomplished by differences between external and internal pressures resulting from fluctuations of temperature within and without, and by compression and expansion of the intercellular spaces caused by swaying of the plant to and fro, and by fluctuations in the turgidity of the tissues as the ratio between absorption and transpiration rises and falls. 'Thus when the temperature of the plant body falls below that of the exterior the air in the intercellular spaces contracts and outside air flows in, and the reverse process takes place when the temperature of the plant rises above that of the outside atmosphere. Again, when transpiration is going on faster than absorption by the roots the cells lose in turgidity, contract, and leave more room for the intercellular spaces, and pressure from without forces more air in. When transpiration subsides following the overclouding or going down of the sun, or increase in the atmospheric humidity, the cells become more turgid and compress the intercellular spaces so that the air in them is in part forced out. The relatively rapid exchanges of air brought about in these ways may be of decided value to the functions employing oxygen and carbon dioxide. Free nitrogen, not being employed by the higher plants, may here be left out of the discussion of gaseous interchange.

\section{Illustrative Studies}

I. Study the stomata of different leaves. Bleach and clear the leaves as described in Illustrative Studies, paragraph 7 of the last chapter. Study with both low and high powers. With objects so transparent as these it is best to illuminate with oblique light by setting the mirror-bar at an angle with the perpendicular. Mount the leaf or a portion of it in chloral hydrate, first with the under side up. With the eyepiece micrometer, and using 
the low power objective, determine the number of stomata in one sq. mm. Measure the stomatal apparatus and the opening. Draw a stoma together with the surrounding epidermal cells, using the high power. Turn the leaf upper side up and determine the number of stomata as before.

2. Study the stomata in leaf cross sections. Sections cut free-hand will do. Mount several of the thinnest sections in glycerine and with the high power find a median section through a stoma. What provision do you find for the distribution of gases after they have entered through the stoma? Compare the stoma with the diagram of Fig. 63, A. Would it probably work as there set forth? Draw the stoma and epidermal cells adjoining it and the intercellular spaces leading from it.

3. Look for intercellular spaces in the permanent preparations prepared for the previous chapters and make drawings and measurements of some of them. Do you find every cell somewhere touching an intercellular space?

4. Study intercellulair spaces in the stems of water lily, Juncus, or other water and marsh plants. Permanent preparations or free-hand sections mounted in dilute glycerine may be used. Draw some of the spaces by outlining the cells bordering them. Estimate the percentage of stem volume occupied by these spaces.

To show that the intercellular spaces in the leaf communicate with those in the stem fill a bottle with water, push in a perforated cork so that its upper surface is below the mouth level; cut off the shoot of a young Ricinus plant and insert the stem through the hole in the cork; remove all water from the top of the cork and pour over it melted rosin one part and beeswax one part, so that no air can enter the bottle except through the intercellular spaces of the plant; set the plant in the sun but shade the bottle. As water evaporates through the leaves air can be seen bubbling from the submerged end of the stem. Explain how this happens.

5. Examine lenticels on any woody stem that shows them well,-elderberry, for instance. Study with a high power a thin cross section of a lenticel and draw it. 
To show that the lenticels are in communication with the general intercellular system of the stem, connect one end of a stem by rubber tubing with a bicycle pump; then submerge the whole stem in water and force air into it. Do bubbles come out through the lenticels? Explain the result. 


\section{CHAPTER IX}

\section{CONSTRUCTION OF THE PLANT'S FOOD}

The Source and Uses of Food.- It is the business of the green plants, known also as the autophytes, or independent plants, to make the food that is consumed by themselves as well as by other plants and animals. This they do by compounding carbon, which they get from the carbon dioxide of the atmosphere, hydrogen and oxygen from water, and nitrogen, phosphorus and sulphur from the soil, into sugars, starches, oils, proteids, and some other less common forms of food. These are the food of plants, made by the green plants for their own use, but consumed also by parasitic plants and by animals, all of which are directly or indirectly parasitic on green plants.

It is sometimes said that plants live on inorganic matter, animals on organic. This, howerer, is not an exact statement. The food of plants and animals is the same. The difference is, rather, in this, that green plants make their food from inorganic matter, namely, from carbon dioxide, etc., as abore stated, while animals cannot make their food, but must take that provided by plants. A bean plant, a corn plant, an oak plant, all green plants, so long as the leaves are green, are making food while the sun shines and furnishes them the energy with which to work.

The food has wo distinct uses: It provides materials for the construction of the body, and energy for carrying on the vital functions. The living protoplasm and the cell-wall.--every part of the plant body in all its details, are made from materials that first appeared as food in the form of sugar, starch. oil, proteid, etc., and practically everything that plants do, aside from food-construction where the sun supplies the needed energy 
directly, is accomplished by energy released in the decomposition of these foods or substances made from them.

The green leaves, therefore, are the organs where the sun's energy is transformed so that it can be stored for use afterward where and when it is needed. They are the organs where the materials of the inorganic world are assembled in such a form that they can be used in the construction of the living body.

How energy is obtained in the decomposition of food will appear from a specific example: When a definite amount of sugar or starch is made within the leaf from carbon dioxide and water a certain amount of sun's energy is employed and transformed from the active or kinetic to the passive or potential state. This energy is not destroyed or lost; it is simply changed from one condition to another. To illustrate: a certain amount of energy is required to lift a brick from floor to table. The energy spent in doing this now rests quiescent in the brick in virtue of its position above the floor, and reappears as active energy when the brick falls. So when sugar or starch is transformed into carbon dioxide and water from which it was made the energy from the sun employed in compounding it is set free (comparable to the falling of the brick) and a part of it can then be used by the plant for other purposes, as in the construction

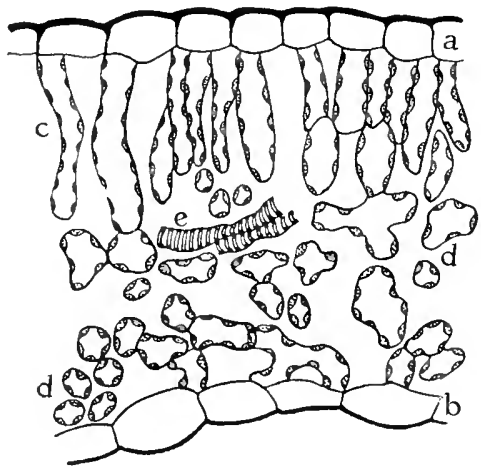

FIG. 69.-Cross section of a portion of the blade of a leaf, showing upper epidermis at $a$, lower epidermis at $b$, palisade parenchyma at $c$, spongy parenchyma at $d$, and tracheids from the end of a vein at $e$. of proteids from carbohydrate, etc., the synthesis of protoplasm, the overcoming of resistance, and in other ways.

The sun's energy made potential in sugar and the like is, by the translocation of these substances, distributed to all parts of the body where every living cell can make use of it, and where, if not immediately wanted, it can be stored for use at some future time. 
Food-building Apparatus.-It is the special business of leaves to make the food, and there the palisade and spongy parenchyma are the tissues directly concerned in the work (Fig. 69), since the new food makes its appearance first in them. Each individual cell of these tissues is therefore a food-building unit, and the factors concerned in food synthesis can be followed out in seeing how one of these cells does its work, namely,

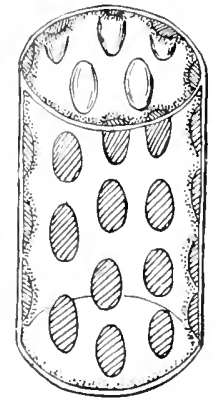

FIG, ;o.-Diagrammatic representation of a single palisade cell, with chloroplasts lining the walls. how it obtains the raw materials and the sun's energy, how the arrested energy of the sun is utilized, how the finished product is disposed of, and how the apparatus of the cell is kept in working order.

The Chloroplasts.--The chloroplasts (Fig. 70) are plastids that contain the green pigment chlorophyll (see page 8). They are the organs of the cell that are directly concerned in food-construction from carbon dioxide and water. This is known from the fact that this process does not go on where chloroplasts are absent; and where starch is formed, as is nearly always the case, it invariably is found within the body of the chloroplast.

The chloroplasts and the green chlorophyll are distinct things, for alcohol will extract the chlorophyll and leave the chloroplasts as before but devoid of color. (See about origin of chloroplasts on page 9.) The chlorophyll is a pigment which the chloroplasts manufacture with the aid of the sunlight. The significance of the chlorophyll is that it arrests a part of the energy from the sun and transforms it in such a way that the chloroplasts can use it in food synthesis. We cannot state, and do not at all know, the details of this process. Clearly the chloroplast, a living body, does the work, but to do this it needs to be energized by the sun, and this is apparently what the chlorophyll is instrumental in bringing about. Because the sunlight furnishes the encrgy for food construction the process is called photosynthesis. 
The first visible food made by the chloroplasts is starch in the form of very minute grains (Fig. $7 \mathrm{I}$ ). There is reason to believe that sugar is formed before the starch appears, and presumably in the chloroplasts also, but it is soluble in the cellsap and probably does not long remain where it is first formed, but passes by diffusion from the chloroplasts into the cell-sap that fills the cell carity, and thence into the tissues devoted to food-conduction,

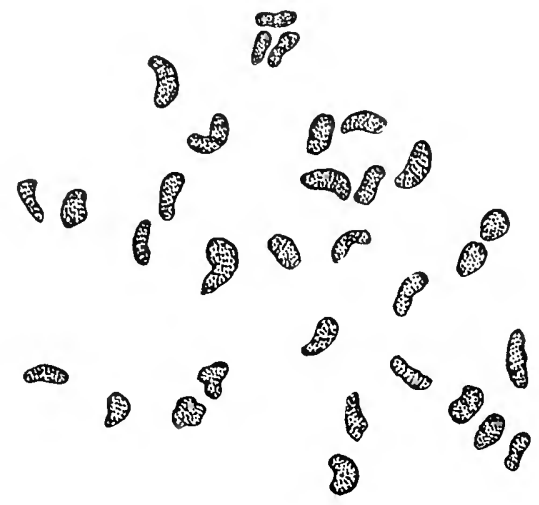
as told in the next chapter.

The minute size of the chloroplasts affords them large surface in proportion to their volume, and this gives a great advantage

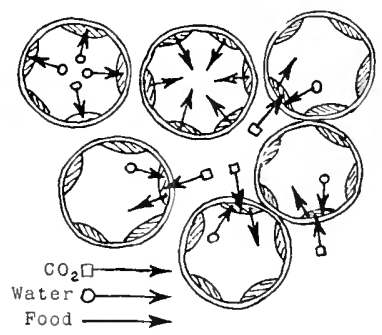

FIG. 72.-Diagram to show the intake of carbon dioxide by the palisade cells from the intercellular spaces, the absorption by the chloroplasts of water from the cell-sap, and the passage of food from the chloroplasts into the cell-sap. The palisade cells are shown in cross section, as they would be if the leaf were cut parallel with the surface, namely, tangentially. in the absorption of raw materials and energy, and in the elimination of the finished product.

The chloroplasts are always embedded in the cytoplasm close against the cell-wall, and this peripheral position is apparently an adrantage to every phase of their work; for, as Fig. 72 will show, on one side water is presented to the chloroplasts from the cell-sap, and on another carbon dioxide from the intercellular spaces, and the vacuole affords an unobstructed way for the removal of the manufactured product. Also by this arrangement the light entering the leaf * from all parts of the sky has a clearer path to every chloroplast throughout the leaf than would otherwise be the case (Fig. 73). 
The Sun's Energy.- The amount of the sun's energy that comes to the earth every day is too vast for us to realize. A part of that which falls upon the leaves of plants is reflected, but the greater part enters and, since the epidermis is transparent, penetrates to the chloroplasts. Fig. 74 shows in a diagrammatic way what happens to it there. It is a matter of common observation that very little light penetrates through a

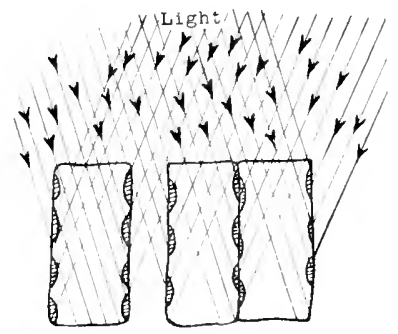

F1G. 73.-Diagram showing how the position of the chloroplasts against the vertical walls of the palisade cells exposes them to good advantage to light from all quarters of the sky. leaf eren in full sunlight; and when the little that comes through is analyzed with a spectroscope it is found that it consists of some red, orange, and yellow, and a relatively large amount of green, while the blue and violet parts of the spectrum have been almost entirely absorbed by the leaf. Less than 2 per cent. of the absorbed light, we know from experiment, the chloroplasts employ in food-building, and approximately 98 per cent. is used in the evaporation of water.

By a very ingenious method, known as Engelmann's bacterium method, it is demonstrated that the red light rays are far more potent in photosynthesis than the others, although the orange and yellow rays are much employed in this work; while the green, blue, and violet rays are of all the least useful. The Engelmann demonstration, based on the fact that oxygen is evolved during photosynthesis, is carried out as follows: Motile bacteria that are known to be attracted by oxygen, together with a filamentous alga, are placed on a glass slip in a drop of water and a coverglass is placed on and sealed around the edges air-tight with vaseline. Examining the preparation with a high power objective it is observed that when it is exposed to the light the bacteria flock together along the alga, showing that oxycren is being evolved by it. If the light is now screened off the bacteria scatter, only to assemble along the alga again immediately the screen is removed. This shows that photo- 
synthesis begins at once in the light and ceases as suddenly in darkness. After these preliminary observations a small spectroscope adapted to the purpose is placed beneath the microscope stage. Light is thrown by the mirror through the spectroscope and the preparation is so adjusted that the colors of the resulting minute spectrum succeed each other along the length of the alga. It is then seen that the bacteria flock about the alga where it is illumined by the red light, gradually thinning out in the orange and yellow until relatively very few hover in the regions of the green, blue, and violet. There seems to be no other inference from this than that the food-constructing or photosynthetic efficiency of each part of the spectrum is measured by the relative number of bacteria collecting in its domain. Fig. 75 shows how the red portion surpasses the others in this respect. It has been found that light that has passed through one leaf is too weak in the red to energize the chloro-

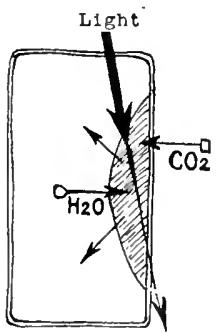

Fic. 74-Diagram to show the activities going on in a palisade cell. The arrows from the chloroplasts into the cell cavity indicate movement of photosynthesized product. The thickness of the arrow shafts under "Light" indicate the relative light intensities. plasts in another.

\section{The Palisade Cell the Chief Photosynthetic Unit.-Most} of the work of food-construction is done in the palisade cells, since they occupy the upper half of the leaf where the incoming light is strongest, and they have four to five times as many chloroplasts as the cells of the spongy parenchyma have. When food synthesis is going on a palisade cell is the scene of great activity. Fig. 74 is a diagrammatic expression of this fact. Here for simplicity a single chloroplast in a palisade cell is made to represent the many smaller ones that actually occur. Light penetrates the chloroplast from above, carbon dioxide flows in from the intercellular spaces, and water enters from the vein below the cell. The food product in the form of sugar diffuses from the chloroplast into the cell-sap and thence into the foodconducting cells in the vein. Oxygen as a by-product of food- 
construction diffuses into the intercellular spaces, and into them water also evaporates from the cell-sap. This stream of activities is none the less real because noiseless and unseen by the eye.

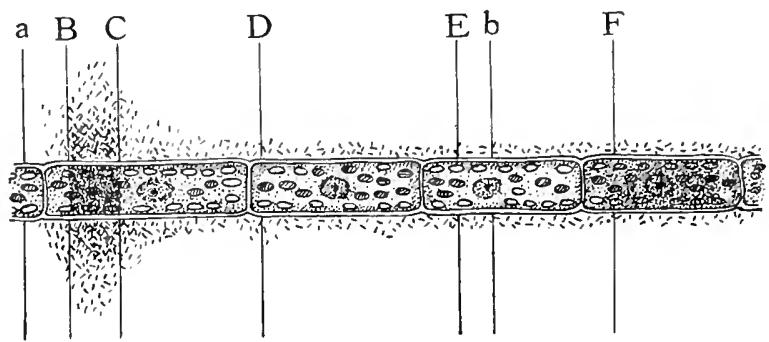

FIG. 75.-Diagram to show the effect of different portions of the spectrum on photosynthesis. $a$, to $F$, different regions of the spectrum from red to blue. A filamentous alga lies across these, and bacteria are collecting about the alga, with greatest frequency in the red between $B$ and $C$, indicating the greatest evolution of oxygen there. (After Pfeffer.)

The steps in the chemical process of food-construction cannot be followed, but it is interesting to note how simple the process might be, as, for example, $6 \mathrm{CO}_{2}+6 \mathrm{H}_{2} \mathrm{O}=\mathrm{C}_{6} \mathrm{H}_{12} \mathrm{O}_{6}$ (glucose $)+6 \mathrm{O}_{2}$.

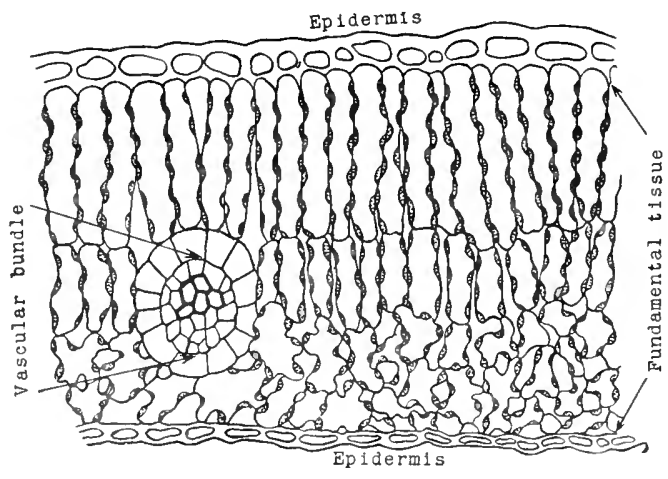

FII, 76.-Diagram to show the three general tissue regions of a leaf.

Relation of Leaf as a Whole to Photosynthesis.-A leaf from the standpoint of its cellular anatomy consists of three distinct parts: the epidermis, the ground or fundamental parenchyma, and the vascular bundles (Fig. 76). The epidermis 
has a waterproofed outer wall after the manner of a typical epidermis (see page 28), and it is perforated on one or both surfaces of the leaf with stomata to allow the entrance of carbon dioxide as described in Chapter VIII. The ground parenchyma, also called the mesophyll, is differentiated into three kinds of tissues: the palisade parenchyma, occupying the upper half; the spongy parenchyma, of the lower half; and the border paren-

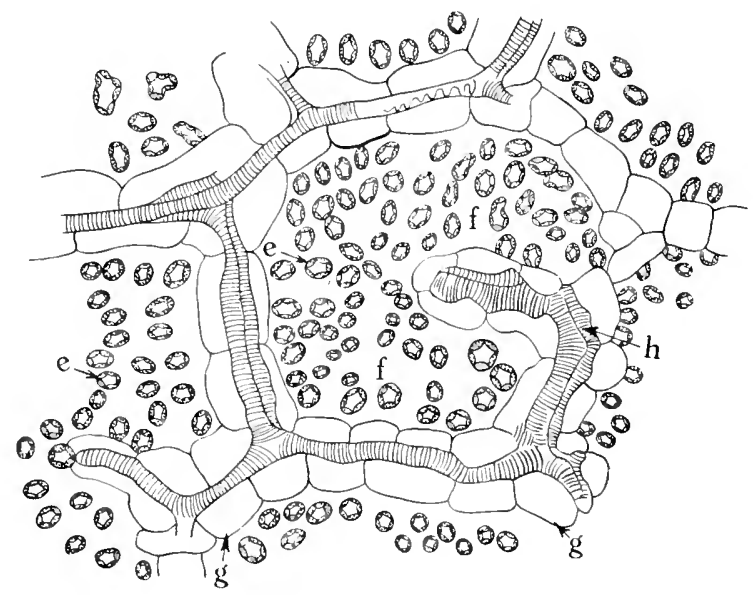

FIG. 77.- Showing intercellular spaces: $f$, between the palisade cells; $e$, in a leaf; $g$, border parenchyma; $h$, tracheal elements of the vein. Camera-lucida drawing of a tangential section of a leaf.

chyma, forming a sheath around the vascular bundles in the reins (Fig. 78). The border parenchyma cells deliver water from the veins to the palisade and spongy parenchyma, and they gather food from these and conduct it to the sieve tubes in the larger reins, as described in the next chapter.

The intercellular spaces in the spongy parenchyma are much larger than those in the palisade parenchyma, and they freely communicate with one another and with the intercellular spaces in the palisade parenchyma, and so are well suited to receive and distribute the carbon dioxide which enters mostly through the under surface because most of the stomata are there as a rule. The intercellular spaces in the palisade parenchyma 
are not easily made out in cross sections of leaves, but in sections parallel to the leaf surface (tangential sections), or when looking through a bleached leaf with a microscope, they appear as in Fig. 77, where every palisade cell borders on one or more of them for a part of its surface. This general view of leaf anatomy shows how all the parts are related in the interest of photosynthesis.

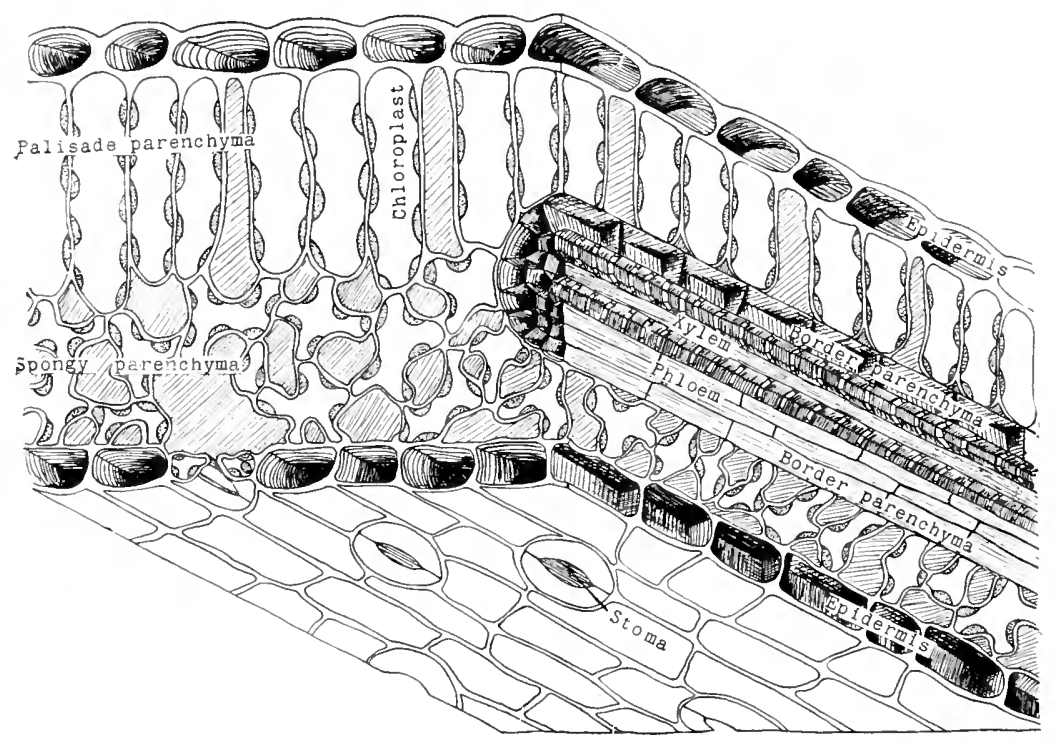

FIG. 78.-Diagram to show the architecture of a typical leaf in the region of one of the lateral veins. The shaded parts amongst the palisade and spongy rarenchyma represent intercellular spaces.

It will be well now to recapitulate briefly the main facts in what has thus far been told about the leaf: The epidermis is transparent and lets the light through. The chloroplasts in the palisade cells absorb most of the light and use approximately 2 per cent. of its energy in carrying on food synthesis. Light that escapes through the palisade parenchyma is arrested so completely by the spongy tissue that not enough goes on through the leaf to be useful to other leaves. The intercellular spaces of the spongy parenchyma receive and distribute to all 
parts of the leaf the carbon dioxide that has entered through the lower surface. The border parenchyma cells deliver water from the veins to the rest of the mesophyll, and receive food from palisade and spongy cells and together with the phloem part of the veins transport it out of the leaf. The conditions necessary to photosynthesis are these: The photosynthetic apparatus must be present in working order; there must be light; the stomata must stand open and admit $\mathrm{CO}_{2}$; the veins must bring water; the veins must carry away the food or its accumulation will hinder its further construction.

Fig. 78 represents in a general way the cellular architecture of a leaf. The leaves of different plants of course vary from this in certain details.

In the leaf of the India rubber tree, Ficus elastica (Fig. 79), at the upper surface the epidermis is succeeded by a clear tissue two to three cell-layers deep which serves as a water-storage tissue. Then follow two to four layers of palisade cells, several layers of spongy cells, two

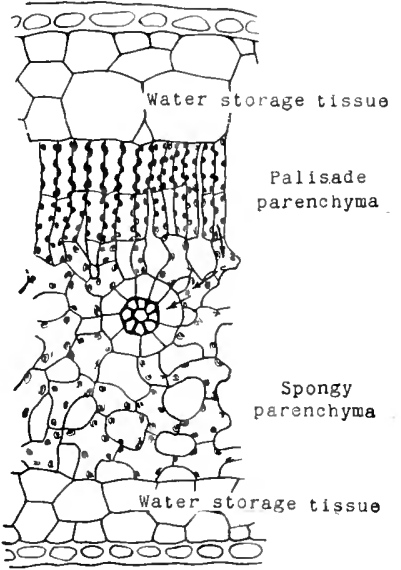

FIG. 79.-Cross section through a portion of rubber leaf, showing the large percentage of water-storage tissues on both sides of the leaf, and the relation of the palisade and spongy parenchyma to the lateral veins. to three layers of relatively small water-storage cells, and last the lower epidermis. In the spaces between the veins where the palisade cells cannot communicate directly with the food-conducting cells the spongy cells collect the products of the palisade cells and deliver them to the veins by the indirect route shown in Fig. 79. This device is by no means peculiar to the rubber leaf, but is very generally employed.

In Indian corn each of the veinlets is surrounded by a sheath of border parenchyma cells, and these in turn by palisade cells radiating from them, as shown in Fig. 8o. In corn, as indeed in many grasses, starch is not formed in the palisade cells at all, 
but the parenchyma sheath on bright days is well filled with it (Fig. 80). Of course the palisade cells manufacture soluble

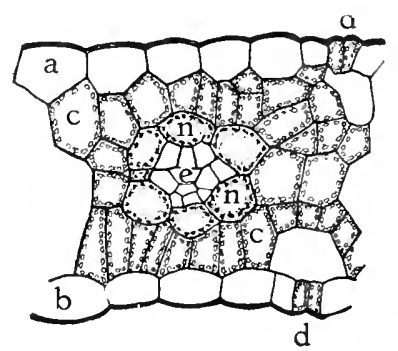

FIG. 80.-Cross section of a portion of a leaf of Indian corn. $a$, upper, and $b$, lower epidermis; $c, c$, palisade cells; $n$, border parenchyma containing starcls within its chloroplasts; $e$, vascular bundle; $d, d$, stomata. carbohydrate abundantly, and the starch in the sheath cells doubtless represents a surplus that comes to the sheath cells from the palisade tissue faster than it can be conducted away.

In the Agave, Codonanthe, etc., the leaves are very thick and palisade parenchyma sometimes stands against the epidermis on both sides, while the mesophyll cells making up the bulk of the leaf serve mainly as water-storage cells (Fig. 8I). Leaves of this sort with large amounts of water stored against time of need are not infrequent in desert regions or where a rainy season is succeeded by a dry one.

\section{Conditions Affecting Photosyn-} thesis. Light.- The amount of photosynthesis varies with the light intensity up to and even beyond full sunlight. Nevertheless a very feeble light is sufficient to sustain photosynthesis to a slight extent, and it may be that in nature plants get as much usable energy for this function out of the diffuse light from all quarters of the sky as from the direct sunlight itself. In dwellings where plants stand before a window they are lighted by only a small part of the sky, and this rapidly diminishes the farther back plants are placed, so that only a few feet from a window they may be actually

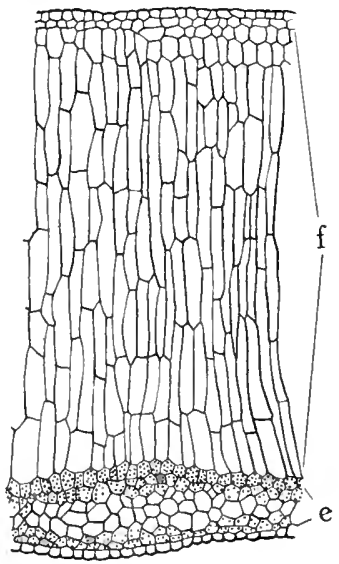

FIG. 8I.-Cross section of a portion of leaf of Codonanthe, showing the waterstorage tissue at $f$, and the chlorophyll-bearing tissues at e. (After Schimper.) losing in weight for lack of sufficient food construction, although they may be growing and having the appearance of some thrift. 
Time Required.-Engelmann's bacterium method shows that photosynthesis begins instantly on exposure to light. It is found, however, that it takes several minutes, and in some cases an hour or more before starch appears in the chloroplasts; and this is evidence that this starch represents carbohydrate that is formed faster than it is being carried away - a surplus that would hinder the constructive process if allowed to remain in solution in the cell-sap. And the starch in the chloroplasts might be of direct benefit in increasing the chloroplastic surface and in refracting and reflecting the light so that more of it would be retained within the body of the chloroplast.

Carbon Dioxide.-It is found that the very small percentage of carbon dioxide in the atmosphere is not the optimum amount for photosynthesis; for this function rises in activity as the $\mathrm{CO}_{2}$ content is increased from .03 per cent. to 8 per cent., and with this increase photosynthesis can go on even with closed stomata. About one-half of the dry weight of a plant is carbon, and it is of great importance that this so necessary element in nutrition is in an extremely mọbile condition and capable of distribution by the unceasing currents of the atmosphere.

Water.-The photosynthetic cells are like all others in being able to perform their functions better when in a state of turgidity. It is found, however, that isolated cells are able to photosynthesize to a certain extent when in a flabby or even plasmolyzed condition; and mosses and lichens are remarkable for their power of photosynthesis even after they have begun to dry up. But the higher plants, with their waterproof epidermis, are unable to photosynthesize after the reduction in the water content has caused the closure of the stomata, and thus prevented the continued inflow of carbon dioxide.

Temperature.-The temperature may rise too high or fall too low for photosynthesis; but, as might be anticipated, plants in different latitudes are not affected alike by the same temperatures. For instance, in the tropics photosynthesis ceases when the temperature becomes as low as $8^{\circ}$ to $4^{\circ} \mathrm{C}$., while in the subtropics and temperate zones to produce a like result 
the temperature must fall almost or quite to $\circ^{\circ} \mathrm{C}$; ; and cooltemperate, arctic and alpine plants continue photosynthesizing until they become frozen. In regard to the maximum temperature, plants in general cease photosynthesizing after long exposure to approximately $38^{\circ} \mathrm{C}$.

Photosynthesis in the Lower Plants.-In the simpler Algæ where each individual consists of a single cell, a chain
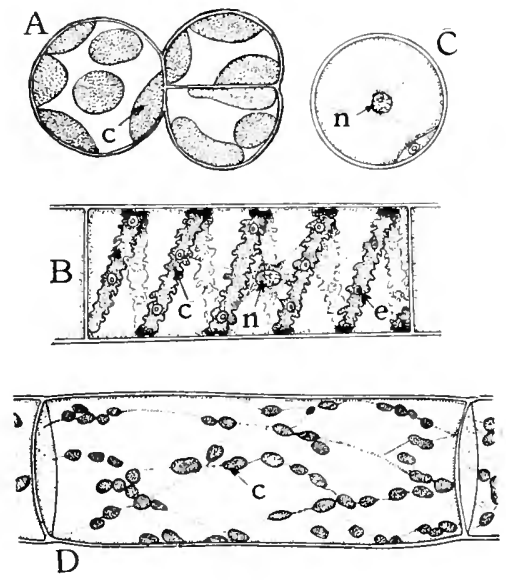

FIG. 82.-Chloroplasts from different sources. A, Pleurococcus, with chloroplast at $c: B$, cell of Spirogyra, with spiral chloroplast at $c$, nucleus at $n$, and pyrenoid at $e$. $C$, cross section of Spirogyra cell, with nucleus at $n$, and section of chloroplast and pyrenoid below. $D$, cell of $\mathbb{E}$ dogonium, with numerous chloroplasts. All highly magnified, but not to the same scale.

of cells forming a filament, or a thin lamina one cell thick, each cell contains one or more chloroplasts and carries on food synthesis. In Pleurococcus the chloroplasts are large in comparison with the size of the cell and seem nearly to fill the cell cavity. In Edogonium and Nitella the chloroplasts are numerous and relatively small. In Spirogyra each cell has one to few chloroplasts each in the form of a spiral band (Fig. 82). In these as well as in the higher plants the chloroplasts lie embedded in the cytoplasmic layer surrounding the vacuole and lining the cell-wall.

In liverworts and mosses the photosynthetic tissue reaches a fair degree of differentiation. The thallus of Marchantia polymorpha has beneath its upper epidermis groups of chloroplast-bearing cells that correspond to the palisade cells in the leaves of higher plants (Fig. 83). Each of these groups is contained in a diamond-shaped compartment as seen from the surface, the partitions at $l$ being a single cell in breadth, and each compartment communicates with the outer air through an unusually large stoma. Each group of photosynthesizing cells is 
therefore in a separate air chamber. The photosynthetic product is delivered to colorless parenchyma cells in the lower half of the thallus. In Marchantia the thallus lies flat upon the ground,

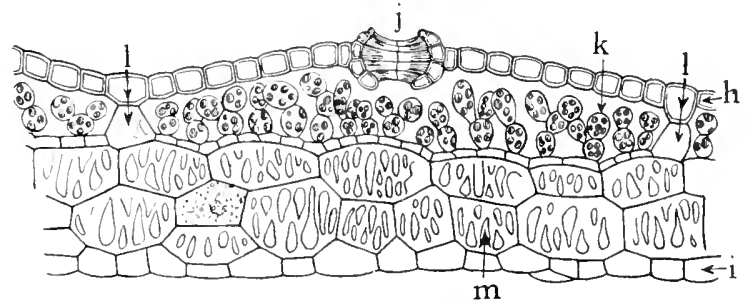

FIG. 83.-Cross section through the thallus of Narchantia. j, stoma leading into a relatively large air-chamber in which arise numerous cells with chloroplasts, $k ; l, l$, cells forming partitions between the air-chambers; $m$, cells destitute of chloroplasts and $w$ ith numerous oblong pits; $h$, upper, and $i$, lower epidermis. (After Sachs.)

and the photosynthesizing cells and stomata can function to best advantage where we find them in the upper part of the leaf.

In Sphagnum the leaf is one cell thick (Fig. 84), and the photosynthetic cells are arranged in the form of an open meshwork as seen from the surface, and between them are large, clear, water-storage cells having minute pores through the outer wall at the under surface through which water can be imbibed. As seen in the figure the photosynthetic cells are elongated parallel with the length of the leaf and are thus adapted to conduct away their own products.

In Polytrichum there are vertical chains of photosynthetic cells, but there is no closed

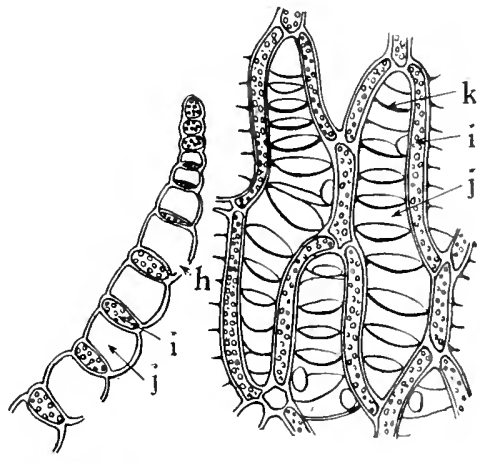

FIG. 84.-Portion of leaf of Sphagnum, in cross section on the left, and surface view on the right. $h$, hole through the wall; $i$, chlorophyll-bearing cells; $j$, water-storage and water-conducting cells. with annular thickenings at $k$. After Strasburger.) upper epidermis, as shown in Fig. 85, and these cells are freely exposed to the outer air excepting when the leaf, in danger of 
losing too much water, rolls up from both edges, so that the free margins of the incomplete epidermis touch or overlap. Here as in Marchantia the products of photosynthesis are given over to elongated conducting cells in the lower part of the leaf.

In many mosses the blade of the leaf on either side of the midrib is one cell thick and all of these cells contain chloroplasts, and being elongated parallel with the long axis of the leaf they conduct away their own products (Fig. 86).

Synthesis of Food Without Light.--Some kinds of bacteria (Nitrococcus and Nitrosomonas) inhabiting the soil oxidize ammonia and its compounds to nitrous acid and its salts

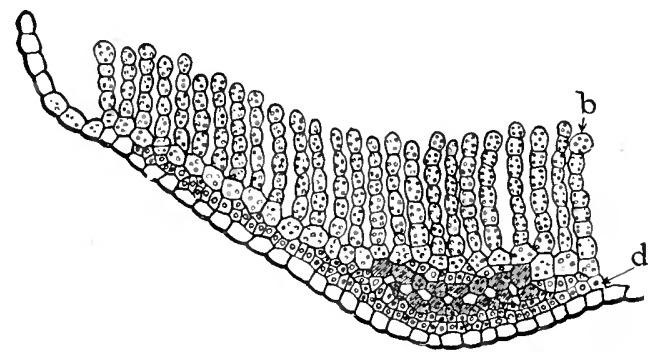

FiG. 85.-Cross section through a portion of leaf of Polytrichum commune. $b$, chains of chlorophyll-bearing cells; $d$, bast fibers. (After Strasburger.)

and utilize the kinetic energy liberated by this oxidation in making food from carbon dioxide and water. Other bacteria included in the genus Nitrobacter oxidize the nitrous to nitric compounds and get energy in this way for food synthesis. Still other bacteria utilize the energy from the oxidation of salts of sulphur and iron occurring in the soil.

In green plants the construction of nitrogenous foods by uniting carbohydrate made in the leaves with salts of nitrogen, and sometimes in addition, with salts of sulphur and phosphorus brought up from the soil, can take place in darkness as well as in the light, and possibly in any living cell. When proteid synthesis goes on in darkness the energy for the work apparently comes from the decomposition of a part of the carbohydrates, in which event sunlight would still be, although indirectly, the source of the energy. 
While the synthesis of nitrogenous foods presumably can take place in any living cell there are reasons for believing that most of this work is done in the leaf. Mature leaves at the height of their activity contain large amounts of the amide asparagin that hardly can be accounted for except by the theory that they are manufactured there. Although there is more asparagin present in leaves in the evening than in the morning this does not necessarily imply that light is required for its production, for both asparagin and carbohydrates would diffuse out of the leaf during the night, and the production of asparagin could not be kept up for lack of carbohydrates which are needed in its manufacture, and which we know can only be made in the light.

Although approximately four-fifths of the atmosphere is nitrogen the vast majority of plants are unable to use it in its un-

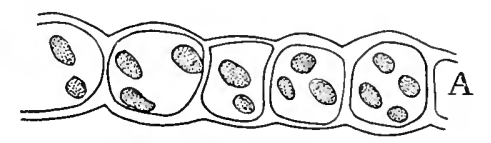

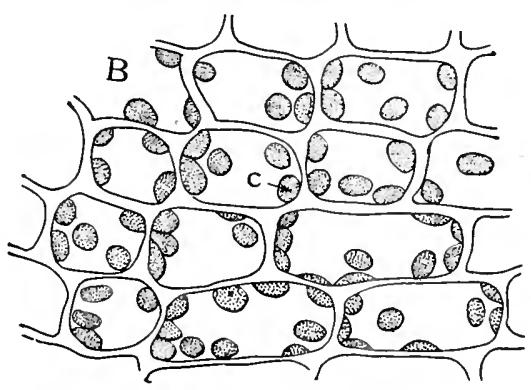

Fis. 86-Cross section, $A$, and surface view, $B$, of a leaf of common moss, showing chloroplasts, $C$.

combined form for food construction, and for this purpose it must be taken, in the case of green plants, mostly in the form of some nitrate, such as calcium or potassium nitrate. The case is different with saprophytic plants, such as the toadstools and their kind, moulds, and many forms of bacteria, for these plants can appropriate for food various nitrogen compounds in the excreta and dead bodies of other plants and animals. Parasitic plants, such as the rusts, mildews, blights and smuts, and those of higher order, such as Cuscuta, appropriate the food of the plants upon which they are parasitic.

Although the green plants and plants in general are unable to appropriate the free nitrogen of the air, there are a few forms of bacteria which have this power, such as Clostridium Pasteur- 
ianum living in the soil, and tubercle bacilli that cause and inhabit the tubercles on the roots of Leguminosæ and some other families of plants. These occur normally in the soil in most localities, and enter the roots through the root hairs and furnish the stimulus for the growth of the tubercles. While these bacteria are parasitic on the green plant to the extent of utilizing carbohydrate made by it, they nevertheless are useful to the green plant in that they compound the free nitrogen of the air into substances which the green plant can use for food. For this reason the soil in which leguminous plants are grown, such as peas, clover, alfalfa, etc., becomes richer in nitrogen, even when the crop is harvested and only the stubble and roots are left to decay and become a part of the soil.

Restating briefly the relation of carbohydrate to nitrogenous foods: carbohydrates, such as sugars and starches, are formed in the chloroplasts by the use of the sun's energy directly. Later some of these carbohydrates are united with salts of nitrogen to form nitrogenous food substances, and from these still more complex nitrogen compounds are formed with the addition of elements from the salts of sulphur and phosphorus. While the energy for the production of carbodydrates must be taken directly from the sun (with the exception of the few bacteria that produce nitrous and nitric compounds from ammonia and its salts, and those that oxidize salts of iron and sulphur as above stated), the energy for the compounding of nitrogenous foods is taken indirectly from the sun (and hence can go on in darkness and in saprophytes and parasites), by the decomposition through oxidation, or otherwise, of carbohydrates and substances derived from them.

\section{Illustrative Studies}

I. Study chloroplasts in a moss leaf. Mount a fresh leaf in water and study it with low and high powers. Note the position of the chloroplasts within a cell and count them. Put a drop of chloral hydrate-iodine (see under this title in Chapter 
XVI) on the slide against the coverglass and as the reagent diffuses under watch its progressive reaction on the chloroplasts. Is starch demonstrated? In precisely what part of the cell did it occur? Measure one of the starch grains. Draw a single cell as seen before and after application of chloral hydrate.

2. Study Spirogyra in the same manner and draw a single cell as before.

3. Make free-hand cross sections of some leaf and mount the thinnest-even the smallest fragments - in a drop of water. Find the palisade and spongy parenchyma. Do the chloroplasts have the same position in the cells as those of the moss leaf were found to have? Treat with chloral hydrate-iodine as above and watch for the first indications of starch. Do you find evidence that the starch was formed by the chloroplasts? How large are these bits of food that have just been compounded from $\mathrm{CO}_{2}$ and water? Draw a portion of the section from one surface to the other as seen before and after the chloral hydrate reaction.

4. Study in the same way leaves from plants that have been kept in the dark for forty-eight hours, and leaves from plants that have been kept all day in strong diffuse light but in an atmosphere from which $\mathrm{CO}_{2}$ has been absorbed. To do this set a potted plant on a glass plate; put a stick of $\mathrm{KOH}$ in a bottle beside it; place a tubulated bell-jar over all and seal it with sealing wax to the glass plate; stop the opening in the bell-jar with a perforated cork, and insert through the cork a glass tube bent at right angles, and into the horizontal arm of this place loosely small lumps of soda lime. Now air can enter but the $\mathrm{CO}_{2}$ will be absorbed from it by the soda lime, and that $\mathrm{CO}_{2}$ evolved by the respiration of the plant will be absorbed by the $\mathrm{KOH}$ under the bell-jar.

Arrange a check experiment in all respects like this one except that sawdust is to take the place of the soda lime and the $\mathrm{KOH}$ under the bell-jar is to be omitted. It will not do to place these plants in direct sunlight because the air in the bell-jar would become too hot. The plants used in this experiment 
must have been kept in the dark for forty-eight hours to eliminate starch from the leaves. Before the experiment and at its close test sections of leaves from both plants with chloral hydrateiodine.

5. With a brush coat half of the under side of some leaves having stomata on the under side only, with melted beeswax one part and cocoa butter one part, after the leaves have been covered from the light for forty-eight hours. The leaves are to remain on the plant through this experiment. Scratch through the upper epidermis with a needle in a few places on the upper side of the coated half of some of the leaves. Now expose the leaves to the light for half a day and then pick them off and plunge them into cold water and peel off the wax. Extract the chlorophyll from the leaves in boiling alcohol and place them in a solution of iodine. Do the two halves show starch alike? What do you note along the scratches? What do these observations teach? Make colored drawings to show your results. 


\section{CHAPTER X}

\section{TRANSPORT OF FOODS THROUGHOUT THE PLANT}

Need of Transporting Tissues.-As we have seen in Chapter IX, most of the food is manufactured in the leaves and must be carried from them throughout the plant wherever it is needed for supplying materials and energy for growth and repair or other purposes, or where food is to be stored up for future use. The higher plants, namely, the Vascular Cryptogams, Gymnosperms and Angiosperms, have attained to such size that the distance to be traveled by the food is often great; and it has been found that short cells such as occur in the meristematic cells of growing points, or in the pith or outer bark of older parts will not suffice for carrying food except through very short distances. The sieve tubes and associated cells of the phloem alone are able to do this. Without them the conduction of food could not take place any more than water could be carried in sufficient amounts without tracheal tubes and tracheids.

In following the phylogeny of tissues in the lower plants we find that the evolution of the food-conducting, as well as waterconducting, tissues is clearly in correlation with the evolution of leaves, which by their efficiency in food-making, and their large transpiration surfaces, have created a demand for means of conducting both food and water more rapidly than can be done by short unperforated parenchyma cells. In the mosses, represented by Polytrichum commune, for example, these conducting tissues have made a distinct beginning. Here the center of the stem is occupied by a vascular bundle of the concentric type (see page 43) with the water-conducting surrounded by the food-conducting tissues.

The development of the phloem from the procambium has been told in Chapter II; but it will be useful here to review the 
different elements of the phloem and give what is demonstrated or conjectured on good grounds to be their functions.

The sieve tubes (Fig. I8), it will be remembered, are formed by the perforation of the end walls in rertical rows of cells, so that the row becomes essentially a tube through which all kinds of foods can flow in solution with less interruption than through relatively short cells with walls intact. The sieve tubes are especially well adapted for the conduction of proteids, which are colloidal and diffuse throughout the cell cavity and through division walls with difficulty. It can be shown that the contents of the sieve tubes can flow en masse through the perforated partitions from one member of the tube to another, for when a stem is cut off the contents of the sieve tubes flow out until the latter are at least partially emptied for one or more internodes back from the cut, and in flowing this distance the contents must in some instances have passed through hundreds of partition walls.

The companion cells and sieve tubes are formed by the longitudinal division of a common mother cell, and they continue in intimate association. When the walls of the companion cells become appreciably thickened they are frequently pitted where they are in contact with the sieve tubes or surrounding parenchyma or medullary ray cells. The companion cells are therefore adapted to take over materials from the sieve tubes and deliver them to tissues that can carry them where they are wanted for immediate use, or where they can be stored for consumption later on. What part the companion cells play in the longitudinal transmission of foods has not been worked out.

The cells of the phloem parenchyma appear to take an active part in the longitudinal transmission of carbohydrates and amido-acids, and through their pitted communications with the medullary rays they send foods of all kinds into the rays for radial distribution and storage; and they themselves, together with the phloem parts of the medullary rays, are the chief place of storage of proteids during resting periods of winter or dry seasons. 
As was stated in Chapter II, all classes of plants do not possess the full complement of phloem elements here described. In Gymnosperms and Vascular Cryptogams the companion cells do not occur, and their place is taken by vertical rows of parenchyma cells; and in Monocotyledons the parenchyma cells are lacking. Neither are the sieve tubes alike in all respects in the different classes and families of plants. In the Gymnosperms the primary end walls of the sieve tube members (cells composing the tubes) are not dissolved away at the bottom of the pits, as seems to be the rule in Angiosperms, and in the latter class the size of the pores varies greatly in plants of different habits of growth.

For the study of sieve tubes the squash and its allies, or the grape, hop, or other climbing plant is chosen, because, in these plants with slender stems, the siere tubes and the pores through the partition walls are found to be larger than in plants of different habit, evidently for the reason that, the stem being slender and the crown of leaves relatively large, the tissues devoted to food-transportation must be unusually efficient. In many plants the pores in the sieve plates or partition walls are discerned with the greatest difficulty because of their minuteness, and in some cases they cannot be made out at all.

Evidence that the Phloem Carries the Food.-Microchemical examination, in which chemical reagents are applied to sections under the microscope, shows that the phloem is filled with food substances. Chemical analysis of the expressed contents of sieve tubes has found 7 to ro per cent. of solid or dissolved substances, of which 20 per cent. was proteid, 30 per cent. amide (a nitrogenous food of simpler composition than proteid), and $3^{8}$ per cent. soluble carbohydrate. That these substances are actually transported by the phloem is shown by experiments in which the continuity of the phloem is wholly or partially interrupted. When a ring of bark is removed down to the phloem there is no significant disturbance in food transport, as shown by the fact that growth in diameter continues below the girdle as well as above, and the storage of food goes on in 
storage cells on both sides of the girdle alike. When, however, the ring of bark is removed clear to the wood, so that the possibility of longitudinal flow through the phloem is prevented, it is found that growth ceases or is greatly lessened below the girdle and the storage of food below the girdle is prevented. Again, when a willow branch, for example, is cut off, girdled close to its lower end, and placed in a vessel of water, adventitious roots spring out much more abundantly and vigorously above the girdle than below it; and when the girdle is incomplete, so that it is spanned by a strip of phloem, roots spring out in line with the strip above and below the girdle alike. When girdling is performed on plants with bicollateral bundles (see page 43), as in the Cucurbitaceæ, the phloem parts next to the pith are, of course, left intact and the food is found to travel up and down without hindrance. The evidence is therefore conclusive that the phloem is the highway for the vertical transmission of food through the stem.

In those Monocotyledons where the vascular bundles are scattered promiscuously throughout the stem the phloem cannot, of course, be removed by girdling, since every bundle, near the periphery or remote, consists of both phloem and xylem.

\section{Evidence that the Tracheal Tissues Assist the Phloem} in the Upward Transport of Food.-No tissues of the plant body are so well adapted for the rapid transportation of food upward as the tracheal tissues, consisting of tracheal tubes and tracheids, for in them are currents of water moving much more rapidly than is possible in the phloem. The evidence that these tissues are so used is found in the chemical analysis of their contents and in the results of girdling. Chemical analysis shows for trees that early in the spring, when a wound results in blecding, water from the tracheal tissues contains in solution sugar, proteids, and amides. At other times of the year these may be present there but in less amount. The maples and birches are notable examples of this, while the grape is an exception, for the sap gathered from the bleeding of graperines, after 
their pruning in early spring, contains solutes from the soil, but not stored food-stuffs, as in the case of maples, birches, box elders, etc.

The evidence afforded by girdling that the tracheal tubes carry foods upward in the spring is this: If girdling is done on trees in the fall, winter, or spring, before the resumption of grow th sets in, and while wood and bark are still stored full of reserve food, nevertheless the storage cells below as well as above the girdle are empticd of their supplies after the spring growth begins, although the only tissues left capable of carrying the reserve foods past the girdle are the tracheal tissues in the wood (Fig. 87).

Furthermore, when the main stem of an inflorescence is girdled near its base and the exposed wood is prevented from drying by tinfoil and scaling wax, still the fruit goes on to maturity. In this case also the tracheal tissues afford the only possible channels for carrying past the girdle the large amounts of food needed for the growth of the fruit and for storage in the seeds.

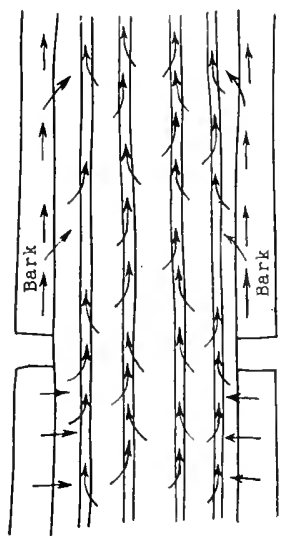

Fig, 87.-Diagram to show path of storel food upwart through the tracheal tubes, ant through the phloem portion of the bark, and showing how this passage is not prevented by girdling.

The inference does not follow from these olsscrvations that the phloem is not neederl and is not employed in the upward transportation of foods. The only thing proven by the girdling experiments is that when the continuity of the phloem is thus broken the tracheal tissues can carry food upward in sufficient quantities past the girdle. There are, on the other hand, anatomical facts to show that the phloem is employed in the upward movement of foods. In inflorescences, for instance, which make no food but use large a mounts that must be brought upward into them, the phloem, and particularly the sieve tubes, attain to a greater relative development than in any other parts of the plant. 
Relation of Phloem Elements to Other Tissues.--The food in its downward or upward course through the phloem may be drawn upon at any point by living tissues for growth, repair, etc., or it may be set aside for storage in medullary rays, xylem and phloem parenchyma. Evidently to facilitate this movement of food-stuffs there are often pores between sieve

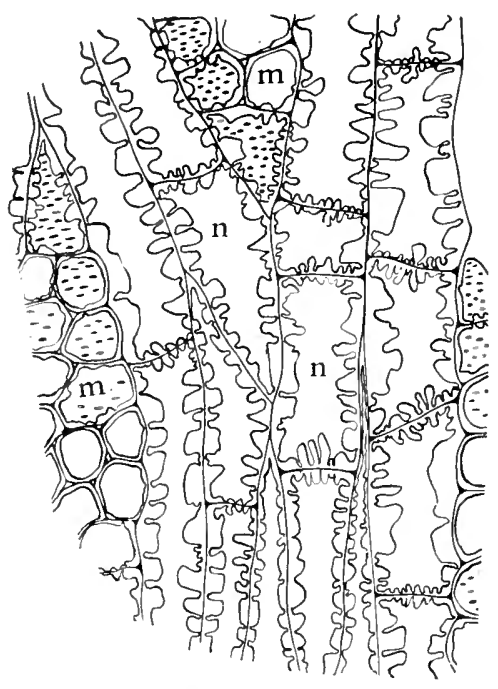

FIG. 88,- Showing pitted connections between medullary rays and xylem parenchyma, and between contiguous xylem parenchyma cells. $m$, medullary rays; $n$, xylem parenchyma. Camera-lucida drawing of tangential section of wood of yellow poplar. tubes and companion cells, and thin places or pits where the medullary rays abut on companion cells or phloem parenchyma. Pits also occur in the tangential walls of the medullary rays to help along the radial movements and storage of foods in the medullary rays; and pits in the walls separating the rays from wood parenchyma cells assist in the transmission of foods to, and storage in, the latter (Fig. 88).

The medullary rays have for their primary function the radial transmission and storage of food. Their intimate relation with the cells of the phloem at their outer end and with the xylem parenchyma along their inner course, and the fact that we usually find them gorged with food, points to this conclusion. The short vertical extent of the rays, and their isolation from each other, renders them unsuited for the vertical or longitudinal transmission of foods. If they were of value in this respect girdling would not prevent the downward flow of foods.

The extreme frequency of the rays is one factor of great importance to their efficiency in radial conduction and storage. In tangential section, that is, as one would see it when facing 
a tree, there are approximately between 20 and 30 medullary rays in every square millimeter (Fig. 89); so that when the leares are at the height of their food-construction it may be inferred the rays are very active in relieving the sieve tubes of their loads.

The Course of Food Distribution.-The logical place to begin the discussion of food distribution is where the food first comes into being in the palisade and spongy parenchyma of the leaves. It will be remembered (see page II5) that the reins ramify throughout the leaf so extensively that the last branches probably average no more than $.2 \mathrm{~mm}$. apart; so that food manufactured in cells farthest from these branches, namely, those half way between them, would need to travel laterally about . I $\mathrm{mm}$. before entering the border parenchyma cells of the veins in which it begins its journey out of the leaf (Fig. 58, C). These border parenchyma cells have already been told about on page 44 , and

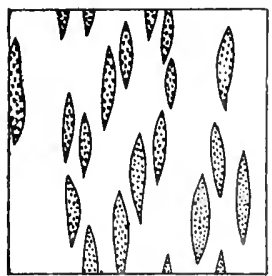

Fir. 8y.-Low-power. camera-lucida outline of tangential section of wood of oak, to show frequency of medullary rays. The section is $\mathrm{I} \mathrm{mm}$. square. The number of rays shown is below the average for woody plants. their relation to the other food-conducting cells of the reins will now be given more in detail.

The vascular bundles in the larger veins of the leaf may have all of the elements in their phloem part that occur in the stem from which they spring $\xi^{*}$ but as the reins in branching get smaller and smaller the phloem parenchyma is left behind, while the sieve tubes and companion cells remain; then farther along these do not appear and their place is taken by elongated cells that are apparently the undivided mother cells of sieve tubes and companion cells (see page 37 ); then these are left out, and the ends of the veins have only border parenchyma cells (which are morphologically a part of the mesophyll or fundamental parenchyma and not of the vascular bundles), surrounding the last tracheids. These facts are represented diagrammatically in Fig. 9o.

'The food from the palisade and spongy parenchyma in the 
form of soluble carbohyhrate such as grape sugar, or in soluble nitrogenous form such as asparagin and other amides, and even in the more complex form of soluble proteids, passes by diffusion into the border parenchyma cells of the smallest reinlets, and then begins its morement, still by diffusion and other ways about which we have no exact knowledge, toward the larger veins which are to carry it out of the leaf or deliver it to the midrib for transportation. A very simple demonstration shows that the food takes this course. After a day of active

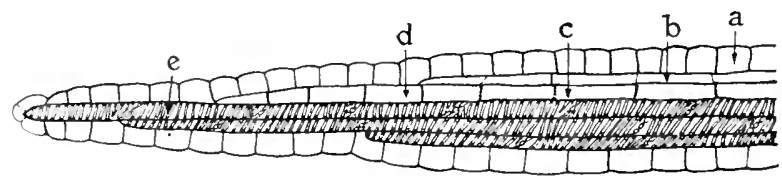

FIG. 90.-Diagram indicating the succcssion of the conducting tissues of a vein from the base toward the apex. $a$, border parenchyma; $b$, companion cells; $c$, sieve tukier, $d$. undivided mother cells of companion cells and sieve tubes; $e$, tracheal elements.

photosynthesis the leares are loaded with starch at sundown. A leaf removed at this time, bleached in boiling alcohol, and stained with iodine, shows the blue starch reaction all over. By sunrise the next morning, however, a leaf when removed and treated in the same manner takes on a yellowish color, showing that the starch has disappeared. But if one of the principal reins is cut in the evening that portion of the leaf between the cut and the extremity of the vein, which of course would be the part tributary to this rein, still retains its starch in the morning, while the rest of the leaf where the veins are left intact have been emptied (Fig. 9I); and when all of the principal veins are cut through at their base the entire leaf is filled with starch in the morning. Clearly the cutting of the reins broke the continuity of the highways through which the food passes out of the leaf.

The passage of the food through the border parenchyma cells of the smallest veinlets by diffusion must be very slow, but since there is a multitude of these veinlets (approximately 6,000 to the square centimeter) tributary to the larger veins 
where the sieve tubes occur, it is plain that a slow movement in the many veinlets could feed a much more rapid flow in the few main channels; and this is presumably what happens.

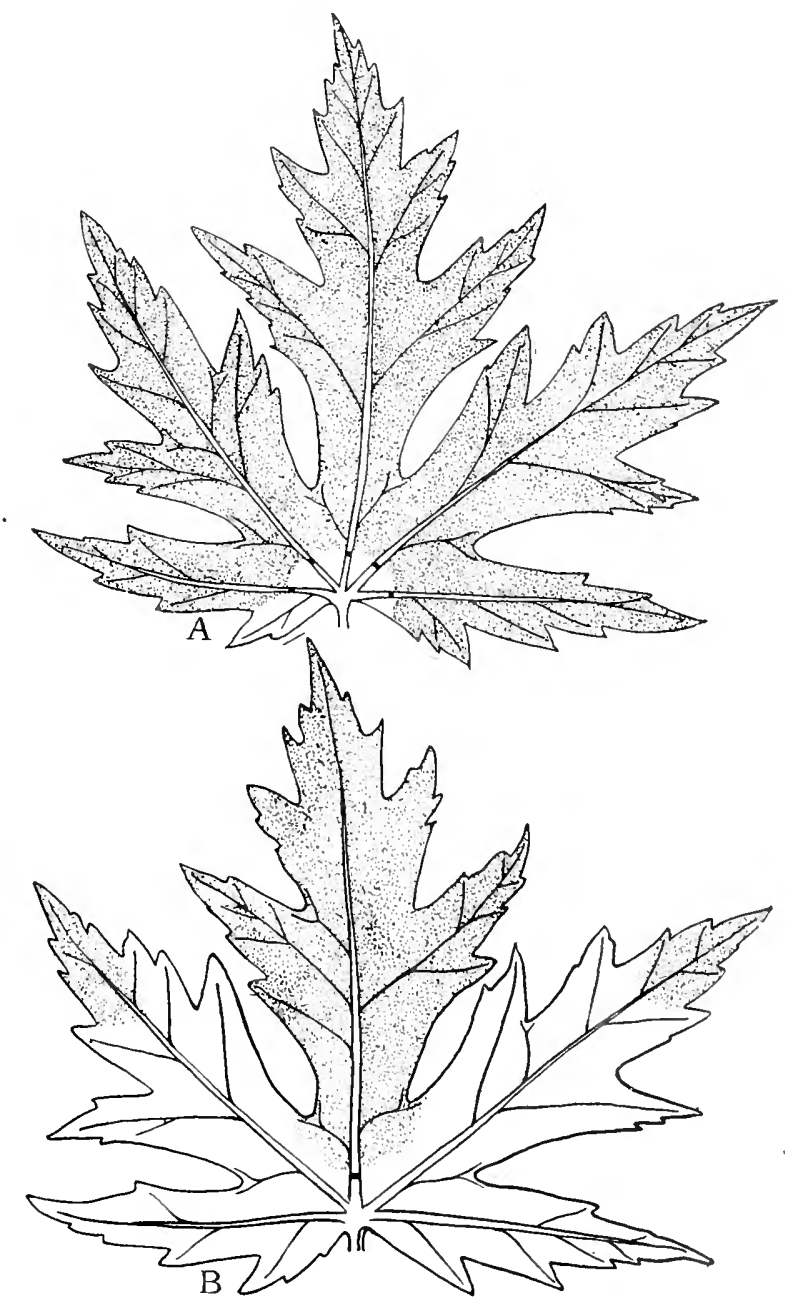

- Fur. gr.-Showing the effect of cutting across the veins on the removal of food from the leaf. $A$, all of the main veins are cut across near their bases; $B$, the mid-vein alone has heen severed. The stippled areas indicate the starch reaction with the iodine test. (After diary Blue.) 
When the food reaches the branch which bears the leaf it may pass through the phloem down or up. or part may pass down and part up at any given moment. Some of the food may also be transferred to the water tubes in which it will be hurried along to the growing apex of the branch or to fruits and seeds in course of formation, and be put to immediate use (Fig. 92). When the branches are still growing in length, or when fruit is developing, a great deal of the food goes up to nourish the new growth. After growth in length has ceased,

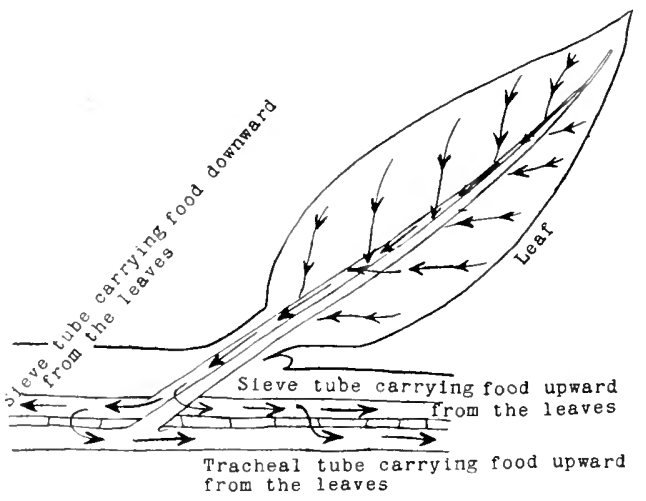

FIti. 92.-Diagram illustrating the descent of food from the leaf into the stem, and its circulation upward anil downwari through the sieve tubes, and upward through the tracheal tissues.

and if fruit is not forming, doubtless most of the food goes downward to sustain the cambium in its production of new tissues, or for storage until demand is made for it at the time of flowering and fruiting in annuals, or when growth is resumed in the spring in the case of perennials and biennials.

In Indian corn, for instance, after blossoming, the food is for the most part sent into the ears, and that which is made by the lower leaves passes up, and that by the upper leaves down, to the ears for storage in the form of starch, proteids, and oils (Fig. 93).

In perennial plants, such as trees, part of the food made in spring and early summer is used at once in growth in length and 
diameter of branches, trunk and roots; but by the beginning of summer, or even in May, much of the food is being stored in roots and trunks.

By August growth has almost ceased in most woody plants, and the bulk of the food made thereafter is stored in branches, trunk, and roots for use during the winter to a certain extent, and for resumption of growth in the spring. In accordance with this the flow of the food would be up as well as down in the first part of the period between the appearance and fall of leaves, and chiefly down for storage after the elongation of the branches and the growth of fruit has practically ceased.

Most of the reserve food is stored in the roots and trunk, and in the spring the larger part must ascend where growth and fruitage is going on in the crown, and where cambial activity is first

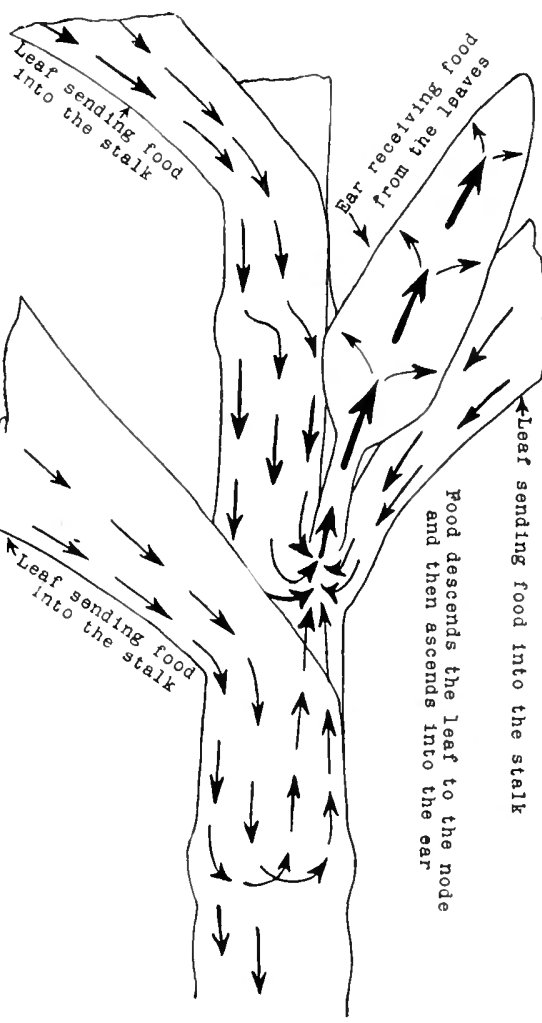

FIt;, 93.-Diagram showing how, in Indian corn, the food from the upper and lower leaves finds its way into the ears.

awakened. The sieve tubes which are empty during the winter can be filled by these ascending currents, and in most instances the tracheal tubes are also pressed into service and carbohydrates, chiefly as sugar, and proteids and amides to a certain extent, are poured in to them from their place of storage in the xylem and phloem parenchyma and medullary rays. 
The tracheal tubes must prove rery efficient carriers, for the ascending currents of water would sweep the food along much faster than it could be moved in the sieve tubes. While most plants make large use of the tracheal tissues in this way there are others, such as the grape, which make little or no use of them and send practically all of their food into the sieve tubes for transportation. The fears that the grapevine may be depleted of its food when bleeding from spring pruning are therefore groundless, since little more than water and a small percentage of salts from the soil are then lost.

It will be noted that just as the sieve tubes can carry food up or down as needed, so the medullary rays are able to transport foods radially inward for nourishing the xylem or for storage. and outward again when they are to be distributed and put to use. There is nothing about the construction of the foodconducting tissues to prevent movement in them in a certain direction at one time and in the opposite direction at another, and it is quite possible that a flow in opposite directions may occur at the same time in a cell or tube.

The growth of seedlings in their earlier stages presents another set of conditions in food distribution. Then the food must move from its place of storage in cotyledons and endosperm before the special food-conducting tissues have become differentiated; but the distance to be traveled is short and the cell-walls are new and thin and offer relatively little resistance. Under these conditions it seems that food can travel fast enough to maintain rapid growth without the aid of sieve tubes. In seedlings the direction of flow of food is down into the roots and up into the shoot from the place of storage, but as soon as the green leaves unfold they at once become an additional source of food supply, and by that time the vascular bundles have been formed and the sieve tubes are ready to take up their work, carrying the food down or up as need compels.

The anastomoses of the vascular bundles described on page 42 are of great use in the distribution of food as well as of water. In the elm tree, for instance, the leaves are two-ranked, so that 
two sides of the branch are throughout its length bare of leaves; and the smaller branches arise from the larger also in two rows, so that if the food descending from the leares took a straight course down the branch this would be without nourishment throughout more than half of its body since the food travels with difficulty out of one bundle through intervening tissues into another as shown on page 160 . But this difficulty does not exist in uninjured plants because the bundles are so knit together by anastomoses (Figs. 20 and $49, B$ ), that the food from one side of a stem can be shunted to another side whenever there is need. Likewise in Indian corn, as a rule more corn is produced on one side of the stalk than on the other, but the more fruitful side has taken contributions from the leaves of the opposite side through the numerous anastomoses at the nodes.

These examples will serve to illustrate the general statement that whenever, or for whatever cause, one side of a plant requires food that the leaves on that side are unable to furnish all other sides may be drawn upon, since all the vascular bundles are knit together in one system.

The course of food distribution will now be simmed up: When growth begins in the spring food is carried to the unfolding louds upward through the sieve tubes and tracheal tissues from its place of storage in branches, trunk, and roots. Soon the leaves have grown forth and begin the construction of new food. This flows out of the leaf through the border parenchyma cells and phloem, and on reaching the branch it takes the direction compelled by the plant's need. It may flow down through the phloem or up through the phloem and tracheal tissues.

Whether the food flowing down or up shall be used at once or stored for future use depends on the neet of the plant. So long as growth is rapid, and during the period of flowering and fruiting large quantities of food are put to immediate use.

As the food travels down or up through the phloem a part of it is removed from these longitudinal highways for the immediate nutrition of the cambium and part is carried farther inward by the medullary rays and used by them and other 
living cells of the wood in nutrition, or some is stored in the rays and wood parenchyma and cells of the pith immediately bordering the wood (Fig. 94). Some of the food taken from the phloem is distributed outward to the living cells of the cortex and pericycle (sce page 31), and used in nutrition or temporarily stored. In short, all living cells of the plant body draw upon the supplies that are in circulation throughout the phloem.

Annual Additions to the Food-conducting Tissues.-In the spring when growth in perennial stems and roots is resumed

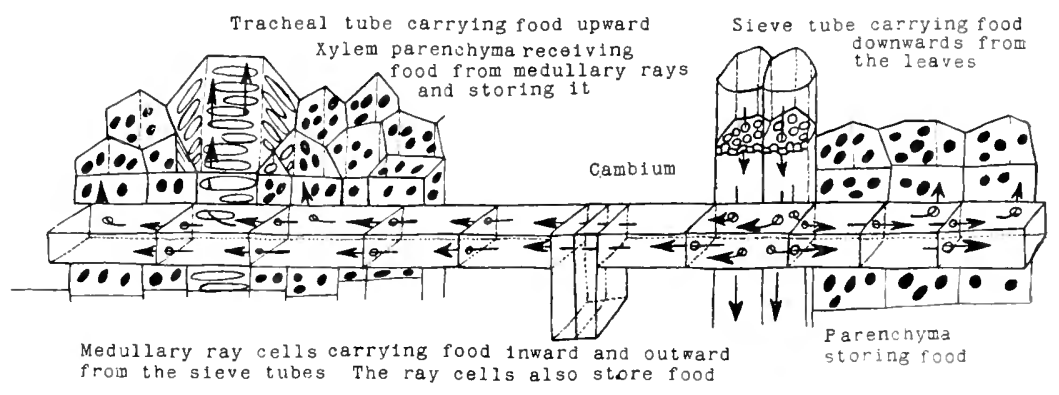

Fli. 94-Diagram showing the transport of food through the sieve tubes, medullary rays and tracheal tubes, and its st rage in the parenchyma cells of the wool and hark. The black bodies ia the cells indicate stored food.

the cambium devotes itself first to the production of watercarrying tissues, as related in Chapter VI. But at the same time, although to a much less extent, it begins to lay down new phloem elements. Early spring additions to the phloem seem to be more imperative in some plants than in others, because in some the sieve tubes are functional but a single year and the advent of their second spring finds them empty and their sieve plates blocked by an accumulation of a peculiar, highly refractive substance called callus, and in this condition they remain until crushed out of existence by the growth of surrounding tissues. In other plants, such as the grape, although in the spring the old sieve tubes are empty and lammed up by callus the latter is soon dissolved away and the tubes again are filled from stored materials in phloem parenchyma and medullary rays. 
The cambium ceases its additions to the xylem or wood side of the bundles early in August, but it may continue its slow additions to the phloem until the close of the growing season.

As to the length of life of the phloem elements, in some plants the sieve tubes live but a single year while in others they may survive and remain functional for a few years at most. The companion and phloem parenchyma cells may die with the sieve tubes, but in some cases they survive these, even until they become cut off from the general circulation during the formation of borke (see page 55). Therefore in stems several years old we are apt to find the outer and older portions of the phloem collapsed and dead (Fig. 24).

\section{Relation of One Year's Phloem} Elements to those of the Next. -Fig. 95 shows diagrammatically how the phloem of one year narrows down at the close of the year's growth in length and lies in immediate contact with the primary (earliest-formed) phloem of the following year. The ending of the year's phloem (where it tapers to a point in the diagram) consists of sieve tubes and companion cells in Dicotyledons, and sieve tubes and vertical rows of phloem parenchyma cells in Gymnosperms; and these join with the corresponding elements that are first differentiated from the

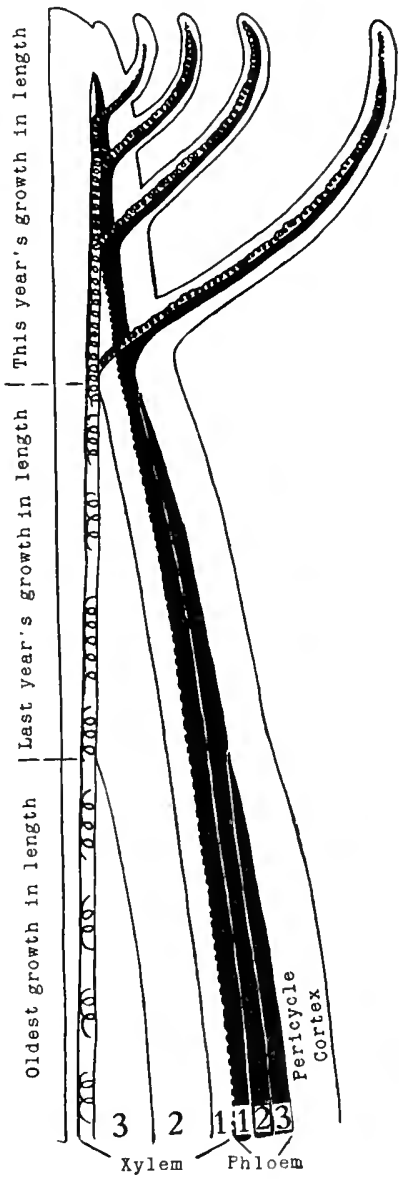

FIG. 95.-Diagran to show the relation of the food-conducting tissues of the leaf to those of the stem; and in the stem the relation of these tissues of one year to those of preceding years. The dotted line between phloem and xylem stands for the cambium. The figures at the bottom of the diagram indicate the age in years of the zones of tissues in phloem and $x y l e m$. 
procambium of the succeeding year's growth in length. It will be seen by this diagram that the food highways in the leaves have direct communication with the primary phloem in the new segment of stem which bears them, and this primary phloem is in turn continuous with the phloem elements which the cambium builds the current season throughout branch, trunk and roots.

As has been said, in some plants the sieve tubes are functional for one year only; in others for two or more years, and it would therefore depend upon the kind of plant to what extent the phloem strands in the older annual segments $(2,3$, of the diagram) assist in carrying food the current season. It is precisely because the youngest and younger phloem tissues are the most active that, in girdling, the bark can be stripped off nearly to the wood without apparently hindering the flow of food.

Character of the Food While in Transport.-The nitrogenous foods circulating in the sieve tubes and other parts of the phloem are mostly in the form of asparagin and other amides which are soluble and more diffusible than the soluble proteids. The insoluble proteids must be changed to the soluble condition before they are capable of translocation.

The carbohydrates are mostly in the form of glucose (grape sugar), but saccharose (cane sugar) is sometimes present. Minute starch grains frequently occur in the sieve tubes; and in some plants the pores in the sieve plates are large enough for the smallest grains to pass through; but it is certain that no significant amount of carbohydrate circulates in this form.

Oils can be absorbed into the phloem elements in the form of a fine emulsion, and in this form they can travel longitudinally through the sieve tubes and parenchyma cells. Chemical analysis shows, however, that very little non-nitrogenous food travels in this form, oil for the most part being transformed in to sugar preparatory to translocation.

The Propelling Power in Food Transport.-The necessary conditions are always present for the distribution of foods in solution by diffusion throughout the length of the phloem, and foods must circulate to a certain extent in this manner; but 
diffusion is a slow process and it alone cannot suffice to carry foods fast enough when growth is rapid or when at the height of photosynthesis the leaves are taxing the utmost capacity of the conductive tissues. To illustrate the slowness of movement by diffusion alone: common salt in comparison with many other substances diffuses rapidly, yet in a ro per cent. solution it required in one experiment 3 I 9 days to transfer a milligram of salt one meter, and under like conditions it would take fourteen years for egg albumin to travel the same distance. So we must assume that in plants diffusion is assisted in various ways, such as jarring due to the wind, etc., changes in temperature, circulation of the cytoplasm, and possibly in other ways. We know that the contents of the sieve tubes are under pressure, for the tubes empty themselves when cut open, and this pressure would propel materials toward the places where for immediate use or for storage they are being remored from the tubes by the surrounding tissues. It is furthermore quite possible that effective conditions and forces are present of which as yet we have no clew.

\section{ILlustrative Studies}

I. Study the phloem elements in the stem of squash, grape, and hop. Mount free-hand cross and longitudinal sections in dilute glycerine. Hunt for sieve tubes, companion cells, and phloem parenchyma. Find the perforations in the sieve plates in both cross and longitudinal sections. How far apart are the plates? and how many of them would food have to pass through in going $\mathrm{I} \mathrm{cm}$.? Draw sieve tubes from both points of riew, showing the sieve plates.

2. Study border parenchyma (page $1_{4} 6$ ) and phloem elements in cross and tangential sections of leares. How far does the food have to travel from the palisade and spongy parenchyma before it can reach the conducting cells of the reins? Make drawings that will best illustrate what you have seen.

Sections made from material imbedded in paraffin are best for this study, but good free-hand sections will do. To cut 
tangential sections of leaves free-hand coat thinly one end of a cork with melted rosin 2 parts and vaseline I part, and while this coating is yet warm press into it a piece of leaf that has lain for a while in 95 per cent. alcohol, first allowing the alcohol to evaporate from its surface. With a little practice several good sections can now be cut from surface to surface. If preferred the sections may be cut on a sliding microtome.

3. Cut some of the veins in leaves about sundown and darken them so that they cannot photosynthesize before they are examined the next morning, when they are to be bleached in hot alcohol and placed in an iodine solution. Does this reveal anything about the food-conducting function of the veins? An outline drawing colored lightly with a blue pencil where starch occurs will make a good record of this observation.

4. Girdle stems in the spring and note thereafter growth in diameter above and below the girdle. Study sections to note storage of food in both regions. 


\section{CHAP'TER XI}

STORAGE OF FOOD AND WATER

Need of Food Storage.-As told in the preceding chapter, plants need food for growth and repair of tissues and to furnish energy to keep the life processes going. If food were being made continuously by the photosynthetic tissues day and night, and every day so long as the plant lives, and if the demand for food were uniform all of the time throughout the whole plant there would be no need of storing food for future use. But the actual conditions are quite the reverse of this.

The photosynthetic tissues do not work at night nor through the winter and dry seasons after the leaves have fallen. And even when the leaves are on the demand for food is by no means the same at all times. More food is needed during the first part of the growing season when growth is most rapid, and more is needed when fruits are forming and advancing to maturity than at other times; and it is of great advantage to plants that they have the power and habit of storing food when the demand for it is relatively slight, for use when the need of it is greater.

Trees and shrubs, denuded and entering upon their winter rest, are packed with reserve food in roots, trunk, and branches (Fig. 96). The greater part of this is kept till spring to sustain resumption of growth and the production of fruit, but some of it is necessary to sustain life during the winter. Every organism, so long as it lives, whether active or dormant, requires a certain amount of food to keep its life going. This is true even of dry seeds, although the amount consumed by them is so slight as to be difficult of detection; and parts intended for reproduction that become severed from the parent plant must first be stored with food for their nutrition until they become independently established and begin to make food for themselves. 
The Kinds of Stored Food.--The best evidence of what constitutes the food of plants is found in seeds. What occurs stored up there must be plant food; and if we find, as we do, that the same stuff is stored in the branches, trunk and roots of mature plants, then we know that the food required for the

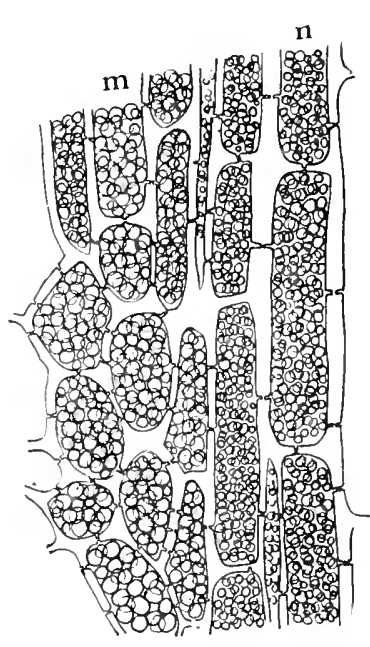

FIG. 96.-Camera-lucida drawing of tangential section through the wood of grapevine, $m$, cells of medullary ray, and $n$, of xylem parenchyma, packed full of starch. embryo plant in the seed is the same as that needed by the adult plant.

Both in seeds, bulbs, tubers, etc., and in the general plant body are found nitrogenous and non-nitrogenous foods. Of the latter class starch, fats, and oils, are far the most common forms used in storage; glycose, lævulose, and saccharose are much employed; and cellulose, inulin, glucosides, and mucilage less frequently. Different kinds of proteids and amides are the chief representatives of the nitrogenous class.

Starch.-Starch occurs in the form of definite grains, either suspended in the cytoplasm or lying loose in the vacuoles. It is insoluble in the cell-sap and is one of the most stable and permanent forms in which food is stored. The sizes, shapes and markings of the grains vary a great deal in different plants, and even in different parts of the same plant. 'The starch grains are, as a rule, much larger in special storage parts, as in fleshy roots and stems, and in the endosperm of seeds than in the ordinary stems and roots, and they range in diameter in different species from $.002 \mathrm{~mm}$. or less to nearly . $2 \mathrm{~mm}$.

Starch grains in the special storage organs usually have characteristic shapes and markings for the different kinds of plants. The forms are spheroidal, ovoidal, ellipsoidal, or polyhedral where the grains crowd one another. Rarely rod and dumbbell shapes are found. The markings are in the form of concentric and excentric striations and more or less irregular cracks. 
These characters are, in fact, so pronounced as to afford the means of detecting adulterations in ground and powdered food and drugs (see Fig. 97).

The light and dark striations in the grains are layers of greater and less density, and are possibly due to periods of greater and less abundance of available sugar from which the starch is made. Some starch grains when partially digested, or swollen in a dilute solution of potassium hydrate, appear as though made up of needle-shaped crystals radiating from the organic center of the grain, and it has been suggested that the denser layers of the grain are composed of denser groups of these crystals. The crystalline nature of the starch grain is also demonstrated by its behaving in polarized light as crystals do.

Treatment of starch grains with boiling water seems to show that
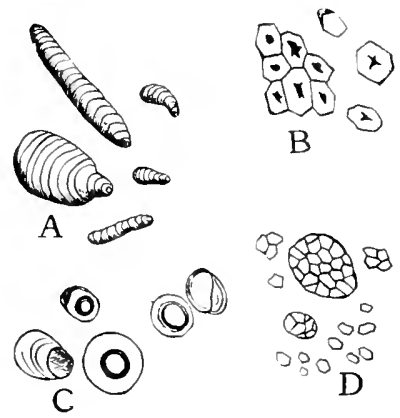

Fig. 97.- Starch from different sources. A, curcuma starch; $B$, corn starch; $C$, tapioca starch; $D$, rice starch, showing compound grains. they are composed of two kinds of starch, one insoluble and the other soluble in boiling water, for the microscope reveals that the paste made in this way is not a complete solution and contains an abundance of undissolved remnants. The insoluble part is called $\alpha$-amylose and the soluble $\beta$-amylose.

The percentage formula for starch is known $\left(\mathrm{C}_{6} \mathrm{H}_{10} \mathrm{O}_{5}\right)$, but the exact number of atoms to the molecule has not been definitely fixed. The number is tentatively expressed by multiplying the percentage formula by $n$, thus, $n\left(\mathrm{C}_{6} \mathrm{H}_{10} \mathrm{O}_{5}\right)$.

Starch grains are almost always colored blue with an iodine solution; but when undergoing digestion they may assume a reddish color with iodine due to the dextrines that have been formed from the amylose. In a few instances starch normally contains so much.amylodextrin that it is colored red by iodine, as in the seed-coats of Oryza and Chelidonium.

At the close of the growing season the amount of stored starch 
is at its maximum in ordinary stems and roots, and in special storage organs. The largest percentage of stored starch occurs, of course, in dry seeds, such as those of the cereals and legumes. Thus the potato is 20 per cent. starch, while beans contain 45 . peas 58 , oats 47 , barley 48 , rye 60 , wheat and millet 64 , maize 65 , and rice 76 per cent. of starch.

Dextrose, Laullose, and Saccharose.-Dextrose (glucose or grape sugar) is the commonest form in which the non-nitrogenous foods circulate throughout the plant. It is probably the form in which food is first made by the chloroplasts, and it arises secondarily by the digestion of starch, fatty oils, inulin, cellulose, cane sugar, etc. It occurs in solution in the cell-sap, and when the sap is evaporated it is thrown down in the form of crusts or warty agglomerations of pseudo-crystals. Small percentages of dextrose frequently occur in storage tissues and sometimes in association with lævulose and saccharose. Dextrose and lævulose (fructose or fruit sugar) are the sugars in sweet fruits, in the nectar of flowers, and in the bulbs of Allium cepa and Ornithogallum arabicum, and in the underground parts of species of Primula and Globularia.

Saccharose (cane sugar, beet sugar) occurs as reserve food in the maples, sugar- and sorghum-canes, beet-root, etc. Sugar maple sap yields somewhat less than 3 per cent. of sugar, sugarcane sap about i 8 per cent., sugar-beet sap r6 per cent., and sorghum-cane about it per cent. of saccharose. Cane sugar also occurs in some fruits such as the banana and pineapple.

Fatty Oils and Fats.-Fatty oils are fluid at ordinary temperatures and the fats are solid. They are, of course, not soluble in, nor miscible with water or the cell-sap; and in the plant cell the fatty oils occur in a very fine emulsion, and the fats in groups of exceedingly minute crystals throughout the meshes of the cytoplasm.

The fats and fatty oils as they occur in plants are mixtures of glycerine esters or glycerides of palmitic, stearic, and oleic acids; and the palmitic ester is called palmitin. the stearic, stearin, and the oleic, olein. Palmitin and stearin are solid at 
ordinary temperatures, and olein is fluid, and whether the mixtures of these be fluid or solid depends upon their relative proportions.

The fatty oils occur in greatest abundance in oily fruits and seeds, as in the fruit of the olive, and the seeds of castor bean, where 60 per cent. of the dry weight is oil, and in rape seed, with 50 per cent. of rape oil, and in walnuts, with 55 per cent. of walnut oil in the embryos. There are many seeds not classified as oily which nevertheless contain enough oil to make them the source of its commercial production; some of the cereals are an example of this, and notably Zea mais.

In reviewing all groups of seed plants it has been estimated that four-fifths of them contain fats and oils as an important part of the non-nitrogenous reserve food in the seeds.

The fats and oils in seeds are reserve food to be used during germination, but when they occur in fruits, as in the olive, they are not food for the embryo, but are useful in alluring animals to gather the fruit and scatter the seeds.

Imulin.-Inulin is a carbohydrate occurring notably in the underground parts of some Composita, such as Taraxacum and
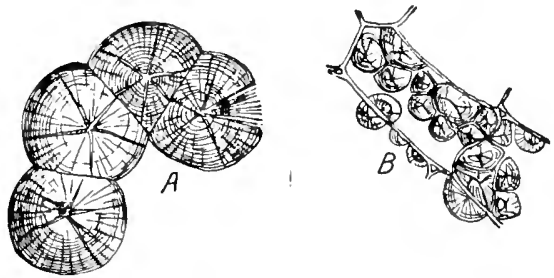

FIG. 98,-Sphæro-crystals of inulin from tuber of Dahlia variabilis. $A$, precipitated from an aqueous solution; $B$, precipitated within the cells by long standing in alcohol. (After Sachs.)

Dahlia, and it also occurs in the Campanulacere, Lobeliacere. Liliaceæ, and Amaryllidacee, and a few other families.

Inulin is soluble in the cell-sap, and on freezing, or when placed in alcohol or glycerine, it is precipitated in the form of sphærocrystals (Fig. 98). It is apparently made from dextrose and levulose, and it is changed back into these or other sugars preparatory to its circulation.

Reserve Cellulose and Amyloid.-Reserve cellulose is deposited in the form of thickenings of the cell-wall in the endosperm of the date and other palms, and in species of Foniculum. 
Strychnos, Coffea. Iris, Allium, Asparagus, etc., and in the cotyledons of some Leguminosæ and doubtless of some other plants. As in the case of inulin, dextrose and lævulose are the materials

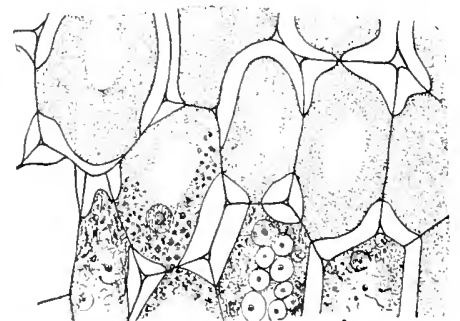

A

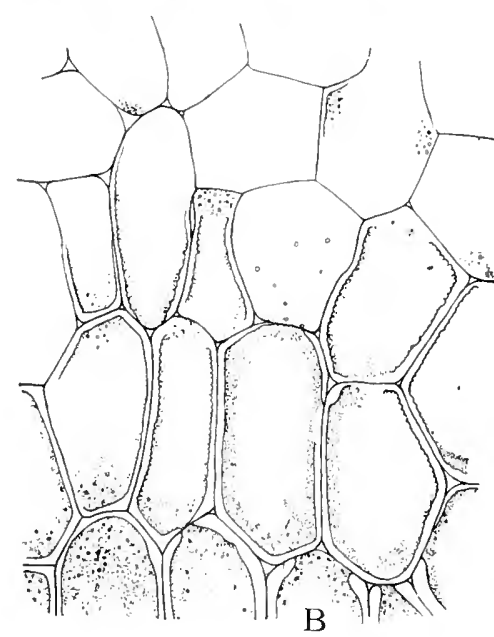

FIG. y9.- - Storage tissues of the cotyledon of Impatiens Balsamina. A, from the resting seed, and $B$, from a germinating seerl. In $B$ the amyloid thickenings of the cell-walls are wartly digested away. (After Frank.) from which reserve cellulose is formed, and when wanted for food it is transformed back to sugar until only a very thin primary wall remains (Fig. 99).

Amyloid, like reserve cellulose, occurs as thickenings to the cell-wall of endosperm and cotyledons. It is colored blue with a solution of iodine, and in this respect is similar to starch. It is found in the cotyledons of Tropæolum and in the sceds of Impatiens, Pæonia, and some Primulaceæ and Leguminosæ. During germination amyloid is converted into sugar and dissolved away, leaving only the primary wall, as in the case of reserve cellulose.

Glucosides. - The sul)stances embraced in this group may be nitrogenous or non-nitrogenous. They are characterized by yielding sugar and some aromatic and other compounds when decomposed by appropriate ferments, or when boiled in dilute acids or alkalies. They are bitter to taste, soluble in water, and may be isolated in crystalline form. Some of the glucosides undoubtedly serve as reserve food, but others may not be of use in this way.

Amygdalin $\left(\mathrm{C}_{20} \mathrm{H}_{27} \mathrm{NO}_{11}\right)$ is a glucoside occurring in bitter 
almonds. The enzyme emulsin, occurring with it, splits it into oil of bitter almond, prussic acid and glucose. Other glucosides are potassium myronate in mustard seeds, solanin in many Solanaceæ. such as bittersweet and Irish potato, salicin in the bark and leaves of willows, coniferin in the wood and cambium of Conifers, digitalin, the poisonous substance in Digitalis purpurea, indican, occurring in species of Indigofera, which by its enzyme is broken down into a kind of sugar and indigo-blue.

The full list of known glucosides would be a long one, and there is a multitude of bitter products in plants apart from the alkaloids, many of which will yet be found belonging to the group of glucosides.

Mucilage.-This is characterized by its swelling enormously in water. It is known to be stored as reserve food in the tubers of some orchids and in the secds of a few Leguminosa. It is clearly related to reserve cellulose in its chemical nature, and like the latter is transformed to sugar in its digestion.

Proteids.-Proteids are the most complex of plant foods and at the same time the most important, since they are the chicf constituent of the living protoplasm itself. 'Their exact chemical constitution has not been determined, but it is known that they contain carbon, hydrogen, oxygen and nitrogen, and many contain in addition sulphur, and a less number have phosphorus also.

The food substances here enumerated before the proteids contain no nitrogen with the exception of some of the glucosides, and it is the proteids chiefly that contain the nitrogen supply of plants, 50 to 90 per cent. of the nitrogen in the vegetative parts being held by proteids, and in sceds and spores 90 to 98 per cent. of the nitrogen is contained in the proteid reserves.

The proteids occur in three distinct conditions: as definite rounded granules known as aleurone grains, as smaller amorphous proteids, and as soluble proteid, which under normal conditions is in solution in the cell-sap.

Aleurone grains occur most abundantly in seeds associated 
with starch or oil. In the garden pea and bean, for example, they occur as very small grains filling up the spaces between the starch grains, while in the castor bean they are much larger and together with the oil fill up the fine meshes of the cytoplasm (Fig. I0o). Hereand in some other oily seeds the aleurone grain is made up of a proteid body, called the ground substance,
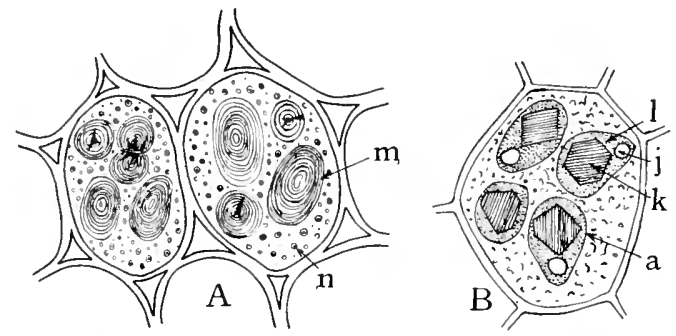

FIG. Ioo.-To show aleurone grains. A, cells from cotyledon of seed of garden bean; $n$, aleurone grains; $m$, starch; $B$, cell from endosperm of castor bean; $a$, aleurone grain; $l$, ground substance; $k$, crystalloid; $j$, globoid. ( $A$, after Sachs; $B$, after Frank.)

inclosing one or more proteid crystalloids, and one to several mineral granules called globoids, composed of a double phosphate of calcium and magnesium.

Amorphous and soluble proteids occur in bulbs and tuluers, and in the storage tissues of ordinary stems and roots.

There are many different kinds of proteids in plants, but they are not yet well enough known to admit of complete classification.

Most proteids are digestible in the animal body, and they are either soluble in water or made so by the enzymes pepsin and trypsin of the animal body or similar enzymes occurring in plants. Of these digestible proteids the globulins and albumoses occur most abundantly in the reserve foods of seeds: the former of these coagulates on heating to $75^{\circ} \mathrm{C}$., while the latter does not. Allumins occur in seeds and in the general cell-sap and like the globulins coagulate on heating, but unlike them are soluble in pure water. Gliadin and glutemin, insoluble in water but soluble in dilute alcohol, occur abundantly in the 
seeds of grasses. These give the sticky character to dough made from wheat and rye flour.

All of the above-named proteids belong to the readily digestible class. Another class of proteids called mucleins are not so easily digestible, and some of them are apparently not at all so. These can be isolated by subjecting cells or tissues containing them to the action of pepsin and other proteiddigesting enzymes, since they remain intact after the other proteids have gone into solution. The nucleins are insoluble in water and dilute acids, but they dissolve readily in alkaline solutions. They invariably contain phosphorus and frefuently iron, but not all have sulphur. They always occur in the nucleus, and possibly to a certain extent in the cytoplasm.

Amides.-The amides contain carbon, hydrogen, nitrogen, and oxygen, and are simpler nitrogenous foods than the proteids. All amides appear to be soluble in the cell-sap, though not with equal ease. They occur as reserve food chiefly in underground parts, such as fleshy roots, bulbs, tubers, and rhizomes; and in these places nearly the whole of the reserve nitrogen may be in amide compounds, such as asparagin, glutamin, tyrosin, and leucin. Of the nitrogen occurring in the beet root and potato, 30 per cent. and more is in the form of amides. Asparagin is the most common form in which nitrogenous foods are distributed throughout plants, and when seeds are germinating their proteids gradually are reduced for the most part to this form.

The Process of Storage.-The leaves being the organs in which the non-nitrogenous, and apparently a good part of the nitrogenous, foods are made from the raw materials, the storage tissues, in whatever part of the plant, must get from the leaves in soluble and transportable form the foods which they are to store up.

As has been said, the non-nitrogenous foods travel to the storage tissues chiefly as glucose, and the nitrogenous for the most part in the form of asparagin. Arrived at the storage tissues these relatively simple, soluble, and diffusible forms of 
food either accumulate there in the same form in which they came, or, as more often occurs, they are converted into more complex, less diffusible, or entirely insoluble forms.

Glucose, for instance, may simply accumulate as glucose, as in the onion, or it may be condensed into the less diffusible saccharose, as in the root of the sugar beet; or it may be converted into insoluble starch, as in the potato, or into oil, as in oily seeds.

Asparagin may be stored as it is or first changed to some other amide such as leucin, tyrosin, and glutamin, as is the case in the roots, tubers, etc., of various plants. Or asparagin may be condensed into some form of proteid, in which case salts of sulphur and phosphorus may also coöperate.

In these processes of transformation the various cell organs (nucleus, general cytoplasm, plasmatic membrane, plastids) play different, though not independent parts. Thus, the leucoplasts make starch from glucose, and apparently the cytoplasm makes oil from glucose, and proteids from asparagin; and in all of this work it is almost certain that the nucleus lends a hand.

We conclude that the leucoplasts make the starch because it first appears as a very minute granule within the leucoplastic body and gradually attains to its full size there. The leucoplasts absorb the glucose and readjust its elements into the more complex starch. We note the fact but cannot tell how it is accomplished, nor the steps in the process. As fast as the glucose is thus taken out of solution more comes to the leucoplasts by diffusion, and the process advances until the leucoplasts are stretched to an almost or quite invisible film outside the starch grain.

If the starch grain makes its beginning at the center of the leucoplast the successive layers are about of equal thickness all around and the grain becomes concentrically striated, as in the garden bean; but if the grain starts outside the center the additional layers are formed faster, and so become thicker. on the side of the greater amount of leucoplastic substance, as we find them in the Irish potato (Fig. IOI). 
Sometimes it happens that the starch begins to be deposited at more than one point in the leucoplast, so that two or more relatively small grains become closely associated, and adhering with more or less tenacity they constitute a compound grain (Fig. IOI).

In storage tissues, where simple grains are the rule, compound grains may also occur; and in some instances, as in oats and rice, compound grains are the rule. In some cases small units of starch may begin to form a compound grain and then all become encased in a common starch sheath deposited by the exterior part of the leucoplast. These grains are called half-compound.

The storage of oils and fats takes place in the vacuoles and throughout the meshes of the cytoplasm, and it may be inferred that the cytoplasm has

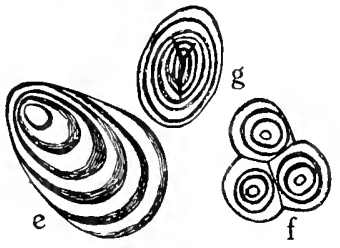

FIG. ror.-Showing concentric and excentric striations of starch grains. $e_{\text {, }}$ potato starch excentrically striated; $f$, compound starch grain from potato; $g$, bean starch concentrically striated. more to do with their construction and storage than have the other cell organs; but the mere fact that reserve food occurs in a certain cell organ is not to be taken as evidence that other cell organs have not coöperated in its manufacture.

In following the ripening of oily seeds it is found that sugars and starch are present in the immature seeds, but little or no oil. As ripening proceeds, however, oil appears and gradually increases in amount, while the sugars and starch disappear, having unquestionably contributed the elements for the construction of the oil.

In the leaves of Vanilla and other Monocotyledons have been found rounded bodies containing oil in their meshes, and these bodies have been supposed to be oil formers and have been named elaioplasts (Gr. elaion, oil, and plassein, to form).

Reserve sugar occurs in solution in the cell-sap of the storage cells, and it probably exists within the cell wherever the cell-sap penetrates. There is no special cell organ devoted to the storage of sugar, and whether the cytoplasm is most active in this process has not been determined. As has been stated. 
dextrose (glucose, grape sugar) is the most common form in which sugar is transported, and when it is to be stored in this form there is little left for the storage cells to do beyond taking it in and aiding in its accumulation after its concentration has become greater than in the surrounding tissues. Undoubtedly the plasma membranes in particular are active in this work, not only allowing but helping the sugar to accumulate when, governed alone by the recognized laws of diffusion, after its concentration in the storage cells equalled that in surrounding cells, its continued entrance would be impossible.

When the dextrose coming to the storage cells is transformed to saccharose, as in the sugar-beet root, the change is apparently advantageous to storage since saccharose is less diffusible and has less osmotic power than dextrose.

It may be assumed that when sugar in solution is stored in cells the osmotic pressure within the cells becomes very great, and saccharose would be more advantageous in high concentrations since its osmotic pressure is only about half that of glucose.

The reserve cellulose, amyloid, and similar thickenings of endosperm cell-walls intended for food on the germination of the seed, as in the case of the date, Tropaolum majus, Impatiens balsamina, etc., appear to be formed by the decomposition of exterior portions of the plasma membrane, or by the more direct transformation of dextrose, which comes to the cells abundantly while storage is going on. No special protoplasmic organ for this work has been discovered, and it may be assumed that the exterior plasma membrane does the same work that it is supposed to do in the building of the ordinary cell-wall (see page 5).

It is noteworthy that in the construction of the cellulose, amyloid, etc., food reserves, the protoplast has accomplished without a special organ the same kind of chemical work as that done in the storage of starch where special organs, namely the leucoplasts, are necessary.

The formation of the proteid reserve foods can be followed to a certain extent where they appear as definite granules (aleu- 
rone grains), as in the seeds of castor oil and garden bean. In the early stages of development of these seeds no aleurone grains are present, but later minute projections from the meshes of the cytoplasm appear which gradually increase in size and fill up the interstices. The cytoplasm thus seems to be the immediate agent in the construction of the aleurone grains. Whether the cytoplasm breaks down its own substance to form the aleurone or constructs this directly from amides, sugars, and salts of sulphur and phosphorus, has not been determined. It is possible, of course, that both methods are employed; but whatever the steps in the formation of reserve proteids, the simpler amides, sugars, etc., that are known to flow to the storage cells during the storage period contribute the necessary elements.

Characteristics of the Storage Tissues.-Tissues primarily designed for the storage of food, as the endosperm of seeds and the bulk of the tissues in fleshy roots, tubers, etc., have relatively large cavities and thin cellulose walls, or where the walls are much thickened they have many thin places in the form of pits. Storage being a vital function the storage tissues are composed of living cells and when these cells die they are no longer functional. Since most of the stored food must be digested before it can be moved from its place of storage the power to make digestive ferments or to carry on digestion directly without the aid of ferments must be one of the leading characteristics of the protoplasts of the storage tissues. When starch is to be stored the cells must be provided with abundant leucoplasts.

Location and Extent of Food Storage Tissues.-Food may be stored for longer or shorter periods in any living cell, but there are certain tissues which have the storage of food for their chief function. These are the endosperm and perisperm of seeds, and sometimes the mesophyll of cotyledons; the medullary rays and wood parenchyma of ordinary stems and roots, and of fleshy roots and stems where the rays and wood parenchyma greatly preponderate over the other tissues; that portion of the pith immediately bordering the wood, and 
sometimes all of the pith; and the phloem parenchyma and thin-walled parenchyma of cortex and pericycle.

The storage tissues in seeds make up their greatest bulk, and, unless the cotyledons are employed in storage, the embryo is only an insignificant part of the seed in size. When cotyledons that have been used for food storage are coming above the ground and turning green their mesophyll cells are delivering up the stored food so that the cotyledons gradually become thin, and the mesophyll, through the secretion of chlorophyll

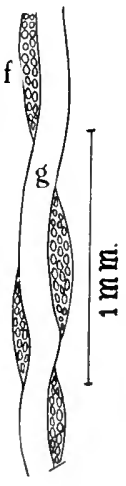

Fir. 102.-Camera lucida, low-power drawing of tangential section of wood of Liriodendron tulipifera. showing frequency of contact of medullary rays with a tracheal tube. $f$, medullary ray; $g$, tracheal tube.

be about thirty rays in a single square millimeter. These rays are thickly scattered amongst the other tissues and with great frequency come into contact with the tracheal tissues and wood parenchyma. The rule is that every ray touches one to many tracheal tubes, and when in longitudinal sections of wood a tracheal tube is examined along its length it is found that it comes into contact with about thirty rays for every centimeter (Fig. 102). These rays not only extend into the wood but also 
to greater or less distances out into the bark between the phloem bundles, and they are therefore in position to take on food as it travels from the leaves through the phloem, and to store it within themselves, or to deliver a part of it to the wood parenchyma for storage. And when the period of storage is over, the rays are in position to deliver the food to the tracheal tubes for quick transportation toward the crown where unfolding buds and flowers and fruits are in need of it (Fig. 94).

The medullary rays in the wood store non-nitrogenous foods in much greater abundance than the nitrogenous, and usually in the form of starch, and these ray cells must therefore possess many active leucoplasts which seize upon the food as it comes in solution and change it to the insoluble condition before it, or more than a fraction of it, has a chance to enter the tracheal tubes and be swept back toward the leaves whence it came. It will be seen that the physical conditions would impel the dissolved food after entering the ray cells to pass on into the adjoining tracheal tubes by diffusion
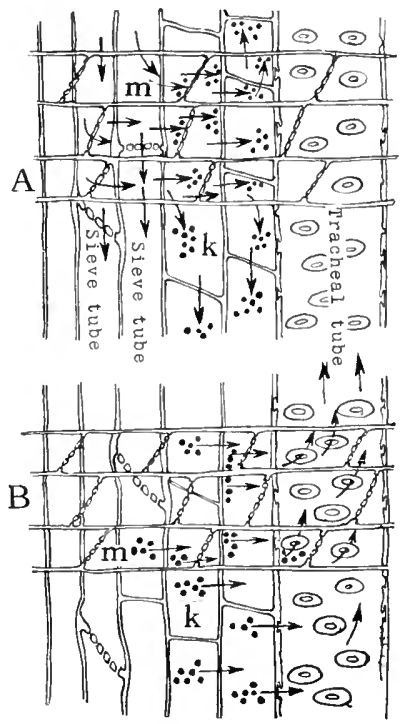

Fig. 103.-Diagram to show food from the leaves descending through the sieve tubes and being stored in the medullary ray cells and xylem parenchyma, in $A$; and the digestion of the stored food and its ascent through the tracheal tubes when growth is resumed in the spring, at $B$. In both diagrams the black bodies indicate stored food; that at the points of the arrows is being stored, and that at the base of the arrow's is being ligested and carried away. (see page 94), unless it were rendered insoluble, or the plasma membrane imposed its interdiction (see page 92). It may well be that the plasma membranes of the ray cells play an important part in this way; but if they do they alter their behavior when growth is resumed in the spring, for they then allow the digested food to pass freely into the tracheal tubes (see Fig. I0,3). 
The phloem part of the medullary rays passes most of the nonnitrogenous foods that come to it over to the xylem part or to the pericycle and cortex for storage, and reserves the bulk of the nitrogenous forms for itself. This fact stands sharply out when a cross section of stem taken in autumn or late summer is placed in a drop of iodine solution. The part of the rays between the phloem strands is then colored yellowish or brown because of its proteid content, and the xylem part is blue or almost black, due to the abundance of its starch.

The wood parenchyma, which is the predominant tissue in the xylem of many herbaceous plants, and occurs in greater or less abundance in the wood of trees and shrubs, assists the medullary rays in the storage of non-nitrogenous foods, and almost the whole of fleshy roots and stems is composed of these two tissues, which there maintain the storage function.

So long as the medullary rays and wood parenchyma remain living they retain the power and habit of storing food. In trees that have heartwood and sapwood all tissues are dead in the heartwood. In other kinds of trees where heartwood is not formed the medullary rays and wood parenchyma may be alive from bark to pith, even in trees that are fifty or more years old. The rule is, however, that most of the stored food occurs in the younger parts of the wood.

The phloem parenchyma, like the phloem part of the medullary rays, stores up nitrogenous food reserves, and apparently for this purpose it is longer-lived than the other tissues of the phloem, living on sometimes for ten years or more when the sieve tubes and companion cells produced at the same time have long since died.

The thin-walled parenchyma cells of the cortex and pericycle store up both nitrogenous and non-nitrogenous foods, and with them in this the collenchyma is often associated, and altogether they constitute a very significant part of the storage system.

Fluctuations in the Solubility and Insolubility of Stored Food. - When the leares of woody perennials have finished 
their work and shrubs and trees stand bare and apparently inactive it might be conjectured that their store of food would wait unaltered for the return of spring; but this is by no means the case, for part of the food is rendered soluble and apparently is used in respiration throughout the dormant period, and the greater part may be changed from insoluble to soluble and back again as the outside temperature falls and rises. The maximum amount of starch is found in the fall, for a large percentage of starch in the bark is changed to sugar or oil during the winter, and in softwood trees and shrubs the same thing happens in the wood. In hardwood trees the change is not so great in the wood. A rise of temperature during the winter or early spring incites a change back to starch again.

Digestion of Stored Food.-The forms in which foods are stored are suited as a rule to their safekeeping, but not to their distribution and use. Most foods are stored in an insoluble form such as starch, oil, and the majority of proteids, and only a few in their storage form are capable both of diffusion and assimilation, as glucose and saccharose. The chemical processes by which stored foods are made soluble, diffusible, and assimilable are called digestion.

In carrying on digestion the protoplast usually employs to do this work a proteid body known as an enzyme or ferment which it has made apparently by a process of self-decomposition that we call secretion; and of these enzymes the protoplasts may possibly make as many kinds as there are varieties of food to be digested; and it is also possible that the protoplasts sometimes incite digestion without the intervention of an enzyme.

Free oxygen is necessary to the formation of enzymes, and these work best at warm temperatures ranging from $20^{\circ} \mathrm{C}$. to $60^{\circ} \mathrm{C}$. according to the variety; they are also more effective in the dark than in the light, since light, particularly of the violet end of the spectrum, tends to destroy them.

It is not known just how the enzymes act in digestion. They incite the necessary chemical changes, but hold themselves 
apart so that they are not themselves destroyed in the process. The result of this is that a small amount of enzyme can digest a relatively very large quantity of food, even up to 100,000 or more times its own volume.

Some of the many kinds of ferments produced by plants have been classified and named. Thus diastase converts starch into maltose (malt sugar). Maltase converts maltose into glucose (grape sugar). Inulase converts inulin into fructose (fruit sugar). Inertase splits saccharose (cane sugar) into glucose and fructose. Cytase changes cellulose to glucose. Pectase changes pectic substances in the cell-wall to regetable jelly. Emulsin and myrosin are representative of enzymes acting on glucosides and breaking them up into glucose and other substances.

A group of enzymes known as lipascs or steapsins split up fats and oils into fatty acids and glycerine. The enzymes,
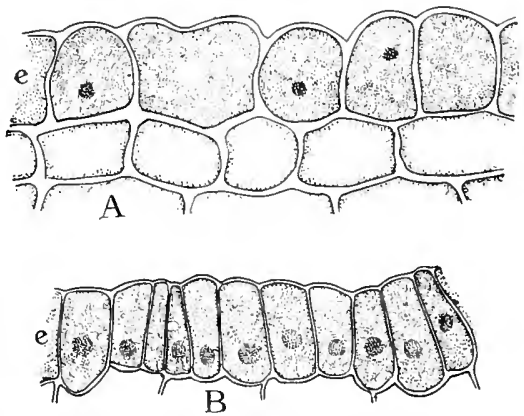

Fis. ro4.-Enzyme-secreting cells of date cotyledon at $A$; and of cotyledon of Infian corn at $B$. The secreting cells are at $\epsilon$. called proteolytic cnzymes, that digest proteids are similar to the pepsins and trypsins of the stomach and pancreas of animals. The pepsins change proteids to the soluble peptones, and trypsins convert peptones or proteids directly into amido-acids. The trypsins are the more common of the proteolytic enzymes in plants.

These enzymes occur in every cell where the food that they are fitted to digest is stored even transiently. In fact, diastatic, inverting, and tryptic enzymes are so common that they seem to be a part of every protoplast. There are, however, in special cases, cells or groups of cells devoted to the secretion of enzymes, as in the root of the horse-radish; and in the whole family of grasses the epidermis of the cotyledon secretes enzyme: 
which help to digest the reserve food in the endosperm, and the same thing occurs in the date jalm (Fig. Iof).

Glands devoted to the secretion of enzymes occur in Drosera, Dionæa and Nepenthes (Fig. I05), but in these instances the enzymes do not act upon food stored within the plant, but upon insects, and the glands are comparable to those in the alimentary canal of animals.

It seems that the enzymes do not reach the maximum amount in the cells until the process of digestion is well started, and it is for this reason that more diastase can be extracted from sprouted than from unsprouted barley. The mere presence of the enzymes is, however, not enough to start digestion going; rather the impulse to grow and the actual inception of growth creating a demand for food seems to supply the stimulus that puts digestion in motion. Such procedure would of course be a vital one initiated by the living protoplast.

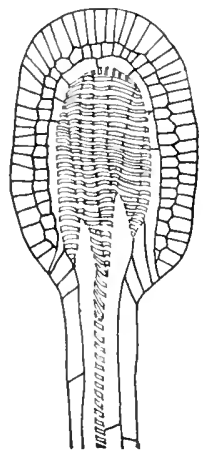

FIl: ro5.- Longitudinal section through a digestive gland of Drosera rotundifolia. (After de Bary)

Assimilation of Food.- We must keep in mind the fact that the proteids, oils, starches, sugars, and other kinds of food have two distinct uses: to furnish chemical elements for the construction of the protoplasts and cell-wall, and other special and useful products, such as nectar, aromatic oils, and enzymes, and to supply energy in the form and place needed to keep the vital machinery in motion. That food which is taken on by the protoplast and made a part of its own body is assimilated. We say that the food is lifeless but the protoplast is living. Necessarily the food passes from the lifeless to the living condition by something that the protoplast does with it. In this process the food loses its identity. Sugar, oil, soluble proteids, etc., enter into new combinations resulting in the formation of protoplasmthe living substance. An attempt to explain how this most wonderful of transformations takes place would be the merest speculation. We know nothing profoundly about it. To 
begin with, we know very little about the sequence of steps in the formation of even lifeless proteids from simpler substances, and protoplasm is supposed to be a complex aggregation of proteids, water, and other possible compounds. When we speak of life we have in mind a kind of energy manifested by the protoplasm alone. We may conceive of this manifestation as being due to a combination of certain rates, amplitudes, and paths of vibrations of the protoplasmic molecules or structural units. When new structural units are built from the food they would be suited to the same mode of motion as the others and they would presumably assume this mode because they are under the same conditions as the others. If this conception were true so far as it goes it offers nothing to clear up the great mystery of the creation of living from lifeless matter. That, however, the protoplasm has power to build its own substance by combinations of different kinds of food and that the application of this power is self-regulating, resulting sometimes in growth, at other times in merely maintaining a balance between destruction and construction, is satisfactorily established.

Relation of Stored Food to Energy Supply.-The energy which plants draw upon to keep the vital activities going comes to them from the sun through the food. It seems that the facts are about as follows: 'The sun's energy is used by the chloroplasts to build carbohydrates. A part of this is decomposed, yielding energy for the construction of proteids from carbohydrates and other substances. Other parts of the carbohydrates and some of the proteids are oxidized, or broken down in other ways, yielding energy for the formation of protoplasm from proteids, etc. Some carbohydrates, proteids, and a part of the protoplasm itself are broken down and energy is thus set free for doing whatever the protoplast as a living agent has to do.

This line of activities traces the source of its energy directly back to the sun. The food, as well as the protoplasm, has sun's energy stored up in it ready to be set free for doing work and subject to the direction of the protoplasts. The construc- 
tion of food is in a manner similar to the winding of a weight, and when the food or the protoplast is decomposed the resulting readjustment of the elements keeps the vital activities going, just as the falling of a weight may set and keep in motion a train of wheels, etc. More than 90 per cent. of the energy released in respiration appears as heat, and the remaining energy probably manifests itself for the most part in chemical reactions attendant on growth, repair, secretion, and other constructive processes.

The Storage of Water.--The need of plants for special water-storage tissues is not so general as their need for tissues in which to store food. Under ordinary conditions water can be freely taken in from the soil which serves as the water reservoir for plants. But plants of desert regions or growing anywhere under xerophytic conditions (conditions making water hard to get, as when it is actually scarce or difficult to absorb because of low temperature in the substratum, or because there are substances in solution in amounts large enough to act as a poison or to retard the osmotic inflow into the roots) to which this reservoir is

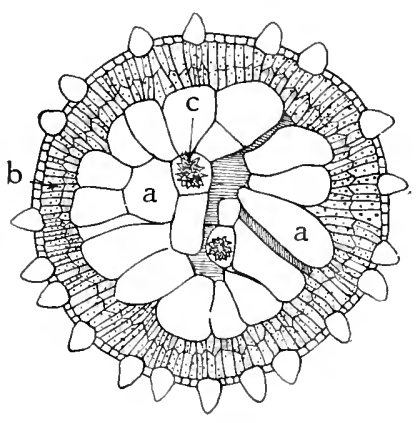

Fig. Io6.-Cross section of leaf of Mesembryanthemum Forskalii showing a large part of the leaf devoted to the storage of water. $a$, water-storage cells; $b$, chlorophyllbearing cells; $c$, crystal of calcium oxalate. (After Schimper.)

denied or more or less inaccessible, have hit upon various compensating devices. One of these is the water-storage tissue. This is seen in its fullest development in succulent stems and leaves. In Mesembryanthemum Forskalii of the Egyptian desert approximately one-half of each succulent leaf is made up of water-storage tissue (Fig. IO6); and in epiphytic species of Codonanthe growing on a dry substratum nearly three-fourths of the fleshy leaf is occupied by cells devoted to the storage of water (Fig. 8r). The fleshy stems of cacti and some Euphorbiaceæ are largely composed of the same kind of tissue. In the leaves of Ficus elastica the protoderm of the upper surface 
dixides tangentially and gives rise to several cell-layers constituting a typical water-storage tissue (Fig. 79).

Water-storage tracheids sometimes occur as terminals of the finer branches of leaf reins, as in Euphorbia splendens and 'Townsendia cespitosa (Fig. I07); and occasionally the mesophyll cells have the characteristic wall thickenings of tracheids and apparently serve in water storage. 'The tubers of the potato and other fleshy underground parts serve for the storage of water as well as of food.

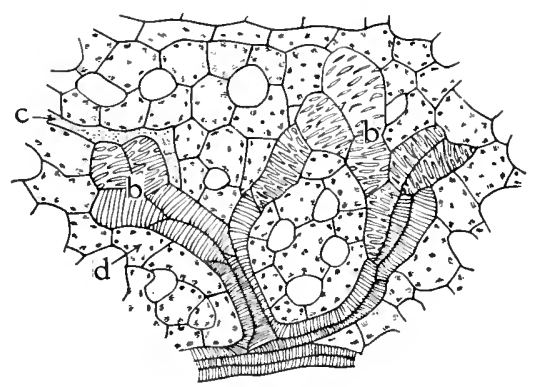

F1r, 107,--Water-storage tracheirls in the leaf of Euphorbia splendens. $b, b$, waterstorage tracheids; $a$, mesophyll cells; $c$, branch from a milk tube. (After Haberlandt.)

Frequently, and especially in xerophytes, cells or groups of cells contain mucilage as a real cell content or as much thickened cell-walls, the inner layers of which have become transformed from cellulose to mucilage. Mucilage has a great affinity for water, imbibing it with power and holding it with great tenacity. When the amount of mucilage is considerable, as is frequently the case in desert plants, such as the Aloes, cacti, certain species of Astragalus, and many others, it plays an important part in the water-storage function.

Characteristics of Water-storage Tissues.-The waterstorage cells are characterized by having thin cellulose walls, or walls, if thickened, haring many pits or thin places. These cells readily imbibe water when plenty is at hand, and when the soil water is scarce they deliver their stores gradually to those tissues, such as the photosynthetic and meristematic, in 
which the scarcity of water would be most harmful to the wellbeing of the plant; and the water-storage tissues keep on distributing their stores until they themselves are wilted while the tissues to which they are tributory are maintained in a fresh and turgid condition.

\section{Illustrative Studies}

I. Cut free-hand sections of potato that has lain for some time in 95 per cent. alcohol to harden it. Mount the sections in a drop of water and after studying them with low and high powers let a drop of iodine solution diffuse under the coverglass. Starch grains will be colored blue to black and proteids yellow. The cell-contents can be seen to best adrantage around the thinnest edge of the section, but there they will have dropped out to some extent and study of a thicker part of the section may be necessary to find out how densely packed are the cells with reserve food. Draw a few cells with their contents. Measure the starch grains.

2. Study in a similar manner thin sections of soaked lima bean. Notice how the striations of the starch-grains differ from those of potato starch. Notice the very distinct granules of proteid stained yellow to brownish by the iodinc. Draw a few cells with their contents, and measure the grains of reserve food.

3. Cut with a dry razor free-hand sections of the endosperm of castor bean and transfer them to a watch glass containing 95 per cent. alcohol 2 parts and castor oil I part and enough eosin to make a light red solution. After a few hours mount the sections in ricinus oil-alcohol without the eosin. 'T'his treatment will bring the aleurone grains out clearly and reveal their several parts (page I82); and it will show the grains to be imbedded in the meshes of the cytoplasm. Draw a few cells to show this, and on a larger scale a single aleurone grain in all its details.

Put other sections for several hours in alcanna tincture (page 
285 ) and mount them in a drop of dilute glycerine. The oil will be stained pink. Notice how it gathers in droplets of various sizes around the edges of the section, and the abundance of it in the uninjured cells.

4. Test the endosperm of germinating and ungerminated castor bean for glucose (see under Copper Acetate and Fehling's solution in Chapter $\mathrm{N} Y \mathrm{I}$ ). How do you interpret the results?

5. Examine with a high power in a drop of water starch from ungerminated and germinating barley. What evidence do you find that starch is digested during germination?

Test both germinating and ungerminated barley for glucose by crushing the grains and boiling them in Fehling's solution.

6. Cut free-hand or on a sliding microtome cross and longitudinal radial and tangential sections of grape stem. Mount the sections in glycerine-iodine (see under Glycerine and Iodine in Chapter XYI). Note the extent of the storage of starch and proteids in phloem, medullary rays, and wood parenchyma. Other woody stems will do, but the graperine is especially fine for showing this. Make drawings from each region of a few cells with contents.

7. Make thin cross sections of rubber leaf and mount them in dilute glycerine. Note the clear tissue between the epidermis and palisade cells. This is for the storage of water. Make a diagrammatic drawing of the leaf expressing the proportion of leaf deroted o water storage.

8. Cut tangential sections (see Chapter $\mathrm{X}$, page I73, par. 2) of a sunflower leaf and mount them in dilute glycerine. The large clear cells are water-storage cells. Draw a few of these cells with the surrounding mesophyll tissue. 


\section{CHAPTER XII}

\section{SECRETION AND EXCRETION}

Nature of Secretions and Excretions.--Secretions and excretions are distinguished from the reserve food told about in the last chapter by their evident uselessness in supplying materials and energy for growth, repair, etc. They therefore, for the most part, remain practically unchanged in special cells or tissues, or are eliminated from the cells by excretion at the surface of the plant or into intercellular spaces. Sometimes they have a biological function, as in the case of nectar, and sometimes a physiological function, as in the case of enzymes, and organic acids excreted by the roots.

By far the larger number of plant secretions belong to the class of ethereal oils and resins. These occur together, the resins dissolved in the oils and forming oleo-resins. When the oil evaporates, as it normally does in time, and can quickly be made to do on heating, the resins are left behind as a solid residue.

The amount of resin present varies greatly, from the merest traces in many epidermal glands to more than 70 per cent. in some of the Coniferæ.

The fragrance of these secretions is due to volatile sulsstances entering into the composition of, and even forming a very large part of, the oils, as, for instance, eugenol in clove oil, safrol in oil of sassafras, and cinnamon aldehyde in oils of cinnamon and cassia.

Turpentine, produced chiefly by the Coniferæ, is the most abundant of the oleo-resin secretions. On distillation this yields oil of turpentine of commerce and resins varying in character with the different genera producing them.

No sharp line can be drawn between secretions and excretions as these words have come to be used in physiological litera- 
ture. So long as the substance is in the cell that formed it we are apt to think of it as a secretion, but as an excretion when it is eliminated from the cell into intercellular spaces or at the exterior. The significance of these terms will be better apprehended by means of their particular application as we proceed.

Secreting Cells and Glands in General.-Probably all living cells secrete digestive and oxidative enzymes, and all cells secrete their cell-walls; but in certain numerous families of plants we find single cells or groups of cells called glands that carry on secretion as their special function. The secreting cells are sometimes descended from the protoderm, and therefore belong morphologically to the epidermis, and sometimes they are descendants of the fundamental meristem and may occur in the cortex, pericycle, medullary rays and pith.
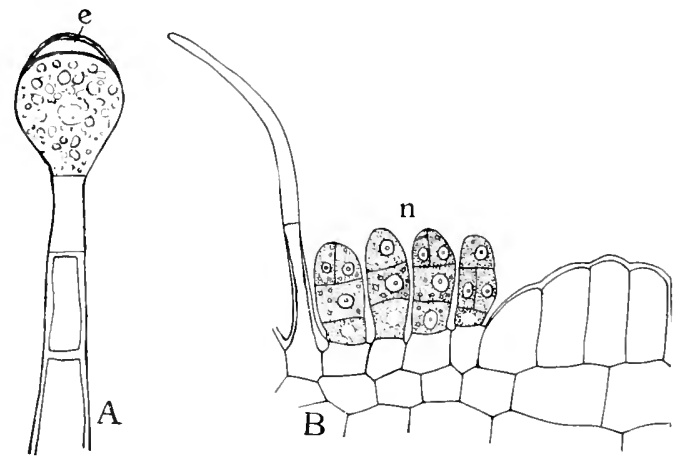

Fis. 1 os - clandulat hair from the petiole of Pelargonium zonale. $\epsilon$, secretion from the globular gland on which it rests; $B$, portion of a cross section through a nectariferous bract of Vicia sepium; $n$, nectar-secreting cells. (After Haberlandt.)

Less frequently we find them descended from the procambium and belonging to the phloem or xylem parenchyma, as in the case of some of the resin-secreting cells of Conifers.

There are three kinds of glands in regard to their location and form, namely, the superficial type which, descended from the protoderm, is borne at the outer surface and may rise above it in the form of hairs or scales; the interior globular type con- 
sisting of a more or less globular group of cells; and the interior tubular type in the form of a tube or canal. Glands belonging to the first type, commonly known as glandular hairs, arise by the tangential division of a protoderm cell producing a multicellular hair, the apical cell of which enlarges and becomes the secreting cell (Fig. Io8, A), or a group of secreting cells may compose the gland at the apex. Nectaries are usually of protodermal origin and their cells are frequently elongated radially in the form of papillæ (Fig. I08, B).

The interior globular glands arise by the division of a cell or group of cells, usually of the ground meristem, and where these glands lie near the surface the protoderm may by cell-division con-
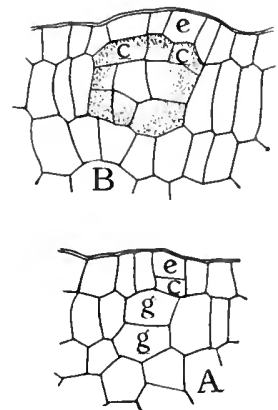

FIt; 10y. -Formation of an interior, globular, lysigenous gland of the leaf of Dictamnus fraxinella. A, g, g and $c$, mother cells of the gland; $c$, from the protoderm, and $g, g$, from the funiamental tissue. $B$, older stage where the cells have begun to form the secretion. The last stage is shown in Fig. I I 2 . (After Sachs.)

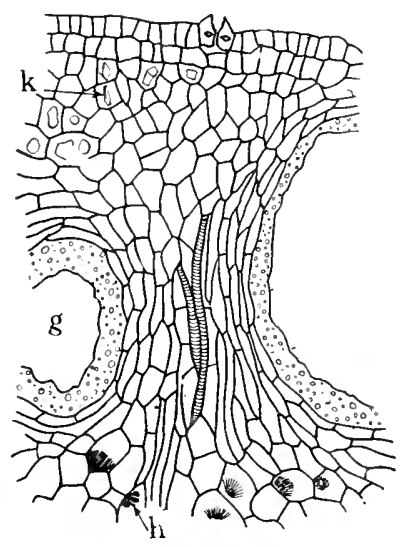

Fil; IIo.-Cross-section through a fortion of orange reel showing the cavity of an interior, globular gland at $g$; crystals of hesperidin at $h_{i}$ calcium oxalate crystals at $k$. (After Tschirch and Oesterle.) tribute cells to their formation (Fig. IO9); or sometimes the protoderm alone gives rise to the gland. Glands of the globular type are found in the clove, rind of orange and lemon, etc. (Fig. I IO).

An intercellular carity into which the secretions of the slandular cells are excreted is formed in one of two ways: The secreting cells may split apart at the center of the group and then draw or grow away from the line of separation, leaving an intercellular carity (Fig. III), or the secreting cells may break down altogether, leaving their secretions in the carity 
formed by their disintegration (Fig. II2). The first method of forming the intercellular space is schisogenous, and the second, lysigenous. Sometimes the two methods are combined by the space beginning schizogenously and then being enlarged
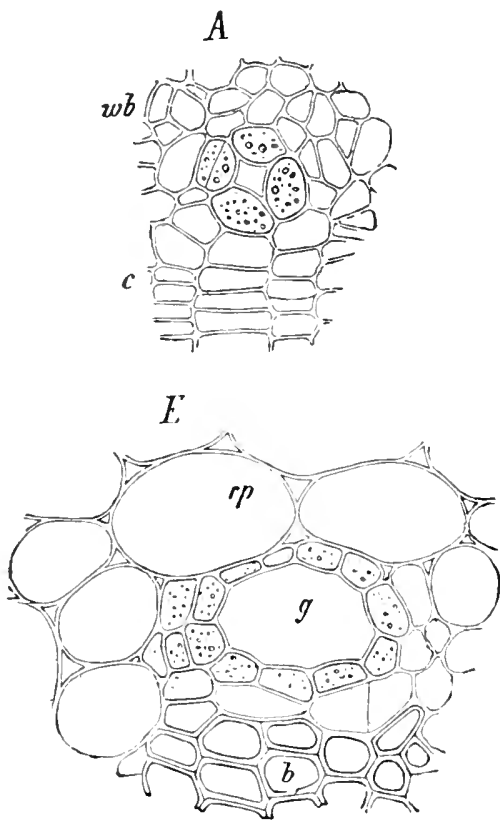

FIG. I I 1 - - Schizogenous resin duct in the young stem of ivy (Hedera helix), as seen in cross section. A, early, and $B$, later stage in the formation of the duct. $g$, the mature duct; $c$, cambium; $w b$, phloem; $b$, bast fibers. (After Sachs.)
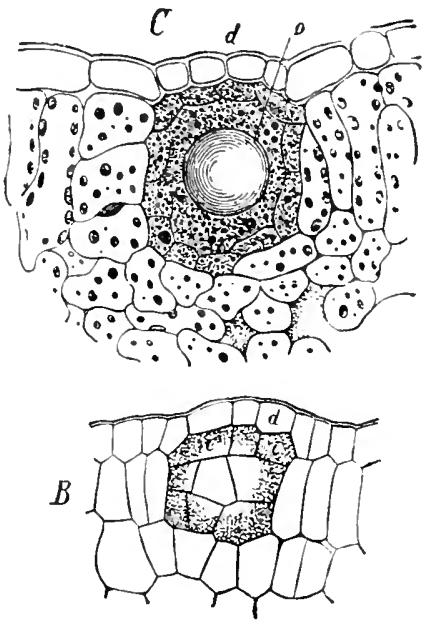

Fic. I $12 .-$ Lysigenous gland in the leaf of Dictamnus fraxinella. $B$, young gland, with cells beginning to secrete oil; $C$, mature gland where the secreting cells have broken down and left their secretion within the cavity thus formed; 0 , large drop of secreted oil. (After Sachs.)

lysigenously, and to designate this method the term schizolysigenous is compounded.

Interior glands of protodermal origin solely are found in Amorpha, Myrtus, Eugenia, Asarum, Croton, Crotonopsis, and some species of the Moracex, Urticacex, Acanthacex, Saxifragacex, Crassulacex, Geraniacex, and other families. By far the larger number of interior glands, however, are formed by the ground or fundamental meristem. 
Interior tubular or canalicular glands are formed in essentially the same manner as the globular. A circular group of cells as seen in cross section, and a long vertical row as seen in longitudinal section, forms an intercellular space schizogenously or lysigneously at its center throughout its length. If formed schizogenously the secreting cells form a sheath around the intercellular canal as seen in Fig. I I3, and into this canal
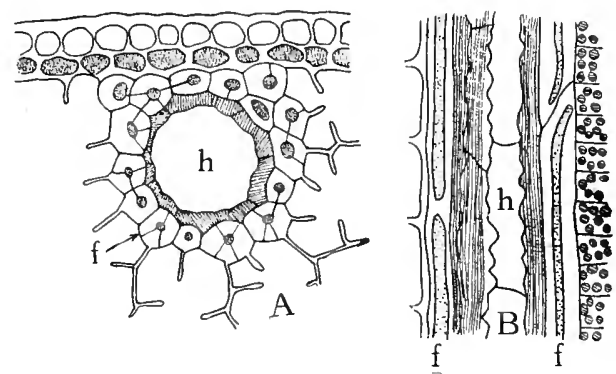

FIG. I I3.- Resin duct in leaf of Pinus silvestris, in cross section at $A$, and in longitudinal section at $B ; h$, cavity surrounded by the secreting cells; $f, f$, sclerenchyma fibers surrounding and protecting the duct. (After Haberlandt.)

are excreted the secretions of the sheath cells. Fine examples of tubular canals are found in the needles and stems of pines.

In the few instances where the tubular glands are differentiated from procambium strands they have the same method of formation as have those from the ground meristem. The tubular glands often branch and anastomose and thus form a complex glandular system.

Laticiferous Vessels or Milk Tubes.-The milk tubes occurring in many families of plants form a much-branched, richly anastomosing system extending practically throughout the whole plant (Fig. IIf). They have two methods of origin. In the Lobeliaceæ, Cichoriaceæ, Papaveraceæ, Campanulaceæ, Papayacer, and a few Euphorbiacex, and many Musacex and Aroidex they are formed by cell fusions which take place early in the primary meristematic condition by digestion of separating walls. The anastomoses which unite the tubes into practically 
one system are formed also by cell fusions, or sometimes by outgrowth of branches from the tubes which push their way

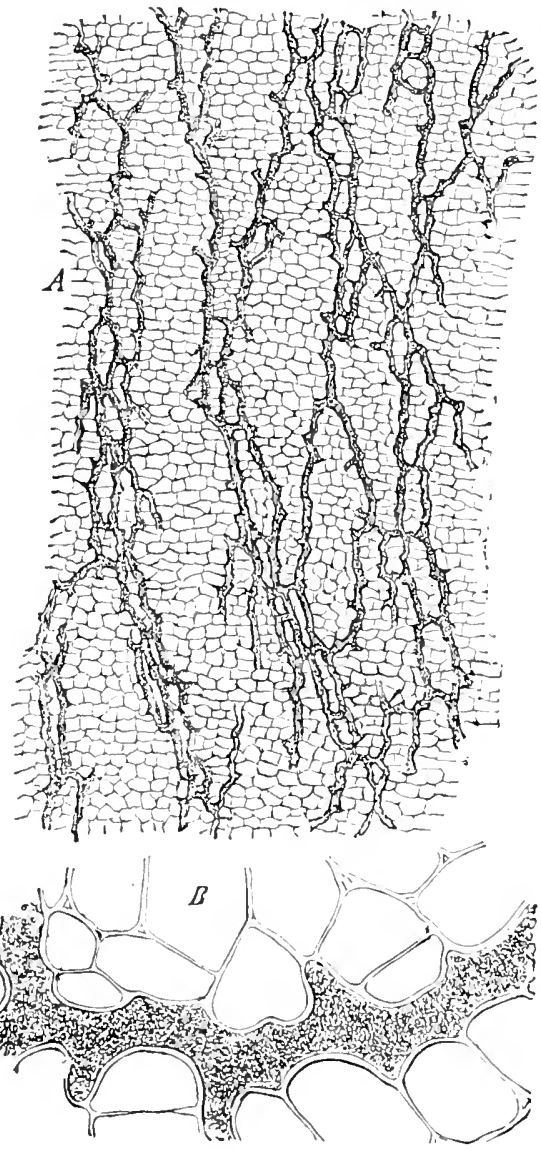

FIG. II 1.-Laticiterous vessels from the cortex of root of Scorozonora hispanica. A. as seen under low power, and $B$, a smaller yortion under high power. (After Sachs.) through intervening tissues and fuse with other tubes or branches.

In the Urticacex, Asclepiadaceæ, Moracex, most Euphorbiacere, and Apocynacee each tube arises from a single meristematic cell which elongates and branches, keeping pace with the growth of the plant, and fusing its branches with those from other tubes and thus forming an intercommunicating system, so that when a wound is made the milk pours forth abundantly.

The milk tubes remain living for a long time and probably take an active part in the production of the very complex latex or milk. which may contain plastic or food substances such as sugar. oil, starch, proteid, and aplastic or non-food substances such as tannins. alkaloids, some varieties of gum, caoutchouc, resins, and salts of calcium and magnesium. Some of these may be mere excretions of useless substances from other tissues, and some of them may be 
products of the tube itself destined for the useful purpose of healing wounds and giving immunity from parasitic attacks, while others are clearly foods which find in the tubes an efficient means of distribution.

Tannin Cells.- Tannin cells are found in various families of plants. They occur as single isolated cells or in small groups. The cells are approximately isodiametric or in various degrees of elongation. The longest known occur in the genus Sambucus, where they become twenty or more millimeters in length and sometimes extend through an entire internode.

Tannin cells are found in the epidermis, primary cortex, pericycle, phloem, medullary rays, and in the mesophyll of leaves. They occur in greatest abundance in the cortex and in the tissues of galls. Tannins seem to be by-products set aside in the tannin cells from the general circulation. It is uncertain whether the tannins are ever used to an appreciable extent in nutrition. They seem to be of service, however, in warding off parasites by their aseptic qualities and astringent taste.

Special Enzyme-Secreting Cells.-In the Cruciferæ, Capparidacex, and a few other families are found special cells deroted to the secretion of enzymes, such as myrosin. The pungency of these plants is due to allylic mustard oil, produced, it is said, at the moment of injury to the plant by the action of myrosin on the glucoside potassium myronate which is associated with the ferment. Glucose and potassium sulphate are other products of this reaction.

The digestive glands of insectivorous plants are unique in that their secretions digest animal tissues and are stimulated to activity by the presence of the captive. On the upper side of the leares of Pinguicula are two kinds of glandular hairs, a long-stalked form secreting a sticky mucilage which holds fast the prey, and a short form, hardly appearing above the epidermis, which, when an insect is captured, secretes and pours forth a digestive enzyme (Fig. I 15). The short glandular hairs on the leaves of Dionæa muscipula behave like those of Pinguicula. 
In the pitchers of the genus Nepenthes unstalked digestive glands occur on the inside near the bottom. These pour forth an abundance of a mucilaginous digestive fluid the water for
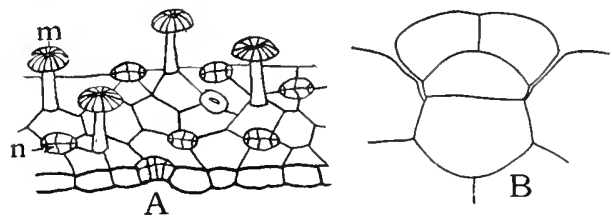

FIG. II5.-Glands from Pinguicula. A, upper surface of leaf showing long-stalked gland at $m$, and short-stalkeu gland at $n$. $B$, cross section through a short-stalked gland. ( $A$, after Kerner, and $B$, after Haberlandt.)

which is supplied to the gland by a bundle of tracheids extending close up to the base of the gland.

The most highly differentiated glands are found on the leaves of Drosera rotundifolia (Fig. 105). Here the gland proper, which is borne at the apex of a slender stalk, is composed of a bundle of tracheids surrounded by three layers of cells. The outer two layers seem to be especially concerned in producing the secretion. The cuticle is permeable, and ordi-
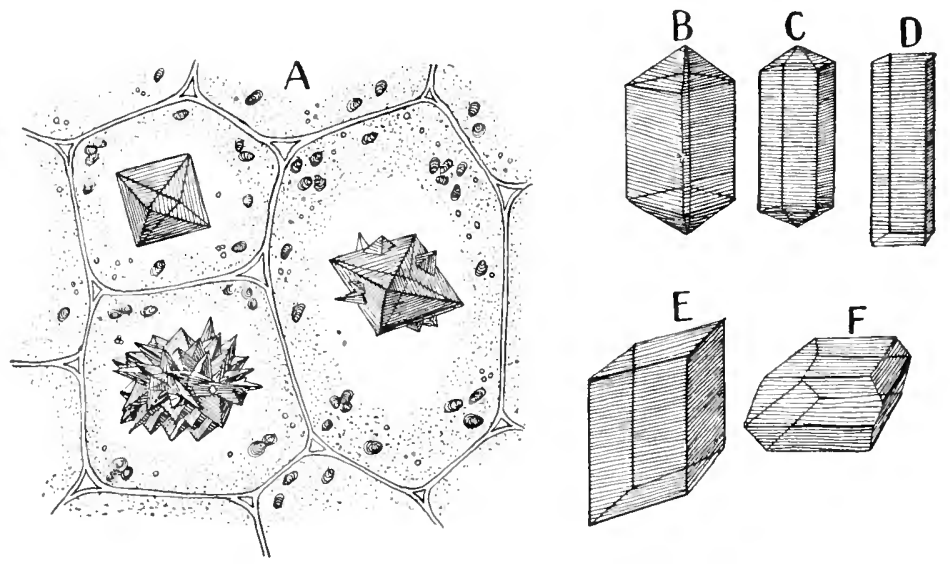

Fro. I r6.-Different forms of crystals of calcium oxalate. A, from the petiole of Begonia manicata. (After Frank.)

narily an acid, sticky secretion is excreted at the surface in which the feet of insects alighting on the surface become entangled. The capture of an insect stimulates the glands to secrete and 
pour forth more acid, and an enzyme similar to animal pepsin, by means of which the insect is digested.

Secretion and Excretion of Minerals.-In some plants single cells, and strands or layers of cells forming a more or less extensive tissue, are deroted to the secretion and excretion of calcium oxalate crystals-excretion in the sense that while the crystals remain within the body of the plant and are contained within cells they have been set apart by themselves where, as a rule, their isolation continues throughout the life of the plant. The calcium oxalate crystals occur singly or in groups in a single cell, and either as simple or compound crystals, as shown in Fig. I 6 . The forms and association of the crystals may be influenced by the strength of the solution in the cell-sap; but evidently the protoplast has a very important influence, for in certain cells and tissues only one kind of crystal may occur, as in the case of the acicular crystals in Tradescantia, Pistia, Arisæma, etc.

A secretion of relatively rare occurrence is that of calcium carbonate in the cystolith cells of some Moraceæ, Urticaceæ, and Acanthaceæ, occurring commonly but not solely in the leaves. Following the development of
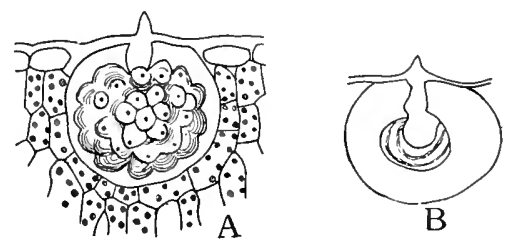

FIG. II7-Cystoliths from the leaf of Ficus carica. A, complete cystolith; $B$, cystolith from which the calcium carbonate has been remored for use in other parts of the plant. $B$ is from a leaf that had fallen off in autumn. (After Haberlandt.)

a cystolith it is found that the outer wall of an epidermal cell, for instance, grows down into the cell cavity, swells out at the end and there becomes warty at the surface (Fig. II7).

When a cystolith is treated with hydrochloric acid it quickly diminishes in size with the evolution of bubbles of $\mathrm{CO}_{2}$, showing that calcium carbonate is being decomposed. At the completion of the reaction a skeleton of cellulose remains. The cystolith is therefore a cellulose outgrowth of the wall infiltrated and encrusted with calcium carbonate. In nature the calcium carbonate of the cystolith comes and goes, and its secre- 
tion seems to be a method of accumulating it for use at some future time.

The Process of Secretion.-Secretion is evidently a vital process, that is, it is carried on by the living protoplasm. The substances may be formed directly from foods, or from the disintegration of the cell-wall, or from the decomposition of the protoplasm itself. It is possible that sometimes all of these methods are employed by a single cell or gland. The distinctive behavior of the cytoplasm of some secreting cells is eridence that it produces the secretion by self-decomposition; for, preparatory to secretion, the cytoplasm becomes relatively very dense and granular, and as secretion sets in this density diminishes, until, when secretion stops, the cytoplasm has become very much depleted. In some Rutacex the cytoplasm and nucleus of secreting cells disappear altogether.

In some instances the evidence is very clear that the secretion has been formed from the substance of the cell-wall, where the
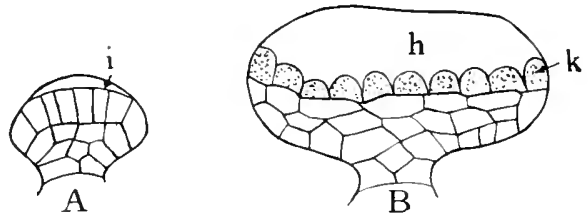

FIG. I 18. Glands from the leaf of Ribes nigrum. $A$. young stage in the development of the gland where the cuticle is already being pushed up by the secretion, $i . \quad B$, complete gland; $k$, secreting cells; $h$, cavity between the secreting cells and cuticle occupied by the secretion. (After Haberlanult.) secretion appears just beneath the cuticle, and accumulating, pushes the cuticle off from the wall, as seen in Fig. I 8 . Secretions of mucilage and of ethereal oils and resins take place in this way. Of course the secretions do not necessarily come entirely from the substance of the wall, for it is possible that the protoplast makes a part of the secretion directly without first repairing the wall preparatory to decomposing it.

The Excretion of Liquid Water.-On summer nights "dew" hangs in droplets at the tips and along the edges of leaves of grass and many other kinds of plants. It was long supposed that in all cases these droplets were real dew formed from condensation from the atmosphere, but that this is by no means always the case is shown by chemical analysis of the 
drops, by the anatomy of the leaves where the drops occur, and by physiological experiment, as will now be set forth.

Droplets from the leaves of Indian corn on evaporation leave behind .05 per cent. of solid residue, from leaves of Brassica cretica I per cent., and so on for different plants; and on incinera tion I 5 to 50 per cent. of this residue turns out to be ash. Real dew being distilled water could not be expected to give such results.

Sections through a leaf where the droplets occur are found under al microscope to have specialized cells or groups of cells having the appearance of glands. These have been named $h_{l}$ datodes. One of the simplest of these is found on the upper and under surfaces of the leaves of Gonocaryum pyriforme, where each hydatode consists of a single epidermal cell differing from the rest in several details, as shown in Fig. i I g. A portion of the outer wall grows out and forms a slender projection traversed longitudinally by a canal extending from the mucilaginous apex to the cell cavity. The cell cavity is broad and funnel-shaped in its upper part, and again broadened below the neck of the funnel. As is the rule with
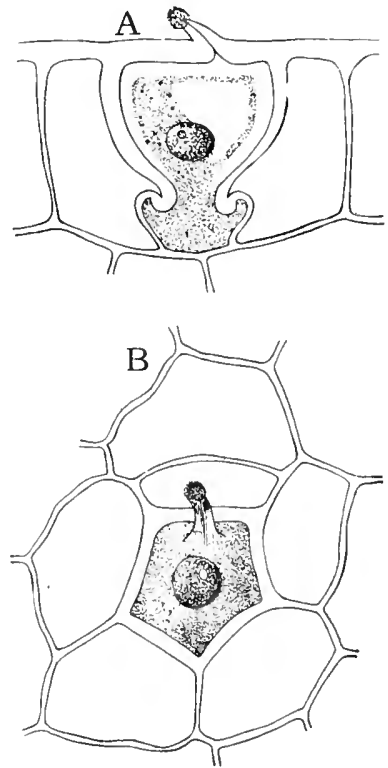

FIG. Im - One-celled hyclatode of Gonccaryum pyrifurme, seen in cross section at $A$, and from the surface in $B$. After Haberlandt.)

secreting cells, the cytoplasm is unusually dense and the nucleus relatively large. In this instance water is absorbed by the hydatode from surrounding epidermal and subepidermal cells and excreted through the narrow canal in the exterior projection.

On the under side of the leaves of Phaseolus multiflorus are curved hairs, as shown in Fig. I 20, with outer walls thin and but little cutinized through which water filtrates and is excreted at the surface. 
In another class of hydatodes bundles of tracheids from the terminations of the vascular bundles supply water to waterexcreting parenchyma cells or themselves excrete water directly

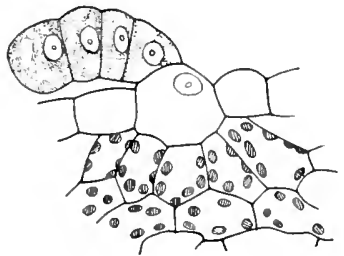

Fig. 120 - Hydatode from the leaf of Phaseslus multiflorus. (After Haberlandt.) into intercellular spaces. Hydatodes of this sort are not uncommon in ferns where they occur chiefly along the leaf margins. This type reaches its highest development where waterstomata are present in the epidermis through which water excreted into the intercellular spaces is expelled. This is illustrated by Primula sinensis where the hydatodes occur in the teeth of the leaf margins (Fig. $\mathrm{x} 2 \mathrm{I}$ ).

Physiological experiments show that many hydatodes excrete water through the activity of their living cells, since excretion stops after they have been killed by brushing over with a solution of corrosive sublimate, and they cannot then be forced to excrete water even when the pressure in the tracheal tubes is made very great by connection with a U-tube with its long arm filled with mercury. The majority of hydatodes equipped with stomata will still excrete water, however, after they have been poisoned, and by artificially increasing the pressure in the tracheal system excretion of water is hastened.

The amount of water excreted by hydatodes is often remarkably large. A young leaf of Colocasia nymphæfolia gave out 48 to 97 cubic centimeters of water in one night, and a mature

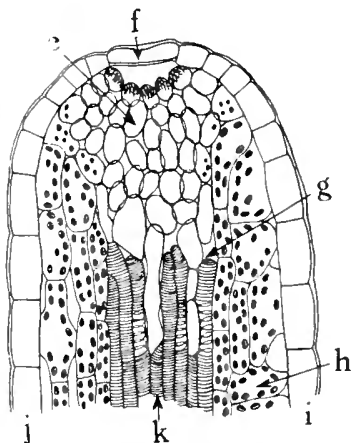

FIG, I 21,-Radial longitudinal section through a hydatode from the leaf margin of Primula sinensis. $i$, upper, and $j$. lower epidermis; $h$, palisade cell; $e$, thin-walled parenchyma, called epithem; $g$, intercellular space; $f$, guard cell of a water stoma: $k$, tracheal elements (After Haberlandt.) leaf of $\mathrm{C}$. antiquorum excreted on the average 9 to 12 cubic centimeters nightly.

The use of hydatodes seems to be that when transpiration 
is checked, as by the going down of the sun, while the absorptive activity of the roots is as yet undiminished, they may by the excretion of water prevent its filtration into the general intercellular system which should be kept open for the storage and circulation of the necessary oxygen and carbon dioxide. Hydatodes may take on other functions in special cases, such as the secretion of nectar or digestive enzymes.

\section{Illustrative Studies}

I. Put small segments of pine branch into a saturated aqueous solution of copper acetate, and after several weeks cut sections free-hand or on a sliding microtome and study them in a drop of dilute glycerine. Resin will be found stained an emerald green. Study longitudinal sections in the same way and draw the tubular glands from both points of riew.

2. Put a small handful of cloves into a widemouth bottle and pour water over them. Stopper the bottle with a perforated cork and insert a U-tube flush with the lower surface of the cork. Let the long arm of the U-tube extend deep into another bottle. Set the bottle containing the cloves into a basin of water kept boiling, and the other bottle into a basin of cold water kept cold by running water or with bits of ice added from time to time; this will condense the steam and oil that distils over. In this way the presence of volatile oil in the cloves can be demonstrated.

3. Soften cloves in water, cut thin sections and mount them in a drop of strong $\mathrm{KOH}$ solution. Numerous oil glands will be found, and possibly needle-shaped crystals of potassium caryophyllate formed by the reaction between the $\mathrm{KOH}$ and the clove oil.

4. Make thin sections of lemon peel hardened in 95 per cent. alcohol and inclosed for sectioning in elder pith. Note the globular glands in different stages of formation. How close to the surface do they come? Do any of them show an opening at the exterior? Draw one of the glands with the surrounding tissue. 
5. With a sharp knife cut germinating date seeds crosswise into slices about $2 \mathrm{~mm}$. thick and put them through the process of fixing, hardening, and imbedding in paraffin, and sectioning, described in Chapter XV. When it comes to staining the sections place the slide on which they are mounted, after the paraffin has been dissolved away in xylene and the xylene rinsed off with alcohol, in a dish of safranin (page 326) for a few hours, and then rinse out the surplus safranin in water, dehydrate quickly in 95 per cent. alcohol, rinse in xylene and mount in balsam. Study the epidermis of the enlarged cotyledon. These cells secrete enzymes for the digestion of the endosperm exterior to them. Draw a few of the secreting cells together with the adjoining cells of the cotyledon and endosperm, and by stippling indicate how the secreting cells differ in appearance from the others.

6. Soak grains of Indian corn over night and cut the thinnest possible free-hand sections across the embryo and endosperm. Mount the sections in dilute glycerine. Compare the appearance of the epidermis of the cotyledon with that of the date. These cells of the corn are also enzyme-secreting.

7. Scrape hairs from the surface of Pelargonium zonale or other plant bearing glandular hairs, mount them in a rirop of dilute glycerine and study them under high magnification. Draw some of the glandular hairs.

8. Study longitudinal sections of the stem of some milkwced or of the greenhouse Euphorbia splendens for laticiferous ressels. Make a drawing showing the branching and anastomosing habit of these vessels. Treat the section with iodine. Are there indications of starch and proteids?

9. Cut cross-sections through the cotyledons of acorns; examine them in water and allow a dilute solution of chloride of iron to run under the coverglass (see under Tannins in Chapter XVII). Note the indication of tannin in some of the cells.

Io. Cut cross-sections of the seed of Strychnos nux-romica and test them for alkaloids as described under Alkaloids in chapter ITII. 


\section{CHAPTER NIII \\ REPRODUCTION}

Is previous chapters we have dealt with the structural provisions for those functions that have to do with the nutrition and maintenance of the individual. We shall now find that the organization of the individual is not related to its own needs alone, but that it provides also for the continuance and progressive evolution of its race. This is accomplished by the sporogenous cells and tissues occurring in the ovules and anthers of the spermatophytes and in their homologues among the lower forms, by spores themselves, by gametes (sperm cells and egg cells), and by nurse cells having for their chief or only function the nutrition of the new generation, such as tapetal cells in sporangia, and antipodal cells within the embryo sac. These tissues are often meristematic it is true, but their purpose is so different from that of the vegetative meristems (see page 24) that they cannot be classed together. Those tissues which have reproduction for their chief or only function should be classed as Reproductive Tissues. For our introduction to tissues of this sort we cannot do better than to trace the derelopment of a fern sporangium.

Development of Fern Sporangium.-Figure I22 has been made from camera lucida drawings of a longitudinal section through the apex of a sporophyll of Aneimia phyllitidis. At $a$ is the primordial meristem of the growing apex, and at $b, c$, $d, e, f$, are successive stages in the formation of sporangia proceeding from this meristem. It appears that a sporangium has its beginning in a group of primordial cells such as is seen at $i$. These evidently divide parallel to the surface (periclinal division) and again perpendicular to the surface (anticlinal dirision), and the growth of the daughter-cells causes the enlargement which we recognize as the beginning of the sporangium, b. At 
a very early period of its develogment, $d$, we find the sporangium composed of a protoderm and a central cell. The protoderm proceeds to the formation of an epidermis or sporangium wall,

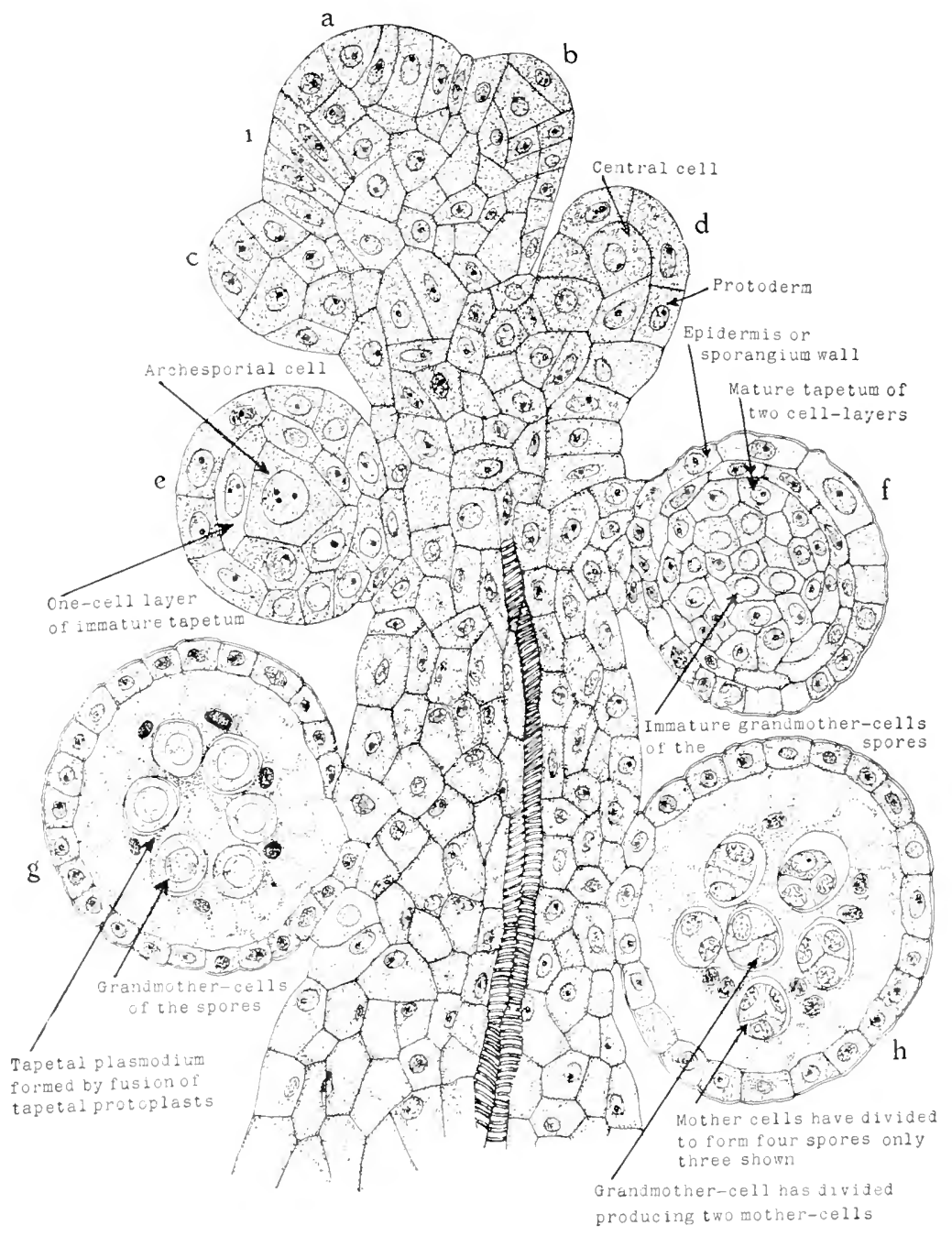

FIG. I 22.- Sporangium and spore formation of a fern, Aneimia Phyllitidis, $a$, growing apex; $i$, group of three protodermal cells which are to give rise to a sporangium; $b, c, d, e$, $f, g, h$, successive stages in sporangium and spore formation. Partly diagrammatic. Further description in the text. 
while the central cell gives rise to two distinct products, namely, an exterior tissue or tapetum averaging two cell-layers in thickness when mature, $e$ and $f$, and surrounded by this an archesporial cell, $e$, which is soon to give rise by division to a group of cells known as the sporogenous cells or grandmother cells of the spores, $f$ and $g$.

It is clear that the tapetal and sporogenous tissues must be classified as reproductive because they serve the purpose of reproduction and no other, the sporogenous cells giving rise to the spores, and the tapetal cells acting as nurse cells to these through all the stages of their development.

Let us now follow these two groups of cells throughout their career. Cell-division ceases for a time in the sporogenous cells, as at $f$, and they enter into a state of preparation for a remarkable series of processes that, as we shall soon see, are apparently of fundamental importance to heredity. Meanwhile the walls of the tapetal cells break down, and their protoplasts fuse, forming a plasmodium that is free to circulate throughout the sporangial cavity, g. The sporogenous, or grandmother cells of the spores, now become separated, and the tapetal plasmodium moves in between them, where, completely surrounding them, it is in position to assist in their nutrition to the best possible advantage, $g$; and in the capacity of nurse the plasmodium continues to function up to the time of the maturity of the spores.

Division of Spore Grandmother Cells.- Now the grandmother cells begin to initiate nuclear division. The processes in this have been followed in detail by Yamanouchi in Osmunda cinnamomea. There at a somewhat later stage than is shown in $g$, Fig. I 22 , the nuclear network resolves itself into a thread lying in two parallel strands in close proximity, Fig. I23, A, $a$ and $b$, and traversing the nuclear cavity in various directions. Later the threads become drawn to one side of the carity into a compact mass where the parallel members become more closely associated. After this the threads go back to the looser arrangement which they had at the beginning. 'They now shorten and thicken and break by transverse fision into twenty-two 
double pieces, or pairs of chromosomes (Fig. 123, B, $c$ and $d$ ). These become thicker and dispose themselves at the equator of the nucleus; the nuclear membrane disappears and protoplasmic threads radiating from the poles of the cell fasten upon the members of the pairs of chromosomes in such a way as to draw them apart toward opposite poles, twenty-two chromosomes to each pole (Fig. I23, C, $e$ and $f$ ). As they move toward the potes it is seen that they have become divided longitudinally
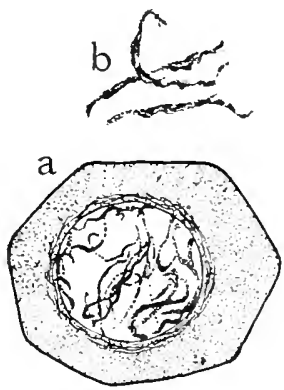

A

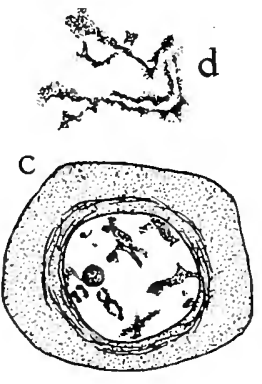

B

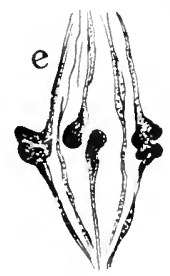

C

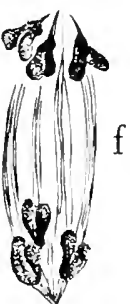

FIG. I23.-Formation and separation of chromosomes in the spore grandmother cells of Osmunda cinnamomea. 4 , $a$, early prophase showing approximation of nuclear thread in parallel strands; $b$, detail more highly magnified; $B$, later prophase showing transverse division of double thread, forming pairs of chromosomes; $d$, two pairs of chromosomes from $c$ more highly magnified; $C, e$, metaphase showing separation of the members of the chromosome pairs; $f$, late anaphase showing that each chromosome is longitudinally split. Further description in the text. (After Yamanouchi.)

through the middle (Fig. 123, C, f), and that the halves spread apart at their equatorial ends while remaining together at their polar ends.

At the poles these longitudinally-split chromosomes branch out more or less into a reticulum and a nuclear membrane is formed; but soon the second division is begun, the split chromosomes become again recognizable, and give evidence by this fact that they had preserved their identity through the resting period. The nuclear membrane now disappears, the chromosomes become lined up at the equator, and strands of cytoplasm pressing in from opposite poles become attached to the longitudinal halves and draw them one to one pole and one to the 
other, where they fuse and form at each pole a resting spore nucleus.

Let us now recapitulate these processes in somewhat briefer terms. (a) The chromosomes that appear in the division of the nucleus of the spore grandmother cell are closely associated in pairs. (b) A pair is not formed by the longitudinal division of a preëxisting chromosome, but by the approximation of two parts of the nuclear thread before its transverse segregation into chromosomes. (c) The members of a pair now separate and are drawn to opposite poles. (d) Traveling poleward each chromosome shows that it has become split longitudinally. At the poles the split chromosomes form a nuclear reticulum which becomes enclosed in a nuclear membrane, thus forming
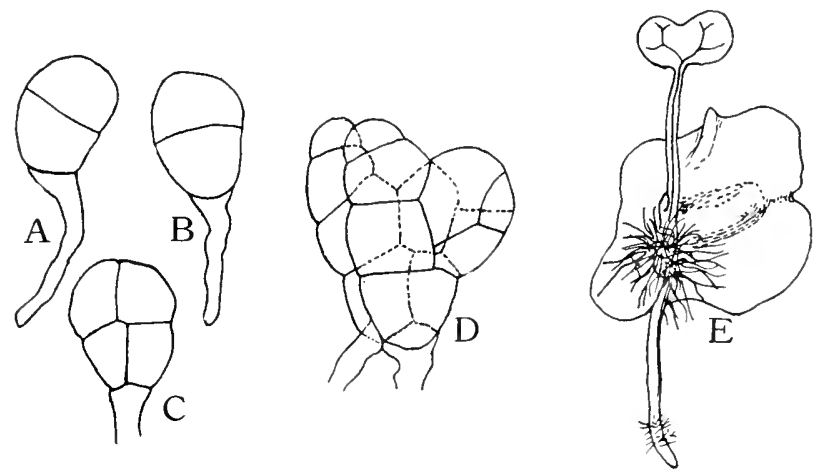

FIG. I $24-\cdots, B, C, D$, Successive stages of growth of prothallitum from the spore in Osmunda cinnamomea; $E$, growth of fern plant from fertilized egg within the prothallium of Osmunda Claytoniana. (After Campell.)

the resting nucleus of the spore mother cell. (f) When this mother-cell nucleus begins division the split chromosomes appear again as such, and in the anaphase their halves are sundered and removed to opposite poles where the spores are now formed, two for each mother cell, four for each grandmother cell.

Germination of the Spores. When the ripe spores of Osmunda have fallen in a farorable situation they immediately germinate (Fig. I24, A, B, C, D), and produce a small, prostrate, chloroplast-bearing body called the prothallium, D, which 
is anchored to the soil by hair-like rhizoids, and bears on its under side two sorts of sacs, one the antheridium (Fig. I25, A), containing sperm cells or male gametes, and the other the archegonium, B, bearing an egg cell or female gamete. Some prothallia, however, bear antheridia only.

Since the prothallium bears the gametes we call it the gametophyte.

Fertilization of the Egg.- The sperm cells swim by means of their cilia to the archegonia, through the water that gathers under the prothallia (Fig. I25, B), being attracted by a substance,

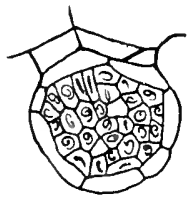

A

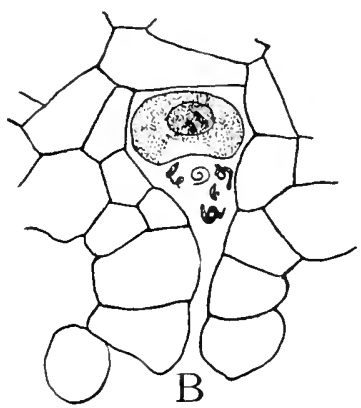

FIs. 125.-A, Antheridium containing sperm cells; $B$, archegonium containing an egg cell which has been found by five sperm cells. All from Osmunda cinnamomea. (After Campbell.)

probably malic acid, diffusing through the water from its place of secretion in the archegonium. The sperm cell now fuses with the egg. Following this the fertilized egg cell begins a series of nuclear and cell-divisions leading up to the full-grown fern (Fig. I24, E); and this produces sporangia and spores essentially as already described for Aneimia. Because of its bearing spores the fern plant is called the sporophyte.

Interpretation of Processes of Nuclear Division.-The interpretation that is now being put on the beharior of the nuclear substance during division as previously outlined is suggested not only by what we see under the microscope but also by what we observe in carrying on pedigree cultures of hybrids, as will soon appear. We can best lead up to the interpretation by 
beginning with the fertilized egg. When the sperm nucleus fuses with the egg nucleus the number of chromosomes borne by the sperm is added to the number borne by the egg, and the fertilized egg, therefore, bears twice as many chromosomes as does the sperm cell or the unfertilized egg cell. Now while these chromosomes lie closely associated in the fertilized egg they do not commingle and lose their identity; there is, rather,

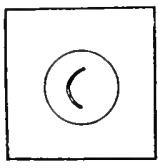

A

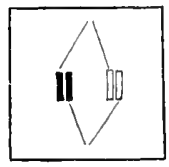

$\mathrm{B}$

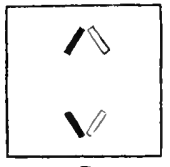

C

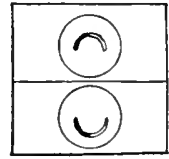

$\mathrm{D}$

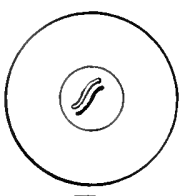

$\mathrm{E}$
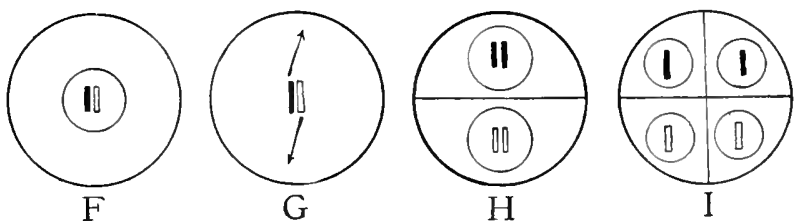

Fig. 126.- Showing method of association of paternal and maternal chromosomes, at 4 in all vegetative nuclei, and $B, C, D$, their manner of separation in all vegetative nuclear divisions. Showing also manner of association of paternal and maternal chromosomes at $E$ in early prophase of spore grandmother cells and the manner of their separation during the division of the grandmother-cell nucleus at $F$ and $G$. Showing also the longitudinal division of the chromosomes in the spore mother cells in $H$, and their separation to form the spore nuclei in $I$, two of the four spores being purely paternal and two purely maternal.

evidence for the conception that they become joined by end-toend contact, as shown in Fig. I $26, \mathrm{~A}$, where the black segment represents a paternal and the white a maternal chromosome. For simplicity only one chromosome from each parent is shown.

When division of the fertilized egg takes place the chromosomes break apart where they are joined end to end, divide longitudinally and line up at the equator, as shown at $B$; and so longitudinal halves of both paternal and maternal chromosomes arrive at either pole, $\mathrm{C}$ and D. Throughout all subsequent cell-divisions leading to the mature plant body this method of division is repeated, and each of the myriad cells is thus sup- 
plied equally with the characters borne by the chromosomes of both parents.

When the grandmother cells of the spores are formed their nuclei are constituted as in Fig. I 26 , A, like the other cells of the body. But now when the grandmother cells begin division a paternal and its homologous maternal chromosome become associated in a pair (Fig. I26, E and F), and so for all of them, and the members of a pair are sent to opposite poles as shown in Fig. I 26, G. It would now follow that when the mother cells divide and form the spores, two of the four spores would have only maternal and two only paternal chromosomes (Fig. I26, H and I) descended from any single pair in the prophases of the grandmother cell (Figs. I 26, F and I 23, B).

It can now be seen that when the paternal and maternal chromosomes become segregated in the division of the grandmother cells the process is the reverse of what happens when the egg is fertilized; in the latter process the number of chromosomes is doubled, and in the former it is halved, or, what is the same thing, the original number is restored. But it will be seen that the question is not simply one of the number of chromosomes, it is also a question of their kind, for even though the two parents belong to the same species, or even to the same variety, they are certain to differ in some manner or degree.

Two Generations in the Life-cycle.-It is now evident that there are two generations in the life-cycle of such an organism as we have been studying, namely, the $x$ gencration and the $2 x$ generation, $\mathrm{x}$ signifying a chromosome number. The $2 \mathrm{x}$ generation begins when $\mathrm{x}$ chromosomes in the sperm cell fuse with $\mathrm{x}$ chromosomes in the egg cell, thus forming the fertilized egg which grows to be the mature fern plant or sporophyte, or, as we may now call it, the $2 \mathrm{x}$ generation. The $\mathrm{x}$ generation begins when in the division of the grandmother cell of the spores as many chromosomes $(\mathrm{x})$ as are supplied by the sperm cell are sent to one pole and as many $(\mathrm{x})$ as are contributed by the egg cell are sent to the other to form the nuclei of the spore mother cells. A mother cell of the spores is therefore the one-celled 
stage of the $\mathrm{x}$ generation just as the fertilized egg is the one-celled stage of the $2 x$ generation. Prothallium, gametophyte, $x$ generation are different names for the same thing. So, too, fern plant, sporophyte, $2 x$ generation are names referring to the same thing. It will be observed that in Osmunda cinnamomea the value of $\mathrm{x}$ is twenty-two.

Spore-formation in Spermatophytes.--Let us now see what are the visible processes in the formation of the spores of Spermatophytes, or so-called flowering plants. In these the spores are of two kinds, the microspores or pollen grains, and the megaspores, which are usually the same thing as the embryo-sac cells.

Formation of the Microspores.-When the stamens first appear as minute outgrowths from the receptacle, and for some time thereafter, they consist solely of meristematic cells. These proceed to construct an anther which early gives indications of a four-lobed outline. The anther itself is at first but a mass of meristematic cells, but soon the outer layer becomes differentiated into an epidermis. Cross sections of such anthers at different stages in their early derelopment show in each lobe a hypodermal cell (Fig. I27, A, a), or sometimes group of cells, of larger size, richer protoplasmic content, and with larger nuclei than the others. A longitudinal section shows these to be really a line, or sometimes plate of cells (Fig. I27, F, a) extending nearly the length of the anther. This line of cells is called the archesporium.

The archesporium divides throughout its length by periclinal walls, producing an outer primary parietal, B, ppr, and an inner primary sporogenous layer, $\mathrm{B}$, ps. By anticlinal divisions the parietal layer is extended part way around the sporogenous cells, and then by periclinal divisions the former gives rise to an outer and an inner layer, $C, o$ and $i$. By periclinal dirisions the outer layer now produces two layers, D and E, oo, which constitute a part of the sporangium wall, while the inner layer proceeds to function as tapetum or group of nurse cells, D and E, $t$, destined to take active part in the nutrition of the spores, as we saw to be the case in Aneimia. The tapetum is extended around the 

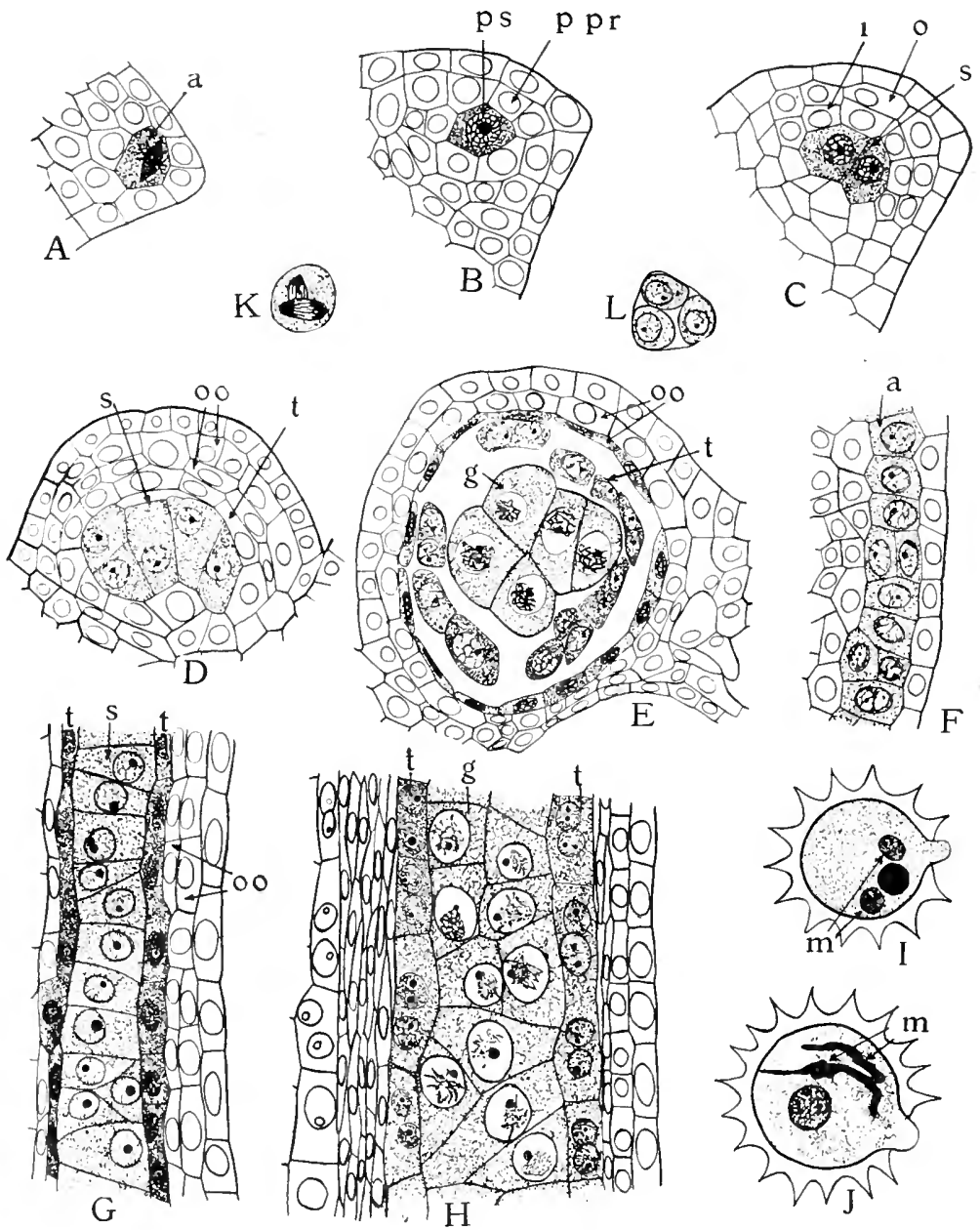

FIG. I 27.- Showing stages in the formation of anthers and pollen grains or microspores of Silphium. A, $a$, archesporium; B, ps, primary sporogenous cell, ppl, primary parietal layer; $C$, $i$, inner layer, $o$, outer layer formed from primary parietal layer; $s$, sporogenous cells formed from division of primary sporogenous cell; $D, s$, sporogenous cells; $t$, tapetum; $o o$, two parietal layers; $k$, cross section of one lobe of mature anther; $g$, spore grandmother cells, 00 , and $t$ as in $D ; F$, portion of longitudinal section of young anther showing $a$, archesporium; $G$, showing longitudinal section of same stage as $D$, parts lettered the same as $D ; H$, longitudinal section of about the same stage as $E$, with parts lettered the same; $l$ and $J$, pollen grains beginning to germinate of two species of Silphium; $m$, male or sperm nuclei; $K$, division of mother cell nuclei leading to microspores in L. (After Merrell.) 
inner side of the sporogenous layer by the participation of cells next the connective. While this is going on the sporogenous cells are undergoing longitudinal division, giving rise to the mass of cells shown in $\mathrm{E}$ and $\mathrm{H}, \mathrm{g}$. These are proven by their subsequent behavior to be the grandmother cells of the microspores or pollen grains.

Details of Nuclear Division.-For the details in the division of microspore grandmother and mother cells we must now turn to the lilies, where these processes have been very critically studied by various investigators. In these plants, as in all others, where sexual reproduction takes place, the nucleus of the microspore grandmother cell has half of its structure from the paternal and half from the maternal side, a constitution that descended to it from the fertilized egg, where paternal chromosomes joined with an equal number of maternal chromosomes in the act of fertilization, as we saw to be the case with Osmunda. We shall now see that there is a remarkable similarity between the ferns and flowering plants in the details of nuclear division in spore grandmother and mother cells.

In a lily, as the grandmother nuclei begin the first steps in division one finds the nuclear reticulum resolving itself into parallel strands (Fig. I28, 2); then the synaptic stage ensues where the strands become indistinguishable (Fig. I28, 3). Soon the mass loosens and the parallel strands again come into riew (Fig. I 28 , 4, and Fig. I29, A). In favorably stained preparations the strands appear built of alternating colored and colorless bodies, as in Fig. I29, A, B, etc., the former called chromatin, and the latter linin. The chromatin bodies are also called ids. In the parallel strands the ids are seen to stand opposite each other. The parallel strands now unite and appear as one (Fig. I28, 5, and Fig. I29. B and C), but soon they separate more widely than before (Fig. I28, 6, and Fig. I29, D). The double strands now become split up transversely into several segments (Fig. I28, 8, and Fig. I30, A), and if we count the pair in one segment as one, then there are half as many of these as there are chromosomes appearing in the dividing nuclei of the rege- 

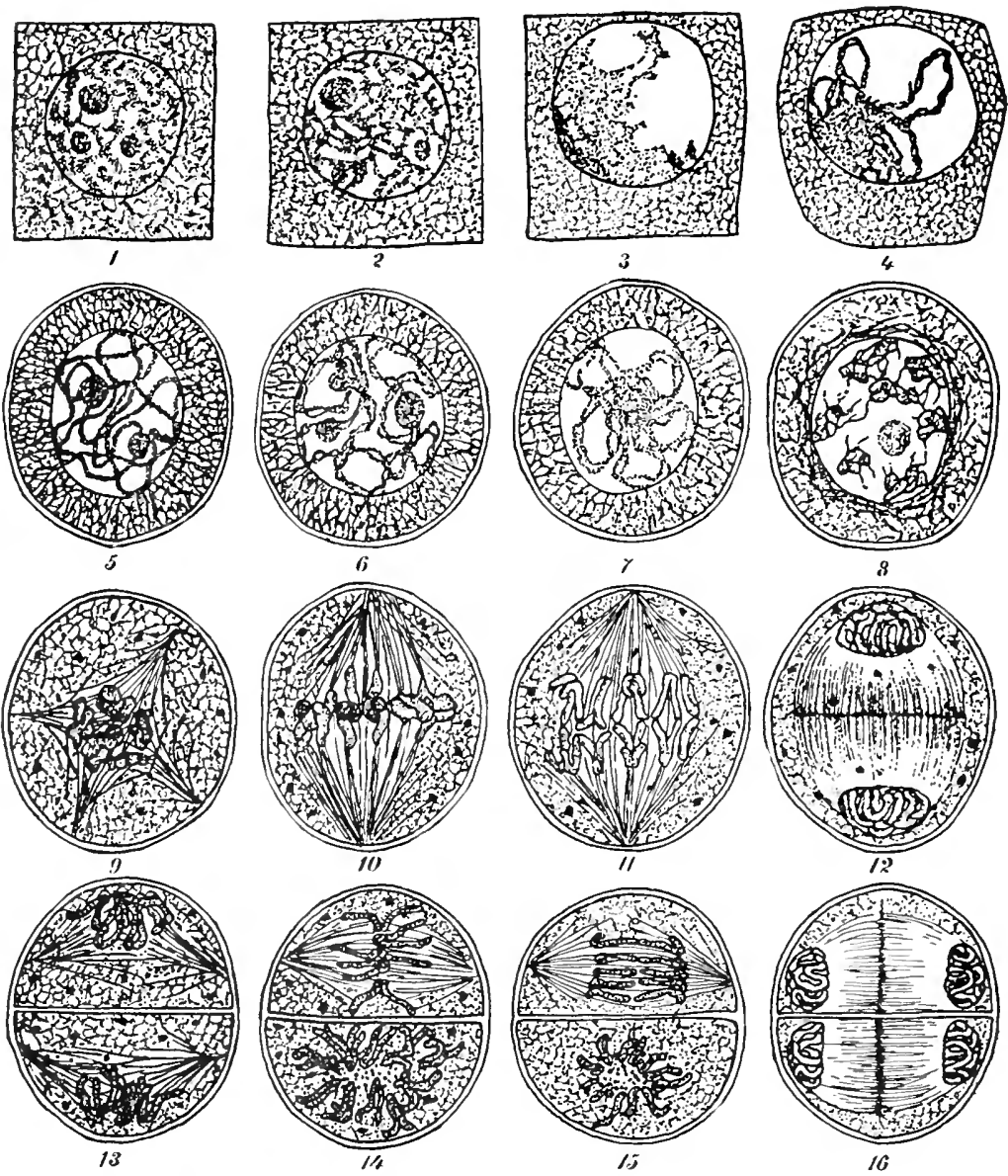

Fig. 1 28.- Stages in the division of a grandmother cell of microspores or follen grains of a lily, sonewhat d agrammatic. I, resting stage of grandmother cell; 2, nuclear thread becoming arranged into parallel threads; 3. synaptic stage; 4, parallel threars uniting; 5 . double threads so united as to aplear as one; 6 , threads again separating; 7 , thread transversely segmented into double chronosomes; 8 , diakinesis, that is, chromosomes dispersed about the nuclear membrane; 9, multipolal spindle stage; ro, bipolar spindle with double chromosomes aligned at the equator; II, reduction division, the double chromosomes separating and at the same time showing longitudinal division, with the longitudinal halves willely apart at their equatorial ends; 12 , formation of daughter nuclei, which are really the nuclei of the mother cells of the spores; 13 , division of mother-cell nuclei, the longitudinally split chromosomes seen in Ir again appearing; I4. Split chromosomes of 13 aligned at the equator ready for the longitudinal halves of each to be drawn apart to opposite poles; 15, separation of the longitudinal halves; I6, formation of the grandrlaughter nuclei, or nuclei of the spores. (After Strasburger.) 
tative cells of root and stem tips, cambium ring, etc.; but if we count each member of the pair a separate chromosome, as we assumed to be the case in Osmunda, and as the earlier stages seem to justify us in doing, one member perhaps of paternal and the other of maternal origin, then there are just as many chromosomes here as in the regetative divisions. Each member of the pair now undergoes a longitudinal division (Fig. 129, E), but this is soon lost sight of, due to the shortening and thickening
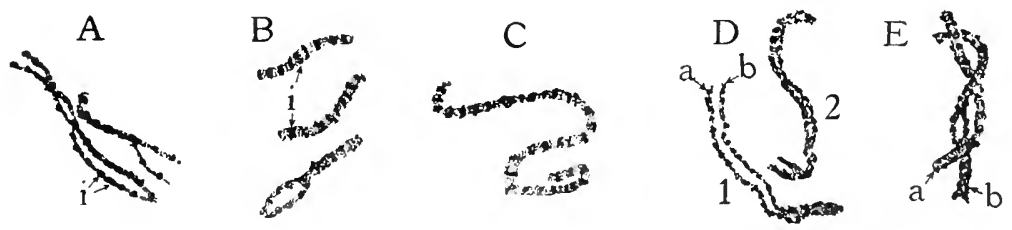

Fig. I 29.-Processes of fusion of double nuclear thread followed by their separation, and longitudinal splitting of each. A, double threads before their union, showing their component ids at $\imath ; B$, double threads in process of uniting, fusion completed in the two upper figures, where pairs of ids have fused as at $2 ; C$, completion of fusion with the pairs of ids united as at $i$ in $B ; D, \mathbf{I}$ and 2 , two pieces such as the one shown in $C$, with their fused threads again separating; at $\mathbf{I}, a$ and $b$, we see the two parts that were fused in $C ; E, a$ and $b$ correspond to $a$ and $b$ of $I$ in $D ; a$ and $b$ are much thicker in $E$ than in $D$, and $a$ and $b$ in $E$ have each split longitudinally; $a$ will be drawn to one pole and $b$ to the other, and as they start their longitudinal halves will spread to form Vs as shown in 1 I of Fig. 128. (After C. E. Allen.)

of the pair (Fig. 128, 9). In this condition the several pairs become lined up at the equator (Fig. I 28, Io).

In the metaphase the members of each pair begin to separate, the one from the other (Fig. I28, IO, and Fig. I30, B, $r$ and $s$ ), and before they are drawn toward opposite poles in the anaphase the longitudinal division in each member again becomes apparent by the actual separation of the halves at their equatorial ends (Fig. I 28, I I, and Fig. I30, B).

It will appear later on that there are good reasons for the assumption we have been making, that when one of thesc longitudinally split chromosomes now traveling to one pole is of paternal origin, its former mate now traveling to the opposite pole is of of maternal origin.

At the poles the chromosomes form the nuclei of the two mother cells of the microspores (Fig. I28, I 2 ), and if we count each 
split chromosome as one, there are only half as many here as appeared in the prophases of the grandmother cell. The division of the mother-cell nuclei which now ensues consists essentially in the separation of the longitudinal halves of the split chromosomes and their distribution to opposite poles, where they form the nuclei of the microspores, four descended from each grandmother cell (Fig. I28, I3, I4, I5 and I6). The microspores have just half as many chromosomes as did the grand-

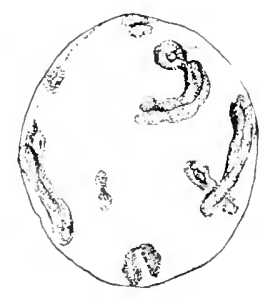

A

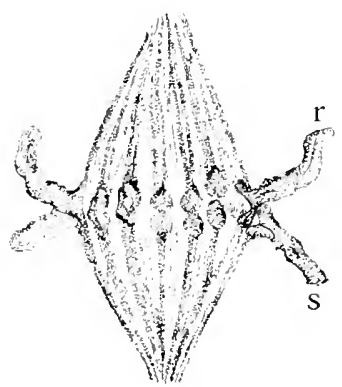

B

FIG. I30.--From nuclei of grandmother cells of pollen grains of Funkia Sieboldiana $A$, in diakinesis showing pairs of chromosomes of different sizes; $B$, metaphase, the members of each pair separating as shown by widely diverging ends of $r$ and $s ; r$ and $s$ each show longitudinal division, with the halves beginning to separate where attached to the spindle fibers. (After Kichi Miyake.)

mother cells, as we found to be the case with the spores of Osmunda, and we must therefore class fern spores and pollen grains as homologues.

According to the theory of the segregation of homologous paternal and maternal chromosomes, two of the four microspores would possess paternal and two maternal characters from any pair in the grandmother cell. We will defer further discussion of this until the origin of the megaspores has been traced.

We must now note that competent observers have found in many instances that in the prophases of the dividing grandmother cells of microspores and megaspores the nuclear thread does not take the position of two parallel strands, and segment into various side-by-side pairs of paternal and maternal chromo- 
somes as just described, but that the thread remains single and segments into end-to-end pairs of chromosomes, the maternal member of each going to one pole and the paternal member to the other, the final result being the same in both cases.

Formation of the Megaspores.-The embryology of the flower of Silphium has been worked out by W. D. Merrell, and his work will be followed in tracing the production of the megaspore, as was done in our study of the microspore.

Early in the development of the ray flowers, which alone are fertile in Silphium, when the ovule has reached the stage shown in Fig. I $3 \mathrm{I}, \mathrm{A}, o$, the archesporium appears at its apex as a single hypodermal cell, D, $a$. As the archesporium elongates, a single layer of cells surrounding it and constituting the mucellus, grows out with it ( $\mathrm{B}$ and $\mathrm{C} a$, and $\mathrm{E}$ ). Then the upper end of the ovule becomes inverted, $\mathrm{C} a$ and $\mathrm{C} b$, and tissue around the base of the nucellus grows forward and forms the integument, $\mathrm{C} a$ and $\mathrm{Cb}$.

When the archesporium enters upon its first nuclear division (Fig. I3 I, F) the number of chromosomes sent to each pole is 8 , which is one-half the number in the ordinary vegetative divisions. The reduction in the number of the chromosomes here points to the archesporium as the homologue of the grandmother cells of the microspores. Each daughter cell of the archesporium divides once, yielding a row of four cells or megaspores within the nucellus (Fig. I3I, G). Only the uppermost megaspore, $m$, proceeds to grow. As it elongates it crowds the three disintegrating megaspores toward the micropylar end (Fig. I3I, H) where they are soon lost sight of.

Details in Division of Megaspore Grandmother Cell.--The details in the division of the megaspore grandmother cell are essentially like those in the microspore grandmother cell, and we assume that here also in respect of a group of characters borne by a single chromosome two of the four megaspores descended from the grandmother cell would be of paternal and two of maternal origin, as shown in I, Fig. I 26. 

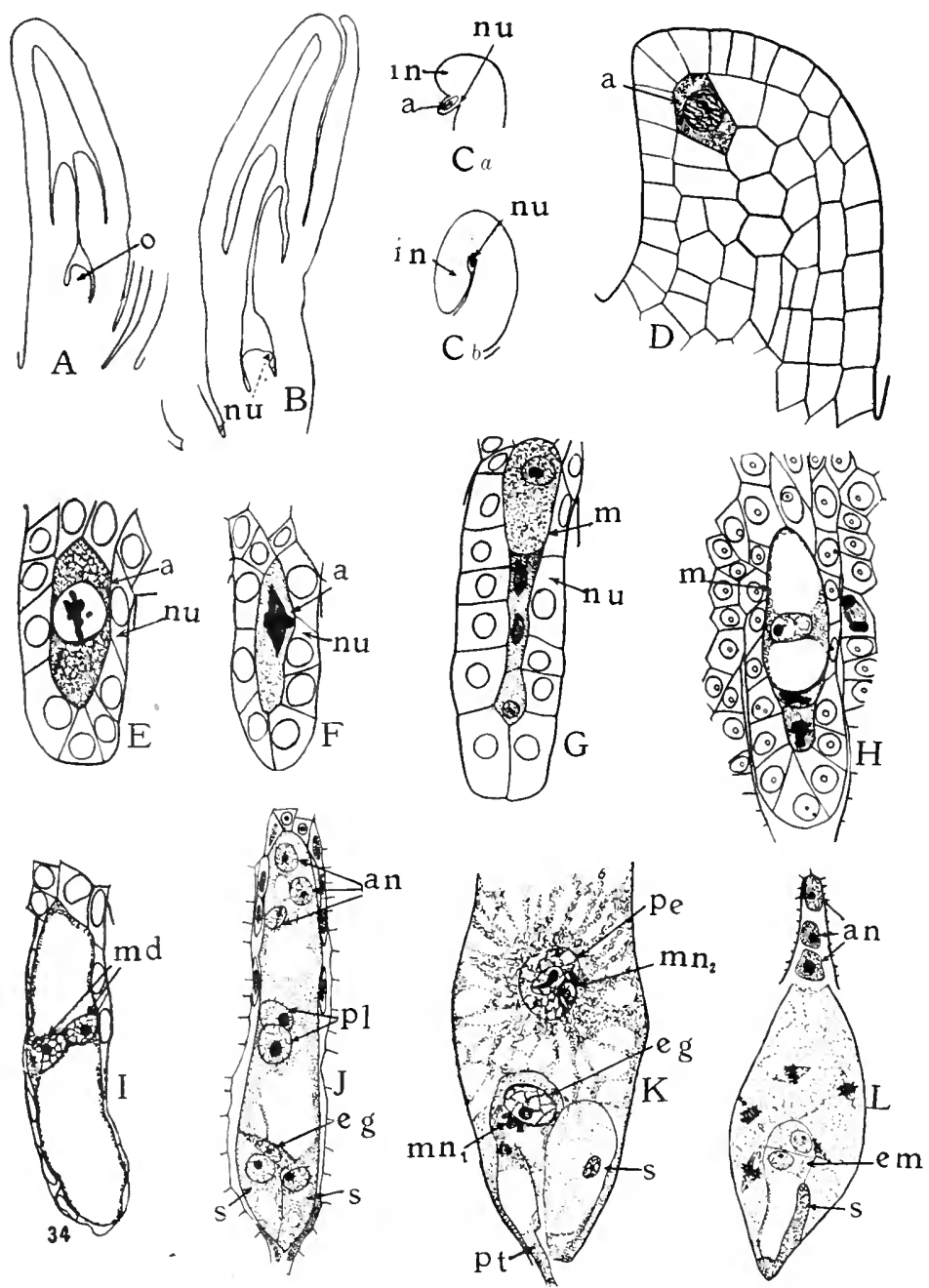

FIG. I3I.-Stages in the formation of the megaspore, its germination, fertilization of the egg and endosperm nuclei, and germination of fertilized egg and endosperm cells. $t$. beginning of ovule at $o ; B, n u$, nucellus; $C a, n u$, nucellus, $a$, archesporium; $i n$, forwarcl growth of tissue to form the integument; $C b, n u$, nucellus; in. integument; $D$, more highly magnified drawing of $o$ in $A$ showing archesporial cell at $a ; E, a$, archesporial cell enlarged and ready for division; $n u$, tissue of the nucellus; $F, a$, archesporial cell dividing, $n u$, nucellus: $G$, row of four megaspores descended from the archesporial cell, only the upper one, $m$. functional, the others soon to disintegrate; $H$, the megaspore, $m$, enlarging, the others disappearing; $I$, nucleus of the megaspore divided into two, ind; $J$, continued nuclear division has resulted in eight, namely, three antipodal nuclei, an, at the upper end of the 
Germination of the Megaspore.-The megaspore now germinates, its nucleus dividing as shown in Fig. I3I. I; the daughter nuclei move to opposite poles and divide, and the youngest nuclei in turn divide giving rise to eight nuclei suspended in the cytoplasm of the megaspore, which we may now call the embryo-sac. Two nuclei, called the polar muclei, one from each of the opposite ends of the embryo sac, move to the center and fuse, forming the primary endosperm nucleus (Fig. I3I, J, pl). This now moves into close proximity to the three nuclei remaining at the micropylar end, one of which is shown by its subsequent history to be the egg cell, and the other two seeming to assist in fertilization are called synergids (Fig. I3I, J, eg and ss). All three are termed the egg apparatus. The three nuclei at the other end of the embryo sac, each associated with a part of the general cytoplasm, become surrounded by cell-walls, and thus are formed the antipodal cells, J and L, an.

Fertilization and Germination of the Egg.- The egg cell is now ready for fertilization, and we shall see the relation of the microspore to this process. When the microspores are first formed each is essentially a protoplast with one nucleus. In the germination of the microspore the nucleus divides once, and one of the daughter nuclei divides once again, giving two that are known as the male or sperm muclei (Fig. I27, $m$ in I and I). The other daughter nucleus which did not divide is called the iegetative muclens (Fig. I 27, I, J). These divisions may take place before or after the microspore has become lodged on the stigma.

The two male nuclei descend within the pollen tube as it makes its way down the style and into the orular carity, and are discharged into the embryo sac, where one fuses with the egg cell and the other with the primary endosperm nucleus (Fig. I3I, K, $m n_{1}$, and $m n_{2}$ ). $s, s ; K$, Showing only the lower half of the megaspore or embryo sac cavity, with pollen tube, $p t$, and male nucleus, $m n_{1}$, fusing with egg cell, eg. and second male nucleus, $m n_{2}$, uniting with pimary endosperm nucleus, te s, synergid; $L$, later stage in the embryo sac, an, antipodal cells, em, beginning of the embryo by division of fertilized egg cell; five dividing nuclei descended from primary endosperm nucleus, ( $K$ after W. J. G. Land, all others after W. D. Merrell.) 
The fertilized egg now begins a series of divisions leading to the formation of the embryo, while the primary endosperm nucleus gives rise to an endosperm or food-storage tissue of greater or less magnitude, sometimes constituting the bulk of the seed, as in castor bean, or dividing the seed about equally with the embryo, as in Indian corn, or holding itself in abeyance and only assisting the embryo to take up the food about as fast as it comes for storage, as in the Lima bean and other Leguminosæ.

The division of the endosperm nucleus usually precedes that of the egg, as illustrated in Fig, I3I, L, where the embryo has reached the two-celled stage, while five endosperm nuclei are in process of division.

The Triple-fusion Nucleus. - The triple-fusion nucleus formed by the fusion of the two polar nuclei to form the primary endosperm nucleus, and the union of this with one of the male nuclei, has still no assured interpretation. One of the polar nuclei is sister to the egg-cell nucleus, and it might be expected that the fusion of a male nucleus with this would produce a second embryo. It has been suggested that the presence of the second polar nucleus is a disturbing element in this; but in some instances only one polar nucleus fuses with the male nucleus, and the result is the same as when both polar nuclei take part. Again it may be that the fusion of these nuclei is not perfect and not of the same nature as the fusion of the sperm and egg cell. This, if true, would class the endosperm with the gametophyte generation (see page $2 \mathrm{I} S$ ), where the general judgment still places it.

That the male nucleus may affect the character of the endosperm is most clearly shown in Indian corn. The wrinkling of sweet corn is due to the fact that sugar is contained in solution in the cell sap, instead of starch that fills the cells of dent and flint corn, and therefore on drying sweet corn shrinks while field corn remains plump. Now when sugar corn is fertilized by field corn the grains turn out plump and starchy instead of sugary, the second male nucleus from the microspore having trans- 
mitted this character. Color residing in outer endosperm celllayers is similarly transmitted.

Behavior of Pedigree Hybrids. - Let us now leare this line of our discussion for the present and turn to the behavior of pedigree hybrids, for in them we have the strongest evidence that paternal and maternal chromosomes become segregated in microspores and megaspores.

It was Gregor Mendel, teacher of natural sciences in the Realschule in Brünn, Austria, between I853 and I868, who, as a result of a long series of experiments in hybridization, inspired by Darwin's then recently published Origin of Species, discovered certain laws in the behavior of his hybrids, which have recently risen to fame under the name of Mendel's Laws. We will now relate some examples to illustrate the nature of his results:

Mendel crossed a variety of pea having lateral flowers with one bearing terminal flowers, and found that the hybrid progeny bore lateral flowers only (Fig. I 32, A, B, C, D. Here $\mathrm{F}_{1}, \mathrm{~F}_{2}, \mathrm{~F}_{3}$ signifies Ist, 2d, $3 \mathrm{~d}$ filial generation), no matter which variety was used as the mother or the father, and he therefore concluded that, since both characters were in the blood of the hybrid, the lateral character was dominant and the terminal character was recessive. When these hybrids began to blossom all possibility of cross-pollination was excluded, and each was caused to fertilize itself; and on planting the resulting seeds it was found that each plant's offspring were lateral-flowered and terminalflowered in the ratio of three bearing lateral (Fig. I32, $a, b, c$ under $\mathrm{F}_{2}$ ) to one bearing terminal flowers $(d)$. Self-fertilization was continued in this generation, and the seeds of each plant were planted separately, with the result that the terminal flowering plants gave only terminal flowering offspring (Fig. I 32, 4)-onethird of the lateral flowering plants gave only lateral flowering offspring (Fig. I32, I), while the remaining two-thirds gave both lateral and terminal flowering individuals in the ratio of three lateral to one terminal (Fig. 132,2 and 3 ).

In thus carrying on pedigree cultures where the seeds of each 


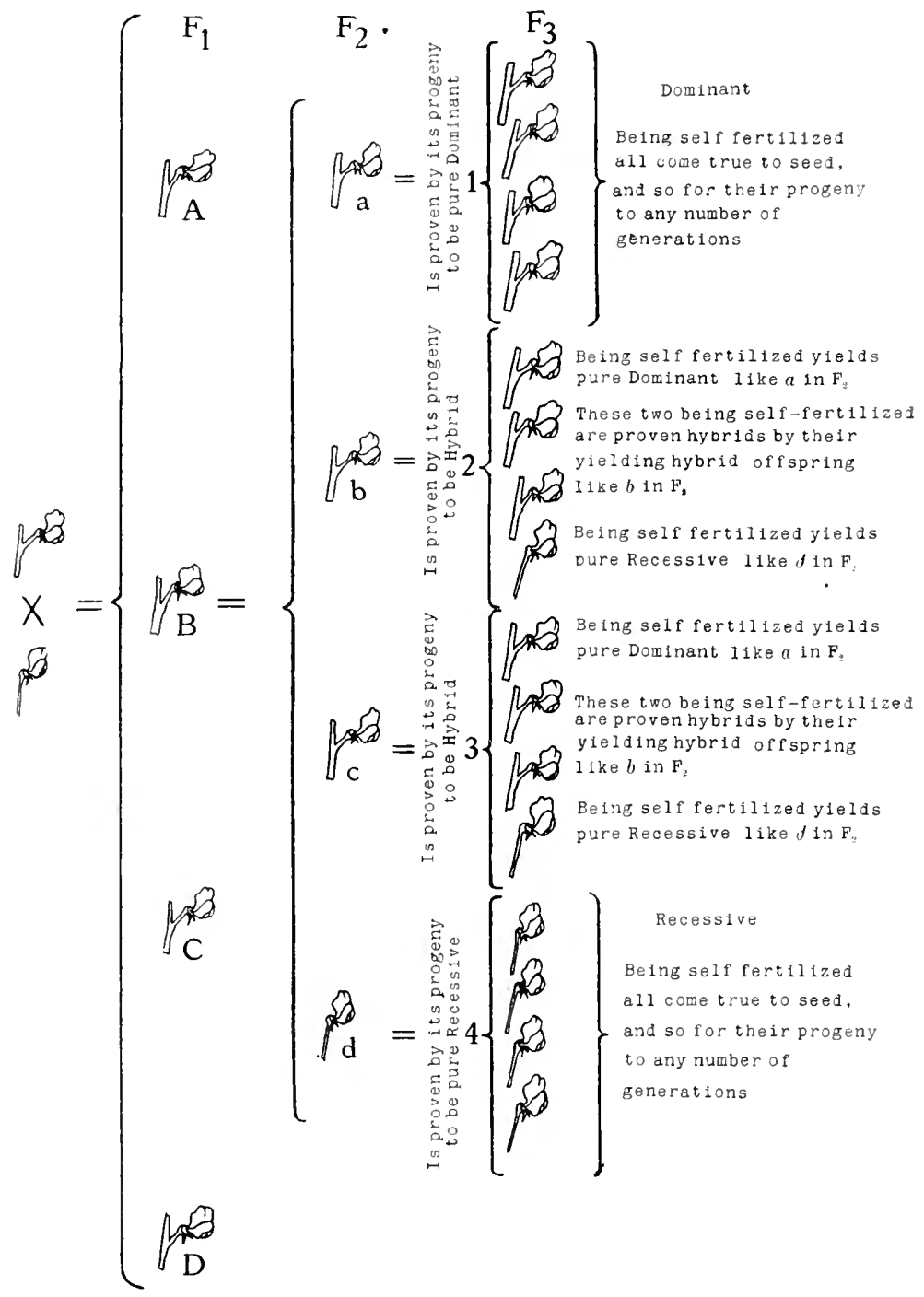

Fis. I32,-Diagram to show results of hybridization, with reference to dominant and recessive characters to the $F_{3}$ generation. Further description in text. (After data by Gregor Mendel.) 
plant were planted by themselves, Mendel was able to judge the character of each plant by its progeny, and so demonstrate to be in the blood characters that did not come to view in the parents.

Interpretation of Mendel's Results.-In seeking an explanation of his numerical results Mendel came to the conclusion that when those special cell-divisions are begun that are to result in microspores giving rise to sperm cells, and megaspores producing egg cells, the inheritance bearers received from the parents of the hybrid become segregated, so that two of the four micro-

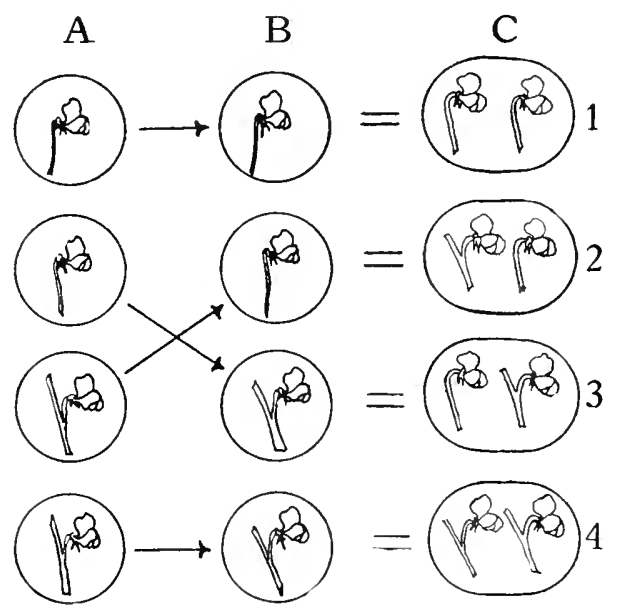

FIG. 133.-Diagram showing possible combination of two contrasting characters zuring self-fertilization of a hybrid. A, row of sperm cells, $B$, row of egg cells, $C$, row of fertilized egg cells. Furthet description in text. (After data by Gregor Mlendel.)

-jores and megaspores from a grandmother cell obtain al particular character from one parent while two receive its mate from the other parent (Fig. I26, I).

Applying this theory to the hybrid pea with tendency toward terminal flowers from one parent and toward lateral flowers from the other, each flower of this hybrid would produce two kinds of pollen or microspores and two kinds of embryo sacs or megaspores, resulting, of course, in two kinds of sperm and egg cells. Now in pollination according to chance, which is the way 
it actually happens, four different combinations would result as suggested by the pointing arrows in Fig. $\mathrm{I} 33$, where at $\mathrm{A}$ is a row of sperm cells, at $\mathrm{B}$ a row of egg cells, and at $\mathrm{C}$ a row of fertilized egg cells. From this it would follow that, on the average, in every four plants of the second generation after the first cross (in $\mathrm{F}_{2}$ ), one would possess only maternal inheritance for any specific character, one only paternal, and two would be hybrids like all the plants of the first generation. Since lateral flowers are dominant over terminal, fertilized egg cells 2 and 3 would produce lateral-flowered plants as well as would 4 which has only lateral flowers in its constitution.

Mendel's explanation, it will be seen, agrees perfectly with the results obtained from his experiments (see Fig. I32).

Paternal and Maternal Chromosomes.-Let us now turn back to Fig. I26, E to I, where attempt is made to show what happens to the chromosomes during the divisions of grandmother and mother cells of microspores and megaspores. Under the microscope it can be seen that chromosomes divide and become distributed as shown in the figure, but it is impossible, at least in most instances, to tell from their appearance that half of them are paternal and half maternal. That they are this we conclude from Mendel's experiments, that is, the results of these are precisely what would follow if the chromosomes become segmented into paternal and maternal kinds as represented in the figure. 'Therefore, when it is said that half of the microspores and megaspores are paternal and half are maternal for a definite character, let it be understood that the conception is based on direct observation through the microscope of processes in the formation of these spores, and on the kinds of progeny resulting from a union of their gametes (sperm and egg cells).

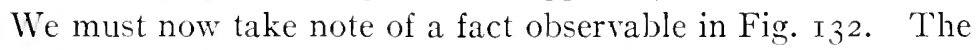
crossing of the lateral- and terminal-flowered peas seems to have given rise to nothing new, the progeny are in appearance exactly like one parent or the other; the only evidence that a cross has taken place is found in the fact that half of the individuals ( $b$ and $c$ under $\mathrm{F}_{2}$ ) show their hybrid origin by producing two kinds of 
progeny. Then hybridization produces nothing new? Mendel, and plant breeders before and after him have obtained results that are quite otherwise. Hybridization does in fact give rise to more new varieties than have been obtained in any other way. In our consideration of hybrid peas, for the sake of keeping the main point in vicw, we ignored the fact that plants are a complex of many characters, and that any two varieties taking part in a cross would be apt to have more than one pair of characters contrasting. In fact Lawrence Balls calls attention to twentythree pairs of such characters in cotton visible to the naked eye, and beyond question there are many others of this kind besides those that are obscure and invisible.

In the two varieties of peas, flowers terminal and flowers lateral made a pair of contrasting characters, and if one of our plants had long leaflets and the other had short, this would give another contrasting pair. Under such conditions Mendel's experiments showed that all possible combinations of characters occurred in the offspring of the hybrid, provided these were numerous enough to give all combinations a chance of appearing. It was found that the number of these combinations might be estimated by the formula $\mathrm{x}=2^{\mathrm{n}}$, where $\mathrm{x}$ stands for the number of combinations sought, and $n$ stands for the number of pairs of contrasting characters. In our example above, the value of $n$ would be 2 , and the number of possible combinations would therefore be 4 , and of the following character; terminal flowers with short leaflets, terminal flowers with long leaflets, lateral flowers with short leaflets, lateral flowers with long leaflets.

Bearers of Hereditary Characters. - When we seek for an explanation of these results in processes going on within the heredity bearers or chromosomes we find ourselves on hypothetical ground, but where, neverthcless, a survey of possibilities may reveal to us the right conclusion. We may start with the assumption that each chromosome is the bearer of more than one hereditary character, because plants certainly possess many more characters than chromosomes, and, furthermore, there is clearly a greater diversity in chromosome numbers than in 
numbers of characters. Thus, Canna indica has six chromosomes while Lilium martagon has twenty-four; but there is no evidence that lilies have four times as many characters as have cannas. A still better confirmation of our assumption is found in the Droseras, where of two species closely allied one has twenty and the other has forty chromosomes. We can, therefore, confidently proceed with the conviction that each chromosome bears an indefinite group of characters.

Can we with the highest powers of the microscope discover organized units composing a chromosome, each of which might be supposed to bear a single character? The utmost we can see under the microscope of the finer structure of the chromosomes is best observable in the early prophases of nuclear division. Here with the most farorable subjects it can be seen in preparations properly stained that the nuclear thread is made up of deeply stained granular masses or chromatin, alternating with unstained portions called linen. The chromatin masses, as has been said, have been termed ids (Fig. I29, i in A and B). It has been proposed that an id is composed of various single character bearers or pangenes and that an id therefore represents a group of characters. With this partly theoretical, partly observational ground to build on a very plausible hypothesis has been erected to explain the occurrence of all possible combinations of characters in the offspring of hybrids. and the possibility of fixing these combinations so that they will come true to seed. Briefly stated it is this: In a hybrid, during the prophases of nuclear division of microspore and megaspore grandmother cells it is possible that an interchange of pangenes may take place between homologous paternal and maternal chromosomes, one chromosome being considered homologous to another when its pangenes are so matched with the pangenes of the other as to make pairs of contrasting characters. This hypothesis is in harmony with the results of hybridization, and it does not conflict with what can be seen under the microscope.

Theory of Pangeneic Interchange.-Let us turn to the 
diagrams of Fig. I34 to illustrate what is meant by the above theory of pangeneic migrations. We will suppose that the parents of a hybrid have four pairs of contrasting characters, namely, flowers terminal, flowers lateral, flowers blue, flowers yellow, stems smooth, stems hairy, leaflets short, leaflets long, and that the hybrid offspring all have lateral, yellow flowers, hairy stems and short leaflets, these characters being dominant and those contrasting with them recessive. Let us suppose that when the cross-fertilization took place, the sperm cell contributed but one chromosome and the egg cell but one; then in the hybrid when the grandmother cells of the microspores and megaspores enter upon the prophases of their first division the paternal and the maternal chromosome would be found in juxtaposition, either side by side as shown at E, Fig. I34, or end to end. In this position there would be a chance of an interchange of pangenes (the paternal chromosome is shown black and the maternal white). Then the chromosomes would be drawn to opposite poles, and there each would split longitudinally into two equal pieces, and these in turn would be drawn to opposite poles (Figs. F, G, and H) to form the nucleus of the spores, namely, two paternal and two maternal spores.

Let us now consider more in detail the interchange of pangenes that might take place in the prophase at E. At I is shown diagrammatically the two chromosomes of $\mathrm{E}$, each chromosome represented as consisting of two ids, and each id as composed of two pangenes. The stippled chromosome is paternal and the white one is maternal. Let us suppose that at the time of pangeneic interchange the pangenes bearing flower color changed places as indicated in $\mathrm{I}$, and then that the chromosomes separated and went through the steps of spore formation as shown in F, G, and $\mathrm{H}$, and, supposing that the same interchange takes place in the mother cell of megaspores as in that of microspores, the result $\mathrm{H}$ would be reached for megaspores also. Now, since the characters possessed by the microspores and megaspores are handed down to their sperm cells and egg cells respectively, sperm cells $A_{1}$ and $A_{2}$ would be formed from microspores $\mathrm{I}$ and 2 

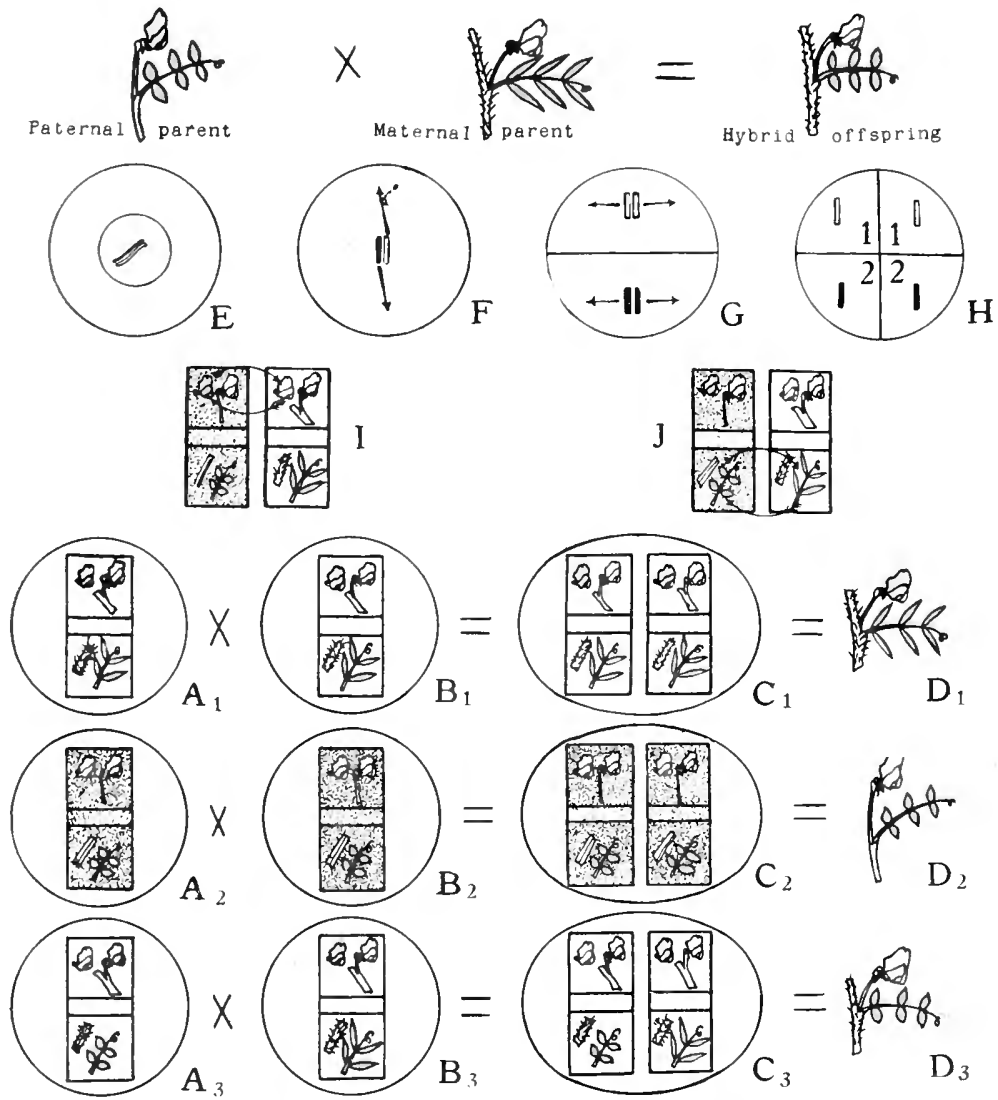

$=\frac{888}{D_{3}}$

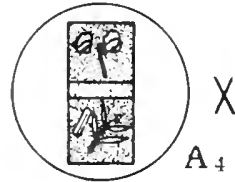

Row of sperm cells

Row of egg cells
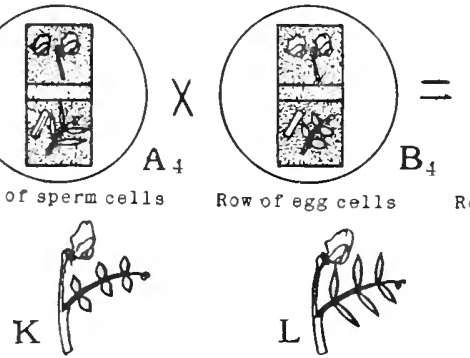

Row of fertilizedegg cells
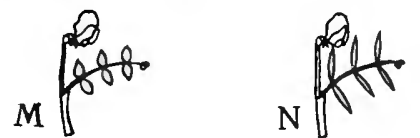

Fig. 134.-Diagram to show dominance, segregation, and recombination of characters in the offspring of hybrids. Discussion of figure in the text. (After data from Mendel, Weismann, de Vries, Strasburger, Lotsy. Bateson, Spillman.) 
in $\mathrm{H}$, and similarly egg cells $\mathrm{B}_{1}$ and $\mathrm{B}_{2}$ would be formed from corresponding megaspores. When it came to pollination it would happen in the long run that pollen grains I and 2 would become so distributed by insects or wind, etc., that sperm cell $\mathrm{A}_{1}$ would chance to fertilize egg cell $B_{1}$ resulting in fertilized egg cell $\mathrm{C}_{1}$; and sperm cell $\mathrm{A}_{2}$ would fertilize egg cell $\mathrm{B}_{2}$, resulting in fertilized egg cell $C_{2}$. These fertilized egg cells would grow into embryos which finally would become mature plants $\mathrm{D}_{1}$ and $D_{2}$. It will now be noticed that $D_{1}$ and $D_{2}$ are unlike the hybrid from which they sprang and unlike either of the parents of the hybrid; and, furthermore, it can be seen from the constitution of the fertilized egg cells $\mathrm{C}_{1}$ and $\mathrm{C}_{2}$ that the offspring of $\mathrm{D}_{1}$ and $\mathrm{D}_{2}$ produced by self-fertilization are bound to come true to the parental characters, because $\mathrm{D}_{1}$ has nothing but lateral, blue flowers, hairy stems and long leaflets in its blood, and likewise $\mathrm{D}_{2}$ has nothing but terminal, yellow flowers, smooth stems and short leaflets. Such organisms are said to be homozygote.

Given a sufficient number of instances, all possible varieties of interchange of pangenes would take place in E. Let us therefore now suppose that the interchange of leaflet characters shown in $\mathrm{J}$ occurs in the formation of microspores, resulting in sperm cells $A_{3}$ and $A_{4}$, and that these by chance came to fertilize the same variety of egg cells shown in $B_{1}$ and $B_{2}$, now represented by $\mathrm{B}_{3}$ and $\mathrm{B}_{4}$. Fertilized egg cells $\mathrm{C}_{3}$ and $\mathrm{C}_{4}$, and mature plants $\mathrm{D}_{3}$ and $\mathrm{D}_{4}$ would result. It will be seen in fertilized egg cell $\mathrm{C}_{3}$ that yellow and blue color of flowers, and short and long leaflets are in the blood of $\mathrm{D}_{3}$; but, as will be seen in the original hylbrid, the yellow flower and short leaflet characters are dominant. Likewise $\mathrm{D}_{4}$ has yellow and blue flowers, and long and short leaflets in its blood. Such organisms as these are called heterozygote.

Now some interesting comparisons can be made. $\mathrm{D}_{1}$ and $\mathrm{D}_{2}$ will come true to seed when self-fertilized, while $\mathrm{D}_{3}$ and $\mathrm{D}_{4}$ will not do this. Under self-fertilization the offspring of $\mathrm{D}_{3}$ will all have hairy stems and lateral flowers, because they are homozygote to these characters, but they will show the following 
variation in leaf and flower combinations: yellow flowers and short leaflets, yellow flowers and long leaflets, blue flowers and short leaflets, blue flowers and long leaflets. The offspring of $\mathrm{D}_{4}$ will all have smooth stems and terminal flowers, but they also will show variations with respect to flower color and form of leaflets, as in the case of $\mathrm{D}_{3}$.

Necessity of Pedigree Cultures.-Our diagrams will illustrate for us how it is that pedigree cultures are a necessity in arriving as soon as possible at a strain of any particular type capable of coming true to seed. Suppose that one in looking over his field finds plants of the types shown in the $D$ row of our figure, and wishes to propagate the sort shown in $D_{2}$ and $D_{1}$. To be certain that no intermixture comes in from the other varieties, he ties bags over the flowers of his chosen plants so that all foreign pollen is excluded. Self-pollination having taken place, he saves the seed from all his chosen plants and puts them together in one package. The following year on planting these seeds, all from plants seemingly alike and self-pollinated, he is surprised to find the four types $\mathrm{K}, \mathrm{L}, \mathrm{M}$, and $\mathrm{N}$ appearing in his scedbed, the impurity having come, as we can see, from $\mathrm{D}_{4}$ plants, which, so far as he could know at the time, were the same as the $\mathrm{D}_{2}$ plants. But now, if in harresting the seeds he had put those from each plant into a package by themselves: and had planted them in separate plots, the pure and the impure strains would have made themselves at once manifest.

Since the parents of the hybrid we are now discussing had four pairs of contrasting characters, we would expect, in accordance with the formula previously given, sixteen varicties of offspring of the hybrid, each showing a different combination of characters from any of the others. 'These are shown in Fig. 135. A great number of seeds would have to be produced to give these various chance combinations opportunity to be made. Moreover, in the long run all of these varieties would be produced capable of coming true to seed. This would happen when each was the product of a homozygote fertilized egg cell, as is the case in $\mathrm{D}_{1}$ and $\mathrm{D}_{2}$ of Fig. I 34 . This possibility is relied on by Burbank 
and other plant breeders in their practice of combining by hybridization the various good qualities of different varieties while eliminating those that are undesirable. It must be remembered, however, that they arrive at their results only after searching over hundreds, and even thousands, of the offspring of hybrids.

We may refer to Fig. I34 to illustrate another fact of importance. $\mathrm{K}, \mathrm{L}, \mathrm{M}$, and $\mathrm{N}$ are, as stated, the different possible offspring of $\mathrm{D}_{4}$ under self-fertilization. Now how can we determine the degree of purity of these varieties? We can, of course, test their purity by the character of their offspring produced by self-fertilization, and this would be an adequate and final test; but there is another way of arriving at a partial answer to our question. We know that when the offspring of a hybrid shows recessive characters it is pure to those characters, for if the contrasting dominant were present it would be expressed and the recessive would not appear. The offspring of $\mathrm{K}$, for instance, produced by self-fertilization, would all have smooth stems and terminal flowers, but they might vary in color of flower and form of leaf. The offspring of $\mathrm{L}$ would all have terminal flowers. smooth stems, and long leaflets, but might vary in color of flower. $\mathrm{M}$ would always give terminal blue flowers and smooth stems, while possibly varying in form of leaflets. $\mathrm{N}$ would have none but pure offspring, since, being recessive in all of its characters. it must be homozygote to all of them.

Mosaic Character of Offspring of Hybrids.-It would appear from all that has now been said that the offspring of a hybrid are mosaics of the characters of the original parents of the hybrid, and that different combinations of these characters may appear in the different individuals. Since in spore production the characters may separate and recombine independently, like the blocks with which children build different forms of houses, etc., according to their fancy, or like the bits of glass in a kaleidoscope which fall apart and reassemble in various patterns, they have been called unit characters. We may conceive of a unit character as the expression of the hereditary power of a pangene; or we may think of it as this power itself. 
Mendel's Laws.-Applying this conception of unit characters to the results of Mendel's work we may make the following summary: (a) In a hybrid where the two parents have contrit)uted contrasting unit characters, one of these (the so-called dominant) expresses itself, while the other (the recessive) is suppressed. This is the dominance of one character over another. (b) The homologous chromosomes of the parents of a hybrid, namely, the chromosomes that bear corresponding groups of unit characters, which became associated in the fertilized egg, and so continued in every cell of the body sprung from the fertilized egg, become again dissociated, after a possible interchange of unit characters, during the formation of microspores and megaspores, so that half of these as to any character are maternal and half are paternal. This is the segregation of unit characters. (c) Paternal and maternal chromosomes, modified to a certain extent by the previous exchange of pangenes, again become associated by the fertilization of the egg, the different varieties of modified homologous chromosomes coming together according to chance, and so giving rise in the long run to all possible combinations of paternal and maternal unit characters. This we call the recombination of unit characters.

In the $\mathrm{F}_{1}$ generation (see Fig. I32) dominance alone in operative; in the division of the grandmother and mother cells of the spores of the $F_{1}$ generation segregation occurs; when sperm cells and egg cells of the $F_{1}$ generation unite in fertilization, giving rise to embryos of the $\mathrm{F}_{2}$ generation, recombination of unit characters takes place, as shown in Fig. I34.

Practical Applications. - Knowledge of the nature and behavior of hybrids has a very important bearing on the problems of plant breeding. In the first place it shows us that we should not expect to realize the possibilities of hybridization in the $F$, generation. Many a culture has been thrown away at this stage because the hoped-for combinations did not appear, when, if it had been carried to the $\mathrm{F}_{2}$ generation the ideal might have been realized, together with many other unlooked-for and valuable combinations. 
In the second place, since all possible combinations of parental characters may be looked for in the $\mathrm{F}_{2}$ genera-
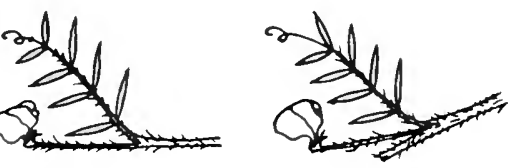
tion, it is evident that the more seeds we plant of the $F_{1}$ generation (these seeds would, of course, contain the embryos of the $\mathrm{F}_{2}$ generation) the greater would be the chance that all possible combinations would come to expression.

In the third place, in order
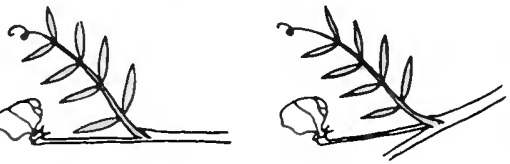
that the possible combinations of the different parents may be worked out without disturbance, self-pollination must be assured in the $F_{1}$

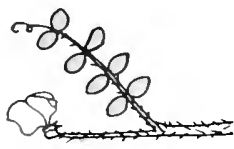
and succeeding generations.

Finally, when a desired combination of characters appears it may at once be multiplied vegetatively by cuttings, budding, grafting, etc.; but if propagation is to take place by seeds the individual bearing the combination must be tested to see if it comes true, that is, whether it is homozygote for each character in the combination. To make this test the selectert
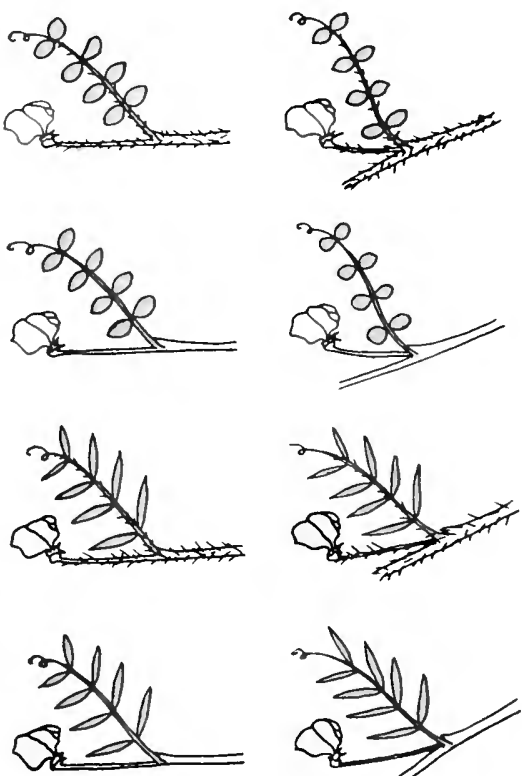
individual is self-pollinated,

FIG. I35.-Illustration of all possible combinations of characters appearing in the offsping of the hybrid shown in Fig. 134 .
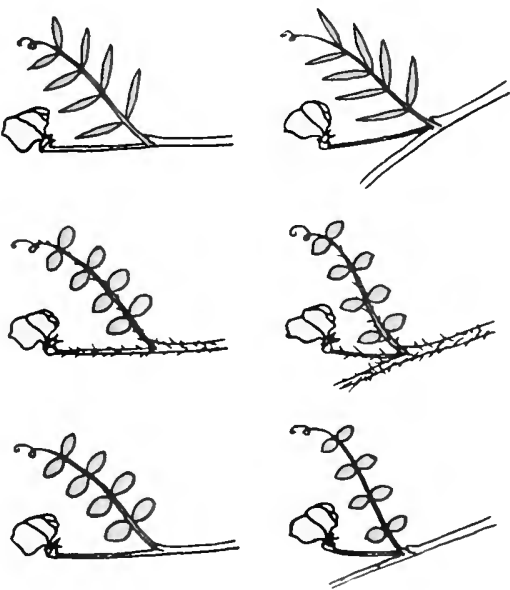
and its resulting seeds, as many as possible, are planted by themselves, and if the offspring show the same combination the homozygote condition is demonstrated, but if they split into new combinations we know that for some characters they were heterozygote. By selecting for seed production only those offspring that show the original combination, and planting the seeds of each of these separately, the homozygote condition will be found sooner of later, and by self-pollination it may be multiplied indefinitely true to its character. Infertility with self-pollen, and serious loss of vigor resulting from self-fertilization are sometimes disturbing factors.

Exceptions to the Rules.- That we might keep to the main path in our discussion, we have left to the end mention of exceptions to the rules that have been formulated for us by Mendel and other experimenters in hybridization. Dominance of one contrasting character over another does not always occur. On the contrary the two characters sometimes blend, or express themselves independently side by side, as when a cross between white and red flowers gives pink flowers, or striped red and white.

It seems, too, that segregation does not always take place during spore-formation of the $\mathrm{F}_{1}$ and succeeding generations, that is, sometimes propagation by seed can straightway take place true to the type that appears in the $\mathrm{F}_{1}$ generation, but this is of much rarer occurrence than is failure in dominance.

Sometimes, again, entirely new or apparently new qualities made their appearance in hybrids, as when a cross between two smooth varieties gives hairy offspring (Matthiola or ten-week stocks), or when red flowers crossed with yellow gives white (sweet peas and stocks), or when a cross between two white flowered varieties gives red flowers (sweet peas), or when red flowers crossed with white flowers gives yellow (Mirabilis jalapa).

These surprising results are not necessarily outside the domain of Mendelian principles. An analysis of the causes of different colors in flowers will sometimes lead to a clear explanation of anomalous results. Let us examine the case of the white- 
flowered stocks from the red and yellow cross. The colors of flowers are due to two causes (see pages ro and 34I), pigments in solution in the cell sap and coloring matters held in the body of plastids. Now the red-flowered stocks have in the petals red-cell sap and colorless plastids (A, Fig. 136), and the yellow flowers have yellow plastids and colorless sap (B). Colorless plastids and red sap are dominant, and therefore, when the red and yellow sorts are intercrossed, in $F_{1}$ the offspring all have

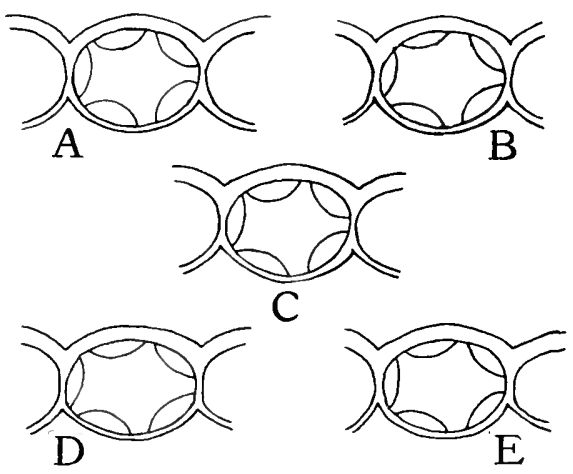

FIG. 136.- Showing how the flower color is produced in the offspring of a hybrid produced by crossing red flowered and yellow flowered ten-week stocks. (After data by Bateson.)

red flowers $(\mathrm{C})$. When, however, segregation of characters takes place in the formation of the spores of the $\mathrm{F}_{\mathbf{1}}$ generation, and recombinations occur in self-fertilization, the following sorts result: red sap plus colorless plastids, giving red flowers (C); red sap plus yellow plastids, giving yellowish-red or orange-colored flowers (D); yellow plastids plus colorless sap, giving yellow Howers (B); and colorless plastids plus colorless sap, giving iillite flowers $(\mathrm{E})$.

In many instances the appearance of what seems to be a new character is but the recurrence of a lost one that belonged, it may be, to a far distant ancestor. This would be a case of atavism. The hairy ten-week stocks from smooth parents would be an example of this. There are purple stocks and red stocks 
whose colors are due to pigment in solution in the cell sap. There are also stocks with cream-colored flowers due to yellowish plastids; and there are white-flowered stocks with colorless sap and plastids. All of these are smooth. When the red and purple varieties are intercrossed the offspring are always smooth, but when the cream or white varieties are crossed with the reds or purples the offspring are hairy, and when the cream and white varicties are crossed the offspring are both purple and hairy. It might be deduced from these facts that both the cream and white rarieties possess the factor for hairiness, and that the purple and red varieties do not contain it. It also appears that the factor for hairiness cannot do its work without the coöperation in some way of the factor for red or purple sap. Furthermore, it appears that the cream and the white varieties possess factors which acting together can produce purple, while separated they are ineffective. Hairiness and purple color are both reversions to an old parental form. Loss of purple color and loss of hairs seems to have been caused by segregation of characters which only by coöperation could produce them. When by crossing these characters were recombined the lost parental characteristics reappeared.

Significance of Sexuality.- - In whatever manner and through whaterer influences sexuality may have arisen, it seems clear that any device so wasteful in the countless pollen grains and ovules that come to nought must in the long run bring some compensating good to the race; and evidence of this has not been wanting. In his "Animals and Plants Under Domestication" Darwin gives a convincing array of evidence to show that crossfertilization as compared with self-fertilization results in very marked increase in vigor. There are, as is well known, many exceptions to this rule; but it has, nevertheless, such extensive application as to warrant the statement that sex-differentiation has in some way been the cause of a marked stimulation of various vital functions.

A very striking illustration of this we find in the behavior of Indian corn under self- and cross-fertilization. Shull has iso- 
lated two strains of corn and propagated them by self-fertilization and selection until they appeared almost if not quite homozyous. In this condition they were weak and stunted, and their ears had degenerated to nubbins (Fig. I37, A and D). He then crossed these two strains reciprocally, that is, the strain that was used as the mother in one cross was employed as the
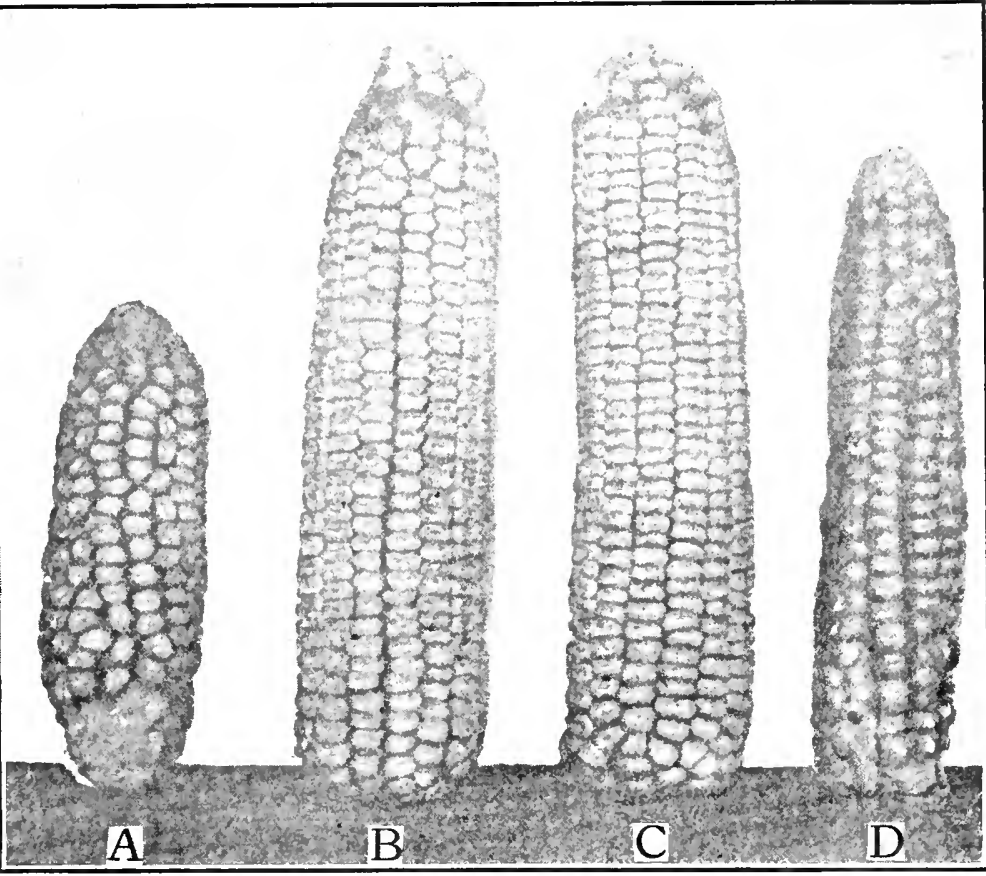

FIG. I37.- $A$ and $D$, Ears from two nearly homozygous strains of Indian corn; $B$. offspring of strain $A$ fertilized by strain $D ; C$, offspring of strain $L$ fertilized by strain $A$. (After Shull.)

father in the next, and wice versa. Immediately the offspring from these crosses mounted in vigor, even above that of the cross-fertilized race from which the strains had been derived; yielding ears as shown in Fig. I $37, \mathrm{~B}$ and $\mathrm{C}$. Here A pollinated by D produced $\mathrm{B}$, and $\mathrm{D}$ pollinated by A produced C.

These results led to the notable suggestion by Shull that since 
corn is richly heterozygous as ordinarily grown, various strains might be derived by self-fertilization and continued selection that are approximately homozygous, now with one combination of characters, and now with another; and that by crossing all possible pairs of these strains the best combination of parents could be determined for each particular purpose for which corn is used, and for the different environments in which it is grown.

Sexuality seems to have possible significance in another very important way, namely, in the evolution of organisms - in the derivation of new varieties and species from others preëxisting. The possibility of thus obtaining new species has been much in dispute. Theoretically it might be confidently expected, for a new combination of unit characters in hybrids might stimulate the expression of entirely new qualities, or bring secretions into new chemical combinations that might cause alterations in various characters. If now such a hybrid should prove to be stable, a new species would have resulted without the aid of artificial self-pollination and continued selection, to bring it to the constant homozygous condition. When we turn to the records, which is much more to the point, we find Focke's list of more than forty wild species that have been proven of hybrid origin by their duplication through artificial hybridization; we find de Vries's hybrid primrose produced by crossing Oenothera muricata and O. biennis, and Burbank's primus and phenomenal berries, both produced by intercrossing a blackberry and raspberry.

This suggests to us that in one thing, at least, there is no dispute, namely, that the fact of sexuality is of tremendous importance to the work of the plant breeder, for the primary reason that its attendant segregations and recombinations of characters make it possible for him to combine in an improved strain the good qualities of related varieties, while at the same time eliminating those that are undesirable.

\section{Illustrative Studies}

I. Cut small pieces bearing only a few sporangia from sporophylls of Aneimia, Osmunda, or Botrychium, taking care to 
include sporangia in all stages of development, and treat them as described under Cytological Methods, page 257. Stain with Flemming's triple stain. Study with $\frac{1}{12}$ or $\frac{1}{16}$ oil immersion objective (see page 277 for method of use). Search for all phases of nuclear division in grandmother and mother cells of the spores, and compare with Figs. 123 and 128. Make drawings to show different stages of sporangial development. These should follow the differentiation of sporangium wall, tapetum, and sporogenous tissue, and the segregation of sporogrenous tissue into single cells or groups of cells, and the formation and migration of the tapetal plasmodium. The fate of the plasmodium as the spores come to maturity should likewise be followed.

2. Make cultures of fern spores as described on page 323 . Make drawings to show spores in process of germination as shown under high powers.

3. Mount mature prothallia under a coverglass in a drop of water. Draw as seen under low power, and study antheridia and archegonia with a high power. Now cut out portions of prothallia bearing antheridia and archegonia, put them in a drop of water on a glass slip, and tease them out under a dissecting lens, so as to separate as nearly as possible the antheridia and archegonia from the rest of the tissue. Look for sperm and egg cells in situ under the oil immersion objective. A more satisfactory seudy of the gametes can be made from sections of prothallia prepared as described under Cytological Methods. Make drawings.

4. Make preparations by cytological methods of anthers of lilies, Tradescantia, Podophyllum, etc., in different stages of development. Stain with Flemming's triple stain. If tips of the anthers are cut off before fixation the fixative will penetrate more surely and quickly. Care must be taken to have the series begin with anthers so young that division of the grandmother cells has not yet taken place. Preliminary tests can be made by teasing out anthers in gentian violet $\left(p .30_{4}\right)$ and soon replacing the stain with water or dilute glycerine. 
5. Prepare ovules of the flowers from which the anthers are taken, beginning with the youngest stages. Several ovules may be removed together from the ovary by cutting out a thin strip of the placenta to which they are attached. Prepared in this way they are much easier to orient as desired on the microtome than where a single orule is handled by itself. Hunt for the stages shown in Fig. I3I, and make drawings.

6. Treat as above ovules taken at different periods after pollination, and make drawings to show processes of fertilization.

7. In connection with the laboratory work read from the following books. Morphology of Angiosperms, by Coulter and Chamberlain. D. Appleton \& Co., N. Y. Fecundation in Plants, by D. M. Mottier. Carnegie Institution, Washington, D. C. Mendel's Principles of Heredity, by W. Bateson. G. P. Putnam's Sons, N. Yr. Die Stofflichen Grundlagen der Vererbung, by Eduard Strasburger. Gustar Fischer, Jena. Vorlesungen ïber Descendenztheorien, by J. P. Lotsy. Gustav Fischer, Jena. Proceedings American Breeders' Association, Vols. IV and V, Washington, D. C. Plant Breeding, by L. H. Bailey. The Macmillan Co., N. Y. Plant Breeding, by Hugo de Vries. The Open Court Publishing Co., Chicago. 


\section{CHAPTER XIV}

\section{THE PREPARATION OF SECTIONS}

The preparation of thin sections of plant tissues is an absolute necessity in the study of plant histology, not only that cell structure may be clearly seen but that the association of cells into tissues and the mutual relationship of the different tissue systems may be brought to light. Whether sections can be cut forthwith without special preparation of the subject to be sectioned depends upon the nature of the material and the particular question regarding it that is to be solved. The method of procedure to fit different cases will now be giren.

Cutting Sections Free-hand.-Good histological work can be done with some materials, such as the mature parts of

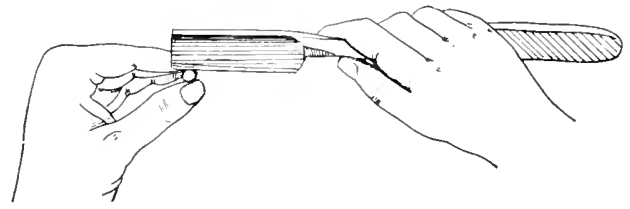

FIs. I38.--Manner of holding the razor and object in cutting sections free-hand.

stems, roots, and leaves, ly holding them between the thumb and forefinger of one hand while the section razor is wielded by the other (see Fig. I 38 ). The forefinger is held horizontal and the razor rests upon it, being pushed from point to heel in cutting the section. There is never danger of cutting too thin sections by this method; rather, most of the sections are too thick, and skill comes only with much practice. Suppose a cross-section of a stem is being cut, it is not necessary that the section be complete, and the small but thin bits which one is sure to get in his efforts to secure thin sections are the most satisfactory under high powers. A very small segment 
of the stem usually suffices, provided it extends from the surface to the pith. Tender, flexilule parts, such as the blades of leaves, will need to be inclosed in elder pith before sectioning, and a good stock of pith should be kept on hand for this purpose. A piece of pith about an inch long is laid on the table and while held firmly between the thumb and fingers to keep it from cracking it is halved longitudinally with a sharp knife. If a leaf section is desired a strip of the leaf is held between the halves of pith while the section is cut through pith and all. Sections of delicate stems and roots and of buds and flowers may be made in the same way, only a groove should be made in the pith, of a size to hold the parts firmly enough while not crushing them. It is surprising how much really good work can be done with simple appliances of this sort.

To get sections of the stone-cell tissue of nuts saw off as thin slices as possible with a hack saw and rub these down to the requisite thinness between two water hones kept wet. This is a slow process but it yields fine sections. A simpler way is to whittle off fine shavings with a very sharp knife. These shavings roll up and must be forcibly straightened out. They will break when this is done but the small bits will do. (See p. 3ro.)

A sharp razor is a necessity to successful section cutting; and it is not sharp enough until it will clip a hair held so it is free to bend before the razor. A razor half hollow-ground on both sides is a good one for this purpose. The dealers offer razors ground flat on one side, but it is impossible to keep them sharp by the usual methods. A good shaving razor, so only the blade is not ground too thin, makes a suitable section razor.

While cutting sections keep the razor blade wet with about 60 per cent. alcohol, and slide the sections into a dish of water before they have time to become dry. Never let sections become dry at any time, else they will shrivel and their cells will become filled with air which will prove a nuisance under the microscope.

In studying stem and root structure three sections, each 
from a different point of riew, are necessary to an understanding of the character and extent of the different tissues; these are a cross-section, al longitudinal section parallel to a medullary ray, known as a longitudinal radial section, and a longitudinal section at right angles to a medullary ray, called a longitudinal tangential section (Fig. 139). Good longitudinal sections are more difficult to get than cross-sections, but much of the difficulty is aroided if most of the surface is pared down so that only a small elevation is left to be sectioned, as shown in Fig. Ito. It is a good plan to keep material that is to be sectioned in equal parts of alcohol, glycerine, and water; in this it may remain indefinitely, but only after several weeks will its best effects in softening the harder tissues and toughening the weaker be produced.

\section{Cutting Sections with a Microtome.}

A simple form of microtome that can be clamped to the laboratory table is often of great adrantage in cutting sections with a razor (Fig. IfI). If the material is hard enough to bear the strain it may be clamped directly in the jaws of the object holder by means of the thumb-screw $S$; or it may first be inclosed in elder pith, in relvet cork, or even in soft wood, before clamping in.
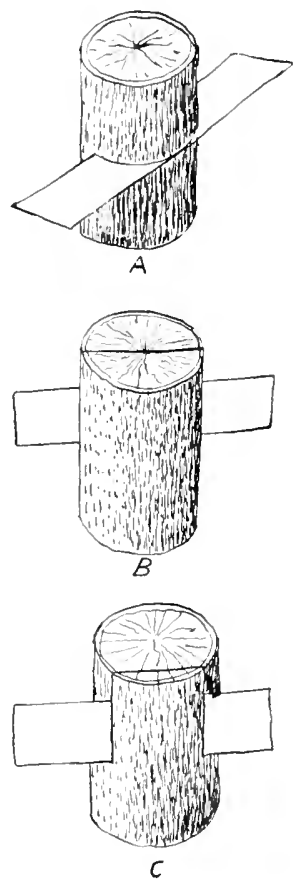

Fif. 1.39- - Showing the planes in which sections are cut, $A$, transversely: $B$, longitudinal radially: C. longiturlinal tangentially: The object is fed up a very little at a time by turning the milled-head $M$ of the micrometer feed-screw. The section razor is laid flat on the plate glass ways $P P$ and pushed across the object with a long sliding motion from point to heel of the razor as shown in Fig. I 42. In doing this the razor must be held firmly against the glass ways. After several sections have accumulated on the razor, which is kept wet with dilute alcohol, they may be swept with the finger into a dish of 
water. If it is desired to keep the sections in the serial order in which they were cut they may be transferred one by one into small phials, a single section to a phial.

More elaborate microtomes have devices for carrying the section

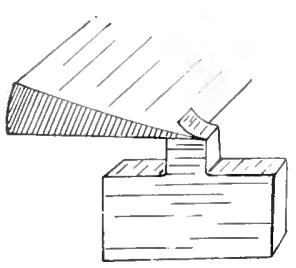

FIG. I 40.- Showing how to trin a block for cutting longitudinal sections. knife, or for holding the knife stationary while the object is made to ribrate back and forth against it, and in this way sections can be cut with increased rapidity and accuracy. In some forms there is an automatic feed which can be set to any desired thickness of section. One of the simpler forms of microtomes with a knife carrier is seen in Fig. I43, where the principle of its operation will quickly be recognized. As there shown the knife should be set at an angle to make a long sliding cut in all cases excepting where material imbedded in paraffin is to be sectioned. In the latter event the knife is to be set square across at right angles to the direction of its motion, so that the sections are chopped instead of whittled off. In this

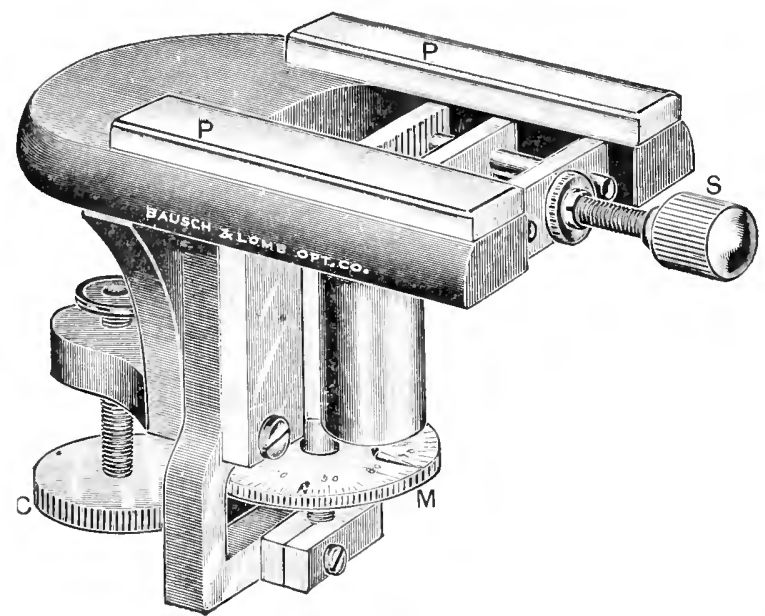

FIr. I +1 - - Simple microtome for clamping to table. $P, P$, plate glass ways for the section knife: $S$, milled head for clamping the olject; $M$, micrometer millerl-head for turning the screw that raises the object as the sections are cut; $C$, millcd-head for clamping the microtone to the table. 
way the edges of the sections adhere as they are cul and form a ribbon which preserves the order of the series perfectly. In cutting paraffin sections with the sliding microtome of the type shown in Fig. 143 the knife needs to move through only a short distance each way, so the elbow may rest upon the table and the knife may be operated with a wrist movement merely.

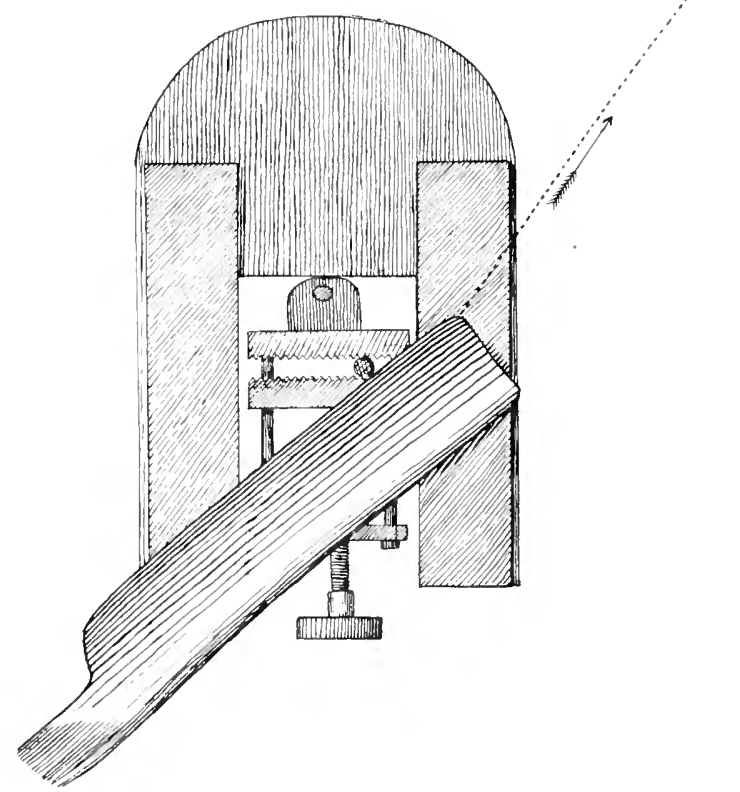

FIG. I 2,--Showing the manner of holding the knife blate on the glass ways, and, by the arrow, the direction of sliling the knife while cutting the sections.

Care of the Section Knife.- As has been said, and it will bear repeating, the section knife or razor must be kept sharpwhat we call perfectly sharp, or as sharp as one can make it. The test is that it should clip a hair at a slight touch. If it will not do this it may need honing on a stone and then stropping on leather, or the stropping may be all that it needs. To tell what to do moisten the ball of the thumb and draw it lightly over the edge of the knife from tip to heel; if the edge gives the 
sensation of taking hold of the skin throughout its length only stropping is needed, but if not, the knife must be honed.

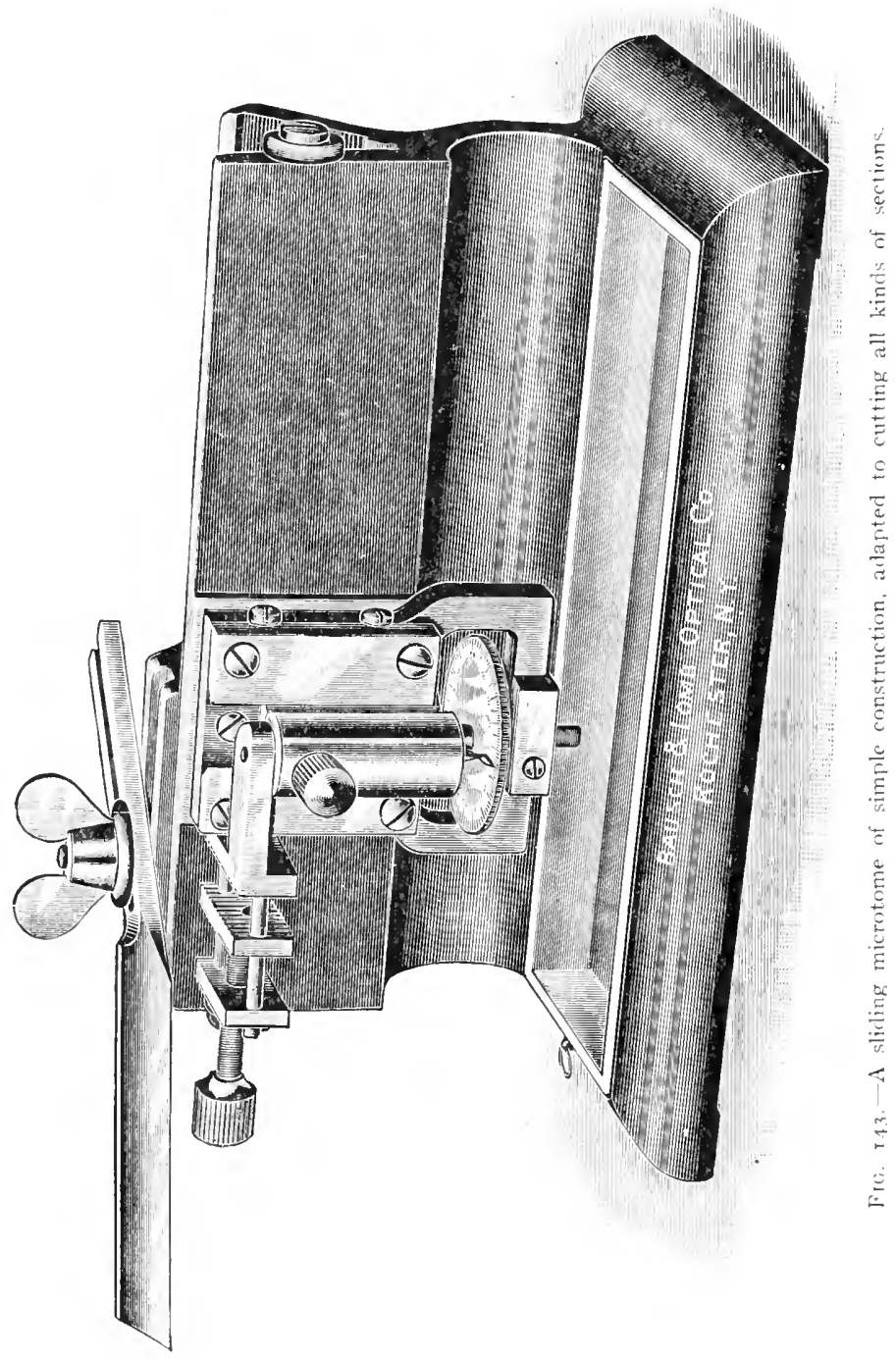

Before honing or stropping a microtome knife a steel back should be slipped on it so as to tip the edge to the proper angle. 
but an ordinary razor will not need this back. While honing hold the knife in the position shown in Fig. I4t, keeping the back as well as edge against the stone, and while pushing the knife edge foremost slide it at the same time from point to heel as shown by the arrow. 'Then turn the other face of the knife to the stone and repeat the stroke from point to heel toward the other end of the stone, and so on until the thumb test above de-

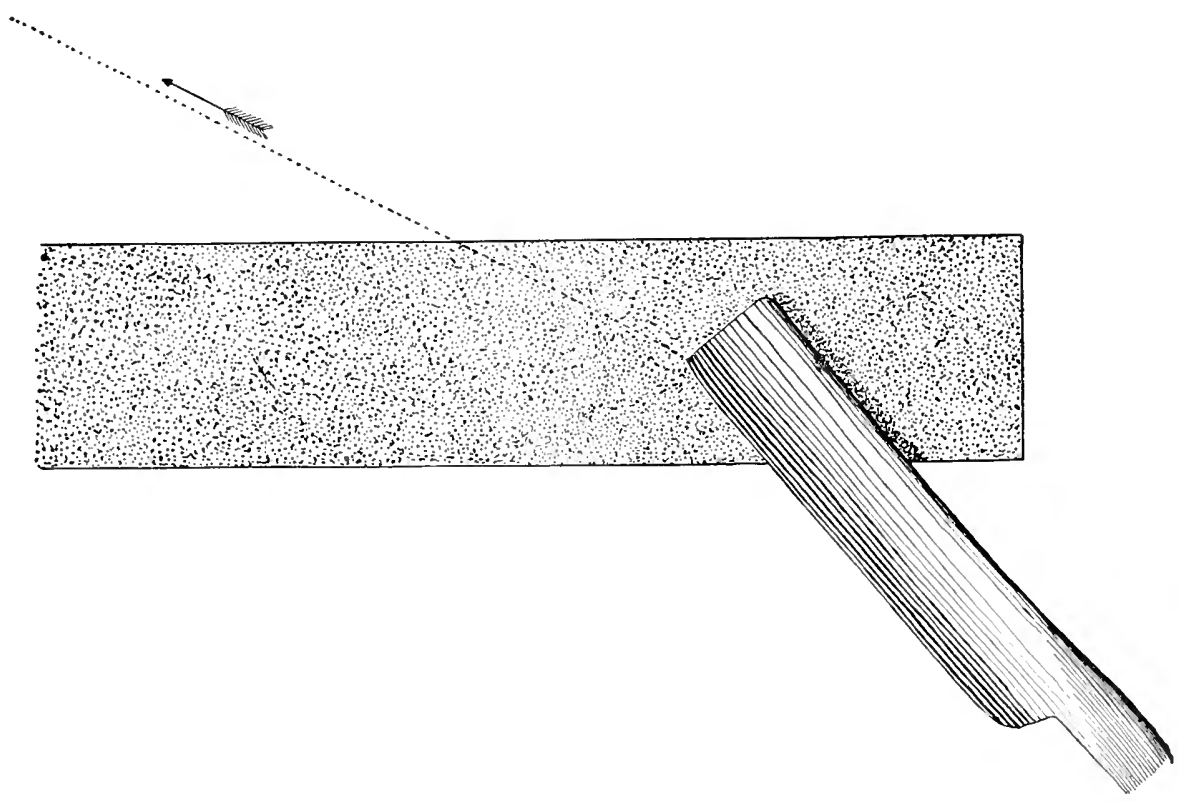

FIG. 144.-Showing the manner of honing the section knife or razor.

scribed is satisfactory. Do not allow the stone to gum up; keep plenty of oil upon it if it is an oil stone, or if a water stone keep it well lathered with soap and water, and wipe the stone clean after honing. Then strop the knife, drawing it over the leather back foremost from heel to point (Fig. I45), reversing the face for the back stroke, and keep this up until the knife readily clips a hair.

Cytological Methods. - Within comparatively recent times methods have been worked out whereby the anatomy of cells 
and tissues can be laid bare in their finest details. These methods are intended first of all to preserve the structure of the protoplasts in its normal form, and then to cut a single cell into several sections while keeping these in their natural sequence, and finally to stain the sections so that different structures will take on different colors.

The preservation of the structure of the protoplasts is accomplished by plunging the material into a solution, known

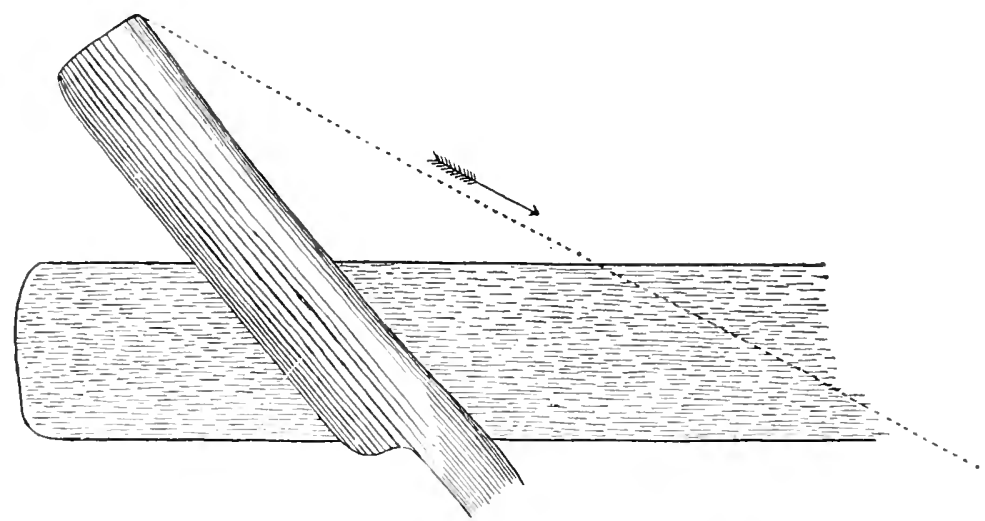

Fil. I 45--lllustrating how the section knife or razor is drawn across the strop.

as the fixative, which instantly kills the protoplasts so that decomposition incident to slow dying is prevented, and then hardening the protoplasts by transferring the material to alcohol, beginning with weak alcohol and gradually increasing its strength until absolute alcohol is reached, so as to aroid undue shrinkage.

The material is next imbedded in paraffin, and sections adhering in ribbons are cut usually $.005 \mathrm{~mm}$. to .010 mm. thick, and these after mounting on a slide and being freed from paraffin are stained with two or three different stains and then sealed in balsam in the form of permanent mounts.

The processes thus briefly outlined will now be given in detail.

The Fixing Process.-For the study of the finer structures 
of the protoplast Flemming's fixative has given on the whole the best results. The formula for this is:

One per cent. chromic acid........ I6 parts,

Two per cent. osmic acid ........ 3 parts,

Glacial acetic acid ............ I part.

Make the I per cent. chromic acid solution by dissolving I gram of chromic acid crystals in 99 c.c. of distilled water, and dissolve I gram of osmic acid in 49 c.c. of distilled water to make the 2 per cent. solution. Then mix together 16 c.c. of the chromic acid solution, 3 c.c. of the osmic acid solution, and $\mathrm{r}$ c.c. of glacial acetic acid. Of course more of the fixative can be made, so only the ingredients are kept in this proportion.

The osmic acid solution must be made with extreme care to avoid all contamination with organic substances, which are sure to spoil it, as shown by the formation after a time of a black precipitate. For this solution procure a glass-stoppered bottle, wash it thoroughly with soap and water, rinse it many times, pour into it a saturated solution of bichromate of potash in strong sulphuric acid, stopper the bottle and shake it vigorously, let it stand for a while and shake again, then pour out the solution and rinse the bottle again and again with distilled water. Clean the stopper as thoroughly as the bottle. The osmic acid comes sealed in glass tubes and it is best to obtain it with one gram to the tube. Clean the outside of such a tube in the manner described for the bottle, stirring it about with a glass rod in the bichromate of potash solution and subsequent rinsings, and keeping the fingers off of it; then guide it with the rod into the clean bottle; pour into the bottle ro c.c. of distilled water, stopper the bottle and strike it against the palm of the hand until the tube of osmic acid is broken; then pour in the remaining 39 c.c. of distilled water necessary to make the 2 per cent. solution. If the whole 49 c.c. of water were poured in at first it would have been more difficult to break the tube. Of course the distilled water must have been kept in receptacles free from organic matter. The fumes of osmic 
acid are hard on the eyes, nose, mouth, and lungs, and the face should be kept away from them.

About twenty times as much Flemming's fixative should be used as of material to be fixed, and the material should be cut into pieces not greater than $2 \mathrm{~mm}$. in any dimension, so that the fixative may penetrate quickly to all parts. It is convenient to do the fixing in small phials, and if the material has a tendency to float it may be pushed under with a piece of filter paper that tightly fits the phial. Material should be fixed at once after it is gathered and if it grows at any distance from the laboratory the fixative should be taken along.

Kcep the material in the fixative for forty-eight hours and then remove it and pin it in little cheese-cloth bags which one can quickly make himself of the size wanted, and put these in running water for about six hours, or over-night. If running water cannot be had then place the material in a bucket of water which is to be changed several times.

A simpler and cheaper fixative which gives good results, but not quite equal to the above for dividing nuclei, is the chromacetic fixative. This is made by dissolving I gram of chromic acid in 99 c.c. of distilled water and adding 0.5 gram of glacial acetic acid. Use as described for the above fixative.

The Hardening Process.-The material still kept in the bags is, after washing, placed in 20 per cent. alcohol for two hours, and then it is carried through a series of alcohols, each of the series Io per cent. stronger than the one before it, remaining in each grade of alcohol for two hours until absolute alcohol is reached. If the material is not to be imbedded in paraffin at once it may be left in the jo per cent. alcohol until needed, and then it may be carried on into the higher grades as if no interruption had occurred.

The process of hardening may be considered complete when the 90 per cent. grade of alcohol has been reached, and the sojourn in absolute alcohol is intended to complete the dehydration of the material preparatory to its imbedding in parafin or celloidin. In order to make dehydration more certain it is 
a good plan to have two bottles of absolute alcohol in each of which the material remains for two hours before it is transferred to the solvent of paraffin or celloidin.

The Process of Imbedding in Paraffin.--Transfer the material from the absolute alcohol to a phial containing equal parts of absolute alcohol and chloroform, and after two hours place it in a phial of pure chloroform, and again after two hours transfer it to another phial of chloroform, and in these instances enough chloroform to keep the material submerged is all that is needed. Chloroform is a solvent of paraffin and the object now is to infiltrate the material with paraffin very gradually. Accordingly after two hours put a small shaving of paraffin into the last phial of chloroform where the material is, and shortly after this has dissolved add another shaving, and so on until the chloroform is saturated with paraffin at the temperature of the laboratory. All this while the material may have been left in the little lag of cheese-cloth for convenience in handling, but now it should be taken out of the bag and laid back loose in the phial of dissolved paraffin. Place this phial on the top of a paraffin oven heated to the melting point of the paraffin, which should be about $52^{\circ} \mathrm{C}$. Remove the cork from the phial and let the chloroform evaporate. Add more paraffin a little at a time if needed to keep the material submerged. Keep the phial on the paraffin oren until the paraffin no longer has a sweetish taste, indicating that all of the chloroform has evaporated. Make a small paper tray by turning up the edges of a piece of paper all around to the height of a centimeter and half fill this with melted paraffin heated hardly above its melting point, and into this pour the contents of the phial-paraffin and material. It is best to have the paper tray on something cold so that a crust of solid paraffin will quickly form at the bottom, and then with heated dissecting needles the material can be disposed in orderly fashion over this crust, and when the paraffin has entirely hardened each piece of the material can be cut out with a good border of paraffin all around it. When the material has been 
arranged over the bottom crust blow upon the surface of the paraffin to harden it the more quickly, and plunge the tray into cold water as soon as the surface crust will bear this. The more quickly the paraffin is cooled the more firmly it sets about the material. The material may be left thus imbedded in paraffin until it is needed for sectioning.

Sectioning Material Imbedded in Paraffin.-Tear off the paper tray and with a knife score deeply around the piece of desired material on both top and bottom surfaces, and then break the piece out. This will be called the paraffin block. Melt a piece of paraffin on the surface of the object carrier of the microtome. In the microtome shown in Fig. I43 the object carrier may be simply a piece of pine wood about a centimeter in cross-section which is to be clamped firmly in the jaws of the microtome. Before the melted paraffin on the object carrier has time to harden press into it the paraffin block, setting it up in the position to give sections in the desired direction; then pass a hot needle around the base of the block so as to fuse it thoroughly with the paraffin bed and make a firm union. Pare the sides of the paraffin block so that the opposing faces are parallel, and adjust the object carrier on the microtome so that the knife, standing at right angles to its line of motion, will have its cutting edge parallel with the face of the block turned toward it. Now the sections may be cut and they should adhere and form a ribbon. In cutting paraffin sections the knife does not need to be wet with alcohol or anything else as in other cases. If the parafin breaks away from the material as the sections are cut the infiltration may not have been successful, or the temperature of the room may be too low. If the sections crumple up as they are cut the room is probably too warm. The ribbons ought to be straight, and if the front and back faces of the paraffin block are trimmed parallel they are pretty sure to be straight. Sections seldom need to be cut thinner than .005 $\mathrm{mm}$., and .oro $\mathrm{mm}$. is a suitable thickness for most purposes. In micrometry 
the term mikron is applied to .oor mm. and the above thickness would be called 5 and ro mikrons.

Mounting Paraffin Sections.-The paraffin sections are made to adhere to the glass slips by means of albumin water. The stock solution of this is made as follows: Shake together equal parts of white of egg and distilled water and add to this a pinch of salicylate of soda to keep it from spoiling. For use add one drop of the stock solution to one ounce of distilled water. This dilute solution will be referred to as albumin water.

Rinse thoroughly and wipe dry a glass slide that has been kept in a saturated solution of bichromate of potash in strong sulphuric acid. Place at the center of the slide a drop of albumin water and with a dissecting needle drag the drop out in a thin film covering the space that is to be occupied with the sections. The albumin water should stay just where you put it without creeping away in the least. If it does creep the slip is not clean enough and it should be rinsed off and rubbed with a cloth moistened with alcohol. Cut the paraffin ribbon up into the desired lengths and lay these on the film of albumin water, keeping the glossy side of the ribbon down, namely the side that was down on the knife after cutting, for this side adheres better to the slide than the other. When as many sections have been put on as will fill out under the coverglass, or a less number if so desired, warm the slip over a flame until the ribbons lie perfectly flat and then draw away the albumin water with filter paper; at the same time keep the pieces of ribbon close together and properly lined up, and then place the preparation where it can dry for an hour or so at a temperature a little below the melting point of the paratfin. After this stand the slip on end in a dish of xylene to dissolve away the paraffin, and then in a dish of 95 per cent. alcohol to rinse out the xylene, and after this the sections will be ready for staining. If the sections have been at all blackened by the osmic acid, as often happens, they should be bleached before staining. To do this place the slide for a few minutes in a 
dish containing one part of hydrogen peroxide to twenty parts of 60 per cent. alcohol.

Staining the Sections.-The finest results in staining are obtained with Flemming's triple stain, safranin, gentian violet and orange $G$, made by Grübler. Prepare the stains separately as follows: Make a saturated solution of safranin in 95 per cent. alcohol and dilute it with an equal amount of distilled water. Make a saturated solution of gentian violet in distilled water, to be used without dilution. Make a saturated solution of orange $G$ in distilled water and dilute it with five times its bulk of distilled water. Put the safranin and gentian violet into Stender dishes or tightly covered tumblers, and the orange $G$ into a drop bottle. In addition to the stains have conveniently at hand:

A drop bottle containing absolute alcohol.

A drop bottle containing clove oil.

A Stender dish or tumbler of xylene.

A Stender dish or tumbler of 95 per cent. alcohol acidulated with a drop of concentrated hydrochloric acid.

Proceed with the staining as follows:

r. Stand the slide on end in the safranin for a few hours or over night.

2. Remove the slide from the safranin, drain it, rinse it quickly in water, and set it on end in the dish of acidulated alcohol until the safranin stops coming off in clouds and the sections seem almost or quite decolorized.

3. Rinse the slide quickly in water and set it on end in the dish of gentian violet for ten minutes.

4. Remove the slide from the gentian violet, rinse it in water, hold it horizontally, and flood the sections with orange $G$ from a drop bottle for four seconds.

5. Rinse off the orange $G$ in water, drain the slide, and while holding it slightly slanting downward thoroughly dehydrate the sections by having absolute alcohol flow over them from the drop bottle.

6. Set the slide horizontally and flood the sections with 
clove oil from the drop bottle. This will gradually extract the gentian violet, and the preparation should be watched under the lower power of the microscope so that this action may be stopped as soon as the gentian stain has lost its too great intensity and become transparent while yet distinct. Then drain off the clove oil and set the slide in the dish of xylene to thoroughly rinse away the clove oil.

7. Remove the slide from the xylene, drain it, place a drop of Canada balsam toward one end of the group of sections and lower a coverglass over it, beginning at the end where the drop of balsam is, by bringing the coverglass into contact with the slide first at that end and gradually lowering ${ }^{2}$ toward the opposite side so as to drive forward any air bubbles that may become entangled with the balsam. Then set the slide where the balsam can dry for several days at about $50^{\circ} \mathrm{C}$.

With this three-color stain the cytoplasm should be gray or brownish, the nucleus violet, the nucleolus red, cellulose walls uncolored or grayish, lignified, cutinized, and suberized walls red. In dividing cells the chromosomes should be red, the spindle fibers violet, and the rest of the cytoplasm gray or brownish.

Where a fine differentiation of the parts of the protoplasts is not so much sought after as a differentiation of the tissues, other simpler methods of staining may be used to good advantage. Double staining with cyanin and erythrosin gives excellent results. For this are needed a saturated solution of cyanin in 95 per cent. alcohol, in a Stender dish or covered tumbler, and a saturated solution of erythrosin in clove oil, in a drop bottle. Set the slide on end in the cyanin for about ten hours, then rinse it in 95 per cent. alcohol until the cyanin no longer comes away in clouds, and this should require only a few moments; then flood the sections for about four seconds with the erythrosin solution, drain and rinse thoroughly with xylene and seal in balsam. If the clove oil is not completely rinsed out in xylene the stains will fade out after a time. The 
time ratios in the stains will need to be varied for different materials. Iodine green may be used in place of the cyanin. It is cheaper than cyanin and is easier to work with.

Cyanin and erythrosin can be used for sections cut freehand or in any other way, and loose sections may be stained in watch glasses. A beautiful differentiation of the protoplast in shades of gray is obtained by iron alum-hæmatoxylin. Place the sections for two hours in a 3 per cent. aqueous solution of ammonia sulphate of iron, then wash in water for half an hour and place for about ten hours in a 0.5 per cent. aqueous solution of hiematoxylin that has ripened in a bottle plugged witu cotton, to let in the air, for two months. Remove from the hrematoxylin, rinse in water five minutes, and place again in the iron alum to reduce the too intense stain. Keep watch of the bleaching process under the microscope until the parts of the protoplast appear no longer muddy, but still well defined. Now wash in water for an hour or more, and pass through alcohol and xylene, and mount in balsam. After the last washing in water the sections may, if desired, be very lightly counterstained in a weak aqueous solution of fuchsin or orange $G$, and then, after again rinsing, be carried through alcohol and xylene for mounting in balsam.

It must be borne in mind that always when sections in water or aqueous stains are to be mounted in balsam they must pass from the water into 95 per cent. or absolute alcohol for dehydration, and then into xylene which is a solvent of balsam. If it is found that the sections look milky or opaque when taken from the alcohol to xylene it is a sign that dehydration was not complete, the alcohol was not strong enough or the sections were left in it for too short a time. Opaque sections of this kind will clear up more or less after long standing in xylene.

Imbedding in Celloidin.- Sometimes material that is not suitable for sectioning iree-hand will also not give good results when imbedded in paraffin, on account of its size, hardness, or brittleness. In such cases we may get help in celloidin or collodion (gun cotton) for imbedding. The process of obtain- 
ing sections in this way is a slow one, and it is difficult to get sections as thin as ten mikrons. Therefore cellodin is to be looked upon as a last resort in a difficult situation.

Material to be imbedded in celloidin is to be prepared in all respects as when paraffin is the imbedding material up to the 90 per cent. alcohol in the dehydrating process. From this alcohol it is put into equal parts of ether and 95 per cent. alcohol (which we call ether-alcohol) for several hours and then into a 2 per cent. solution of celloidin in ether-alcohol, where it should remain for several days and then be transferred to a 5 per cent. solution of celloidin in ether-alcohol, whence after a few days it is to go into a I2 per cent. solution of celloidin, and after it has remained here a few days longer it is ready to be mounted on a pine block preparatory to being sectioned.

Prepare a pine block large enough in cross-section to support the material and with other dimensions adaptable to its being clamped in the object carrier of the microtome. Leave one end of the block rough and soak this end in ether-alcohol for a while and then dip it for a moment in the 2 per cent. celloidin solution. Remove the material from the thick celloidin and set it in right position on the prepared end of the block. Let the celloidin on the block stiffen for a moment only and then dip the celloidin end into the thick solution, remove it and hold it upright so that the new coating of celloidin may spread out somewhat over the end of the block and make a solid union, and as soon as the celloidin has hardenerl a little at the surface drop the preparation into a dish of chloroform. After the celloidin has hardened in the chloroform for a day put the preparation into equal parts of glycerine and 95 per cent. alcohol where it is to remain until wanted for sectioning.

If it is more convenient to olstain ordinary collodion or gun cotton in place of celloidin it will do just as well as the latter.

When wood tissue is to be imberded in celloidin it has been found helpful first to boil it thoroughly to drive out the air, then to soak it for about two weeks in equal parts of commercial hydrofluoric acid and water, or in stronger solutions up to the 
pure acid with very hard woods, to remove silicious deposits that add much to the difficulty of sectioning. After this wash out the acid completely and put the material for several days into equal parts of 30 per cent. alcohol and glycerine preparatory to starting in 90 per cent. alcohol on the way through celloidin, as above described. The hydrofluoric acid solutions must, of course, be used in a dish coated with paraffin.

Sectioning Celloidin Material.-Clamp the block in right position in the object carrier of a sliding microtome (Fig. I43), set the knife slanting so that a long gliding cut will be made, wet the knife with the alcohol-glyccrine mixture, and proceed to cut the sections as thin as they can be made; but hope not for success if the knife is dull. With a camel's-hair brush sweep the sections from the knife into a dish of $; 0$ per cent. alcohol.

Staining Celloidin Sections.--Transfer the sections from the 70 per cent. alcohol to the safranin solution described under the three-color method (page 264), and after ten hours or longer rinse them in 70 per cent. alcohol containing one drop of concentrated hydrochloric acid for every fifty cubic centimeters, until the safranin is very faint in the celloidin but still of sufficient intensity in the subject itself. Then pass the sections quickly through 95 per cent. alcohol and transfer them to a mixture of equal parts of bergamot oil, cedar oil, and carbolic acid where they will be further dehydrated and cleared, and then they are ready for mounting in Canada balsam.

Safranin and Delafield's hæmatoxylin combine well for double staining celloidin sections. To make the hæmatoxylin solution dissolve one gram of hæmatoxylin in 6 c.c. of absolute alcohol and add this drop by drop to roo c.c. of a saturated acqueous solution of ammonia alum. Leave this exposed to light and air for one week, then filter it and add 25 c.c. each of glycerine and methyl alcohol and after five hours filter again. Let this ripen about two months before using.

To double stain the celloidin sections place them in safranin for a day, rinse them in 50 per cent. alcohol, put them into 
hæmatoxylin for about ten minutes, rinse them thoroughly in water and then in 35 per cent. alcohol and again in 50 per cent. alcohol; pass them quickly through acid alcohol (one drop hydrochloric acid in 50 c.c. of 70 per cent. alcohol), and then put them through 7o, 85 , and 95 per cent. alcohols, leaving them about two minutes in each grade. Now clear the sections for about two minutes in the mixture of equal parts of bergamot oil, cedar oil, and carbolic acid, and mount them in Canada balsam. Here, as in all staining, the time ratios for the different reagents will need to be determined for different materials.

\section{Making Permanent Mounts in Glycerine or Glycerine} Jelly.-Filamentous algæe and fungi are pretty certain to shrink and become plasmolyzed when put through the process of mount-

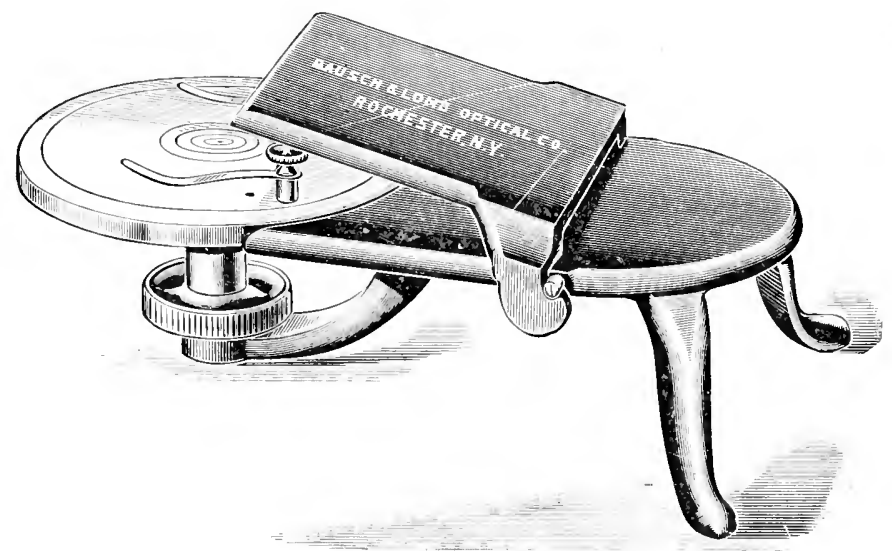

Fig. I 46. - Turn table for cementing coverglasses to slides. For use where the mounting medium is glycerine or glycerine jelly.

ing in balsam, but this danger can be easily avoided by mounting them in glycerine or glycerine jelly, preferably the latter. Fix the subjects in the chrom-acetic fixative described on page 260 ; wash them in running water for a few hours and place them in a 0.5 per cent. aqueous solution of eosin for several hours; place for five minutes in a one per cent. solution of acetic acid in distilled water; wash out the acid completely in water and transfer the material to a ten per cent. solution of glycerine; 
tie a cloth over the dish to keep out the dust and allow the glycerine to concentrate by evaporation, and when it appears like undiluted glycerine place the material in a drop of glycerine on a glass slip, put on a coverglass, wipe away all sur.plus glycerine with a moist cloth, dry the slide thoroughly, and with a turn table (Fig. I46) spin a ring of shellac cementing the coverglass to the slide. To make the shellac cement make a thick solution of ordinary gum shellac in 95 per cent. alcohol and add twenty drops of castor oil to the ounce.

A more durable preparation is made by mounting in glycerine jelly. To make the jelly, soak one gram, of best gelatine in six grams of distilled water for two hours or so; add seven grams of pure glycerine and 0.15 gram of concentrated carbolic acid; heat this and stir it with a glass rod until it becomes clear; put filter paper into a funnel, run distilled water through it, set it in an incubator or oven just warm enough to keep the jelly fluid, and filter the jelly into a bottle; cork the bottle. For use set the bottle in warm water until the jelly liquefies. To mount material in the jelly warm a slide, put a drop of the liquefied jelly on it and transfer the material from the concentrated glycerine to the drop, put on the coverglass and after the jelly stiffens spin the ring of cement. 


\section{CHAPTER XV}

THE USE OF THE MICROSCOPE

Adjusting the Microscope.-A type of microscope adapted to all histological purposes is shown in Fig. I47, where all the parts are plainly indicated. In lifting the microscope grasp

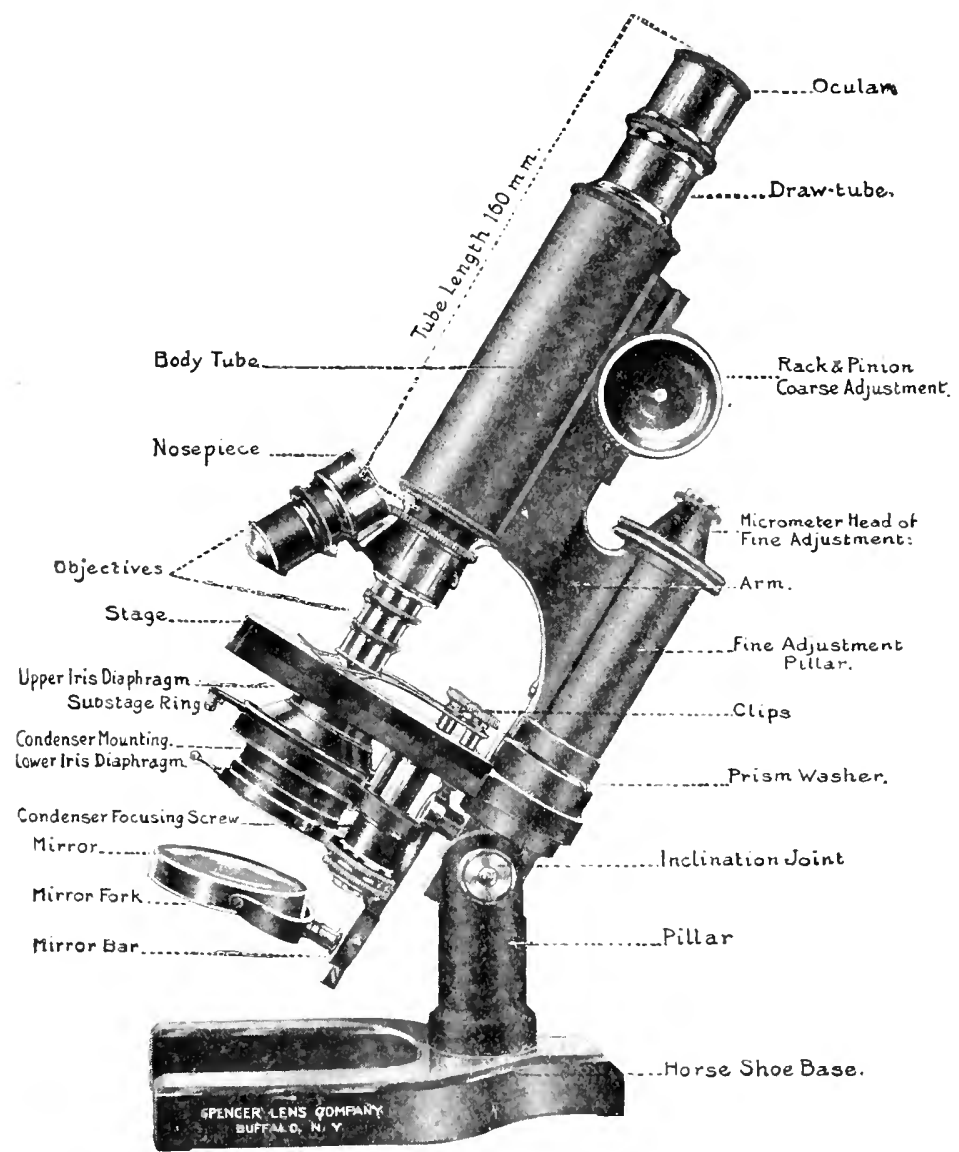

FIG. I 47.- Illustrating the parts of a compound microseope. 
it by the pillar below the stage, never by the arm or fine adjustment pillar, since the fine adjustment bearings might be injured in that way. Take a position near a window where the light from the sky will be unobstructed, but where direct sunlight will not fall upon the microscope. A north window is preferable where the too bright light from the sun cannot interfere with good vision. Place the microscope on the table, as shown

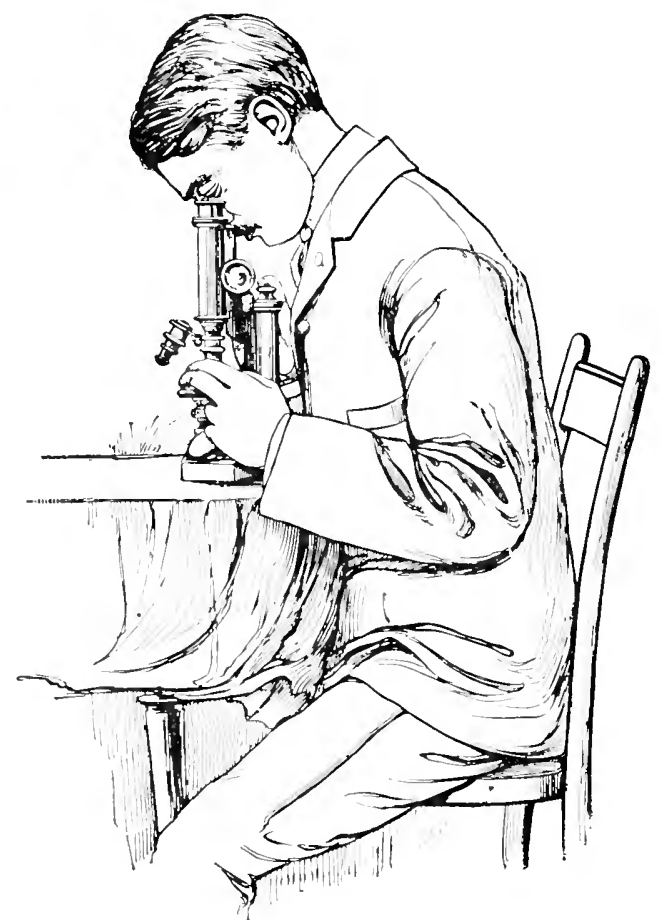

Fic. I 8. - Showing correct position at the compound microscope.

in Fig. I 8 , so that with the microscope erect you can look into the eyepiece without putting yourself in a constrained position. The better microscopes have an inclination joint, so that the microscope can be inclined to suit the height of the observer; but since in histological work fluid reagents and mounting media are to be used it is better to keep the microscope upright 
and adjust yourself to it by adjusting the height of the table or chair. If the microscope is to be inclined pull back on the fine adjustment pillar and not on the body tube.

In nearly all histological work the object is seen by transmitted light; that is, by light that shines through the object, and this is accomplished by reflecting the light from below by means of the mirror, and where high powers are employed the light should pass through a condenser. The mirror has a plane and a concave surface, and where there is a condenser the plane surface only should be used, and without a condenser the concave mirror can in a measure fill its place, but it does not give so good results with high powers as does the condenser. 'The condenser should have an iris diaphragm by means of which the light can be adjusted to the object used, as will appear later on.

For histological work there should be a medium and a high power objective, such as a $\frac{2}{3}$ and a $\frac{1}{6}$ in. or a 16 and $\mathrm{a} 4 \mathrm{~mm}$., mounted on a rerolving double nosepiece, as shown in Fig. I47. Assuming that the microscope is thus equipped revolve the lower power, that is, the $\frac{2}{3} \mathrm{in}$. or the $16 \mathrm{~mm}$. objective into position (in the figure the higher power is shown in position) and get ready some object for examination. To begin with there is nothing better than starch from the potato. To prepare this for examination a glass slip and coverglass obtainable from dealers in microscope supplies will be necessary. A good supply of these should be at hand. Clean a glass slip thoroughly so that it is crystal clear when you look through it; lay it flat and put a small drop of water on it near the middle. Cut open a potato and with the point of a pocket knife scrape up a very small portion of the pulp not more than the size of two pin heads. Better take too little than too much. Put this in the drop of water on the slip. Clean a coverglass thoroughly and lay it over the drop. The coverglass must be put on with some care else air bubbles will become entangled in the preparation, and they are a nuisance, particularly to a beginner who may mistake them for some part of the thing he is studying. To 
aroid the air bubbles place one edge of the coverglass on the glass slip first and then gradually lower the coverglass while holding it between thumb and finger pressed against opposing edges, and support it with a dissecting needle held under the upper edge as the coverglass begins to flatten out the drop of water. If now air bubbles are being entangled in the water the coverglass may be rocked gently up and down with the dissecting needles until the bubbles are broken and driven out. When the coverglass is in position the water should fill out under it to the edges, but no more. If it runs out over the slip the drop was too big and the surplus should be wiped off with a piece of filter paper or clean cloth. Take note in this first preparation whether the drop was too large or too small so as to avoid the mistake in the future. The potato in the preparation should now appear as a very thin film. If it is in a lump it may be flattened out by pressing on the coverglass with the dissecting needle. Now place the slip on the stage under the clips (see the figure for the parts of the microscope as they are mentioned) and bring the preparation over the center of the condenser or to the center of the opening in the stage if there is no condenser. With the plane mirror, if there is a condenser, reflect light from the sky into the condenser and adjust the mirror so that the preparation is seen to be illuminated while looking at it directly and not through the ocular. Then with the rack and pinion coarse adjustment run the body tube down until the lower power objective, which has been revolved into position, is within a quarter inch of the coverglass. Look in through the ocular and the field of view should appear circular and brightly illuminated; if it is not, adjust the mirror slightly until it is so. Now, still looking through the ocular, slowly rack the tube back until the object comes into view, and with the micrometer head of the fine adjustment, turning to right or left as seems to be necessary, bring the olject into sharp focus. The torn and crushed tissue of the potato will be seen and many very minute grains of starch which need to be seen with the higher power objective. Accordingly draw the body tube up with the coarse adjustment 
and swing the high power objective into position, and then while watching outside the microscope run the body tube down until the objective all but touches the coverglass. It must be very close indeed, and you must hold your eye on a level with the stage to be certain about it and see that the objective does not press against the coverglass. Now look through the ocular and slowly draw the body tube up by turning the micrometer head of the fine adjustment contra-clockwise, until the preparation comes sharply into view. Starch grains of the potato have circular, excentric striations, and if you can see these clearly with the high power it is an indication that the microscope is adjusted to give a good image. If the striations cannot be seen you may be sure something is the matter. See that the mirror is adjusted to give plenty of light and that the opening in the iris diaphragm is hardly more than $\frac{1}{8}$ in. in diameter, and see that the lenses of the ocular and the front lens of the objective are perfectly clean. These are the chief things to look to in securing a good image. If the lenses need cleaning breathe upon them and quickly wipe them off with a clean soft cloth; or dip the cloth into water and wash the lenses and then dry them with gentle pressure of a dry part of the cloth. A good tentative rule about the diaphragm opening is to have it about the size of the front lens of the objective in use. If there is then not enough light the opening may be made somewhat larger, but it will be seen that the image becomes less sharp the larger the diaphragm opening is made to be. Make it a rule from the beginning never to put up with a poor image.

There are some details about the working of a microscope that need special mention. The tube length should be adjusted to I60 mm. by sliding the draw tube in or out (see Fig. I 47). When a revolving nosepiece is used the tube length should be measured from the eyelens to the lower edge of the nosepiece. The corerglasses should be No. 2, excepting when oil immersion objectives are employed with a working distance so short as to require the thinner No. I coverglasses. It is to be noted that the micrometer fine adjustment works through only a 
short distance, and therefore the coarse adjustment should always be used excepting for the finishing touches in getting a sharp image. If at any time the fine adjustment has been run to the extreme end of its range one way or the other the body tube should be run up with the coarse adjustment and the micrometer head of the fine adjustment should then be turned in the requisite direction to bring the fine adjustment to about the middle of its range.

In some microscopes the condenser is provided with a focusing screw, by means of which the condenser can be raised or lowered to give the best results. Where there is a fixed mounting for the condenser the latter should be kept with its front lens flush with the upper surface of the stage. It is important that the lenses of the condenser should be kept as crystal clear as those of the ocular and objectires.

For nearly all work the mirror bar should be kept parallel with the long axis of the microscope, so that the light will be reflected along the axis of the entire system of lenses.

The clips (Fig. I47) are intended to press gently upon the glass slide so that it can be moved about over the stage steadily with gentle pressure of the fingers, but this cannot be done well unless the stage is kept clean.

It has already been said that where there is a condenser the plane mirror should be used. The reason for this is that the condenser is made to bring parallel rays of light to a focus in the plane of the object, and if the concave mirror is used convergent rays would enter the condenser and be brought to a focus within the condenser system and the object would not be so well illuminated.

Keep the fingers off from the surfaces of the lenses, for they are sure to leave a film that will need to be washed off. Most of the trouble which beginners experience in the use of the microscope comes from dirty lenses due to contact with the fingers or reagents, and to water or other fluids in which the object is mounted running out from under the coverglass and coming between the latter and the objective. These troubles 
are easily avoided with a little thoughtful attention. One can soon get into the habit of not touching the lenses with the fingers, and reagents will not run out from under the corerglass unless more than is necessary has been used. One should soon learn how large a drop of reagent is needed for a given size of coverglass.

For bacteriological and cytological work an oil immersion objective will be necessary. A $\frac{1}{1^{2}}$ in. or a $2 \mathrm{~mm}$. objective is best for general work in these lines. If such an objective is to be used it would be best to have a triple revolving nosepiece to carry the medium, the high, and the immersion objective all at once. The use of the oil immersion objective is very simple. Put a small drop of cedar immersion oil on the coverglass directly over the object and run the body tube down with the coarse adjustment until the front lens of the immersion objective enters the drop and comes almost into contact with the coverglass. This is to be done while watching the objective outside the microscope. Then while looking through the ocular draw the objective up with the fine adjustment until the object comes into focus.

The higher the power of the objective the smaller the field of view, and when it comes to the oil immersions one sees but a very small area at once, and it is therefore much more difficult to find a small object with them than with the lower powers. For this reason it is a good plan to find the object with a lower power and bring it to the center of the field, and then it will probably be in view when the immersion objective is used, but if it is not it cannot be far out of the way and a very slight movement of the preparation one way and another should suffice. With the oil immersion, when the object has been stained, the opening of the diaphragm may be made as wide as is necessary to let in plenty of light. Indeed a good image can under these conditions be secured with a wide open diaphragm. When through with the oil immersion objective wipe it off with a clean soft cloth or with a piece of "Japanese lens paper, and wipe off the coverglass in the same way. 
A very good artificial light for use with the microscope can be obtained with a Welsbach gas mantle and a balloon flask filled with a light solution of ammoniacal copper sulphate (Fig. I 49). Dissolve a very small crystal of copper sulphate in enough water to fill the flask and add ammonia a little at a time until the solution loses all opalescence and becomes perfectly clear blue. Adjust the light and the blue condenser in front of the microscope until an image of the mantle, about natural size, falls on the mirror. Looking through the micro-

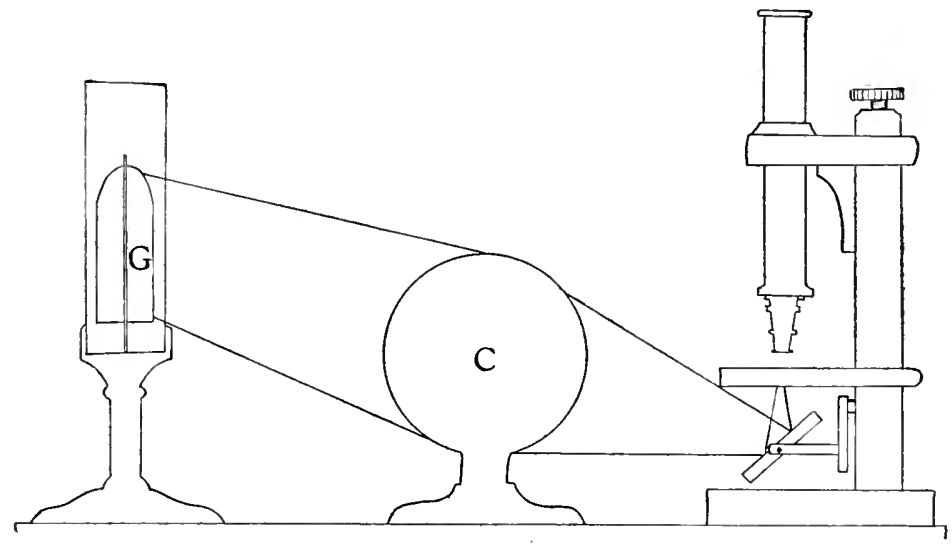

FIG. I 49.-Method of illuminating compound microscope with gas lamp. $C$, Balloon flask filled with ammonio-sulphate of copper: $G$. Welshach mantle.

scope the light should appear white; if yellow, add more copper sulphate; if blue, dilute the solution. This light cannot be excelled and makes one independent of the weather conditions or the time of day.

Drawing to Scale from the Microscope.-There are two ways of drawing from the microscope to a scale that can be accurately determined; one is by the use of an eyepiece micrometer, that is, an eyepiece containing a glass disc with a fine scale etched on it. For purposes of drawing, a disc ruled off in very small squares is preferable (Fig. I50). In using this we need to know how large with a given objective an object would be that just fills out the space across one of these squares 
or divisions of the scale. This we can determine with a stage micrometer scale, which is simply a glass slip with a scale etched on it divided into tenths and hundredths of a millimeter. Put this in position on the stage and focus with the medium power and find how many of its smallest divisions extend across one of the squares or divisions on the eyepiece scale. Suppose it takes fifteen of them to do this, then we know that any olject that is found with the same objective to extend across one of the divisions on the eyepiece scale is exactly . $5 \mathrm{~mm}$. in diameter. Try the high power in the same way, and of course the scale on the stage will be magnified more and a less number of its dirisions than before will now cover a division in the eyepiece scale. If three of them now do this we know that any object under the high

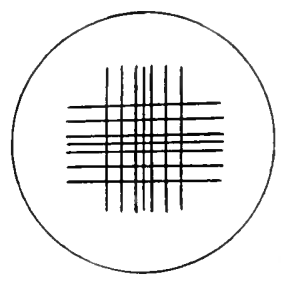

Fiti. 150.-Glass disc ruled into squares to serve as a micrometer eyepiece and microarea computer. This is to be flaced in an ordinary evepiece. power extending across one division of the eyepiece scale has an actual diameter of $.03 \mathrm{~mm}$. An arbitrary but accurately determinable scale can now be fixed, upon for drawing from the microscope. We may decide to draw $5 \mathrm{~mm}$. long anything that covers one eyepiece scale under the medium power, in which case the magnification of the drawing would be $\frac{5}{15}=$ 33.3. This will serve to illustrate the method. When the eyepiece micrometer is ruled in the form of squares it can be conveniently used in determining the number of any particular structures in a given area, as in a square millimeter. For instance, using the medium power with which an object. I $5 \mathrm{~mm}$. in diameter would extend across the diameter of the square of the eyepiece scale, suppose we can count 9 stomata in the under epidermis of a leaf within one of these squares and we want to determine how many there would be in a square millimeter. That portion of an oljject which fills one of the squares would have an area equal to. .I 5 X.I5 mm. $=.0225$ sq. mm. How many times would this area have to be taken to make up one square millimeter? Of course the answer would be found by 
dividing I by .0225 , which would give $4+4$. Then the number of stomata in one square millimeter would be 9 times $4+4=399.6$.

The other method of drawing to scale is carried out with a camera lucida, the most convenient form of which is shown in Fig. I 5 I. 'The main structural details of this instrument are, behind the opening $P$ a prism silvered on one of its surfaces excepting for a narrow circular area at the center; and the plane

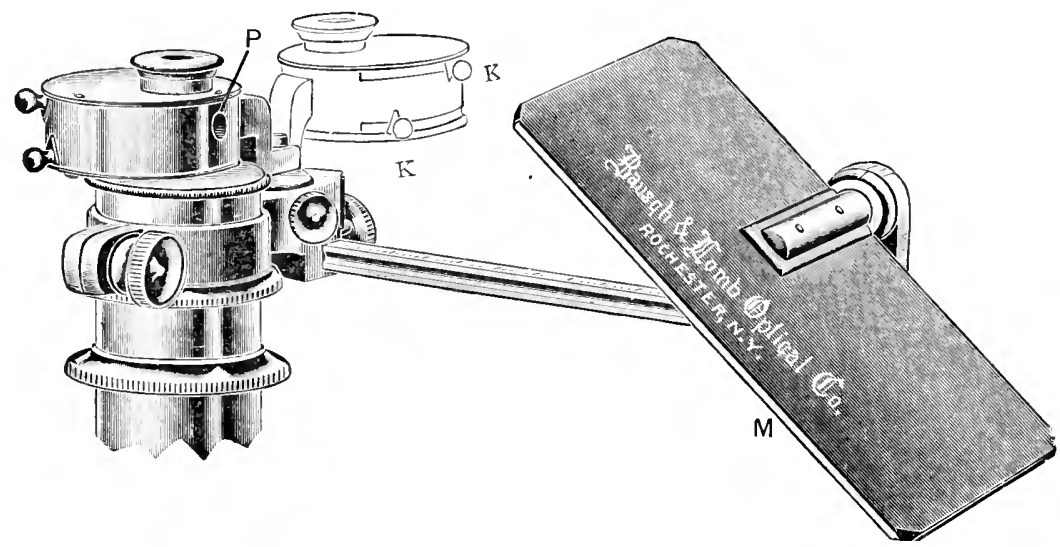

FIG. I5 I. Camera lucila. $M$, Mirror; $P$, opening to reflecting prism; $K$, knobs for regulating diaphragms that govern illumination from object and drawing paper.

mirror at $M$. Through the unsilvered part of the prism one can look and see the object; the mirror reflects the drawing paper placed on the table below it to the silvered surface of the prism and this reflects it into the eye. In this way the object and the drawing paper and the pencil held over the drawing paper are all seen at once superimposed; the object appears spread out over the paper and with the pencil its outlines can easily be traced. To use the camera lucida successfully it is necessary to have some means of illuminating the object and drawing paper with equal intensity, for if one appears brighter than the other they cannot both be seen with equal clearness. If the object, for instance, is too bright the point of the pencil cannot be accurately followed, and if the paper has the stronger illumination the 
pencil can be seen distinctly enough but the outline of the object becomes too dim. In the camera lucida of Fig. I5I there are two revolving diaphragms with handles at $\mathbf{K}$, with a series of

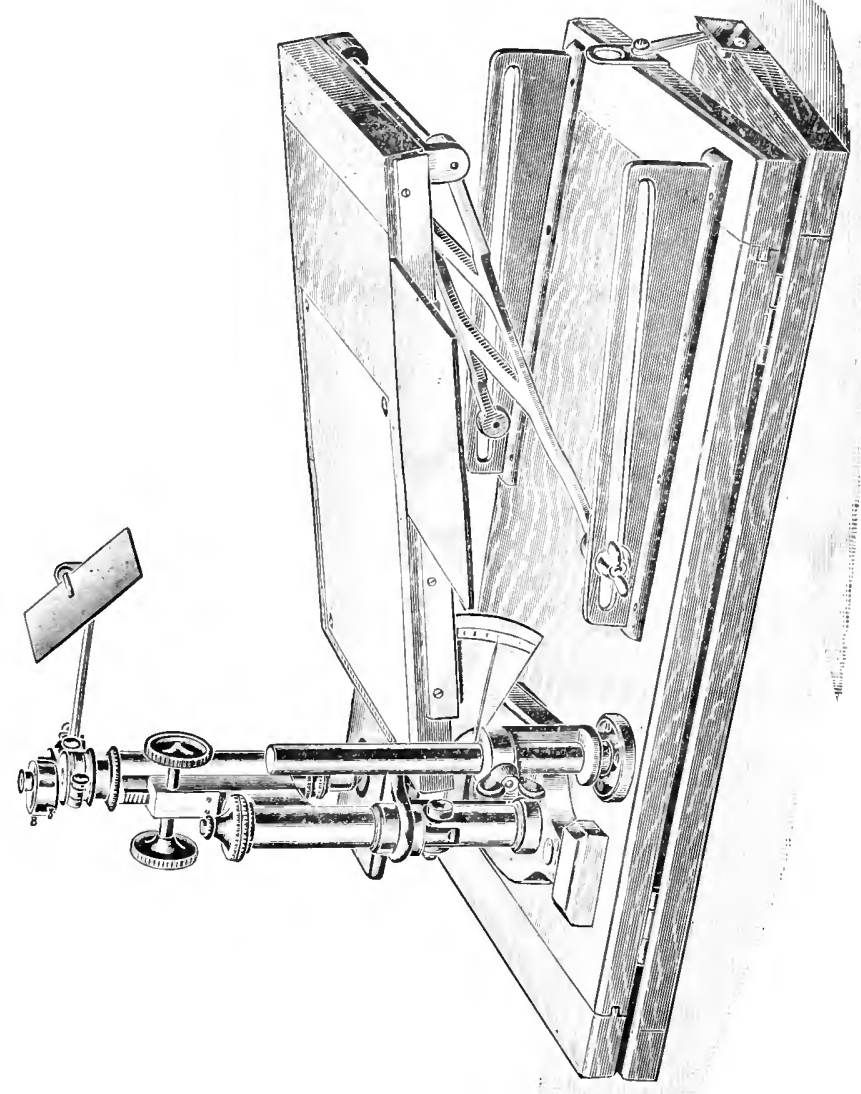

FIG. 152.-Convenient drawing board for use with camera lucida.

openings, all but one of which in each series are covered with a graduated series of different intensities of smoked glass. With this provision one can decrease the light entering the eye from the drawing paper or from the object until the object and the point 
of the drawing pencil can be seen with equal clearness. It is best to begin the adjustment with the free opening in both diaphragms in position, that is. with no smoked glass intervening between drawing paper or object, and then if the object, for instance, should be too bright the diaphragm relating to it can be revolved until this is corrected, or if the drawing paper is too bright its diaphragm is to be revolved until the right degree of smoked glass is in position.

In drawing from the camera lucida it is a convenience to have a drawing board (Fig. I52) adjusted to the same height as the microscope stage, and if the microscope is used tilted the drawing board should be set to the same angle as the stage. The mirror should be adjusted to bring the center of the drawing vertically below the middle part of the mirror, for the projection of the image off to one side of the mirror causes its distortion.

The determination of the magnification of a drawing done with a camera lucida is made by projecting the scale of a stage micrometer upon the drawing paper by means of the camera lucida and drawing it there and measuring the drawing with a millimeter scale. Then the magnification is obtained by dividing the value of the magnified drawing by the actual value of the scale. For example, if one of the finest divisions of the micrometer scale $(.0 \mathrm{I} \mathrm{mm}$.) measures $5 \mathrm{~mm}$. in the drawing the magnification would be $. \frac{5}{01}=500$. Of course the magnification would have to be determined for each objective used and the tube length must be kept the same for the micrometer scale as for the object, and the distance of the drawing paper below the mirror must lee kept the same.

Use of the Polariscope. - The polariscope is very useful in detecting the presence of minute starch grains and crystals and in bringing out sharply fragments of sclerenchyma tissues in powdered drugs, etc. The polariscope consists of the polarizer which is placed beneath the stage, and the analyzer surmounting the eyepiece. Proceed with the polarizer as follows: Adjust the mirror so as to reflect light into the microscope, and looking into the eyepiece rotate the analyzer. It will be seen that during this 
rotation through $360^{\circ}$ the illumination of the field changes from brightness to blackness and back to brightness again. Turn the analyzer so that the field is at its brightest and place on the stage some potato starch mounted in a drop of water or dilute glycerine; these will then appear when looking through the eyepiece as though no polarizing apparatus were employed. Now turn the analyzer through $\mathrm{I} S 0^{\circ}$ or until the field is black and each starch grain will be seen to be traversed with a bright cross. It will be found that when thin sections of plant tissues containing crystals of calcium oxalate are treated in the same way some portions of them shine brightly out in the dark field, and the same thing is true of many sclerenchyma cells and fibers. It will be seen from this that the use of the polarizing apparatus may be of great service in identifying the parts of powdered foods and drugs where the fragmentary condition of tissues, cells, and cell contents increases the difficulty of finding out what the different parts are.

The Use of Reagents on Microscopic Preparations.When an object has been mounted in a drop of water under a coverglass the water can be replaced with other fluid reagents without removing the coverglass or removing the preparation from its position under the objective. Suppose we wish to treat with a solution of iodine, starch from the potato that we have already examined in water: put a small drop of the iodine upon the glass slip close to but not touching the coverglass, and then with a dissecting needle or broomstraw drag the drop into contact with the coverglass, when it will diffuse under and give to the starch the characteristic blue color which iodine is known to impart to it. The drop of reagent is not put at first in contact with the coverglass because there would then be danger of its running over the top of the latter, wetting the front lens of the objective and preventing a good image. If this accident should ever happen in the use of a reagent there is nothing to do but to remove and wash the coverglass, and wash and wipe dry the objective lens. Sometimes it is desirable to hasten the replacement of the water under the coverglass by the reagent, and to do 
this it is only necessary to put a strip of filter paper in contact with the edge of the corerglass opposite the drop of reagent, when the water will run into the paper and the reagent will be drawn under the coverglass by capillarity. This process is called irrigation. It must be remembered, however, that very minute objects such as starch grains are pretty certain to be swept along in the currents, so that the slower process of diffusion should be depended on wherever practicable.

Some reagents should not be diluted with water at all. Such, for instance, is chloroiodide of zinc. If a preparation already mounted in water is to be treated with such reagents the coverglass should be removed and all of the water drawn off with filter paper; then the reagent should be put on before the preparation has time to become dry. If acid reagents are to be used especial care must be taken not to allow them to get upon any parts of the microscope; if this should happen they must be washed off at once with plenty of water. The use of such acids as hydrochloric and sulphuric must be quickly over with, since their fumes are injurious to the eyes as well as to the microscope.

When through with the microscope see that it is clean in all its parts and put it away under cover, where it will be free from dust. 


\section{CHAPTER XII}

\section{REAGENTS AND PROCESSES}

The different kinds of cell-walls and cell-contents may be demonstrated by the use of reagents which, in some cases, impart characteristic colors to walls and contents; in other cases act as selective solvents, dissolving some of the walls and contents, leaving others undissolved; or the reagents may produce precipitates the nature of which furnishes good evidence regarding the character of the substance which has united with the reagent to produce the precipitate.

These reagents together with their uses, will now be given in alphabetical order.

Acetic Acid dissolves most ethereal oils, while most fatty oils are insoluble in it; dissolves calcium carbonate with erolution of $\mathrm{CO}_{2}$, while calcium oxalate is unaffected by it, and it therefore serves to distinguish between these two salts of calcium; solvent of crystals of hesperidin which have been deposited from the cell-sap of oranges, etc., when these have lain for some time in alcohol; when various lichens are treated with it, crystals of calycin in acicular form are deposited after the lichens thus treated have been powdered and dried; I per cent. solution dissolves globoids in aleurone grains, while any crystals of calcium oxalate present are unaffected by it; when pieces of potatoes, carrots, etc., are macerated in it, the separate cells become isolated. Used in the preparation of various fixatives.

Albumen.-The white of egg is used with an equal amount of glycerine and a trace of salicylate of soda for fixing microtome sections to the glass slide, the sodium salicylate acting partly as an antiseptic. (Page 263).

Alcannin.-This is a coloring matter, obtained from the roots of Alcanna tinctoria. A tincture of alcannin to be used 
as a reagent is prepared by placing alcanna root in 95 per cent. alcohol for about ten hours, or until a deep red solution is obtained, and then filtering off the solution and diluting it with an equal bulk of water.

(I) Suberized and cutinized walls, when treated with a solution of alcannin for some hours, take on a pink color. Alcannin tincture mixed with I per cent. glacial acetic or formic acid is used to fix and stain sections of elaioplasts from fresh material. (3) When sections containing fatty oils are treated with tincture of alcannin, the oil is colored pink. Sections containing ethereal oils and resins behave in the same manner.

Alcohol.- The commercial alcohol obtained in this country is about 95 per cent. alcohol. In making alcohols from this of different strengths it answers all practical purposes to proceed as if the commerical 95 per cent. alcohol were absolute-that is, very nearly Ioo per cent. Thus, if 50 per cent. alcohol is desired, 50 c.c. commercial alcohol and 50 c.c. distilled water will give sufficiently accurate results for all histological work. If absolute alcohol is desired, it may be prepared by pouring the commercial alcohol over unslacked lime, and then distilling from this. Or better still, drive off the water of crystallization from copper sulphate by heating in an iron vessel. Put the powder into a bottle and pour 95 per cent. alcohol over it. Keep the bottle tightly stoppered. Water will be extracted from the alcohol and absolute alcohol results.

Ammonium Molybdate.-A concentrated solution of ammonium molybdate in a saturated solution of ammonium chloride. This gives a yellow precipitate in sections containing tannins.

Ammonium Vanadate.-This is used as a test for solanin. The sections are treated with a solution prepared by dissolving I part of ammonium vanadate in 1000 parts of a mixture of $9^{8}$ parts of concentrated sulphuric acid and 36 parts of water. If solanin is present, a yellow color appears, which merges into orange, then different shades of red, and finally into violet, and then all color disappears. 
Aniline Oil.--Excellent for dehydrating sections, since it will dissolve about 4 per cent. of water and may be kept dehydrated by a small piece of solid $\mathrm{KOH}$ which is insoluble in it. The sections may be transferred from the aniline immediately into Canada balsam.

Aniline Sulphate.-Make a saturated aqueous solution. As a test for lignified membranes mount the sections in the solution and add a drop of sulphuric acid, and a yellow color is given to the lignified membranes.

Or pour sulphuric acid slowly into aniline oil until a precipitate is produced throughout and then add water until the precipitate is dissolved. This will not require the addition of sulphuric acid to the sections.

Balsam.-Canada balsam dissolved in xylol is, on the whole, the best medium for making permanent mounts of sections under a coverglass. For the method of doing this see page 265. Balsam in xylol can be obtained ready prepared of the dealers.

Barium Chloride.-This is sometimes used to distinguish calcium oxalate from calcium sulphate. When barium chloride is run under the coverglass, calcium oxalate, if present, is left unchanged, while a fine granular layer of barium sulphate comes to incrust any crystals of calcium sulphate. To determine the presence of tartaric acid, barium chloride and antimonic oxide in hydrochloric acid is run under the coverglass, producing, with tartaric acid rhombic crystals of antimonium-barium-tartrate, whose obtuse angles measure $\mathrm{i} 28^{\circ}$.

Benzol.-Used in detecting caffeine, thus: Sections are heated on the slide in a drop of distilled water until bubbles arise, then the water is allowed to evaporate, and the residue is dissolved with a drop of benzol. The benzol is then allowed to evaporate and the caffeine is deposited on the edge of the drop in the form of colorless needle-crystals.

Berlin Blue.- Useful in the study of the growth in thickness of the cell-membranes. In the study of marine alga-notably, Caulerpa prolifera-it is used in the following manner: A vigorous 
alga is submerged for a few seconds in a mixture of one part of sea-water with two parts of fresh water in which has been dissolved sufficient ferrocyanide of potassium to give it the specific gravity of sea-water. The alga is then rapidly rinsed in seawater and placed for about two seconds in a mixture of two parts of sea-water and one part of fresh water, to which has been added a few drops of freshly prepared ferric chloride. This produces in the membranes of the alga a precipitate of Berlin blue. The alga is then transferred to sea-water for further growth. In case new lamellæ are added to the membranes, the new portions will appear colorless, while the older portions will appear blue because of the Berlin blue which was precipitated in them.

Bismarck Brown.-This is preëminently a nuclear stain. The powder is soluble with difficulty in water. It is a good plan to treat with boiling water and after a day or two to filter. Or a saturated solution may be made in 70 per cent. alcohol. Although Bismarck brown stains rapidly, it does not overstain. It may be used for staining in toto or for staining sections on the slide.

Boracic Acid.--Used as a mounting medium for sections containing mucilaginous membranes. The sections are cut from dry material and placed in a ro per cent. solution of neutral lead acetate to harden the mucilaginous layers. Then the sections are stained in a solution of methyl blue, washed in water, and mounted under a coverglass in a 2 per cent. solution of boracic acid. The coverglass should be sealed down with a mixture of paraffin and vaseline, which is applied with a brush while melted.

Borax-carmine. - A + per cent. solution of borax in water is made and to it is added 3 per cent. of carmine; an equal bulk of 70 per cent. alcohol is then added to this. The mixture is left standing for a day or so and then filtered. Sections should lie in the stain for about twenty-four hours, and should then be transferred without previous washing to acidulated alcohol, made by adding four drops of hydrochloric acid to roo c.c. of alcohol. Here they should remain until they become bright 
and transparent. This is a useful stain for aleurone grains, for differentiating cell-contents from cell-walls when the sections are subsequently stained with methyl green, and much used also in the differentiation of the cell-contents of filamentous alge.

Bordeaux Red.- Used in conjunction with hæmatoxylin in staining nuclear figures, particularly where Heidenhain's platinic chloride fixative has been used. The sections are placed in a weak aqueous solution of the Bordeaux until they are intensely stained; they are then rinsed and placed in a 2 to 5 per cent. solution of ferric-ammonium sulphate for three hours. If the sections are mounted on a slide, they should be placed upright in this solution, so that any precipitate may not gather on the slide. Then the sections are carefully washed in an abundance of water, and placed for twenty-four hours in a solution of hæmatoxylin prepared as follows: I gm. of hematoxylin is dissolved in $10 \mathrm{gm}$. of alcohol and $90 \mathrm{gm}$. of water. This is allowed to stand for about four weeks and then an equal bulk of distilled water is added. The stain is then ready for use. When the sections are taken from the hæmatoxylin, they will be found overstained; they are, therefore, rinsed and placed in a 2.5 per cent. solution of ferric-ammonium sulphate, where they remain until examination of the sections under the microscope shows the desired intensity of color. Then rinse in water I5 minutes, dehydrate in alcohol, and pass through xylol for mounting in Canada balsam.

Borodin's Method.-To determine the nature of a precipitate Borodin treats it with a saturated solution of the same substance as the precipitate is supposed to be. Thus, if the precipitate is supposed to be asparagin, it is treated with a saturated solution of asparagin. If the precipitate dissolves by this treatment, it is then some other substance than asparagin. This method is not very reliable for substances which are very readily soluble, such as potassium nitrate. Care must be taken that the solution used for the test is entirely saturated.

Brown Discoloration of Material in Alcohol.-Some plants, such as Monotropa, are apt to become quite brown in 
alcohol. This can be prevented by placing the fresh material in alcohol which is acidulated by vapor of sulphuric acid in the following manner: For each roo c.c. of alcohol several cubic centimeters of concentrated sulphuric acid are poured over $\frac{1}{2} \mathrm{gm}$. of sodium sulphite, and the vapors arising are conducted into the alcohol. This operation need require hardly more than a minute. After twenty-four hours the material should be transferred from the acid alcohol to neutral alcohol. Thereafter the material will not discolor and will take stains very well when used for histological purposes.

Calcium Nitrate.-(r) Used to differentiate more clearly the lamellæ of starch grains. Potato starch, for instance, is placed in a rather strong aqueous solution of methyl violet. After the grains have become deeply colored, they are treated with a weak solution of calcium nitrate, when the methyl riolet becomes precipitated, particularly in the less dense lamellæ of the starch grains. (2) Calcium oxalate is precipitated in the form of crystals when sections containing oxalic acid are treated with a solution of calcium nitrate. The calcium nitrate is thus a test for the presence of oxalic acid.

Canarin.-This is often used as a stain for tissues which have been cleared in caustic potash. Canarin is not affected by this reagent.

Carbolic Acid (Phenol).- Used as a clearing agent. If leaves which have been hardened and bleached in alcohol are placed in three parts of turpentine and one part of carbolic acid, or in pure carbolic acid, the leares will become so transparent that their cellular structure may be made out from one surface to the other. Pollen grains may be made transparent in the same manner.

Carmalum, Mayer's.--Carminic acid I gm., alum ı gm.: discolve in 200 c.c. of hot distilled water; filter and add a few crystals of thymol, or o. I per cent. of salicylic acid, or 0.5 per cent. of sodium salicylate. This stains material well in bulk, with little danger of overstaining. If this happens, it may be corrected by washing with a o. I per cent. solution of hyclrochloric 
acid. Material which has been stained in bulk with carmalum may be sectioned, and the sections may then be double-stained with some aniline stain, such as blue de Lyon. See Boraxcarmine for another carmine stain. Very fine double staining may be achieved by placing sections first in an aqueous solution of iodine green and then for a somewhat longer time in carmalum. By this treatment lignified membranes are stained by the iodine green, while the unlignified membranes are stained by the carmalum.

Cedar Oil.--Sections which are to be mounted in balsam may first be examined in cedar oil to determine their fitness for permanent mounts; if they are satisfactory, the cedar oil may be drained off and the balsam immediately added to the slide. Cedar oil has a clearing effect on sections which are treated with it.

Thicker cedar oil with a refractive index of about $\mathrm{I}_{5} \mathrm{I}_{5}$ is used as an immersion fluid for homogeneous immersion lenses.

Cedar oil is often used as an intermediary between alcohol and paraffin in paraffin-imbedding, but for plant tissues chloroform is rather to be recommended.

Chloral Carmine.-This is useful in clearing pollen grains and staining their nuclei at the same time. It is prepared as follows: Carmine $0.5 \mathrm{gm}$. and 30 drops of officinal hydrochloric acid (specific gravity, I.I 3 or $I 7^{\circ}$ B.) are added to 30 c.c. of alcohol, and this is heated for about thirty minutes on the water-bath; then, after cooling, $25 \mathrm{gm}$. of chloral hydrate are added, and the solution is filtered until clear.

Chloral Hydrate.-Dissolve five parts of chloral hydrate in two parts of water. The chloral hydrate may be taken in grams and the water in cubic centimeters. This is one of the best clearing agents. Whole leaves, when boiled in this solution, clear quickly to such an extent that they may be studied by transmitted light throughout all of the cell-layers. Crystals in leaves may be plainly demonstrated in this way. This reagent is also very useful in clearing pollen grains, and embryos within the ovules. 
Chloral Hydrate-iodine.-Dissolve five parts of chloral hydrate in two parts of water and add enough finely powdered iodine to leave an excess undissolved after long standing. Shake before using. This is the best reagent for demonstrating the presence of starch in chlorophyll corpuscles and in pyrenoids, or in any situation where the starch is surrounded and obscured by other substances.

Chloroform.- Used as a solvent for fatty oils and of carotin. Used as a solvent for paraffin in the process of imbedding in paraffin. See page $26 \mathrm{I}$.

Chloroiodide of Zinc.-Dissolve $30 \mathrm{gm}$. of chloride of zinc, $5 \mathrm{gm}$. of potassium iodide and $0.89 \mathrm{gm}$. of iodine in It c.c. of distilled water. Chloroiodide of zinc solutions should be kept in the dark. This reagent is one of the most generally useful in determining the character of plant membranes. By it cellulose walls are colored violet, lignified membranes a yellowish-brown, cutinized and suberized membranes from yellow to yellowish-brown. When sections containing sieve tubes are treated with chloroiodide of zinc and a rather weak solution of potassium iodide-iodine, the walls of the sieve tubes appear violet, while the pits in the sicve plates are a reddish-brown, due to the strands of protoplasm which penetrate them; the callose plates are stained a reddish-brown. Mucilaginous walls are colored riolet by this reagent. Chloroiodide of zinc stains protoplasmic cell-contents from yellow to brown, and starch from purple to almost black.

Chlorophyll Solution.-A freshly prepared strong solution of chlorophyll in alcohol is used to demonstrate suberized and cutinized membranes. When sections are kept in the chlorophyll solution for an hour or so in the dark, cutinized and suberized membranes are stained green, while lignified and cellulose membranes remain unstained. The chlorophyll solution will not keep, and should be freshly prepared whenever needed.

Chromic Acid.-Solutions of I per cent. and 0.5 per cent. have been much used for fixing plant tissues. The material to be fixed should lie in the chromic acid for a day or more, 
according to the size of the pieces of material to be fixed. 'The material should then be thoroughly washed out in water and dehydrated by slow degrees in ascending grades of alcohol (see page 260). A concentrated aqueous solution of chromic acid may be used as a macerating fluid to cause the separation of tissues into their separate cells. To this end rather thin bits of the tissue to be macerated should be placed in the chromic acid for about half a minute, and then carefully washed in water. This operation may be carried on with sections under the coverglass. Silicious skeletons of diatoms, incrustations on the epidermis of Equisetum, etc., may be prepared by allowing the material to lie in concentrated sulphuric acid until it becomes black, and then, after transferring to a 20 per cent, solution of chromic acid for some minutes, washing thoroughly in water. In the case of Equisetum and the like the tissues should be scraped away from the inside down to the epidermis before treatment with the acids. Chromic acid is useful in the recognition of tannins, since sections containing tannins, when treated with a I per cent. solution of chromic acid, yield a brownish precipitate.

Clearing.-For clearing media see Carbolic Acid, Cedar Oil, Chloral Hydrate, Canada Balsam, Clove Oil, Eau de Javelle, Glycerine, Origanum Oil, Turpentine, Xylol. A very successful method of clearing whole leaves is to boil them, if fresh, in 95 per cent. alcohol to extract the chlorophyll, place them in 5 per cent. hydrochloric acid for about ten hours, and then leave them until quite transparent in a saturated solution of chloral hydrate. In the case of leaves that have been dried, or preserved in formalin or alcohol, and have in consequence become discolored and difficult to clear, place them in a ro per cent. solution of hydrochloric acid overnight and then keep them for three to seven days in a saturated aqueous solution of chloral hydrate. From this they are to be taken and thoroughly washed in water and brought into a 5 per cent. solution of potassium hydrate, and there kept until they are clear and transparent; then they are to be thoroughly washed and transferred to dilute glycerine, or, if they are to be 
stained, to saturated chloral hydrate. To stain the leaves transfer them to a deep red solution of safranin in saturated chloral hydrate for a few hours or overnight; then rinse in water and place them in saturated chloral hydrate till all but the tracheal elements of the reins is clear of the stain. Now the leaves are to be put into dilute glycerine and, after this has concentrated by evaporation in a place free from dust, the leaves may be permanently mounted in glycerine gelatine (see page 269).

This clearing and staining method may be used to advantige with sections of leares, stems, etc., and for these a double staining with safranin and Bismarck brown is often desirable. If this is to be done, after clearing out the safranin stain from all but the lignified walls in chloral hydrate, rinse the sections in water and stain for five to fifty seconds in a saturated aqueous solution of Bismarck brown, then rinse quickly in water and transfer the sections to dilute glycerine, from which they can be brought into glycerine gelatine as above suggested. If the brown stain is too intense at first, it must be used for a shorter time. Experience only will show for the specific subject in hand what the time length for this stain should be.

Clove Oil.- This is an excellent clearing medium, but it has the power of extracting certain stains, and so cannot be used in all cases; it is, however, for this very reason of great advantage in the safranin-gentian violet-orange method of staining. See under this head.

Collodion.- Used as an imbedding medium (see page 267).

Congo-red.--This stain is particularly useful in studying the growth of membranes. Old membranes are, as a rule, left unstained by it, while the newly formed membranes are colored red. In a 0.0 I per cent. solution-that is, I part of the stain to 10,000 of water-algx may continue to live and grow. and they are, therefore, well adapted to the study of the growth of membranes with the employment of this stain.

Copper Acetate.-Used in the determination of tannins. Small bits of the plant to be tested are placed in a saturated solution of copper acctate, where they remain for eight or ten 
days; the sections are then placed on a slide in a drop of a 0.5 per cent. solution of ferrous sulphate; after a few minutes the sections are washed in water, then in alcohol, and are finally treated with a drop of glycerine and examined under a coverglass. 'This gives an insoluble brown precipitate with tannins.

An alcoholic solution of copper acetate, to which has been added a small amount of acetic acid and glycerine, is used to demonstrate glucose in position within the cells where it occurs. The sections are laid in a mixture of the above solution, and an equal rolume of sodium hydrate in alcohol, and the whole is brought to boiling on the water-bath. Since glucose is insoluble in alcohol, the cuprous oxide which indicates the presence of glucose in this reaction is found to be deposited within the cells which contain the sugar. For other tests for sugar with a salt of copper see Fehling's Solution. See under Resin in next chapter.

Corallin.-This stain is to be dissolved in a 30 per cent. or a saturated solution of sodium carbonate. It is particularly useful in staining the callose of sieve tubes. It is best to overstain the sections and then to reduce the intensity of the color by immersing the sections in a 4 per cent. solution of sodium carbonate.

Corrosive Sublimate.-See Fixatives.

Cuprammonia.- This should be freshly prepared as needed in the following manner: Put copper filings into a bottle or flask, which is provided with a ground-glass stopper. Pour concentrated ammonia upon the filings and rock back and forth. Only sufficient ammonia should be used to cover the filings. When the solution will dissolve cotton, it is ready for use. This reagent is a solvent of cellulose. When sections are placed in it for some time and are then rinsed with ammonia and finally with distilled water, crystals of cellulose are precipitated within the cells which are stained blue with chloroiodide of zinc and red with Congo-red. The crystals are again dissolved on the addition of cuprammonia.

Cyanin.-This stain is almost insoluble in water, and should be dissolved in 50 per cent. alcohol. This is a useful stain for 
fats and all ethereal oils. Sections of fresh material, or material fixed in an aqueous fixative, such as an aqueous solution of corrosive sublimate or picric acid, will be sufficiently stained when left in the cyanin solution for about half an hour. Overstaining may be reduced with glycerine. 'The alcoholic solution of cyanin, to which has been added an equal bulk of glycerine, is a good stain for suberized membranes, particularly after the sections have been treated with eau de Jarelle, which destroys the tannins that prevent the membranes from taking the stain. When sections are placed in a dilute solution of cyanin,- say 20 drops of a concentrated alcoholic solution of cyanin in Ioo c.c. of water,-for ten hours or longer, and are then washed in alcohol and placed in oil of cloves containing eosin, the lignified and suberized walls will be stained blue, while cellulose walls will be red. The sections may then be mounted in Canada balsam. When sections are placed for a quarter of an hour in a concentrated alcoholic solution of cyanin, and are then washed in alcohol and transferred for a quarter of an hour to a 5 per cent. ammoniacal solution of Congo-red, the lignified membranes will appear blue, while the unlignified membranes will appear red. After washing in alcohol and afterward in xylene, such sections may be mounted in Canada balsam. See also page 265 .

Dahlia.-An aqueous solution of from o.00I per cent. to 0.002 per cent. is used for staining live nuclei. The dividing nuclei of Tradescantia I'irginica, for instance. when kept in this stain for a few hours, become weakly stained. The structure of pyrenoids is well demonstrated by fixing them in equal parts of a ro per cent. solution of potassium ferricyanide and a 55 per cent. solution of glacial acetic acid and then staining with dahlia, and finally swelling the pyrenoids somewhat in a weak solution of potassium hydrate.

Decalcification. - Three per cent. of nitric acid in 7o per cent. alcohol is a good decalcifying reagent. The material should be left in the solution for several days. Chromic acid has a decalcifying action; a $\mathrm{I}$ per cent. to 2 per cent. solution 
should be used, and the material should be left in this until decalcification is found to be complete.

Decolorizing.--Material which has become brown in alcohol may be decolorized in the following solution: 'To each roo c.c. of alcohol is added from 0.2 to 0.5 c.c. of concentrated sulphuric acid and as much potassium chlorate as can be transferred on the point of a knife. The material is to lie in this solution for eight or ten days, and is then to be transferred to alcohol or to equal parts of alcohol, glycerine and water for preservation. See also under Brown Discoloration and under Clearing.

Dehydration.--This is best accomplished by cutting the material into as small pieces as is practicable, and then placing it in 20 per cent. alcohol, and then into ascending grades of alcohol of to per cent. increase at intervals of about two hours. Microtome sections mounted on the slide may be transferred to strong alcohol without injury. In passing from water or aqueous stains to Canada balsam, the material should first come into strong alcohol, and then into xylol to insure complete dehydration, and to infiltrate the material with a solvent of balsam-namely, xylol. Aniline is also a good dehydrating agent. The preparations may pass directly from water into the aniline and from the aniline into the balsam. A stick of potassium hydrate placed in the aniline will keep the latter dehydrated. Potassium hydrate is not soluble in aniline. Very thin microtome sections which are found not to be injured by drying may be allowed to dry, and then may be placed in xylene and thereafter transferred to balsam. See page 260 for further description of the process of dehydrating.

Desilicification.-This is accomplished by hydrofluoric acid. A glass ressel is coated on the inside with melted paraffin to prevent the action of the acid on the glass. Alcohol is then poured into the ressel and the material is immersed in the alcohol; then the hydrofluoric acid is added, drop by drop. The process should be completed in a few minutes. Care must 
be taken not to breathe the fumes of the acid, since they attack the mucous membranes.

Diastase.-This may be prepared as follows: Germinate barley in the incubator between pieces of blotting-paper until the plumule has reached a length of about $2 \mathrm{~mm}$.; then dry the barley on the water-bath and grind to a fine powder. When a diastatic solution is desired, pour over $10 \mathrm{gm}$. of the powdered barley I liter of water containing 2 c.c. of chloroform; let stand for ten hours at about $\mathrm{I} 5^{\circ} \mathrm{C}$. and filter. 'The water filtered off will contain the diastase in solution. Add a little chloroform and preserve in a dark place. Starch grains may be mounted in this solution under a coverglass and kept from drying in a moist incubator, and the effect of the diastase on the starch may be studied from time to time under the microscope; or a I per cent. starch paste may be made to which about an equal amount of the diastatic solution may be added, and then at intervals samples from the mixture of starch and diastase may be tested with a solution of iodine. The starch will, after a time, be changed into dextrines and grape-sugar and will no longer give a blue color when tested with a solution of iodine.

Digestive Fluids.- To remove from sections aleurone grains which are so numerous as to obscure the nucleus, the sections should be treated for twenty-four hours with a digestive fluid prepared by mixing I part of pepsin-glycerine with I part of pancreatin-glycerine, and 20 parts of a 0.3 per cent. solution of hydrochloric acid. Differences in the character of the protoplasmic cell-contents, and particularly in the dividing nucleus, may be demonstrated by treating sections of fixed material with a digestive fluid made by mixing I part of pepsin-glycerine with 3 parts of water acidified with 0.2 per cent. of chemically pure hydrochloric acid.

Diphenylamine. - This is a test for nitrates in plant tissues. Five centigrams of diphenylamine are dissolved in ro c.c. of pure sulphuric acid. The presence of nitrates is to be assumed when sections treated with this reagent take on a blue color. It 
seems, however, that in the presence of lignified tissues the reaction may fail, even when nitrates are present in abundance. Diphenylamine is also used to distinguish between crystals of asparagin and potassium nitrate. Asparagin dissolves without color in this reagent, while potassium nitrate assumes a deep blue color on dissolving in it.

Eau de Javelle.-Prepared by adding to an aqueous solution of chloride of lime a solution of potassium oxalate so long as a precipitate is formed. The solution is then filtered and diluted somewhat with water before using. Or 20 parts of a 20 per cent. solution of calcium chloride is diluted with Ioo parts of water, and after this has stood for some time, a solution of $\mathrm{I}_{5}$ parts of pure potassium carbonate in roo parts of water is added. If a film should form on the surface of this on exposure to the air, a few drops of the solution of potassium carbonate should be added and the precipitate filtered away.

Lignin is extracted from sections of woody tissues which have lain in the eau de Javelle solution for some time, and thereafter, on treating with chloroiodide of zinc, the membranes show only a cellulose reaction, staining only purple with the chloroiodide of zinc.

Starch grains included in chloroplasts may be demonstrated by first treating sections, or even whole leares, with eau de Javelle until the chloroplasts are dissolved (this may take from one to twenty-four hours), and then treating the material with a solution of potassium iodide-iodine. The starch grains will take on a blue or violet color. In some cases, however, the starch grains themselves are dissolved with the eau de Javelle. In such cases, and indeed in most cases, chloral hydrate and iodine is to be preferred for demonstrating starch inclusions in chloroplasts (see under this head).

When the forms of the cells simply are to be studied, eau de Javelle is very useful in clearing the sections by dissolving the cell-contents. If the sections become too clear in the eau de Javelle, this defect may be corrected by treating the sections with alcohol or with a solution of alum. See under Cyanin for 
usc of eau de Javelle in differentiating cutinized and suberized membranes.

Eosin.-An aqueous solution of eosin is an excellent stain for protoplasmic cell-contents and cellulose walls. The solution should be quite dilute. For the use of eosin in double staining see under Cyanin and Gram's Method. Sce also in the next chapter under Aleurone Grains.

Fehling's Solution.-Prepare three separate solutions: I $7.5 \mathrm{gm}$. of copper sulphate in 500 c.c. of water; (2) $86.5 \mathrm{gm}$. of sodium-potassium tartrate in 500 c.c. water; (3) $60 \mathrm{gm}$. of caustic soda in 500 c.c. of water. To prepare for use, mix I volume of each of these with 2 volumes of water. The solutions keep well separately, but the mixture becomes changed after a time, and for this reason the solutions should not be mixed until needed.

Sections may be treated with this solution on the glass slip. Two small drops of distilled water are placed on the slip with I small drop of each of the three solutions; then sections, not too thin, of the material which is to be tested for glucose are placed in the mixture on the slide. It is best to cut the sections without wetting the razor, and the sections should not be placed in water, but should be transferred directly to the mixture on the slide. The sections should be covered with a coverglass and the slide carefully heated over the flame of an alcohol lamp, or a very small flame from a Bunsen burner, until bubbles rise in the solution. If glucose is present, the sections will appear reddish from very small crystals of cuprous oxide which have been reduced from the solution. If it is not desired to obscrve the crystals of cuprous oxide within the cells, but simply to demonstrate the presence of grape-sugar, small pieces of the tissues to be tested may be placed in a test-tube containing a few cubic centimeters of the solution, which is then heated to boiling; if grape-sugar is present in considerable quantity, a copious precipitate will after a time settle to the bottom of the tube. See under Copper Acetate. This is particularly suitable for demonstrating the presence of grapesugar in those cells which contained it in the uninjured tissues. 
Ferric Chloride.-An aqueous solution is used as a test for tannin. When sections containing tannin are placed in this solution on the slide, a color is produced which may vary from dark blue to green.

Ferricyanide of Potassium.-Used in demonstrating the structure of pyrenoids. Alge containing pyrenoids are placed in a mixture of equal parts of a ro per cent. solution of ferricyanide of potassium and a 55 per cent. solution of acetic acid, and then treated as described under Dahlia.

Fixatives and Fixation.-See page 258.

Fischer's Method of Demonstrating Cilia.-The following method is highly recommended for demonstrating cilia of certain bacteria: An exceedingly small amount of the culture containing the bacteria is spread out as thinly as possible on the coverglass. After the film has dried on the coverglass the latter is passed through the flame of an alcohol lamp or Bunsen burner (care being taken to aroid a too excessive heat), and then a few drops of a mordant are put on the film on the coverglass. The mordant is prepared by dissolving $2 \mathrm{gm}$. of tannin in 20 c.c. of water. The coverglass is then passed back and forth orer a small flame until vapor arises from the mordant. The mordant is now washed off by means of water from a wash-bottle, and then one edge of the coverglass is held in contact with a piece of filter paper to draw away the surplus water. Next, a concentrated aqueous solution of fuchsin is spread orer the film on the coverglass, and the coverglass is held over a flame until the fuchsin solution begins to boil; the coverglass is then washed off, and is allowed to dry. At any time thereafter the coverglass, with the film side down, may be cemented to the slide with balsam. In successful preparations made by this method cilia, when present, will stand out quite sharply.

Fuchsin.-Dissolve I gm. of fuchsin in Ioo c.c. of absolute alcohol and too c.c. of water. An excellent single stain. Especially to be recommended for preparations that are to be photomicrographed. It stains different tissues different tints of red. 
An excellent double stain with fuchsin and methyl blue is obtained as follows. Leave sections in the above fuchsin solution overnight or for several hours. Wash the sections thoroughly in water and rinse in 95 per cent. alcohol quickly and remove them quickly to water while the stain is still coming off in clouds and transfer them to a saturated solution of methyl blue diluted with an equal bulk of water. Leave the sections in this for a few minutes, then rinse them in water and again in 95 per cent. alcohol; transfer them to xylene and mount them in Canada balsam. The time ratios for the two stains will vary with different materials, and the ratios are to be changed as experience teaches.

Fuchsin, Acid.-Excellent for staining crystalloids. The material containing the crystalloids should be fixed in a concentrated alcoholic solution of corrosive sublimate. Then the sections should be immersed for twenty-four hours in a 0.2 per cent. solution of acid fuchsin, to which a little camphor has been added. To demonstrate crystalloids in plastids the sections should be treated as follows: The sections are placed in a solution of 20 per cent. acid fuchsin in $100 \mathrm{gm}$. of aniline-water. This solution is heated somewhat while the sections remain in it from two to five minutes; they are then rinsed in a solution of $I$ part of a concenrated solution of picric acid in alcohol and 2 parts of water. This solution should be warmed to about $40^{\circ} \mathrm{C}$, and the sections should be rinsed in it until they cease giving off color to it. Thereafter they are dehydrated in strong alcohol, passed into xylene, and mounted in Canada balsam.

Acid fuchsin is an excellent stain for leucoplasts and plastids in general. The material is fixed in a concentrated alcoholic solution of corrosive sublimate in absolute alcohol, where the material remains for twenty-four hours; then the fixative is washed out in alcohol containing iodine. Sections from this material are placed in a 0.2 per cent. solution of acid fuchsin in distilled water. After remaining twenty-four hours they are taken out, washed in running water for a time. and then are examined in glycerine or are allowed to dry, after which they 
are mounted in Canada balsam. 'The sections cannot be dehydrated in alcohol, because this will extract the stain from the plastids. The following method may also be used: The material is fixed in a solution of $5 \mathrm{gm}$. of corrosive sublimate in roo gm. of absolute alcohol, which is acidulated with ro drops of hydrochloric acid. Then the fixative is removed by placing the material in pure alcohol, which is several times replaced. Sections from this material should be stained by immersion for about twenty minutes in a solution of $20 \mathrm{gm}$. of acid fuchsin in 200 c.c. of distilled water and 3 c.c. of aniline oil. They are then washed in a mixture of 50 c.c. of a saturated alcoholic solution of picric acid and roo c.c. of water until color ceases to be given off from the sections. Then the picric acid is washed from the sections in pure alcohol. The sections are next placed in chloroform for ten minutes and are then ready to be mounted in Canada balsam.

When desired, sections cut from fresh material may be fixed and stained as above. Or the material may be fixed and imbedded, and after microtome sections have been cut and mounted on the slide they may be stained as above directed.

A beautiful double stain for nuclei is prepared from acid fuchsin and methyl blue as follows: The microtome sections mounted on the slide are immersed for half an hour in a 0.001 per cent. aqueous solution of acid fuchsin, then quickly washed in water, and immersed for about one minute in a 0.002 per cent. aqueous solution of methyl blue. The surplus stain is then washed off in alcohol and the preparation is allowed to dry; then the sections are immersed in olive oil from six to twentyfour hours, after which they are washed in absolute alcohol or in a mixture of absolute alcohol and xylol until the stains are quite clear, and the preparation is ready to be nounted in Canada balsam.

Gelatine.-Motile swarm spores and the like are sometimes mounted for observation in a solution of gelatine, which renders their movements less rapid, and in this way facilitates the study of these bodies. About I gm. of gelatine is dissolved 
in roo c.c. of water; a drop of this is placed upon a slide which has been somewhat warmed, and then a drop of the fluid containing the motile bodies is added to the drop of gelatine solution and mixed with it by stirring, after which the coverglass is put on. See also under Nutrient Media.

Gentian Violet.-A I or 2 per cent. solution of acetic acid, to which gentian violet is added until the solution appears of a deep violet color, is effective in instantaneously fixing and staining the nuclei of fresh tissues. Anthers and sporangia need only to be teased out with a needle in this fluid or crushed under the coverglass, when the nuclei of the pollen grains and spores or the mother cells of these will be fixed and stained for immediate examination. See also page 264 and Gram's Method.

Glycerine.-This is frequently used as a mounting medium, but since objects are apt to become very transparent in it, only those sections which have been stained should be mounted in it. Sections, such as of wood, which are not apt to shrink easily may be mounted in glycerine directly from water, but delicate tissues should first go from water into a mixture of to parts of water and I part of glycerine; this should then be allowed to concentrate by the evaporation of the water, when the sections may be mounted on the slide in a drop of pure glycerine. The coverglass should be quite clean and the glycerine should not be allowed to run back over it. After putting on the coverglass the surplus glycerine should be taken up with a bit of filter paper and the slide about the edge of the coverglass should be made quite clean with a cloth moistened in water and then wiped dry with a dry cloth; then the slide may be put in position on the turntable, where a ring of Brunswick black, or of shellac to each ounce of which 20 drops of castor oil have been added, may be spun around the edge of the coverglass. This process should be repeated several times, allowing each coat to harden before putting on the next, until a strong ring of the cement bas been formed. When certain stains are used, such as hæmatoxylin, the glycerine must be entirely free from acids; but with other 
stains, such as the carmine stains, an acidulation with I per cent. of acetic acid is of advantage.

Dilute glycerine, in which sufficient chrome-alum has been dissolved to give a clear blue color, is recommended as a mounting medium for the Schizophycex and Floridex, since the natural colors of these plants are retained in this medium.

Sections containing mucilaginous membranes may be mounted in a drop of pure glycerine in which the membranes will not swell, and then, by irrigating the mount with water the process of the slow swelling of the membrane may be observed.

Glycerine-gelatine.-This is for most subjects a better mounting medium than glycerine alone. It is prepared as follows: One part by weight of the best gelatine is soaked for about 2 hours in 6 parts by weight of distilled water. 'Then 7 parts by weight of chemically pure glycerine are added, and finally, to each $100 \mathrm{gm}$. of this mixture I gm. of concentrated carbolic acid. The mixture is warmed for about I 5 minutes, and at the same time constantly stirred until it becomes clear; then, by means of a hot-water funnel, or while kept warm in an incubator, the mixture is filtered through glass-wool or filter paper which has been washed with distilled water after being placed in the funnel.

To mount sections in glycerine-gelatine the glass slip is warmed and a small bit of the gelatine is placed upon it. If the slip is not warm enough to melt the gelatine, it should be passed back and forth above the flame of an alcohol lamp. If the sections are of a character not liable to shrink, they may be transferred directly from water to the melted gelatine; if, however, there is danger of shrinking, the sections should first be placed in a ro per cent. solution of glycerine, which is then allowed to concentrate by evaporation of the water, and then, from the concentrated glycerine the sections may be transferred to the drop of melted glycerine-gelatine. To avoid air-bubbles the coverglass should be put on with the precautions given on page 265 for putting on the coverglass when Canada balsam is the mounting medium. If several sections are being mounted under 
one coverglass, and these should come to lie over each other in putting on the coverglass, they may be properly arranged without attempting to remove the corerglass (which usually makes the matter worse) by heating the slide until the gelatine becomes quite soft, and then drawing a hair under the coverglass, with which the sections may be manipulated. It is sometimes a difficult matter to put just the right amount of the gelatine on the slip. To overcome this difficulty, heat the gelatine and pour it out in a thin film orer a clean glass plate. When it has become cool, strip it from the glass; then cut off small squares of different size, melt them separately on glass slips, and cover with the coverglasses of the size to be used with subsequent preparations. The film of gelatine should then be cut into wafers of the size found to exactly fill out the space under the coverglass. These wafers should be kept from drying too much and free from dust in tightly-stoppered bottles.

Glycerine Gum.-Dissolve Io gm. of powdered gum arabic in Io c.c. of water and add about 40 drops of glycerine. This is useful for imbedding hard seeds, pollen grains, etc., preparatory to sectioning them. The wood tissues of hard seeds may be softened as described on page 267. Put a drop of the glycerine gum on a suitable pine block and submerge the material in it, and leave the preparation in the air to dry. Sections may then be cut free-hand with a razor or on a microtome. Wash out the grum from the sections in water.

Glycerine-iodine.-See under Iodine and Glycerine.

Gram's Method.--This method is specially recommended for staining bacteria, either in coverglass preparations or in sections. The sections are stained in a mixture of 100 c.c. of aniline water (prepared by combining about 5 c.c. of aniline with 95 c.c. of distilled water), and I I c.c. of a concentrated alcoholic solution of gentian violet or, better, methyl violet. This is filtered, and to c.c. of absolute alcohol are added to it. The preparation is taken from the stain, rinsed in alcohol, and transferred to a solution of 2 parts of potassium iodide, and I part of iodine in 300 parts of distilled water, where it remains 
from $\mathrm{x}$ to 3 minutes. Then it is rinsed in alcohol, transferred to clove oil, and thence mounted in Canada balsam. A good double stain is obtained if the clove oil has some eosin dissolved in it.

Gunther's modification of the Gram method is as follows: The preparation is stained and passed through the potassium iodide-iodine solution as above. Then it is placed for $\mathrm{I}$ to 2 minutes in alcohol, next for 10 seconds in a 3 per cent. solution of hydrochloric acid in alcohol, then again for several minutes in pure alcohol, until no more color comes away, and then it is passed on into xylol, and finally is mounted in Canada balsam.

Gum Arabic.-The study of the spermatozoids of ferns, etc., is facilitated by adding a Io per cent. solution of gum arabic to the drop of water containing the spermatozoids, which are then unable to move so rapidly in the thicker fluid.

Hæmatein.-Dissolve with heat I gm. of hæmatein in 50 c.c. of 90 per cent. alcohol, and add to this a solution of $50 \mathrm{gm}$. of alum in I liter of distilled water. After cooling, filter if necessary, and add a crystal of thymol to prevent the growth of fungi. The solution is ready for use at once. Sections stained in this solution should be washed in water and transferred to glycerinegelatine for mounting, or may be dehydrated and mounted in Canada balsam. The stain may be reduced in overstained sections by allowing the preparation to stand for some time in a I per cent. solution of alum. A sediment is apt to settle from this solution, but this is not an indication that the stain is spoiled. The sediment can be partly prevented by adding to the solution about 2 per cent. of glacial acetic acid, which, on the whole, increases the effectiveness of the stain. The acid should be entirely washed from the sections with water before permanent mounts are made.

Hæmatoxylin, Delafield's.-Prepared by mixing + c.c. of a saturated solution of hæmatoxylin crystals in absolute alcohol with I 50 c.c. of a saturated solution of crystals of ammonium alum in water. After standing for a week exposed to the light and air, this should be filtered and mixed with 22 c.c. 
of glycerine and 25 c.c. of methyl alcohol. Before using this it should be allowed to stand until all precipitates have settled.

Sections are transferred from water into the stain, where they remain for several minutes; they are then placed in a dish of 70 per cent. alcohol, acidulated with a drop of $\mathrm{HCl}$, and after a minute they are rinsed in 95 per cent. alcohol, then in xylene, and mounted in balsam.

Hæmatoxylin and Safranin.-Sections stained in safranin and washed in water may be placed for a few minutes in Delafield's hæmatoxylin, where they are treated as described under this stain. By this treatment lignified and suberized walls are stained red and cellulose walls violet.

Hanging-drop Culture.-A hanging-drop culture is useful in the study of various microörganisms. Spin a ring of melted paraffin on the slide the size of the coverglass to be used. Wash the coverglass with soap and water, rinse it and rub it bright with alcohol on a clean cloth, and sterilize it by baking in an oven. Handle it thereafter with sterilized forceps. By means of a sterilized glass rod or pipette transfer a drop of nutrient solution (see under Nutrient Media) to the middle of the coverglass, and to this drop transfer with a sterilized needle a rery minute portion of the culture or material to be studied. Invert the culture over the paraffin ring and press it down firmly so that a tight union is made. This is necessary to keep the drop from evaporating. If the paraffin is too hard to make a close union, put a thin layer of vaseline over the ring before putting on the coverglass. The drop should of course hang free in the cell and not touch the slide. Sometimes it is desirable to draw the drop out a little over the coverglass with a sterilized needle, or even to flatten it out entirely by placing over it a coverglass enough smaller than the first not to touch the paraffin ring.

The dealers furnish hollow-ground slides that are excellent for hanging drop cultures. With these no paraffin ring is needed.

Cultures prepared in this way can be studied at any time, eren with high powers, without disturbing them.

Hardening Processes.-The hardening of tissues is accom- 
plished by the withdrawal of water from them. 'This is in most cases best accomplished by means of successively higher grades of alcohol, as described on page 260.

A quick method of hardening fresh tissues, and at the same time preparing them for immediate sectioning, is to freeze them by the evaporation of ether or the expansion of liquid carbonicacid gas. This process requires the use of special apparatus, for a description of which the student is referred to the catalogue of Bausch \& Lomb, Rochester, N. Y. For an imbedding mass, either a drop of the white of egg or a thick solution of dextrin in a solution of carbolic acid $\mathrm{I}$ part, water 40 parts, may be placed about the object before freezing. If the dextrine solution is used, it would be better to pump the air from the object while immersed in the solution; then place the object on the object-holder, pour a small amount of the solution about it, and freeze. This method will answer very well in some cases when it is desired to prepare a large number of sections quickly for class use, but it can by no means take the place of fixing the material in an appropriate fixative, hardening slowly in alcohol, and imbedding in paraffin or collodion.

The mucilaginous layer of certain seed coats may be hardened with a ro per cent. solution of neutral acetate of lead. The sections are cut from dry seeds, hardened in the lead acetate. and stained with methyl blue. They are then washed in water and mounted in a 2 per cent. solution of boracic acid.

Hydrochloric Acid. - This reagent has such manifold application in histology that its uses are best learned in the specific cases of its application. See in the next chapter under Amylose, Berberin, Caffeine, Calcium Oxalate, Calcium Sulphate, Ethereal Oils, Magnesium Sulphate, Middle Lamella, Myrosine, Pectic Substances, Phloroglucin. Theobromine, Vanillin. See also in this chapter under Maceration.

Hydrogen Peroxide.- One part of hydrogen peroxide mixed with 20 parts of 60 per cent. alcohol will, in a few minutes, remore from sections the dark discoloration due to osmic acid which has been used as a fixative (see page 263). 
India Ink.-The gelatinous sheath of the conjugatæ may be demonstrated by placing the alga under investigation in water in which India ink has been rubbed up until the water has a dark gray color. In this the gelatinous sheath becomes sharply demarked.

Infiltration.-For infiltration with glycerine gum see page 306 , with paraffin, page 26I, with cclloidin, page 266 . The stony tissues of seeds, etc., which are too hard and brittle to be sectioned with a knife, and must, therefore, be ground to the requisite thinness on a stone or by means of emery powder, may be protected against breaking during this process if fairly thin sections are first cut with a fine saw and then placed in a rather thin solution of Canada balsam or copal in chloroform, which is then allowed to evaporate to the thickness of syrup; the sections are allowed to dry and are then cemented by means of a thick solution of gum arabic to a glass plate preparatory to grinding. Only a thin layer of gum arabic should be used, and this should be quite dry before the grinding is begun. The sections may now be ground thin on a clean, dry Arkansas or Wichita stone. Before the section has been brought to the desired thinness, the surface should be polished by rubbing it on a piece of soft leather which has been dressed with tripoli. The stone on which the sections are ground may be cleaned of the balsam from time to time by means of a cloth dipped in xylol or turpentine. When one side has been polished, the section may be freed from the glass plate by soaking in water. and then the polished side should be cemented to the glass plate and the reverse side ground and polished as before. The sections should be examined from time to time with the microscope, so that the process of grinding may be stopped as soon as the desired transparency has been obtained. They may then be washed from the glass plate with water, and after drying should be stained with fuchsin and mounted in Canada balsam.

Iodine.-The fumes from heated crystals of iodine serve well in many cases as a fixative. Small objects in drop cultures may be readily fixed by pouring over them the fumes arising 
from iodine heated in a test-tube. Algæ may be fixed by placing a few crystals of iodine in the bottom of a test-tube, cautiously inclining the tube slightly with the mouth downward, then placing the algæ in the test-tube near the mouth directly from the water in which they were growing, and thereafter heating the crystals so that the fumes from them pour down over the algx. The iodine may afterward be expelled by warming the fixed material to $30^{\circ}$ or $40^{\circ} \mathrm{C}$, and the material will then need no further washing out.

Iodine has a wide application in plant histology and microchemistry. See under Aconitine, Atropine, Carotin, Cellulose, Colchicine, Gums, Gram's Method, Lipochromes, Lignin, Nicotine, Proteids, Starch, Suberin.

Iodine and Alcohol.-A good fixative for very small organisms is a solution of 3 parts of iodine in 100 parts of 70 per cent. alcohol. This at the same time permits the staining effect of iodine on the cell-wall and cell-contents.

Iodine and Glycerine.-A mixture of potassium iodideiodine with glycerine in equal parts gives good results when the action of iodine is to be observed. The glycerine keeps the preparation from drying and at the same time has a clearing effect.

Iodine and Phosphoric Acid.-Used as a test for cellulose, which it colors violet. Prepared by dissolving with heat 0.5 gnt. of potassium iodide and a few crystals of iodine in 25 c.c. of concentrated aqueous solution of phosphoric acid.

Iodine and Potassium Iodide.-This solution is prepared by dissolving $0.5 \mathrm{gm}$. of potassium iodide and I gm. of iodine in a small amount of water, and then diluting this with roo c.c. of water. The solution is left standing over any iodine which may crystallize out. This formula is recommended by Arthur Meyer in his work on "Stärkekörner" as best adapted to the study of starch grains. A rough-and-ready method of preparing an iodine solution is to dissolve a small amount of potassium iodide in distilled water and then dissolve crystals of iodine in this until a brown color is obtained. This can be 
diluted with water as is found necessary. A rather pale solution of iodine is sufficient to color starch blue. To stain modified cell-walls the solution needs to be stronger.

Iodine Green.--See page 266 for the use of iodine green in double staining. A 2 per cent. solution of glacial acetic acid with iodine green dissolved in it serves well in the instant fixing and staining of the nuclei of fresh material.

Iron Acetate.-Used in the detection of tannins, which see in the next chapter.

Lactic Acid.-Dried alga and fungi may be prepared for study with the microscope by soaking them first in water and then in concentrated lactic acid, in which they are heated until small bubbles are formed; they may then be studied in the lactic acid. A ro per cent. solution of lactic acid is recommended for fixing bacteria. This fixative is said not to interfere in any way with the subsequent processes of staining with alcoholic solutions of aniline dyes.

Lead Acetate.-A ro per cent. solution of neutral lead acetate is used to harden the mucilaginous layers of seed coats. For subsequent treatment see under Boracic Acid.

Lithium Carbonate.-Useful in removing from material picric acid, which has been used as a fixative. A few drops of a cold, saturated, aqueous solution of lithium carbonate are added to the alcohol, used to wash out the fixative.

Maceration.-In studying the forms of cells it is sometimes desirable and even necessary to isolate them by the process of maceration. Where cells with lignified walls are to be isolated Schultze's maceration process is best employed. Put a small amount of concentrated nitric acid into a test-tube and add a small crystal of potassium chlorate. Heat this to boiling and drop into it sections containing the tissues under investigation. The sections will soon turn quite white. When this occurs, and before the sections hare time to dissolve altogether, pour the contents of the test-tube into a large dish of water. Select a section and tease it out in a drop of water on a glass slide with dissecting needles, and examine the preparation 
under a coverglass. Bast and wood fibers and stone cells can be isolated by this process, but thereafter they give the reaction for cellulose instead of for lignin.

Another process, known as the Mangin process, gives good results with sections. Place the sections for forty-eight hours in a mixture of four volumes of alcohol and one volume of hydrochloric acid. Wash the sections in water and put them into so per cent. ammonia for fifteen minutes, then mount a section in a drop of water under a corerglass and press upon the coverglass until the cells are forced apart.

Chromic acid also is used for maceration. Place sections in a concentrated solution for a minute or so, then rinse them in water, mount them in a drop of water under a coverglass and press upon the coverglass. If the cells do not then come apart they should be put for a longer time in the acid.

Methyl-blue.-An aqueous solution is an excellent stain for cellulose membranes. It may be used as a double stain with safranin as follows: Stain in safranin over night (see under Safranin) and then rinse in water and acidulated alcohol; place in a concentrated aqueous solution of methyl-blue for fifteen minutes, rinse in strong alcohol and xylene and mount in balsam. See also under Fuchsin.

Methylene-blue.-A good nuclear stain. For cells filled with protein granules it is particularly good in differentiating the nucleus. Methylene-blue is useful in differentiating pectin compounds. The protoplast and lignified walls are stained a bright blue, while pectin compounds are stained a violet blue. Cells containing tannin will accumulate methylene-blue from very dilute solutions. The sections of living tissues are placed in a solution of I part of the stain in 500,000 parts of filtered rain-water. The cells containing tannin soon take on a distinct blue color, and, later, a deep blue precipitate is formed in them. The gelatinous sheaths of live conjugatæ may be stained by dilute aqueous solutions of methylene-blue without injury to the living organism. A $0.00 \mathrm{I}$ per cent. solution of methyleneblue in water will stain the living nuclei of diatoms and other 
simple organisms. The central body of the Cyanophycere may be stained by the above dilute solution if, after twenty-four hours' treatment, the stain is strengthened to a o.I per cent. solution. Methylene-blue and carmine form a good differential stain for bacteria occurring in sections of tissues.

Methylene-blue and Carbol-fuchsin.-This double staining method is used in the differentiation of Bacillus tuberculosis. The material first coughed up from the lungs by the patient on waking in the morning should be expectorated into a wide-mouthed bottle or corcred jar. The person who is to make the examination should afterward pour this out into a shallow glass dish. This should be placed on a dead-black background, and one of the small, yellowish, lenticular bodies which usually occur in tuberculous sputum should be removed and placed on a coverglass. A second coverglass should be placed over this; then press the corerglasses gently between the thumb and forefinger, and rub to and fro until the material is spread out in a thin film on the coverglasses. Then slide the coverglasses apart, and allow them to dry in the open air. When dry, hold them with a pair of forceps and pass them three times through the flame of the Bunsen burner or alcohol lamp. (The film should not be allowed to turn brown, else the preparation will be ruined.) Next pour over them carbolfuchsin prepared by rubbing $\mathrm{I}$ gm. of fuchsin with Ioo c.c. of a 5 per cent. aqueous solution of carbolic acid, with the gradual addition of ro c.c. of alcohol. Hold the coverglasses over a flame with forceps until vapor begins to arise from the surface of the stain. Then hold away from the flame, except in intervals of gentle heating, by which they are kept warm for a minute or two. They are next washed in water and decolorized by being moved about in a 25 per cent. solution of nitric or sulphuric acid. When the previously deep red color has changed to a greenish tint, the preparation is washed in 60 per cent. alcohol to remove the color set free by the acid. If any red color still remains, the preparation should be rinsed in water and again treated with the acid-bath. By the above process the fuchsin 
has been removed from everything but the tubercle bacilli. The double staining is accomplished by now pouring over the preparation a mixture of 3 parts of water with I part of a concentrated alcoholic solution of methylene-blue. After a few minutes the methylene-blue is washed off with water, and the preparation is allowed to dry; when dry, it may be mounted in Canada balsam. Other bacteria than the tubercle bacilli are decolorized by the acid-bath, and are subsequently stained blue by the methylene-blue.

Methyl-violet.-Starch grains may be stained by treatment with a dark aqueous solution of methyl-violet. If the starch grains after staining are treated with a very dilute solution of calcium nitrate, the stain becomes deposited particularly in the less dense layers of the grains. Useful as a stain for elaioplasts. See under this head in the next chapter. See also in this chapter under Staining Intra Vitam.

Millon's Reagent.-This should be prepared fresh, as needed, by dissolving mercury in an equal weight of nitric acid and then diluting this solution with an equal weight of distilled water. Proteids are colored a brick-red with this reagent. Sections to be tested are to be mounted in a drop of the reagent on a glass slip. Warming the slip hastens the reaction.

Nutrient Media.-Nutrient media must be sterilized by heat to keep them from spoiling and to make it possible to grow in them pure cultures-that is, cultures of organisms of any desired single species. Sterilization may be accomplished by steaming the medium for about twenty minutes each day on three days in succession, after having poured it into testtubes or flasks which have previously been tightly plugged with cotton rolled into the form of a stopper of the proper size and baked in an oven until the cotton is slightly scorched. The tubes and cotton plugs should be baked together. Or, if an autoclav is available in which steam can be generated under pressure, and accordingly at a higher temperature than that of boiling water at ordinary atmospheric pressure, the cotton 
plugs and tubes, or flasks, will not need to be baked, but may be sterilized, together with the nutrient medium already poured into them, by subjecting then for fifteen minutes to a temperature of $\operatorname{II} 5^{\circ} \mathrm{C}$. in the autoclav. At this temperature a single sterilization suffices.

A good artificial nutrient medium for yeasts is made by adding 0.05 per cent. of tartaric acid to a 10 per cent. solution of canesugar. A filtered aqueous extract of malted barley also gives good results. To prepare this, barley is germinated until the plumule just begins to protrude; the barley is then dried and ground up, and water is poured over it until there is about twice as much water by volume as of the powdered malt. The water should stand over the malt, with occasional stirring, for about an hour, when it may be filtered off and sterilized. Sterilized grape juice is also an excellent nutrient medium for veasts. Cultures of yeasts grown in the above media may be made to produce spores in about twenty-four hours if some of the culture is transferred to the surface of sterilized bits of flowerpot which are half submerged in water and kept covered by a bell-jar.

Cohn's normal solution for the culture of bacteria is prepared as follows: Dissolve in $200 \mathrm{gm}$. of distilled water I $\mathrm{gm}$. of acid potassium phosphate, I gm. of magnesium sulphate, 2 gm. of neutral ammonium tartrate, and o.r gm. of calcium chloride.

An infusion of meat for the culture of bacteria is prepared by covering finely chopped lean beef with water and allowing it to stand for twenty-four hours in an ice-chest, after which it is to be filtered through a muslin bag, using pressure of the hands to make the filtration more complete. The filtrate is then cooked and again filtered, and neutralized by the gradual addition of a solution of carbonate of soda. The solution should be tested with litmus paper, and the addition of carbonate of soda should cease as soon as neutralization is accomplished. To this solution is added 0.5 per cent. of common salt. Ten grams of peptone may be added to a liter of the infusion. 
In place of the meat infusion as prepared above, meat extract may be used in the ratio of 4 to $5 \mathrm{gm}$. per liter of water.

Bouillon is prepared by adding I liter of water to I pound of chopped lean beef. This is cooked for half an hour, then filtered and neutralized with carbonate of soda, then again boiled for an hour to precipitate albuminoids. After a final filtering the boullon is poured into flasks or test-tubes and sterilized.

Infusions of hay and dried fruits may also be used for nutrient media. A hay infusion for the growth of Bacillus subtilis may be prepared as follows: Chopped hay is placed in a beaker and barely covered with well-water; this is kept in an incubator at a temperature of $36^{\circ} \mathrm{C}$. for four hours, after which time the extract is poured off and diluted, if necessary, to a specific gravity of about r.004. The extract is now poured into a flask which, having been closed with a cotton plug, is placed in a steam sterilizer and subjected to a gentle evolution of steam for about an hour. The flask is then placed in an incubator at $36^{\circ} \mathrm{C}$. for a day or two, after which time a film produced by colonies of Bacillus subtilis will have formed over the surface of the extract. The spores of this bacterium are particularly resistant to heat, and for this reason while the spores of other bacteria are killed by the process of steaming, those of Bacillus subtilis still retain their vitality.

Solid culture media may be prepared by adding to any of the fluid culture media a sufficient amount of a gelatinous substance to keep the mixture from liquefying at the temperature of the laboratory, or, if desired, at the higher temperature of an incubator. One of the most used of the solid media is prepared by adding to the peptonized infusion of meat, as above described, ro per cent. of the best French gelatine. 'The gelatine may be increased up to twice this amount, as the temperature may require. One hundred grams of gelatine is allowed to soak in I liter of the meat infusion until the gelatine becomes swollen, and then a gentle heat is applied until the gelatine is completely dissolved. After the gelatine is dissolved the solu- 
tion should again be neutralized, if necessary, with carbonate of soda. When the solution stands at a temperature of about $50^{\circ} \mathrm{C}$., an egg stirred up in $100 \mathrm{gm}$. of water is adder while the mixture is stirred with a glass rod. The mixture is then kept at the boiling-point for about ten minutes. This coagulates the egg-albumen and clarifies the liquid. The clarified liquid is now filtered by means of a hot-water funnel or while kept warm in an incubator, the high temperature being necessary for the reason that the mixture would become stiff at a low temperature, and so incapable of being filtered. The medium should be distributed while warm in sterilized test-tubes or flasks, which are then stoppered with baked cotton plugs. It should then be subjected to a temperature of $100^{\circ}$ in the steam sterilizer for ten minutes at four successive intervals of twenty-four hours. For the reason that gelatine loses its power of solidifying at ordinary temperatures after being subjected to the temperature of boiling water for a long period, the time of each sterilization is necessarily reduced to about ten minutes and the number of sterilizations is increased to four; whereas, with other solidifying substances, such as agar-agar, the length of each sterilization may extend to one hour, and the number of sterilizations need be only two or three.

In pouring the filtered medium into the test-tubes care should be taken not to get any of the medium on the upper portion of the tube where the cotton plug would be likely to come in contact with it, else the plug would later be difficult of removal.

A solid nutrient medium which will remain solid at a higher temperature than the gelatine medium may be prepared from agar-agar, a substance obtained from certain gelatinous alga, as follows: 'Two gm. of the agar are broken into small pieces and soaked in cold water for twenty-four hours. 'Then the water is poured off and the swollen agar is added to I liter of the peptonized meat infusion. The mixture is boiled for several hours until the agar is completely dissolved. The solution is then neutralized with a solution of carbonate of soda, filtered, distributed in flasks or test-tubes, and sterilized by 
steaming for I hour at two or three successive intervals of twentyfour hours.

Cooked potatoes afford a solid nutrient medium which is quickly prepared and which is particularly adapted for the culture of chromogenic bacteria. Potatoes free from wounds are selected and scrubbed in water until they are perfectly clean, and the eyes and any unsound spots, if these could not be avoided, are cut out with a knife. Then the potatoes are placed for an hour in a solution of I part of mercuric chloride in 500 parts of water to disinfect the surface. They are next steamed for about an hour in a steam sterilizer, and after twentyfour hours the steaming is repeated for about half an hour. The sterilized potatoes are then placed in glass Petri dishes, are cut in halves with a sterilized table-knife, and the cut surfaces are inoculated. If the source of the inoculation is not a pure culture, an isolation of forms may be approximated by making long scratches over the surface of the potato with a sterilized platinum needle which has been in contact with the source of the inoculation. It will add to the security of the process of sterilization if each potato, before being placed in the bath of mercuric chloride, is wrapped in a piece of tissue paper, and so protected until it is cut open for inoculation.

Another method of preparing potatoes which is, on the whole, more convenient and certain, is to cut out long cylindrical plugs from sound potatoes by means of a cork-borer or any metal tube of the proper size, and then to cut the potato cylinders very obliquely in two pieces, each of which is then to be placed in the bottom of a test-tube so that the oblique surface stands uppermost. After plugging the tubes with baked cotton, the potato cylinders are subjected to a temperature of $100^{\circ} \mathrm{C}$. in the stean sterilizer for one hour at three successive intervals of twenty-four hours. A sterilized paste made from potatoes or bread serves well for the culture of molds as well as of bacteria.

A decoction of horse-dung furnishes a good medium for the culture of Mucor and various other molds. The decoction is prepared by boiling the dung in water, then filtering and sterilizing 
the solution. By placing the dung of different kinds of animals in a moist chamber, as, for instance, in dishes floating on water and covered with a bell-jar, characteristic fungi will after a time appear on it.

Single spore cultures of Mucor may be obtained in the following manner: Glass slides are thoroughly cleaned and sterilized by baking. By means of sterilized forceps a single sporangium of Mucor is picked from a spontaneous growth of this fungus on horse-dung or stale bread kept in a moist chamber. The sporangium is placed in a sterilized decoction of horse-dung contained in a sterilized watch-glass, which may be placed on an inverted tumbler in a plate of water and then covered with a belljar which should dip into the water and form a germ-proof moist chamber. After a few hours the sporangium will have burst open and the spores, which are now distributed through the decoction, will have swollen to several times their original diameter, and can all the more readily be discerned in subsequent manipulations. A needle which has been disinfected by heating in a flame is now dipped into the decoction and the point of it drawn along the surface of a glass slide which has been cleaned and sterilized as above directed. By this process the decoction which has adhered to the needle is drawn out in the form of a narrow streak, and if several spores of Mucor are present, they will be separated from each other. A single spore may be located with a medium power of the compound microscope, and all other spores present in the streak may be wiped off with a cloth which has been, sterilized by heat. Then a drop of the decoction of sterilized horse-dung should be added to the small a mount containing the spore on the slide. The slide should be placed in a moist chamber where the spore will soon give rise to a mycelium visible to the naked eye, and from the mycelium numerous sporangia will be produced after a time. The slide mal be taken from the moist chamber from time to time and the stages in the development of the fungus examined, but as much care as possible should be taken to prevent the contamination of the culture. Knop's nutrient solution, which is particularly good for the 
culture of algæ, consists of 4 parts of calcium nitrate, I part of magnesium sulphate, I part of potassium nitrate, I part of potassium phosphate. These should be dissolved in sufficient water to make a 0.2 per cent. solution of the combined salts. The potassium salts should first be dissolved, then the magnesium salt, and last the salt of calcium should be added after having been dissolved by itself. By this procedure only a small amount of insoluble calcium phosphate is formed. The zoöspores of Vaucheria may be induced to form at almost any time by transferring this alga from the above solution, in which it has been growing exposed to a bright light, to pure water; or cultures in a 0.1 per cent. or 0.2 per cent. nutrient solution which have been exposed to the light need only be placed in a dark place in order to incite the production of zoöspores.

A 2 per cent. to 4 per cent. solution of cane-sugar may be used as a nutrient medium for alga. Filaments of Spirogyra may be made to conjugate by transferring them from the water in which they have been growing to a solution of cane-sugar as above, which is then placed in a well-lighted place.

The formation of zoöspores may be incited in QEdogonium by transferring filaments of the alga from water at a low temperature (say at the temperature of the early morning) to a 2 per cent. or 3 per cent. solution of cane-sugar which is kept at a constant temperature of about $26^{\circ} \mathrm{C}$.

Convenient flasks for the preservation of sterilized fluid nutrient media may be made from glass tubing as follows: A piece of glass tubing 0.2 inch in diameter, or larger, is held with its lower end in the flame of a blow-pipe, the tube being constantly revolved about its long axis to insure an eren heating of the end of the tube until the end of the tube becomes soft and just begins to draw downward in the form of a large drop. By this time the mouth of the tube has become closed. Then quickly the tube is removed from the flame, and while the melted end of the tube is still held downward, air is blown in at the upper end of the tube by means of the mouth, so that the molten glass at the lower end of the tube is forced outward in the form of a rounded flask. 
After cooling so that it may be handled, the tube is held in the flame close to the bulb, and by constant turning the tube is heated equally on all sides until it becomes so soft that it may be drawn out. This process is accomplished by taking the tube from the flame and pulling on it gently so that it may be drawn out quite long and narrow. The length of the stem of the bulb should be equal to the depth of the ressel from which the nutrient medium is to be drawn into the bulb. The stem may be severed from the tube by holding it in the flame of the blow-pipe at the proper distance from the bulb, where it will soon become soft enough to be pulled off from the main tube. Then the end of the capillary neck is held in the flame until a bead is formed; in this way the flask is hermetically sealed. To fill the flask with nutrient fluid the neck is sterilized near the end by passing it through a flame, and the head is broken off with sterilized forceps. The bulb is then heated in the flame of an alcohol lamp or Bunsen burner to expand the air. The end of the neck is next quickly dipped into the nutrient fluid, which is forced up the neck into the bulb as the air in this cools. When the bulb is two-thirds full, the neck is withdrawn from the fluid and hermetically sealed in a flame. In filling the bulb the greatest care must be taken to keep the stock of nutrient medium from any source of contamination, if it has once been sterilized. Chemical flasks with narrow necks serve well for a common receptacle. These should be kept stoppered with a cotton plug, and to fill the small flasks the plugs need only to be lifted slightly while the sterilized capillary neck of the small flask is thrust past the plug into the nutrient fluid. If the nutrient fluid is freshly prepared, and has not yet been sterilized, the small flask may be filled, sealed up in the flame, and sterilized in the steam sterilizer or in a vessel of boiling water for an hour each day on three successive days. The nutrient fluid will keep indefinitely in the little flasks, and when a drop is wanted for a drop culture, it is only necessary to sterilize the end of the capillary neck in a flame, break off the bead with sterilized forceps, invert the flask, and place the palm of the hand over the bulb. The heat of the hand will expand the air over the fluid and force 
the latter down the neck. With a little practice just the desired amount of fluid can be forced out by the heat of the hand. The hand must not be placed on the bulb until the flask is inverted. If it is desired to make cultures within the little flasks, snip off the end of the capillary neck as before, and thrust a long platinum needle, the end of which has been in contact with the source of inoculation, down the neck into the fluid. Then withdraw the needle and hermetically seal the neck in the flame. When cul tures are to be made in the flasks, these should be only one-third filled by the nutrient medium; there will then be sufficient air in the flasks for the success of the culture after the flasks have been inoculated and hermetically sealed.

Pollen grains may be made to germinate in hanging-drops composed of 100 parts of well-water, 3 to 30 parts of cane-sugar, and I.5 parts of gelatine. This should be made as needed, or it may be sterilized and kept indefinitely in the little flasks just described. The amount of cane-sugar to give the best results varies with the species of pollen, and can only be determined by experiment, but 3 parts will probably answer for most pollen grains.

Spores of ferns may be made to germinate on pieces of flowerpot which are kept half submerged in water and are covered by a bell-jar. 'They should be set before a north window. They should never be exposed to the direct light of the sun, since in such a position the temperature under the bell-jar would become very great.

Osmic Acid. - The method of preparing a solution of osmic acid and of its use in Flemming's fixative is given on page 259. The vapor of osmic acid may be used as a fixative for very small organisms. In order to accomplish this a drop of water containing the organisms need only to be inverted over a bottle containing a 2 per cent. solution of the acid. Osmic acid colors ethereal and fatty oils from brown to black, but other organic substances are also darkened by it; and as a test for oils it is not absolutely reliable. Aleurone grains in sections of Ricinus which have been freed from their oil by standing for a time in strong alcohol may be stained brown, and the crystalloid and ground 
substance differentiated by immersing the sections for a short time in a I per cent. solution of osmic acid.

Paraffin.- The directions for imbedding material in paraffin are given on page 261. Paraffin of about $52^{\circ} \mathrm{C}$. melting-point sections to good advantage at a temperature between $2 \mathrm{I}^{\circ}$ and $24^{\circ}$ C., or $70^{\circ}$ and $75^{\circ} \mathrm{F}$. Good cells for hanging-drop cultures may be made by placing glass slides on the turn-table and spinning rings on them by means of a camel's-hair brush dipped in melted paraffin.

Pepsin.-One part of pepsin-glycerine and 3 parts of water acidulated with 0.2 per cent. of chemically pure hydrochloric acid. When sections containing protoplasts are subjected to this reagent at blood temperature, certain structures of the protoplast which are insoluble in the reagent may be isolated from those which are soluble. In the dividing nucleus the kinoplasmic spindle-fibers persist after the chromosomes and nuclear plate have been dissolved by this reagent. By the action of digestive ferments on aleurone grains the ground substance is first dissolved and then the crystalloid more slowly, while the limiting membrane of the vacuole occupied by the aleurone grain persists. Digestive ferments are thus found to be excellent reagents for demonstrating the difference in constitution of the finer structures of the protoplast and protoplasmic cell-contents.

Phloroglucin.-This furnishes one of the most reliable tests for lignin. Sections are placed in alcohol containing a trace of phloroglucin, transferred to a drop of water on a slide and covered with a coverglass. A drop of hydrochloric acid is then applied to the edge of the coverglass and, as the acid comes in contact with the lignified members, these are colored a bright violet-red.

Phospho-molybdic Acid.-This is used as a test for proteids. Sections are treated for an hour or two with a solution of I gm. of sodium-molybdenum phosphate in $90 \mathrm{gm}$. of distilled water and $5 \mathrm{gm}$. of concentrated nitric acid. Proteid materials then take on the appearance of yellow granules.

Picric Acid.-The structures of aleurone grains are well differentiated by fixing in a concentrated alcoholic solution of 
picric acid and subsequent staining with eosin. The sections are to remain in the alcoholic fixative for several hours. They are then to be washed out in alcohol and stained for a few minutes in a solution of eosin in absolute alcohol. Then the sections are successively washed in absolute alcohol, transferred to oil of cloves, and mounted in Canada balsam. The ground substance is dark red, the crystalloid yellow, while the globoid remains colorless. The pyrenoids and chloroplasts of algæ may be simultaneously fixed and stained by placing the algæ for an hour or longer in a concentrated solution of picric acid in 50 per cent. alcohol, to which has been added about 5 drops of a solution of $20 \mathrm{gm}$. of acid fuchsin in roo c.c. of aniline water. The aniline water is prepared by shaking up $3.5 \mathrm{gm}$. of aniline in $96.5 \mathrm{gm}$. of water. The algæ are then washed in alcohol, transferred to xylol, then to a thin solution of balsam in xylol, and are finally mounted in the thicker solution of Canada balsam in xylol.

Alcohol is a better solvent of picric acid than water, and accordingly it gives quicker results in washing out the acid from the fixed material than water does, but running water may be used to wash out the fixative whether the latter has been dissolved in alcohol or in water.

Picro-aniline Blue.-A double stain, which is very rapid in its action, is prepared by adding aniline blue to a saturated solution of picric acid in 50 per cent. alcohol until the solution has a blue-green color. $\mathrm{By}$ this treatment the unmodified cell-walls and the cell-contents are stained blue, while the lignified walls are stained by the picric acid.

Picro-nigrosin.-A solution of nigrosin in a concentrated solution of picric acid in water or 50 per cent. or 95 per cent. alcohol is a good fixative and stain for algæ and leucoplasts, and for double-staining modified and unmodified cell-walls. The solution may, in some cases, need to act for twenty-four hours. The strong alcoholic solution is particularly recommended for material containing chlorophyll, since this will be extracted by the strong alcohol. Nuclei and leucoplasts are stained a steel blue by the nigrosin. 
Potassium Alcohol.- Used for bleaching sections. It may be prepared by mixing a concentrated aqueous solution of potassium hydrate with 90 per cent. alcohol until a sediment is formed. This is allowed to stand for twenty-four hours with frequent violent shaking, and then the clear liquid is poured off and is diluted for use with 2 or 3 parts of water.

Potassium Hydrate.-For general use, dissolve $5 \mathrm{gm}$. of potassium hydrate in 95 c.c. of distilled water. This is used as a clearing agent for sections and small organisms. The process of clearing may require from several hours to several days. After clearing, the potash should be washed out in plenty of water. and then the preparation may be neutralized with acetic acid. This will tend to make the objects more opaque, and if too much is added, the objects may be cleared again by caustic potash or ammoria. A dilute solution of caustic potash, as above, may be used for the maceration of cork, while delicate tissues in general may be macerated by boiling for a few minutes in a 50 per cent. solution of potassium hydrate in water; the tissues should then be washed in water and teased out on a slide in a drop of water.

Ruthenium Red.-An aqueous solution is an excellent stain for pectic substances and for gums and slimes which have been derived from these. Ruthenium red is not soluble in alcohol. clove oil, or glycerine, and, therefore, preparations stained by it may be dehydrated and mounted in glycerine or balsam.

Safranin.-A saturated solution of safranin in alcohol should be made, and this should be diluted with an equal bulk of water. or with an equal bulk of a saturated aqueous solution of safranin. This is an excellent general stain, and gives good differentiating effects when used singly. It is one of the few stains which are particularly adapted to the staining of pectic compounds. It also gives beautiful results in staining the cellcontents of Spirogyra and other algx. The alga, after fixing in a fixative containing chromic acid, should lie in the alcoholic solution diluted with an equal bulk of water for twelve or twentyfour hours. They should be transferred to 50 per cent. alcohol. 
to which strong alcohol is then added, drop by drop. 'The color will begin to be extracted in the alcohol, and when the right intensity has been reached, the material should be transferred to dilute glycerine, where it is to remain while the glycerine slowly concentrates in a place protected against dust. Then permanent mounts may be made in glycerine or glycerine-jelly. The stain given by safranin is quite permanent. See also page 264 and the directions there given for the three-color method.

Salicylate of Soda.-A clearing reagent which for small objects is not inferior to chloral hydrate is furnished by dissolving crystals of salicylate of soda in an equal weight of distilled water. With tincture of iodine added this reagent will cause starch to swell, at the same time imparting a blue color to it.

Salt.-A 4 per cent. or stronger solution of common salt, or of potassium nitrate, may be used to cause plasmolysis in living cells. This process may be all the more clearly seen by adding eosin to the salt solution.

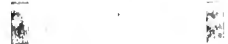

Shellac.-A thick solution of shellac in alcohol, to each ounce of which are added 20 drops of castor oil, makes an excellent sealing medium for preparations mounted in glycerine or glycerinejelly, or in an aqueous medium.

Silver Nitrate.-A solution of silver nitrate is used to bring out more clearly the striations in bast fibers and starch grains. Sections containing striated bast fibers are allowed to dry and are then impregnated with the silver salt. Without previous washing the sections are transferred to a 0.75 per cent. solution of common salt. They are then placed in distilled water and exposed to the light for a considerable time; thereafter they are allowed to dry and may be examined to good advantage in anise oil.

Dry starch grains are put to soak in a 5 per cent. solution of silver nitrate. After a time they are allowed to dry superficially and are then treated with a 0.75 per cent. solution of common salt, in which they are finally exposed to the direct light of the sun to reduce the chloride of silver which has been formed within the grains. The less dense laminx of the starch 
grains will show a gray color, due to the reduced silver. See page 177 for a description of the structure of starch grains.

Staining Intra Vitam.---Living protoplasts may accumulate certain stains from very dilute solutions without injury to themselves. Dahlia, methyl-violet, mauvein, and methyleneblue are particularly suitable for this purpose. Solutions containing 0.001 per cent. or 0.002 per cent. of any of the first three stains have given good results in staining living nuclei, while I part of methylene-blue in 500,000 parts of filtered rain-water is used for staining living cells containing tannin. A large amount of these very dilute solutions should be employed in order that a sufficient amount of coloring matter may be at hand for accumulation by the living cells. Living protoplasts have the power of reducing and accumulating metallic silver from solutions of certain of the salts of silver, while dead protoplasts have not this power. The simplest method of producing this reaction is to place a few filaments of Spirogyra in a liter of a mixture of I part of silver nitrate in 100,000 parts of water with 5 c.c. of lime-water. The experiment will be completed in about half an hour if the temperature is approximately $30^{\circ} \mathrm{C}$.

Tannin and Antimonium-potassium Tartrate.-These are used successively as a mordant for methyl- and gentianviolet, fuchsin, and safranin when sections stained with these are to be mounted in glycerine. The sections before staining are placed in a 20 per cent. solution of powdered tannin in cold water. After washing well in distilled water, they are placed for twenty-four hours in a 2 per cent. solution of antimoniumpotassium tartrate. After washing again in distilled water. they are transferred to the stain. From the stain the sections are washed quickly in distilled water and placed in strong alcohol, where the color is washed out until the desired degree of intensity is reached. They are now ready for mounting in glycerine, or. if desired, they may be placed in xylol and then mounted in balsam. If the sections are so deeply stained that they cannot be sufficiently washed out in alcohol, they should be placed for a time in a 2.5 per cent. solution of tannin. 
Turpentine.-This may be used to dissolve paraffin from sections which have been cut from material imbedded in paraffin. See also under Carbolic Acid.

Venetian Turpentine.-To prepare a mounting medium from Venetian turpentine, the product as it comes from the apothecary is diluted with an equal volume of strong alcohol, and after the mixture has become clear by long standing or by filtering after being well shaken, it is thickened somewhat on the waterbath. Objects may be mounted directly from strong alcohol into Venetian turpentine as above prepared. Objects which are found to shrink by this treatment may be transferred from strong alcohol to a mixture of Io parts of the turpentine with Ioo parts of alcohol. The alcohol is then to be withdrawn from this mixture by placing the latter, together with a dish of calcium chloride, under a bell-jar. In order to keep the mixture of turpentine and alcohol from mounting the sides of the vessel which contains it, the rim of the ressel should be coated over with hot paraffin. The turpentine hardens quite slowly, and in order to quickly fasten a coverglass to the slide when the turpentine is being used for a permanent mount, a wire which has been heated in a flame should be quickly drawn around the edge of the coverglass.

Xylene.-This is used as a solvent for paraffin, either in removing parafiin from sections or in preparing a dilute solution of paraffin to be used in the gradual infiltration of tissues with this substance. Used also as a solvent of Canada balsam. Xylol is the trade name for xylene 


\section{CHAPTER XVII}

\section{MICROCHEMISTRY OF PLAN'T PRODUCTS}

Aconitine, $\mathrm{C}_{33} \mathrm{H}_{45} \mathrm{NO}_{12}$.- An alkaloid occurring in especial abundance in the rootstocks of Aconitum Napellus. To demonstrate aconitine treat sections with potassium iodide-iodine, or with a solution of potassium permanganate. The first reagent produces a carmine-red coloration in the presence of aconitine and the second gives a red precipitate of aconitin permanganate.

Aleurone.-See page I8I for a description of the nature of aleurone grains. The protein nature of aleurone is demonstrated by its dissolving with a red color in Millon's reagent and by its being colored yellow or brown with iodine reagents. Aleurone grains should be studied in a mixture of equal parts of castor oil and 95 per cent. alcohol slightly colored with eosin. In water they are in danger of going more or less into solution. Permanent preparations of the aleurone of Ricinus may be made by placing small bits of the endosperm in a saturated alcoholic solution of picric acid, rinsing in alcohol, imbedding in paraffin (see page 26I), sectioning on the microtome (see page 262), staining in an alcoholic solution of eosin, rinsing in oil of clores, and then in xylene, and mounting in balsam. By this process the ground substance should be red, the crystalloid yellow, and the globoids colorless. For reaction of aleurone to other reagents see in the last chapter under Borax-Carmine, Digestive Fluids, Pepsin.

Alkaloids. - Sections to be tested for alkaloids should be thick enough to leave one cell layer intact. In order to make the determination of the alkaloid more certain, sections for control should be soaked for a day or so in a solvent of alkaloids prepared by dissolving I part of tartaric acid in 20 parts of alcohol, 
and rinsing in water for a day to wash out the acid. Mount sections thus treated under a coverglass with untreated sections and apply reagents for detecting alkaloids. The following reagents give with alkaloids amorphous or crystalline precipitates: potassium iodide-iodine, potassium bismuthiodide, chloroiodide of zinc, potassium-mercuriciodide, chloride of gold, ammoniummolybdate, potassium permanganate. See under Aconitine, Atropine, Berberin, Brucine. Caffeine, Corydalin, Curarin, Cytisin, Morphine, Narceine, Narcotine, Nicotine, Piperine, Sinapine, Strychnine, Theobromine, Veratrine.

Allyl Sulphide or Garlic Oil, $\left(\mathrm{C}_{3} \mathrm{H}_{5}\right)_{2} \mathrm{~S}$. - This may be demonstrated by treating sections of species of Allium with palladous nitrate which produces a kermes-brown precipitate; or sections may be treated with a solution of silver nitrate, when sulphide of silver will be formed.

Amygdalin, $\mathrm{C}_{20} \mathrm{H}_{27} \mathrm{NO}_{11}$. - This nitrogenous glucoside is particularly abundant in bitter almonds and in the bark, leaves, and flowers of Prunus padus. It can be extracted in boiling water, and on addition of alcohol it crystallizes out in the form of pearly scales. It is split into prussic acid, oil of bitter almonds and sugar by the enzyme emulsin which occurs associated with the glucoside.

Amylodextrine.-This carbohydrate occurs in those starch grains which take on a reddish color with iodine, and it is formed by the action of diastase and acids from the amylose of those starch grains which are colored blue with iodine. By the action of diastase on the starch of germinating seeds the amylose of the starch is converted first into amylodextrine, and this in turn into dextrine and isomaltose. The microchemical beharior of amylodextrine is given by Arthur Meyer as follows: Water at $70^{\circ} \mathrm{C}$. dissolves crystals of amylodextrine slowly, while at $100^{\circ}$ the crystals are dissolved at once. A solution of to gm. of pure calcium nitrate in $\mathrm{I} 4 \mathrm{gm}$. of water dissolves crystals under the coverglass very slowly. After some hours, if a solution of iodine is added, the calcium nitrate solution is colored brown, which indicates that the crystals of amylodextrine have at least been 
partially dissolved. A solution of $2 \mathrm{gm}$. of purest potassium hydrate in $100 \mathrm{gm}$. of water dissolves small crystals within two hours, while the solution of larger crystals requires a longer time. A solution of iodine, prepared as directed on page 3II, colors the crystals dark brown. A 25 per cent. solution of hydrochloric acid dissolves large and small crystals immediately. When this solution is diluted with 4 parts of water, it takes on a brownishred color with the iodine solution. When I drop of malt extract is added to 5 drops of a neutral solution of amylodextrine this becomes inverted within ro minutes, so that it no longer is colored by the iodine solution. To prepare the malt extract treat I part of malt with 3 parts of water and filter the solution. The solution of crystals of amylodextrine by the malt extract requires several days. At a temperature of $40^{\circ} \mathrm{C}$. saliva dissolves the amylodextrine crystals within forty-eight hours. To prepare the saliva, mix human saliva with a drop of chloroform, filter, and preserve over a few drops of chloroform.

Amyloid.-This carbohydrate occurs as reserve material in the seeds of Tropaolum majus, Impatiens balsamina, Paonia officinalis, and in many other plants. It is colored blue by dilute solution of iodine, but with a concentrated solution it is colored a brownish-orange. It is soluble in cuprammonia only after a day. Treated with a 30 per cent. solution of nitric acid it swells strongly, and finally dissolves. This is different from the amyloid produced by the action of acids and certain chlorides on cellulose.

Amylose.-Starch grains which are colored blue by iodine - that is, most starch grains-are, according to Meyer, composed of crystals of two kinds of amylose, named by Meyer $\alpha$-amylose and $\beta$-amylose. The $\alpha$-amylose has been isolated in crystalline form, but the $\beta$-amylose has not been isolated, and its microchemical behavior has only been determined by experiments with starch grains. 'The microchemical behavior of the $\alpha$-amylose is as follows, the reagents being prepared as directed under amylodextrine: Water at from $60^{\circ}$ to $100^{\circ}$ C. does not soon dissolve the crystals of this amylose. Treat- 
ment with the calcium nitrate solution for 30 minutes does not appear to affect the crystals. The solution of iodine does not color the crystals at first, but after a longer time it imparts a brownish color. The solution of hydrochloric acid dissolves the crystals at once, and the solution, diluted with four times its bulk of water, is colored deep blue with the iodine reagent; but after the solution has stood for 12 hours it is colored brownish or not at all by the iodine. The solution of potassium hydrate at ordinary temperatures affects the crystals so that they are colored blue by the iodine after the solution has heen neutralized with acetic acid. In boiling potassium hydrate the crystals are changed into viscid drops. If the solution is now neutralized with acetic acid and diluted with four times its bulk of water, it takes on a deep blue color with the iodine reagent.

If a drop of malt extract is added to the solution formed by boiling crystals of $\alpha$-amylose with the potassium hydrate solution, and exactly neutralizing with acetic acid, it is found after 5 minutes that the solution takes on a red color, due to the formation of amylodextrine by the influence of the malt extract. Saliva and malt extract have very little effect upon $\alpha$-amylose. After treatment with these reagents for $I_{5}$ days at a constant temperature of $40^{\circ} \mathrm{C}$., no essential change could be detected.

$\beta$-Amylose is insoluble in cold water, but at a temperature of $70^{\circ} \mathrm{C}$. it forms viscid masses or minute droplets. 'The solutions of calcium nitrate, potassium hydrate, and hydrochloric acid have the same effect as water, excepting that the solution in hydrochloric acid is more complete than in water. The solution of $\beta$-amylose acts precisely as the solution of $\alpha$-amylose. Undissolved $\beta$-amylose, however, is colored blue by the iodine solution. The swelling of starch in hot water is probably due to the $\beta$-amylose which it contains. Meyer considers $\alpha$-amylose and $\beta$-amylose to be the same substance, but that the latter contains water of crystallization, while the former does not.

Anthochlorin.-A yellow coloring matter occurring in solution in the cell-sap and differing from the yellow coloring matter xanthin occurring in chromoplasts in that it is not 
changed to a blue color by the action of concentrated sulphuric acid.

Anthocyanins.-These are coloring matters of flowers, leaves, and other parts of plants which impart red, violet, blue, blue-green, or green colors, the character of the color being dependent on the alkalinity or acidity of the cell-sap. The anthocyanins are soluble in water, alcohol, and ether, and are decolorized in strong alkalies.

Anthoxanthin.-This yellow coloring matter in the chromoplasts of flowers and fruits takes on a blue color with concentrated sulphuric acid. Since the chromoplasts of flowers and fruits were first of all green, anthoxanthin is probably a derivative of chlorophyll. Anthoxanthin is also called xanthin and xanthophyll.

Arabin.--This is the gum derived from species of Acacia and known as gum arabic. Arabin is soluble in hot and cold water, and insoluble in alcohol and ether. The aqueous solution will mix with glycerine, but concentrated glycerine has little effect on the hard gum.

Asparagin, $\mathrm{C}_{2} \mathrm{H}_{3} \mathrm{NH}_{2}$. $\mathrm{CONH}_{2}$. COOH.- This is a nitrogenous compound of simpler constitution than proteids. It is formed within plants both analytically by the decomposition of proteid, and synthetically probably by the combination of simpler substances. Asparagin is soluble in water and in the cell-sap, and is one of the most important nitrogenous compounds capable of solution and circulation within plants. It combines with non-nitrogenous compounds to form proteids, and is apt to accumulate in those parts of plants where there is not sufficient non-nitrogenous material at hand for the formation of proteids. The accumulation of asparagin is particularly apt to occur in plants which are grown in the dark, so that carbon assimilation does not take place. Thus, Pfeffer found that when seedlings of lupin were grown in the dark, they contained a large amount of asparagin, but when they were brought to the light, the asparagin disappeared. . He found that this was not due simply to the influence of the light, 
for when the seedlings were exposed to the lignt in an atmosphere destitute of carbon dioxide, the asparagin persisted in the secdlings. For the ready demonstration of asparagin, tubers of Dahlia may be employed. Rather thick sections are cut from a tuber while the razor is kept dry and transferred to a few drops of alcohol on a glass slide and covered with a coverglass. On the evaporation of the alcohol crystals of asparagin in the form of rhombic plates are deposited on the coverglass and slide. To determine whether the crystals are asparagin, they are treated with a few drops of an entirely saturated solution of asparagin, which must be of the same temperature as the preparation. If the crystals are asparagin, instead of being dissolved they will increase in size, while other substances than asparagin will dissolve in the saturated asparagin solution just as they would in water. It is characteristic of asparagin that if the crystals are heated to $100^{\circ} \mathrm{C}$., they lose their water of crystallization and appear like bright droplets of oil. At $200^{\circ}$ asparagin becomes decomposed and forms frothy brown droplets which are no longer soluble in water.

Atropine, $\mathrm{C}_{17} \mathrm{H}_{23} \mathrm{NO}_{3}$.- This alkaloid with its isomers, hyoscyamin, pseudohyoscyamin, and hyoscin, occurs widely distributed in the Solanacer. Sections of roots of Atropa Belladonna contain atropine and yield a brownish precipitate when treated with potassium iodide-iodine.

Bassorin.-Gum tragacanth, obtained from certain cells of the pith and medullary rays of several species of Astragalus. Swells strongly in water, but does not go into complete solution. Is not colored either by iodine or chloroiodide of zinc.

Berberin, $\mathrm{C}_{20} \mathrm{H}_{17} \mathrm{NO}_{4}+6 \mathrm{H}_{2} \mathrm{O}$. - This yellow alkaloid occurs in the young parenchymatous tissue, and in the older xylem portions of Berberis vulgaris, and in representatives of the most various families. With potassium iodide-iodine it forms a reddish-brown precipitate which, by treatment with alcoholic potassium iodide-iodine, becomes changed into tubular or hair-like forms having a brownish or iridescent green color. Ammonia and nitric acid impart to berberin a reddish- 
brown color. A solution of potassium bichromate or potassium iodide in 50 per cent. sulphuric acid produces, with berberin, an intense purplish-red color. One part of nitric acid mixed with roo parts of water added to sections containing berberin will produce clustered acicular crystals of berberin nitrate within the berberin-bearing cells.

Betulin, $\mathrm{C}_{14} \mathrm{H}_{18} \mathrm{O}_{8}+\mathrm{H}_{2} \mathrm{O}$.- This glucoside occurs in the form of fine granules in the thinner walled cork cells of birch bark. It is accompanied by the enzyme betulase, which splits it into glucose and methylsalicinic ester. In order that it may be studied to good advantage under the microscope, the air should be pumped from sections immersed in water, and then the sections should be examined in water under the microscope. Betulin is insoluble in water, but is soluble in alcohol. It is strongly antiseptic, and protects birch bark against the attacks of lower organisms.

Betuloretic Acid, $\mathrm{C}_{36} \mathrm{H}_{66} \mathrm{O}_{5}$. - This is secreted by the glandular hairs on the leaves of Betula alba. It is obtained from the thick, pale yellow secretion by successive solution in boiling alcohol, ether, and an aqueous solution of sodium carbonate. It is colored a beautiful red by concentrated sulphuric acid.

Brucine, $\mathrm{C}_{23} \mathrm{H}_{26} \mathrm{~N}_{2} \mathrm{O}_{4}+{ }_{4} \mathrm{H}_{2} \mathrm{O}$. - The alkaloid brucine occurs along with strychnine in the seeds of various species of Strychnos. Ammonium vanadate in sulphuric acid gives with brucine a yellowish-red color. When sections containing brucine are treated with a mixture of nitric and hydrochloric acids, the cell-contents are colored a reddish-orange, which merges into yellow.

Caffeine, $\mathrm{C}_{8} \mathrm{H}_{10} \mathrm{~N}_{4} \mathrm{O}_{2}+\mathrm{H}_{2} \mathrm{O}$.- The narcotic alkaloid in many foods and drugs. It occurs in plants of various families; for instance, in Thea, Coffea, Theobroma, Cola, Ilex, Sterculea, Neea. When sections containing caffeine (theine, methyltheobromine, trimethyl-xanthin) are treated with a drop of concentrated hydrochloric acid, and then after a minute with a drop of a 3 per cent. gold chloride solution, somewhat slender. 
yellowish, silken crystals of a double chloride of gold and caffeine begin to be formed on the evaporation of the reagent. However, theobromine forms quite similar crystals when treated as above. Another method for the detection of caffeine is to place sections in a few drops of water and heat to boiling; then to allow the water to evaporate slowly and to treat the residue with a drop of benzol. On the evaporation of the benzol, caffeine appears in the form of fine needle-crystals.

Calcium.- When the ash of plants is treated with sulphuric acid, this unites with the calcium present to form crystals of gypsum. If calcium sulphate is already present in the ash, its characteristic crystals may be detected when an aqueous solution of the ash is allowed to dry slowly. If calcium is present in sections, it may be deposited in the form of crystals of calcium oxalate if the sections are treated with a solution of ammonium oxalate.

Calcium Carbonate, $\mathrm{CaCO}_{3}$.- This rarely occurs in the crystalline form within the cells. It may, however, be found imbedded in, or incrusted on, the cell-walls. Calcium carbonate dissolves with effervescence when treated with ditute acetic acid. When treated with concentrated hydrochloric acid, it dissolves with the evolution of carbon dioxide gas. The ingrowths from the walls of certain cells of the leaves of Ficus elastica, known as cystoliths, are thickly incrusted with calcium carbonate and afford excellent material for the demonstration of this salt within plant tissues.

Calcium Phosphate, $\mathrm{Ca}_{3}\left(\mathrm{PO}_{4}\right)_{2}$. - This salt of calcium occurs usually, if not always, in solution in the cell-sap. It may be deposited in the form of sphærocrystals when plant tissues containing it are kept for a long time in strong alcohol. When treated with sulphuric acid, the sphærocrystals are dissolved and crystals of calcium sulphate are formed in their stead. When sections containing calcium phosphate are heated on a slide in a drop of ammonium molybdate acidulated with nitric acid, a yellow precipitate is produced. This reaction may be hindered by the presence of certain organic compounds, such 
as potassium tartrate, in which case the sections should be treated with a mixture of 25 volumes of a concentrated aqueous solution of magnesium sulphate with 2 volumes of a concentrated aqueous solution of ammonium chloride and 15 rolumes of water. In this case a crystalline precipitate of ammoniomagnesium phosphate is formed.

Calcium Oxalate, $\mathrm{CaC}_{2} \mathrm{O}_{4}$. - Crystals of calcium oxalate occur so commonly in plants that it is safe to assume that any crystals observed in fresh tissues are of this substance until the contrary is demonstrated. The crystals may occur singly in the cells, in which case their definite crystalline form can be made out, or in the form of agglomerated star-shaped clusters of crystals, or in bundles of parallel needle-shaped crystals, or they may occur very numerously in cells in the form of very minute crystals. The crystals are insoluble in water and acetic acid, but dissolve without effervescence in hydrochloric acid. When they are treated with sulphuric acid, crystals of calcium sulphate are formed in their place. Calcium oxalate appears to be an excretion formed by the union of salts of calcium, which have been absorbed from the soil, with oxalic acid which is formed by the plant.

Calcium Sulphate, $\mathrm{CaSO}_{4}$ - - Minute crystals of calcium sulphate occur in many desmids. They are insoluble in concentrated sulphuric acid. A solution of barium chloride dissolves them with the formation of barium sulphate.

Callose.-The chemical nature of callose is not precisely known; it is supposed by some to be a proteid. Callose occurs in sieve tubes, where it may close up the sieve pores. It also occurs commonly in cystoliths, and in the membranes of pollen grains and various fungi. Callose is insoluble in water, alcohol, and cuprammonia, but is is readily soluble in cold sulphuric acid, calcium chloride, and concentrated chloride of zinc. It is insoluble in cold alkaline carbonates, but swells up without dissolving in ammonia. Corallin, aniline blue, and a mixture of soluble blue and vesurin, or of vesurin and orseillin, are suitable stains for callose. The corallin should be dissolved 
in a saturated solution of sodium carbonate. After remaining in this solution for a time, the sections should be examined in glycerine. If the sections are overstained, the intensity of the stain may be reduced in a 4 per cent. solution of sodium carbonate. The aniline blue should be used in dilute aqueous solutions, in which the sections are to remain for about half an hour. Overstaining may be remedied by washing out in glycerine.

Calycin, $\mathrm{C}_{18} \mathrm{H}_{12} \mathrm{O}_{5}$.- This occurs in the tissues of many lichens. Its presence may be demonstrated by moistening some of the powdered lichen with glacial acetic acid, and when the preparation dries, the long, doubly refractive crystals of calycin are deposited. When a section of lichen containing calycin is treated on the slide with a few drops of chloroform and a drop of sodium hydrate, that portion of the section which contains calycin assumes a color varying from brick-red to blue-red.

Cane-sugar (Sucrose), $\mathrm{C}_{12} \mathrm{H}_{22} \mathrm{O}_{11}$ - -This carbohydrate is of common occurrence in plant tissues. At $15^{\circ} \mathrm{C}$. it is soluble in $\frac{1}{3}$ part of water. It is difficultly soluble in alcohol. When boiled with Fehling's solution, it does not at first precipitate cuprous oxide, but on longer boiling it becomes converted into glucose and lærulose, which are capable of reducing Fehling's solution. If rather thick sections containing cane-sugar (the sugar-beet affords good material) are placed for a short time in a concentrated solution of cupric sulphate, and then quickly rinsed in water, transferred to a solution of I part of potassium hydrate in I part of water, and heated to boiling, the cells containing the sugar take on a sky-blue color. A blue color is also produced by Fehling's solution when sections containing canesugar are heated in a drop of the solution on a slide until bubbles arise.

Carotin, $\mathrm{C}_{26} \mathrm{H}_{38^{-}}$- Carotin occurs in the orange and red chromatophores of many flowers and fruits, and, indeed, most orange and red colors of both plants and animals seem to belong to the carotins; carotin seems also to be an essential part of 
chlorophyll; it occurs in crystalline form in the roots of carrots, which have a yellow color in consequence. To demonstrate the presence of carotin in chloroplasts place pieces of fresh leaves in a 20 per cent. solution of potassium hydroxide in to per cent. alcohol, and leave them thus in a tightly closed ressel for several days. When the chlorophyll has been extracted from the leares, they should be washed in distilled water and sections from them should be mounted in glycerine. Yellowish and red crystals will then be found in the cells which formerly contained chlorophyll. Carotin is insoluble in water and with difficulty in alcohol, but is readily soluble in petroleum ether. benzol and benzine. When freshly dried leaves or roots of carrots are powdered and treated with one of these solvents, and the solution is allowed to dry or it is treated with alcohol. carotin crystallizes out in the form of reddish or yellowish crystals. With a solution of iodine carotin is colored greenish or bluish; with concentrated sulphuric acid it is colored from violet to indigo-blue.

Cellulose, $\mathrm{C}_{6} \mathrm{H}_{10} \mathrm{O}_{5}$.- Cellulose is one of the most important constituents of cell-walls; the first-formed walls are nearly always of cellulose, together with certain pectic compounds. Modified cell-walls-namely, those which have become cutinized or lignified - have arisen by the chemical modification of cellulose, or by the infiltration of new material between the cellulose molecules, or by both of these processes. Cellulose is characterized by being soluble in sulphuric acid and cuprammonia; by being colored from violet to blue by sulphuric acid and iodine, chloroiodide of zinc, chloroiodide of calcium, iodine and aluminum chloride, iodine and phosphoric acid. See under these heads in the chapter on Reagents.

Chitin. - The chemical composition of chitin is not precisely known, but it has been estimated to be $\mathrm{C}_{18} \mathrm{H}_{30} \mathrm{~N}_{2} \mathrm{O}_{12}$. The walls of many fungi consist of chitin instead of cellulose. This may be demonstrated by cutting the pileus of an Agaricus into small pieces, which are then to be treated successirely with dilute potassium hydrate, dilute sulphuric acid heated 
to boiling, alcohol, and finally ether. When this process is completed, a white substance remains which becomes hard and horny on drying, and which is insoluble to all reagents except concentrated acids, and in all other respects possesses the characteristics of chitin.

Chlorophyll, possibly $\mathrm{C}_{10} \mathrm{H}_{20} \mathrm{NPO}_{9}$ - - Chlorophyll may be extracted from the chloroplasts by means of strong alcohol. When this extract is shaken up with benzole and a few drops of water, and allowed to stand for a short time, the benzol which rises to the top will contain two pigments, amorphous chlorophyll-green and carotin; while the lower stratum of alcohol will contain a crystallizable chlorophyll-green and xanthophyll. The amorphous and the crystallizable chlorophyllgreen differ in the character of their spectra and in their solubility in different reagents. The amorphous form is soluble in alcohol, petroleum ether, carbon bisulphide and benzine; while the crystallizable is soluble only in the alcohol.

Coffee-tannin, $\mathrm{C}_{15} \mathrm{H}_{18} \mathrm{O}_{8}$. - This occurs in the endosperm of the coffee-bean. Its presence is indicated when sections give an abundant precipitate with lead acetate, a deep yellow color with ammonia and caustic potash, and a dark green color with ferric chloride.

Colchicine, $\mathrm{C}_{22} \mathrm{H}_{25} \mathrm{NO}_{6}$. - This occurs in a few rows of cells immediately surrounding the vascular bundles of the corm of Colchicum autumnale. Treated with a mixture of I part of sulphuric acid and 3 parts of water colchicine is colored yellow, and this color is changed to a brownish-riolet by the addition of a crystal of potassium nitrate. Iodine stains it brown, and potassic-mercuric iodide and hydrochloric acid produce with it a yellow precipitate.

Coloring Matters.--See under Anthochlorin, Anthocyanin, Anthoxanthin, Berberin, Carotin, Crocin, Frangulin, Indican, Lipochromes, Pezizin, Phycoerythrin, Phycocyanin, Phycophaein, Ruberythric Acid, Rutin, Santalin, Xanthine.

Corydalin, $\mathrm{C}_{22} \mathrm{H}_{27} \mathrm{NO}_{4}$. - This is an alkaloid which is found in the idioblasts of the Fumariacee. When corydalin is present, 
ammonia produces a dark gray precipitate, picric acid a yellow, and potassium iodide-iodine a deep reddish-brown precipitate.

Crocin (Saffron-yellow), $\mathrm{C}_{44} \mathrm{H}_{70} \mathrm{O}_{28}$. - This is a glucoside occurring in the stigmas of Crocus sativus. When concentrated sulphuric acid is added to crocin, a deep blue color is produced which passes into violet, cherry-red and then brown. Nitric acid also produces a blue color which passes into brown.

Curarin.- This alkaloid occurs in the parenchyma and bast of several species of Strychnos. Concentrated nitric acid produces with it a blood-red, and dilute or concentrated sulphuric acid a carmine-red color.

Curcumin, $\mathrm{C}_{14} \mathrm{H}_{14} \mathrm{O}_{4}$-Curcumin occurs, dissolved in an ethereal oil, in certain cells of the ground parenchyma of the rhizome of species of Curcuma and probably in other members of the Zingiberacer family. It crystallizes in the form of yellow needles which have a bluish tint by reflected light. Lead acetate forms a brick-red precipitate with curcumin, and sulphuric acid gives it a crimson color.

Cutin.-Cutin is a substance which is nearly related to suberin (which see), but is not identical with it. None of the acids derived from cutin is identical with any derived from suberin. However, the micro-chemical reactions of suberin and cutin are the same. They are insoluble in concentrated sulphuric acid and cuprammonia, and are colored from yellow to brown with the iodine reagents. When heated with concentrated potassium hydrate, they form yellowish droplets and granular masses. When heated in nitric acid and potassium hydrate, they form droplets which melt between $30^{\circ}$ and $40^{\circ} \mathrm{C}$, and which are soluble in boiling alcohol, ether, benzol, chloroform and dilute potassium hydrate. Both suberized and cutinized walls resist concentrated chromic acid at ordinary temperatures. Chemical analysis shows that cutin is composed of compound esters and fatty acids, and when heated to $300^{\circ}$ in glycerine, it behaves as a fatty body. For staining cutinized walls, see under Cyanin. Alcannin, Chlorophyll Solutions.

Cytisin, $\mathrm{C}_{11} \mathrm{H}_{14} \mathrm{~N}_{2} \mathrm{O}$.- This alkaloid occurs in the seeds of 
Cytisus laburnum and of other species of Cytisus and in species of Laburnum, Genista, Ulex, Sophora, Thermopsis, Baptisia, Anagyris, Lotus, Colutea and Euchresta. It occurs in less abundance in other parts of the plant, such as the petals and peripheral tissues of the stem. Potassium iodide-iodine produces with it a reddish-brown, granular precipitate which is soluble in sodium hyposulphite. Chloride of iron gives an orange-red color with cytisin. With phospho-molybdic acid a light yellow precipitate is produced, and picric acid when added to thin sections containing cytisin produces crystal groups of a reddishyellow color.

Datiscin, $\mathrm{C}_{21} \mathrm{H}_{22} \mathrm{O}_{12}$.- This glucoside is found in the cellwalls of the wood and bark of Datisca cannabina. Lime and baryta waters produce with it a yellow solution which loses its color on the addition of acetic or dilute hydrochloric acid. In the presence of datiscin, acetate of lead and chloride of zinc produce a yellow, oxides of copper a greenish, and chloride of iron a dark bluish-green, precipitate.

Dextrine, $\mathrm{C}_{12} \mathrm{H}_{20} \mathrm{O}_{10}$. - This carbohydrate is one of the intermediate products between starch and maltose (see Amylose). It is easily soluble in water, and from its aqueous solution it may be precipitated by strong alcohol. It is not colored blue by iodine, and does not reduce salts of copper.

Dextrose (Glucose, Grape-sugar).-Dee under Glucose.

Diastase.-To demonstrate the presence of diastase in sections they are laid for a time in a dark brown solution of guaiacum in absolute alcohol. When the sections are completely infiltrated with this solution the alcohol is allowed to evaporate, and then the sections are placed in a rather dilute solution of hydrogen peroxide. By this treatment cells containing diastase are colored a beautiful blue. See also under Diastase Solution in the last chapter.

Dulcite, $\mathrm{C}_{6} \mathrm{H}_{14} \mathrm{O}_{6}$. - Dulcite may be demonstrated in sections from one-year-old stems of Euonymus japonicus. The sections are placed on a slide in a few drops of alcohol, and covered with a coverglass. After the alcohol has slowly evaporated from 
under the coverglass, crystals of dulcite will be deposited in the form of long, branched prisms or needles radiating from a common center. They are distinguished from crystals of potassium nitrate by dissolving in diphenylamine and sulphuric acid without coloration, and by being insoluble in a concentrated solution of dulcite.

Elaioplasts.-These are rounded or irregularly polygonal, more or less granular bodies, consisting of a protoplasmic stroma and inclosed oil, which occur closely applied to the nucleus in the epidermal cells of many monocotyledonous and some dicotyledonous plants. In old cells the elaioplasts have the appearance of a sponge saturated with oil. The oil in the elaioplast of Ornithogalum umbellatum may be almost instantly dissolved by means of alcohol. The elaioplasts may be fixed and stained at the same time by treating sections containing them with a dilute solution of alcannin in I per cent. acetic or formic acid. The acid fixes the protoplasmic stroma, while the alcannin stains the oil a beautiful red. The fixing and staining process should be complete in five minutes. If desired, the sections may be doublestained by transferring them from the alcannin to a solution of iodine-green and glycerine, after which they may be mounted in glycerine-jelly. The sections may also be stained in a mixture of a dilute solution of alcannin and a solution of iodine-green in 5o per cent. alcohol and I per cent. acetic acid.

Emulsin.-This is a glucoside-splitting ferment which occurs in certain cells of the almond and of the bundle-sheath of the leaves of Prunus laurocerasus and in other Rosaceæ, where it splits up the glucoside amygdalin into glucose, hydrocyanic acid and benzaldehyde. When sections are treated with Millon's reagent, the cells containing emulsin take on an orange-red color, while the surrounding cells are colored a pale rose-red. A solution of copper sulphate and caustic potash produces a riolet color in the emulsin-bearing cells.

Ethereal Oils.--Ethereal oils are distinguished from fatty oils in that they may be distilled from plants along with vapor of water, and are soluble in glacial acetic acid, and an aqueous 
solution of chloral hydrate. At $130^{\circ} \mathrm{C}$. all ethereal oils may be driven from sections, while the fatty oils remain behind. Ethereal oils are only slightly soluble in water, but they impart their smell strongly to it. 'They are easily soluble in ether, chloroform and fatty oils. The spot produced on paper by ethereal oils soon disappears. They agree with the fatty oils in being browned or blackened by osmic acid and in being stained by alcannin and cyanin.

Eugenol, $\mathrm{C}_{6} \mathrm{H}_{3} . \mathrm{OH} . \mathrm{OCH}_{3} \cdot \mathrm{C}_{3} \mathrm{H}_{5}$. - Eugenol occurs in clove and pimento oil. When sections containing either of these oils are treated with a concentrated solution of potassium hydrate, long columnar or needle-shaped crystals of potassium caryophyllate are produced. When sections of cloves are used, they often become covered by the forming crystals.

Fats and Fatty Oils.- These are insoluble in cold and hot water, and, with the exception of castor oil, hardly soluble in alcohol, but readily soluble in ether, chloroform, benzol, ethereal oils, aceton and wood spirit. They make a spot on paper which does not disappear, as in the case of ethereal oils. Most fats and fatty oils are colored brown or black by I per cent. osmic acid. When a drop of fat or fatty oil is placed on a glass slide in a drop of a mixture of equal parts of concentrated potassium hydrate and ammonia, the oil becomes saponified, and may assume a form like a bunch of grapes, or it may be partly or wholly changed into clusters of soap crystals. Vapor of hydrochloric acid has been used to distinguish between ethereal and fatty oils. A large and a small glass ring, such as are used for hanging-drop cultures, are cemented to a glass slide, the small one being shallower than the large one, and placed within it concentrically. Hydrochloric acid is placed into the space between the rings, and the sections to be tested are placed on a coverglass in a drop of glycerine containing a strong solution of sugar.

The coverglass is then inverted and placed on the larger ring. After the vapor of hydrochloric acid has had time to act, any ethereal oil present in the sections will take on the form of bright rellow drops which finally disaplear. Fatty oils do not form 
yellow drops by this treatment. A solution of alcannin colors the fats red, but several hours may be required to accomplish this. A solution of cyanin in 50 per cent. alcohol is also a good stain for fats. The sections will not need to lie in this stain longer than half an hour. If the sections are overstained they may be washed out in glycerine or a concentrated solution of potassium hydrate.

Frangulin, $\mathrm{C}_{20} \mathrm{H}_{20} \mathrm{O}_{10}$ - - This glucoside occurs in the cortex of species of Rhamnus. It forms yellow crystalline masses which are insoluble in water, but soluble in alkalies, which produce with it a cherry-red color. Concentrated sulphuric acid produces with frangulin an emerald-green, which changes into purple, and finally the frangulin dissolves with a dark red color. Water will precipitate it from this solution.

Fungus Cellulose.-The membranes of very few fungi give the reactions of cellulose. The membranes of most fungi are insoluble in cuprammonia, and are colored from yellow to brown by chloroiodide of zinc, sulphuric acid and iodine. Neither do they react in the same manner as suberized and lignified membranes. They are, therefore, considered to be a distinct substance, which is termed fungus cellulose. See also under Chitin.

Gelatinous Sheaths.-The homogeneous gelatinous sheaths which cover the entire outside of certain algæ-notably, species of Spirogyra and Zygnema-may be demonstrated by the use of certain stains and other substances, such as India ink, which may become deposited in the sheaths. Aqueous solutions of vesuvin, methyl-violet and methylene-blue will stain both the cell-walls and gelatinous sheaths, but the latter with less intensity. Chloroiodide of zinc will stain the wall without affecting the sheaths. Turnbull's blue may be deposited in the gelatinous sheaths in the following manner: A small number of Zygnema filaments, for instance, may be tied together with a thread and placed for about two minutes in a 2 per cent. solution of ferrous lactate, then quickly washed in water, and transferred to a 0.2 per cent. solution of ferricyanide of potassium. A small amount of 'Turnbull's blue will then be deposited in the gelatinous sheaths. 
This process should be repeated several times, until the deposit of Turnbull's blue is sufficiently dense to cause the sheaths to stand out quite sharply. By this method very instructive doublestains may be achieved with algæe which have been growing in a dilute solution of Congo-red (see under this head in the last chapter), which stains the cell-walls, but not the gelatinous sheaths. See also in the last chapter under India Ink.

Globoids. - The globoids found in aleurone grains consist of a double phosphate of calcium and magnesium, which is insoluble in alcohol and dilute potassium hydrate, but is soluble in dilute mineral acids and in acetic, oxalic, and tartaric acids. In an ammoniacal solution of ammonium phosphate the globoids are replaced by groups of crystals of ammonium-magnesium phosphate. Treated with ammonium oxalate, they become replaced by crystals of calcium oxalate. The globoids may be isolated to a certain extent by extracting the oil from sections of endosperm containing them by means of alcohol or alcohol and ether, and then dissolving the ground substance and crystalloid by means of a I per cent. potassium hydrate. If crystals of calcium oxalate are present along with the globoids, they may be distinguished by means of the polarizer, since they are doubly refractive, while the globoids are not.

Glucose, $\mathrm{C}_{6} \mathrm{H}_{12} \mathrm{O}_{6}$.-This carbohydrate occurs in sweet fruits and in the leares and other members of plants, being one of the most common forms in which carbohydrates circulate within the plant. The warty crystals of glucose which are deposited from aqueous and alcoholic solutions at low temperatures melt at $86^{\circ}$, and become free from water at $110^{\circ} \mathrm{C}$. At from 30 to $35^{\circ} \mathrm{C}$. glucose crystallizes from concentrated solutions in water, ethyland methyl-alcohol in the form of hard crusts, which melt at $146^{\circ}$ C. The presence of glucose may be easily demonstrated in the fruit of the pear, for instance, and in the leaves of Balsamina, or other rather translucent leaves which have been cut from the parent plant and kept fresh under a bell-jar for several days. Pieces of the flesh of a ripe pear may be put into a test-tube with Fehling's solution and brought to a boil, when a reddish precipi- 
tate of cuprous oxide will be thrown down. This reaction is characteristic of dextrose, maltose, lactose, lærulose and many glucosides. In this instance, however, we are dealing with dextrose. This reaction may also be carried out on the microscope slide. Sections from the pear three or four cell-layers thick should be placed on the slide in a few drops of the solution, the coverglass should then be put on, and the solution heated until bubbles begin to arise. The microscope will then reveal the granular precipitate of cuprous oxide within the cells. Portions of the leaf of the Balsamina may be treated on the slide as directed for the sections from the pear. See under Fehling's Solution and Copper Acetate in the last chapter.

Glucosides.--See page I80, and under Amygdalin, Betulin, Datiscin, Frangulin, Hesperidin, Indican, Potassium Myronate (under Myrosin), Phloridzin, Ruberythric acid, Rutin, Salicin, Saponin, Solanin, Syringin.

Glycogen, $\mathrm{C}_{6} \mathrm{H}_{10} \mathrm{O}_{5}$. - This is a colorless, amorphous, highly refractive substance occurring quite commonly in the cells of fungi. It is soluble in water, but within the cells it may be stained a reddish-brown by means of iodine.

Gums.-These are amorphous, transparent substances which dissolve in water more or less completely and form a sticky solution. They may be precipitated from their aqueous solutions by alcohol. Those gums which dissolve in water completely, such as the gum of the cherry, apricot, peach, and gum arabic, are called true gums, while those which contain cellulose and are not completely soluble in water are known as mixed gums. Gum tragacanth is an example. One of the most striking characteristics of gums which may be used in their identification is their great capacity to swell in water. To follow the process of swelling with the microscope, sections should be cut from dry material with a razor which may be wetted with alcohol, but not with water. The sections should be placed on a slide in a drop of strong alcohol, the coverglass should be put on, and a drop of water placed on the slide so that it just touches the edge of the coverglass. As the water mixes with the alcohol and comes in con- 
tact with the section a slow swelling of the gum will begin, which may be followed very accurately through the microscope. For directions for staining see under Mucilage, and for making permanent preparations of sections containing mucilages and gums see under Boracic Acid in the last chapter.

Hemicelluloses.--These are carbohydrate reserve materials which are deposited as additions to the cell-walls in the endosperm of seeds and in wood parenchyma and wood-fibers. By means of enzymes they may be converted into gums and sugars, in which forms they may be transported to those parts where growth is taking place. The hemicellulose or reserve cellulose in the endosperm of the date seed acts like ordinary cellulose in being colored blue by chloroiodide of zinc and in dissolving in cuprammonia. The reserve cellulose in the endosperm of the seeds of Lupinus luteus is not dissolved in cuprammonia, and does not assume a blue color when treated with chloroiodide of zinc.

Hesperidin, $\mathrm{C}_{21} \mathrm{H}_{26} \mathrm{O}_{12}$. - This glucoside occurs dissolved in the cell-sap of many plants. It may be precipitated from its solution in the cell-sap by means of alcohol. The precipitate is in the form of crystals, which are colorless or slightly yellow, and are doubly refractive, so that they may be studied to good advantage by means of the polarizer. Hesperidin is also precipitated on the drying up of the cell-sap. The crystals of hesperidin are insoluble in cold and boiling water, alcohol, ether, benzine and dilute acids, but they are soluble in solutions of caustic potash and soda, and in ammonia, yielding a yellowish color to the solvent. Hesperidin may readily be obtained for study in the unripe fruit of the orange and in the epidermal cells of Capsella bursa-pastoris. Hesperiden may become deposited in the form of sphærocrystals, when the tissues containing it have lain for some time in strong alcohol or glycerine, acting in this respect similarly to inulin. The constituent acicular crystals of the hesperidin sphærites can be more easily distinguished than those of inulin, and when the hesperidin sphærites are treated with a drop of $\alpha$-naphtol, and then with two or 
three drops of concentrated sulphuric acid, they dissolve with a yellow color, while, with like treatment, inulin sphærites dissolve with a violet color.

Indican.- The glucoside indican is a substance of the consistency of syrup, and of a yellewish or brownish color. It is found in Isatis tinctoria, Phajus grandifolius, and in other indigo-bearing plants. When tissues containing indican are exposed to the air, they may take on a blue color due to the conversion of the indican to indigotin, which may be precipitated in alcohol in the form of small, tubular, bluish crystals. To demonstrate the presence of indican, tissues containing it should be placed under a bell-jar and over a dish of absolute alcohol. After standing exposed to the vapor of alcohol for twenty-four hours, the tissues will be colored blue by the indigo blue which will have been formed from the indican. A piece of moistened filter-paper should be placed under the bell-jar to keep the tissues from drying.

Inulin, $\mathrm{C}_{12} \mathrm{H}_{20} \mathrm{O}_{10^{\circ}}$-- Inulin is a carbohydrate which occurs dissolved in the cell-sap of many plants, particularly among the Compositæ. It may be deposited from its solution in the cell-sap by means of alcohol. To study the sphærocrystals of inulin, pieces of dandelion or Dahlia roots should be placed in $5^{\circ}$ per cent. alcohol for a week or more, and then thin sections should be prepared and examined in a drop of the alcohol under the microscope. The sections should not be placed in water, since the crystals of inulin are soluble in it. The sphærites will appear applied to the walls of the cells as shown in Fig. 98. When the alcohol is replaced by water which is then heated over a flame, the sphærites will dissolve. If sections containing inulin sphærites are treated with a 20 per cent. solution of $\alpha$ naphtol, and then 2 or 3 drops of concentrated sulphuric acid are added, the sphærites will be seen to dissolve with a violet color. Inulin does not reduce Fehling's solution.

Leucin, $\mathrm{C}_{5} \mathrm{H}_{10} \mathrm{HN}_{2}$. COOH.-Leucin belongs to the amidocompounds. It has been found in the etiolated leaves of Paspalum elegans and Dahlia variabilis, and associated with as- 
paragin in seedlings of various Leguminosæ, particularly in those of Lupinus. Leucin crystallizes in thin plates, which are lighter than water and have the appearance of mother-of-pearl. If sections containing leucin are carefully heated on a slide under a coverglass to a temperature of $170^{\circ} \mathrm{C}$., the coverglass will become covered with minute, scale-like crystals, which are doubly refractive and may be studied to advantage by means of the polarizer. The crystals of leucin may also be obtained if sections are treated with alcohol under a coverglass, and the alcohol is then allowed to slowly evaporate.

Leucoplasts.-For methods of fixing and staining leucoplasts, see in the last chapter under Acid Fuchsin, Gold Chloride, and Picronigrosin.

Lignified Membranes.-Lignified membranes are distinguished from cellulose membranes by their insolubility in cuprammonia, and by being colored from yellow to brown by iodine or chloroiodide of zinc. One of the most reliable tests for lignified membranes will be found in the last chapter under Phloroglucin. Aniline sulphate is also a good test for lignified membranes. The sections are first mounted in a drop of a concentrated solution of aniline sulphate, and then this is replaced by a drop of concentrated sulphuric acid. By this treatment lignified membranes are stained a golden yellow.

Lipochromes.-These are yellow and red pigments which are for the most part dissolved in fatty substances within the cells, and which are colored blue by sulphuric or nitric acid, and green by potassium iodide-iodine.

Magnesium.-To demonstrate the presence of magnesium within plant tissues, sections are placed on the slide in a drop of a solution of sodium phosphate or sodium-ammonium phosphate, and a little ammonia is added. In the presence of magnesium, crystals of ammonio-magnesium phosphate are then formed, which have a coffin-lid form. When the ash of tissues containing magnesium is treated as abore, the crystals are apt to form in $\mathrm{x}$ - or $*$-shaped groups.

Maltose.-Maltose is a sugar which is produced from starch 
by the action of diastase. Maltose reduces Fehling's solution, but only about two-thirds as much as does grape-sugar (dextrose, glucose.)

Morphine, $\mathrm{C}_{17} \mathrm{H}_{19} \mathrm{NO}_{3}+\mathrm{H}_{2} \mathrm{O}$. - This was the first alkaloid to be extracted pure and studied. It is the chief alkaloid in opium obtained from the latex of Papaver somniferum. When the latex containing morphine is treated with potassium iodide-iodine, a reddish-brown precipitate is produced, with potassium-bismuth iodide a reddish-orange, and with potassiummercuric iodide a yellowish-white, precipitate, while phosphomolybdic acid produces a yellow precipitate. A solution of 5 drops of methylal in $\mathrm{r}$ c.c. of concentrated sulphuric acid gives a violet color to latex containing morphine. Codeine, $\mathrm{C}_{18} \mathrm{H}_{21}$ $\mathrm{NO}_{3}$, associated with morphine in opium, has essentially the same color reactions. On treating opium infusion with ammonia, morphine is precipitated and codeine is left in solution.

Mucilages (see also under Gums).-Mucilage contained in sections of plant tissues may be differentiated by staining with methylene-blue. Place the sections in a deep blue solution of methylene-blue in equal parts of alcohol, glycerine, and water. This operation may be done on the glass slide. The staining will soon be completed and the sections will then be ready for examination under a coverglass. If the sections are taken from fresh materials, the razor should be moistened with alcohol. Dry materials should be soaked in water to soften for cutting. If it is found that the mucilage dissolves too much in the water, the mucilage may be hardened and the tissues scftened at the same time in the lead acetate solution described under Gums.

Mustard $\mathrm{Oil}, \mathrm{C}_{3} \mathrm{H}_{5} \mathrm{CNS}$.--Seeds and the vegetative organs of the Cruciferæ, Resedaceæ, Capparidaceæ, Tropæolaceæ, and Lemnanthaceæ contain peculiar nitrogenous glucosides which become decomposed into sulphur-bearing substances. long known as mustard oils, by means of the enzyme myrosin.

Myrosin. Iyrosin is an enzyme occurring in certain specialized cells in the seeds and other parts of many Cruciferæ. etc. The cells containing myrosin are stained a deep red by 
Millon's reagent, while the surrounding cells may be stained a pale rose color. When sections containing myrosin are heated in a concentrated solution of hydrochloric acid which contains a drop of a 10 per cent. aqueous solution of orcin in each cubic centimeter, a violet color is produced in the cells containing the myrosin. Myrosin produces allylic mustard oil from potassium myronate, a glucoside which occurs in the parenchyma cells which are associated with those containing myrosin.

Narceine, $\mathrm{C}_{23} \mathrm{H}_{27} \mathrm{NO}_{8}+{ }_{3} \mathrm{H}_{2} \mathrm{O}$. - This is an alkaloid occurring associated with morphine in the latex of Papaver somniferum. When a yellow color follows the addition of methylal to the latex, the presence of narceine is indicated.

Narcotine, $\mathrm{C}_{22} \mathrm{H}_{23} \mathrm{NO}_{7}$.- An alkaloid associated with morphine in opium. Sodium selenate produces with it an orangered color.

Nicotine, $\mathrm{C}_{10} \mathrm{H}_{14} \mathrm{~N}_{2}$. - The alkaloid occurs in most species of Nicotiana, especially in $\mathrm{N}$. 'Tabacum. It has not been found outside this genus. When sections containing nicotine are treated with potassio-mercuric chloride, a yellowish-white precipitate is produced. Phospho-molybdic acid gives, with nicotine, an abundant yellow precipitate. In the presence of nicotine mercuric chloride produces a white, and platinum chloride a yellow, precipitate, while potassium iodide-iodine causes first a carmine-red color and finally a reddish-brown precipitate, which gradually bleaches out.

Nitrates.-When nitrates are present in a solution. a drop of barium chloricle added to a drop of the solution will produce a precipitate of octahedral crystals of barium nitrate. See also under Diphenylamine in the last chapter.

Nucleus. - The nucleus can best be demonstrated in tissues which have been fixed according to the directions given under Fixatives in the last chapter. Also under Iodine-green and Acetic Acid, and Methyl-green and Acetic Acid, are given directions for instantly fixing and staining nuclei. The three-color method of staining detailed on page 264 gives the best results for the dividing nucleus. 
Oils.-Ethereal and fatty oils have already been discussed under separate heads, where the methods for distinguishing between the two will be found. See also in the last chapter under Alcannin, Cyanin, and Osmic Acid.

Oxalic Acid.-When calcium nitrate is added to sections containing oxalic acid, crystals of calcium oxalate are formed. With uranyl acetate crystals of uranium oxalate are formed in tissues containing oxalic acid. The crystals are rhombic, of rectangular form, and when large, appear of a yellow color, and, being doubly refractive, they may be studied to advantage with the polarizer.

Paragalactan.-This occurs as a thickening of the cell-walls in the cotyledons of Lupinus luteus. When it is heated with nitric acid, mucic acid is formed, and when heated with dilute sulphuric acid, galactose, $\mathrm{C}_{6} \mathrm{H}_{12} \mathrm{O}_{6}$, and a pentaglucose are formed. When heated with phloroglucin and hydrochloric acid, a cherry-red color is produced. Paragalactan is not dissolved by cuprammonia, and is stained slightly or not at all by chloroiodide of zinc.

Paramylum.-Paramylum grains are flattened, cylindrical, stratified bodies occurring in the bodies of the Euglenæe and in the cysts of Leptophrys vorax. The paramylum grains are hardly affected by water, alcohol, ether, nitric acid, or concentrated chromic acid; and while they are hardly soluble in 5 per cent. potassium hydrate, they are easily soluble in a 6 per cent. solution. They may also be dissolved in concentrated sulphuric acid. They are not stained by iodine, chloroiodide of zinc, or by any of the organic coloring matters.

Pectic Compounds.--The pectic substances (pectin, pectose, and pectic acids) are widely distributed in the membranes of plants. Pectose occurs associated with cellulose in the membranes of embryonic tissues, where it is distributed throughout the entire thickness of the membrane. Pectose also occurs in most lignified, suberized, and cutinized membranes. The middle portion of cell-walls-the so-called middle lamellaconsists, for the most part, of calcium pectate. When thin 
sections of plant tissues are treated for several hours with a mixture of I part of hydrochloric acid and 4 parts of alcohol, the calcium pectate becomes changed, so that pectic acid is liberated and calcium chloride is formed. The pectic acid is insoluble in water, but is soluble in a 10 per cent. solution of ammonia, so that after rinsing the sections in water and treating with the ammonia solution, the cells may be separated from each other by a slight pressure on the coverglass. When the sections are placed for a considerable time in cold alkaline solutions, a double pectate is formed which swells in cold water and finally dissolves in it. After the calcium pectate of the middle lamella has been remored, the pectose which permeates the cell-wall still remains, but by treatment with cuprammonia it may be removed from sections which have already been acted on by dilute hydrochloric acid. The pectic substances may be stained only in neutral or slightly acid solutions. For this reason it is a good plan to place sections for a short time in a 3 per cent. solution of acetic acid, and then to wash them in water before transferring them to the staining solutions. Safranin, methylene-blue, bleu de nuit, and ruthenium-red are excellent stains for pectic substances. Safranin stains the protoplasts and the lignificd, subcrized, and cutinized cell-membranes a cherry-red, while the pectic compounds are stained orange-yellow. Methylene-blue and bleu de nuit stain the protoplasts and the lignified membranes blue, and the pectic substances a violet color. See also in the last chapter under Ruthenium-red.

Pezizin.-Pezizin is an orange-red coloring matter which occurs in solution within the paraphyses of Peziza aurania and P. convexula. It is soluble in alcohol and ether, and is not altered by alkalies and organic acids. It dissolves without color in hydrochloric acid and is colored bright green by nitric acid.

Phloridzin, $\mathrm{C}_{21} \mathrm{H}_{24} \mathrm{O}_{10}$ - - A glucoside occurring in the leaves and in the cortex of the roots and stems of the Pomacee. When tissues of Pirus malus containing phloridzin are treated with ferric chloride, a dark brown solution is formed, while treatment with ferrous sulphate causes a yellowish-brown precipitate. 
The tissues of the pear, cherry, and plum are apt to contain large amounts of tannins which produce a green color with salts of iron, and so mask the phloridzin reaction.

Phloroglucin, $\mathrm{C}_{6} \mathrm{H}_{3}(\mathrm{OH})_{3}$ - - This occurs in solution in the cell-sap. To demonstrate its presence treat previously dried sections with a solution prepared by dissolving $0.005 \mathrm{gm}$. of vanillin in $0.5 \mathrm{gm}$. of alcohol, and adding $0.5 \mathrm{gm}$. of water and $3 \mathrm{gm}$. of concentrated hydrochloric acid. When phloroglucin is present, this solution produces a light red color.

Phosphoric Acid, $\mathrm{H}_{3} \mathrm{PO}_{4}$ - - This can be best demonstrated in the ash. The ash is dissolved in hydrochloric acid and the solution is eraporated to dryness; then the residue is treated with ammonium molybdate, which, if phosphoric acid is present, produces a precipitate of ammonium phospho-molybdate, the crystals of which have a greenish-yellow color under the microscope. If the presence of phosphoric acid is to be sought for in fresh tissues, sections should be heated in a drop of ammonium molybdate on the glass side. This method also produces a precipitate of crystals of ammonium phospho-molybdate in the presence of phosphoric acid. If ammonium tartrate is present in the tissues, ammonium molybdate does not serve so well as a test for phosphoric acid. In such a case a solution should be used, consisting of 25 volumes of a concentrated aqueous solution of magnesium sulphate, 2 volumes of a concentrated aqueous solution of ammonium chloride, and 15 volumes of water. With phosphoric acid this solution produces a precipitate of ammonio-magnesium phosphate the crystals of which are frequently formed in $\mathrm{x}$ - and $*_{\text {-shaped clusters. }}$

Phycoerythrin.- The red coloring matter in the Floridex or red algæ. It is soluble in fresh water, leaving chlorophyll behind in the plastids, while in ether the chlorophyll is extracted and the phycoerythrin is left.

Phycocyanin.--The blue coloring matter in the blue-green algæ. It is soluble in cold water, glycerine, and alkalies, giving a blue solution with red fluorescence. It is insoluble in alcohol and ether. 
Phycophæin.--The brown coloring matter of the brown alga. It is soluble in fresh water and more readily in hot water, leaving chlorophyll and carotin behind in the plastids. It is insoluble in strong alcohol, ether, etc.

Piperine, $\mathrm{C}_{17} \mathrm{H}_{19} \mathrm{NO}_{3}$.-Piperine is an alkaloid occurring in the fruit of the Piperacex, and notably in black pepper, and it has not been found outside this family. Very thin sections may be rubbed out somewhat under a coverglass to press out the ethereal oil, which will then evaporate and leave the piperine to crystallize in the form of minute short needles. A section becomes of a deep red color when treated with concentrated sulphuric acid, while with nitric acid an orange color is produced. When sections are moistened with sodium molybdate, and then treated with concentrated sulphuric acid, they take on a blue color. Piperine is easily soluble in acetic acid.

Proteids (Albuminoid Substances).-Proteids are stained from yellow to brown by a dark solution of potassium iodideiodine. The dilute solution of iodine recommended for starch should not be used, for proteids are stained less readily than starch. Millon's reagent (see under this head in the last chapter) colors proteids a brick-red color. If the solution is old and has lost its efficiency, a few drops of a solution of potassium nitrate will probably restore it. Concentrated nitric acid colors proteids yellow, and the addition of ammonia produces a still deeper yellow. When sections lie for an hour or two in a solution of $\mathrm{I} \mathrm{gm}$. of sodium phospho-molybdate in $90 \mathrm{gm}$. of distilled water and $5 \mathrm{gm}$. of nitric acid, which has been filtered after standing for several days, the proteid substances appear in the form of yellowish granules. A concentrated solution of nickel sulphate colors proteid granules yellow or bluc. When rather thin sections are placed in a concentrated solution of copper sulphate for about half an hour, and then are placed in water for about an hour, and then are transferred to a concentrated solution of potassium hydrate, proteids are colored red or violet, which becomes deeper when the solution in which the sections are lying is heated somewhat. The pepsin-glycerine and pan- 
creatin-glycerine ferments prepared by Dr. G. Grübler in Leipzig are solvents of proteids. Sections are treated for an hour at a temperature of $40^{\circ} \mathrm{C}$. with a mixture of I part of pepsinglycerine and 3 parts of water, to which is added 0.2 per cent. chemically pure hydrochloric acid. Pancreatin-glycerine is employed in the same manner as the pepsin-glycerine.

Protein Crystalloids.-Under Aleurone in this chapter are given methods for differentiating crystalloids in aleurone grains. Protein crystalloids also occur in the cytoplasm, nucleus, and chromatophores, and in all of these cases the crystalloids have essentially the same nature, but they may vary considerably in form. For staining crystalloids, see also in the last chapter under Acid Fuchsin.

Protoplasm.-The protoplasm of the cell can be studied to advantage by means of the microscope only after being killed and fixed by such reagents as those formulated under Fixatives in the preceding chapter. The different constituents of the protoplasm can then be differentiated by means of stains or by means of digestive ferments, such as pepsin and pancreatin. Iron hæmatoxylin, or a combination of fuchsin and iodine green, or of safranin, gentian violet, and orange $G$, are specially to be recommended for differentiating the different parts of the protoplasm. For staining the leucoplasts and chromatophores in general, see under Acid Fuchsin, page 302.

Protoplasmic Connections.-The protoplasmic connections between the plates of sieve tubes may be strongly stained by acid fuchsin and aniline water (see page 302). More delicate protoplasmic connections require the use of a swelling agent for their demonstration. Sections of fresh material may be fixed with a solution of $0.05 \mathrm{gm}$. of iodine and $0.2 \mathrm{gm}$. potassium iodide in I $5 \mathrm{gm}$. of water, and then the iodine should be replaced by chloroidide of zinc, which should be allowed to act for about I 2 hours. At the end of this time the membranes traversed by the protoplasmic connections will be swollen to greater or less extent, so that the chloroiodide of zinc may be washed out in water and the sections stained by acid fuchsin and aniline water. 
as already suggested. Sulphuric acid may be used instead of the chloroiodide of zinc as the swelling agent. For demonstration purposes sections through the endosperm of the Gramineæ, or tangential sections through the green bark of Rhamnus frangula, may be used. Sections are placed on a coverglass in a drop of sulphuric acid. After a few seconds the acid is washed away by immersing the coverglass and moving the sections about in at dish filled with water. 'I'he sections remain in the water for only a short time, and are then to be stained in an aqueous solution of aniline blue, washed in water, and mounted for examination in dilute glycerine. Or the sections may be stained in a saturated solution of picric acid in 50 per cent. alcohol, to which aniline blue is added until the solution has a blue-green color.

Pyrenoids.--The pyrenoids may be simultaneously fixed and stained by placing the material in a concentrated solution of picric acid in 55 per cent. alcohol, to a watch-glass of which is added about 5 drops of the acid fuchsin and aniline water solution described on page 302 . The material should remain for about 2 hours in a watch-glass of this solution. It should then be washed for a quarter of an hour in alcohol and mounted for examination in dilute glycerine. If permanent mounts are clesired, the material should be placed in a watch-glass of dilute glycerine, which should then be allowed to concentrate in a place free from dust. The material should finally be mounted in glycerine-jelly. The material may be mounted in Canada balsam by transferring it from the alcohol in which it was washed to successively stronger solutions of balsam in xylol until the ordinary solution used for mounting is reached.

See under Dahlia in the previous chapter for other methods of treating pyrenoids.

Reserve Cellulose.--Those hemicellulose thickenings of cell-walls in seeds, etc., which are essentially reserve food materials, and are made soluble by diastatic ferments, and employed as food material in the germination of seed, are known as reserve cellulose. Sections taken from a sprouted date seed and treated 
with potassium hydrate and stained with alizarine show the inner layers of the cell-walls which have been acted on by the diastase unstained, while the outer layers which have not yet been affected by the diastase are stained an intense riolet. If Congo-red is used instead of the alizarine, the intact layers are scarcely stained, while the layers which have come under the influence of the diastase are stained a dark red. See under Henicellulose.

Resin.-When sections containing resin are treated for some time with a tincture of alcannin, the resin assumes a red color. When sections from tissues which have lain for about a week in a concentrated aqueous solution of copper acetate are examined under the microscope, the resin will be seen to be colored an emerald green.

Ruberythric Acid, $\mathrm{C}_{26} \mathrm{H}_{28} \mathrm{O}_{14^{-\cdots}}{ }^{-}$This glucoside occurs in the roots of Rubia tinctorium, and is the chief constituent of the madder dye obtained from the roots of this plant. It gives a yellow color to the cell-sap of the young roots; the cell-walls of old roots, however, have absorbed it and are colored by it. It is colored a purple-red by potassium hydrate, and an orange color by acids. In dry roots it takes on the form of red flakes, and in the injured cells of fresh material it assumes the same form. It may be extracted by alcohol from its yellow solution in uninjured tissues, but in the red flake form it is not dissolved by alcohol.

Rutin, $\mathrm{C}_{42} \mathrm{H}_{50} \mathrm{O}_{25}$.- This glucoside is widely distributed in plants. It crystallizes from an aqueous solution in the form of minute light yellow crystals. The yellow cclor of straw is, in part, due to it. When treated with ammonia or lime-water. rutin forms a deep yellow solution, which turns to brown on exposure to the air.

Salicin, $\mathrm{C}_{13} \mathrm{H}_{18} \mathrm{O}_{7}$.- Salicin is a glucoside which occurs in particular abundance in the cortex of many poplars and willows. It may be dissolved by water, but more readily by boiling water. by aqueous solutions of alkalies, and by acetic acid. It is insoluble in ether. It crystallizes in the form of needles, scales. 
or thin plates. It is colored by concentrated sulphuric acid, and, on the addition of a little water, a red powder is thrown down in the sulphuric acid solution.

Santalin.-Santalin is the coloring matter of the red sanclalwood, Pterocarpus santalinus. It is insoluble in water, but is soluble in ether with a yellow color, and with 80 per cent. alcohol it gires a blood-red solution. Stronger alcohols give the same result. It is also soluble in acetic acid and in aqueous alkaline solutions.

Saponin, $\mathrm{C}_{19} \mathrm{H}_{30} \mathrm{O}_{10^{\circ}}$ - This glucoside occurs in solution in the cell-sap of many Leguminosæ. Quillaja saponaria contains in the bark 2 per cent. of saponin. It is easily soluble in water and is precipitated from solution by the addition of strong alcohol. When treated with a mixture of equal parts of alcohol and sulphuric acid, a yellow color is produced which soon changes to red, and later to violet. If it is then treated with a concentrated solution of chloride of iron, a brown or bluishbrown precipitate is formed, the intensity of the bluish color increasing with the amount of saponin present.

Seminose.--Seminose is one of the products resulting from the hydrolysis of hemicellulose by sulphuric acid. It is dextrorotary, reduces Fehling's solution, and is fermentable.

Silica, $\mathrm{SiO}_{2}$.- Silica occurs in the skeletons of diatoms, and as incrustations over the epidermis of the Equisetacee and Graminea. It also sometimes occurs in masses in the interior of cells. It may be isolated from the organic matter with which it is associated by burning over a flame bits of epidermis incrusted by it, or diatoms, which are placed in a drop of concentrated sulphuric acid on a piece of platinum foil. By this treatment the organic matter will be destroyed, and the silica will remain behind as a pure white ash. The silica may also be obtained pure by placing bits of tissues incrusted by it in a drop of concentrated sulphuric acid, and then after a time adding 20 per cent. chromic acid, and following this with additions of still stronger chromic acid until a considerable strength has been reached, and, finally, washing in water and alcohol. Silica is distinguished by being 
insoluble in all the acids excepting hydrofluoric acid. Silicious skeletons may be removed from diatoms by placing the latter in hydrofluoric acid which is contained in a platinum ressel. 'The ressel should be kept on a water-bath, and the diatoms should remain in the acid for 24 hours. At the end of this time the acid should be thoroughly washed out from the diatoms. On examination with the microscope, the diatoms will then be found to have lost their silicious skeletons. In some instances a thin exterior membrane which is stained brown by iodine is to be observed; but in other instances this membrane has been a too insignificant part of the skeleton to retain its identity after the removal of the silica.

Sinapine, $\mathrm{C}_{16} \mathrm{H}_{32} \mathrm{NO}_{5}$. - This is an alkaloid occurring in the seeds of the white mustard. When sections of these seeds are placed in a concentrated solution of potassium hydrate, they assume a yellow color, which changes to orange on warming. 'This reaction loses some of its value, howerer, from the fact that a glucoside called sinalbine also occurs in the seeds of the white mustard and turns yellow on the application of potassium hydrate.

Solanin, $\mathrm{C}_{28} \mathrm{H}_{47} \mathrm{NO}_{14}+\mathrm{H}_{2} \mathrm{O}$. - This glucoside occurs in the tissues of Solanum tuberosum, in the berries of Solanum nigrum and S. Dulcamara, and in many other species of the Solanacer. To demonstrate its presence, sections should be placed in a mixture of I part of ammonium vanadate and I,000 parts of a mixture of 98 parts of sulphuric acid with 36 parts of water. This produces with solanin a yellow color, which changes successively into orange, purple-red, brown, red-orange, carmine-red, raspberry-red, and blue-riolet. The color then passes into a grayish-blue and disappears. With concentrated sulphuric acid solanin assumes a yellow color, which changes to red, and then riolet, and then passes into gray and disappears.

Starch, $\mathrm{C}_{6} \mathrm{H}_{10} \mathrm{O}_{5}$.--A solution of potassium iodide-iodine stains starch from pale violet to purple, depending on the strength of the iodine solution. Chloroiodide of zinc stains starch-grains purple. and at the same time swells them. A solution of chloral 
hydrate and iodine dissolves the protoplasmic cell-contents and stains included starch-grains purple. This reagent is particularly adapted to demonstrate the presence of starch in chloroplasts or amyloplasts. The bleaching effect of the chloral hydrate is so great that starch may be demonstrated in whole leares by the chloral hydrate and iodine reagent. For the further treatment of starch with reagents, see in the preceding chapter under Eau de Javelle, Calcium Nitrate, Diastase, Methyl-violet, Silver Nitrate. For the structure of starchgrains, see page 177 .

Strychnine, $\mathrm{C}_{21} \mathrm{H}_{22} \mathrm{~N}_{2} \mathrm{O}_{2}$. - This alkaloid occurs associated with brucine in the seeds of Strychnos nux vomica, S. multiflora, and S. Malaccensis. When sections containing strychnine are treated with a solution of $\mathrm{I} \mathrm{gm}$. of ammonium vanadate in roo c.c. of sulphuric acid, they quickly take on a violet-red color, which after a time changes to brown. If sections of the seeds of Strychnos nux vomica are treated with sulphuric acid containing an excess of ceric sulphate, the walls of the cells are colored a bluish-riolet. The sections must have been previously treated with petroleum ether and absolute alcohol to remove the fatty oils, grape-sugar, and brucine. The reagent should be applied immediately before the observation is to be made. If sections are treated with concentrated sulphuric acid, and crystals of potassium bichromate are then added, a violet color is produced.

Suberin and Suberized Walls.-Suberized walls are stained green when treated for about an hour in the dark by a freshlyprepared strong solution of chlorophyll. A cold concentrated solution of potassium hydrate colors suberized walls yellow. When the potassium hydrate is heated yellow drops and granular masses are formed. When suberized walls are heated in a solution of potassium chlorate in nitric acid, they become changed into droplets which melt between $30^{\circ}$ and $40^{\circ} \mathrm{C}$., and which are soluble in hot chloroform, alcohol, ether, benzol, or dilute potassium hydrate. At ordinary temperatures concentrated chromic acid solutions have little effect on suberized walls. A 
solution of potassium iodide-iodine, and chloroiodide of zinc colors suberized membranes from yellow to brown. After long treatment with a dilute solution of potassium hydrate, suberized membranes may be stained violet with chloroiodide of zinc. Alcannin stains suberized walls red. Under the polariscope suberized walls are seen to be doubly refractive. They lose this property on heating and regain it on cooling. It may be deduced from this that the constituents of the walls are in part, at least, in crystals which are melted by heat, but reappear on cooling. See under Methyl-blue and Cyanin.

Syringin.-Syringin is a glucoside occurring in the cortex, and to a certain extent in the xylem and medullary rays of Syringa vulgaris, Robinia pseudacacia and species of Ligustrum. It is especially abundant in early spring. Sections containing syringin, when treated with concentrated sulphuric acid, acquire a dark blue color, which changes to violet. Nitric acid dissolves syringin with a blood-red color. Syringin crystallizes from aqueous solutions in the form of colorless, needlelike crystals which are grouped in the form of a star. The crystals are dissolved with difficulty in cold water, but readily in boiling water or in alcohol.

Tannins.-Various substances occurring in plants having an astringent taste, and turning dark blue or green with salts of iron, are termed tannins or tannic acid. Tannins occur in greatest abundance in the bark and in pathological gall formations. Oak-galls furnish excellent material for the demonstration of tannins. When sections are treated with an aqueous solution of ferric chloride, they take on a deep blue color, due to the presence of tannin. Aqueous solutions of ferrous sulphate give the same result. If the reaction is watched under the microscope, it is noticed that at first a deep blue precipitate is formed, which soon dissolves and imparts its color to the surrounding fluid. When sections are placed in a ro per cent. aqueous solution of potassium bichromate, a flocculent reddishbrown precipitate is formed in the tannin-bearing cells. When sections are placed in a concentrated solution of ammonium 
molybdate in concentrated ammonium chloride, the same character of precipitate is produced as when potassium bichromate is used. Lead acetate produces a white precipitate with tannins. 'The following method may be employed: Sections are placed in a 7 per cent. solution of copper acetate for about a week or longer, and are then placed on a slide in a drop of a 0.5 per cent. solution of ferrous sulphate. After a few minutes, and before the cell-walls begin to turn brown, the sections are washed in water and transferred to a watch-glass of alcohol to drive out air-bubbles and extract chlorophyll, if any is present. The sections are then mounted in glycerine for examination under the microscope. By this treatment an insoluble brown precipitate is produced in the presence of tannins. The sections may be transferred from the glycerine to glycerine-jelly if permanent mounts are desired. If the sections are taken from the alcohol in which they are placed to remore the chlorophyll, etc., and placed in a solution of iron acetate, a blue or a green color will be produced, according to the kind of tannin present. If it is desired to fix the cell-contents while testing for tannins, the sections should be placed in a concentrated alcoholic solution of iron acetate instead of in the aqueous solution, as above. When living tissues are placed in a solution of I part of methyleneblue in 500 parts of distilled water, those cells which contain tannins take on a blue color, and later a decp blue precipitate is formed in these cells. Cells containing phloroglucin act in the same way to this reagent as those containing tannins.

Theobromine, Dimethyl-xanthin, $\mathrm{C}_{7} \mathrm{H}_{8} \mathrm{~N}_{4} \mathrm{O}_{2}$ - - This alkaloid occurs in the cocoa-bean and in different parts of several species of Theobroma. Its presence may be demonstrated by the use of hydrochloric acid and chloride of gold, as directed under Caffeine. The reactions for caffeine and theobromine are sometimes difficult to distinguish. When sections containing theobromine are heated in distilled water on the slide to the boiling-point, and the sections are allowed to dry slowly, and a drop of benzol is added to the residue, crystals of theobromine appear in the form of a fine powder on the evaporation 
of the benzol; whereas, when sections containing caffeine are treated in like manner, the crystals containing caffeine take on the form of needles.

Tyrosin, $\mathrm{C}_{6} \mathrm{H}_{4} \mathrm{OH} . \mathrm{CH}_{2}$. $\mathrm{CHNH}_{2}$. COOH.-Tyrosin may be demonstrated in abundance in the tubers of the Dahlia. When sections are mounted under a coverglass in glycerine for several days, needle-shaped crystals of tyrosin are deposited in radiating groups. In an abundance of glycerine the crystals are not deposited, for the reason that the tyrosin becomes too much diffused through the glycerine. The crystals appear brownish by transmitted, and white by reflected, light. When a portion of a Dahlia tuber is placed in a dish of about the same size as itself, and covered for about two-thirds of its length with alcohol, an abundance of tyrosin crystals will collect at the exposed cut surface. 'The crystals of tyrosin are colored a deep red by means of Millon's reagent, and when nitric acid is poured over them and then evaporated, a yellow residue is left.

Vanillin, $\mathrm{C}_{6} \mathrm{H}_{3}$. OH.OCH $\mathrm{H}_{3}$. CHO.-The aldehyde ranillin occurs abundantly in the dry, but not in the fresh, pods of Vanilla. It is often found in a crystalline condition on the surface of dried pods. It is soluble in alcohol and ether, and to a certain extent in hot water, but it is soluble with difficulty in cold water. When sections containing vanillin are wetted with a 4 per cent. solution of orcin, and then treated with concentrated sulphuric acid, they take on a deep carmine-red color; and when they are treated. in like manner with a solution of phloroglucin in place of the orcin, a brick-red color is produced. It seems probable that vanillin is always present in lignified walls, judging from the colors which these assume with phloroglucin and orcin.

Veratrine, $\mathrm{C}_{37} \mathrm{H}_{53} \mathrm{NO}_{11}$. - The alkaloid veratrine occurs in the tissues of Veratrum album. When sections are placed in a mixture of I drop of concentrated sulphuric acid and 2 drops of water on a glass slide, and examined under a microscope, it is to be seen that the walls or cell-contents of the cells containing veratrine assume a yellow color, which soon changes to an orangered, and finally to a dusky violet. 
Wax.-Wax frequently occurs in plants as a crust-like, or granular, or rod-like layer over the cuticle. It consists of fats and free fatty acids, together with other substances. Wax is insoluble in water, but it will melt and form droplets in water at $100^{\circ} \mathrm{C}$. It is hardly soluble in cold alcohol, but will quickly dissolve in boiling alcohol. When sections containing wax are heated in a solution of alcannin in 50 per cent. alcohol, the wax runs together in droplets, which become stained red by the alcannin. Wax is not wetted by water, and sections are best mounted for study in cold alcohol, which will dissolve the wax but little, if at all.

Wound Gum.--The wounded surfaces of deciduous trees become protected by the formation of wound gum from starch contained in the live cells. Sections taken through the wounded surfaces of such plants several days after the wound has been inflicted show brownish granules of wound gum in the medullary rays, tracheal tubes, and wood-cells. The wound gum may be found lying free in the cytoplasm, or surrounding starch grains which have contributed to the formation of the gum. Wound gum is not soluble in warm water, but may be dissolved in hot nitric acid or in eau de Javelle water after several hours. It is not soluble in sulphuric acid, potassium hydrate, alcohol, or ether, but it may be dissolved in alcohol after treatment for a few minutes with a solution of potassium chlorate in dilute hydrochloric acid. It may be stained with a solution of fuchsin, iodine green. safranin, or methyl-green. It is stained red by phloroglucin and hydrochloric acid.

Xanthine, $\mathrm{C}_{5} \mathrm{H}_{4} \mathrm{~N}_{4} \mathrm{O}_{2}$. - Xanthine occurs in an amorphous condition or in the form of granules in yellow chromoplasts. It differs from carotin in being soluble in alcohol, and in being deposited in amorphous and resin-like masses on the evaporation of its solvent. It is but little soluble in ether and benzine. Some varieties of xanthine are soluble in water while others are not. It becomes green and then blue when treated with sulphuric acid, and with potassium iodide-iodine it is colored green. 


\section{CHAPTER NVIII}

\section{DETECTION OF ADULTERATIONS IN FOODS AND DRUGS}

How to Begin.- The microscope is indispensable to the detection of adulterations in powdered foods and drugs, and the enforcement of our pure food laws will require men skilled in the application of the microscope to this kind of research.

Before proceeding with the microscopic examination of a powder a knowledge is necessary of the histology of the plant part which is supposed to constitute the powder. If, for example, powdered cinnamon is to be investigated, the different kinds of cinnamon barks on the market must be obtained for study, from a reliable source, and these must be examined in cross and longitudinal sections and in powdered form. The directions that will now be given for the study of cinnamon bark will serve for dried barks and woods in general. The bark is hard and brittle and will need to be put in better condition for sectioning. Place in warm water and let it soak over night, and then transfer it to equal parts of alcohol, glycerine, and water and let it remain there for two weeks-the longer the better. It can then be sectioned free-hand (see page $25 \mathrm{I}$ ), while held between two pieces of cork free from grit; or it can be sectioned in a sliding microtome (Fig. I 4 ). Keep the knife wet with 70 per cent. alcohol and transfer the sections to a watch-glass of water. Mount the sections for the first study in a drop of dilute glycerine. Water would do but it may evaporate before the examination is completed. If it is found that the thinnest sections are too opaque to make the cells out clearly they may be remounted in a drop of saturated chloral hydrate solution. In this case or in any other where the material has become dry and brown if the chloral hydrate does not clear the sections well enough they 
may be left over night in hydrochloric acid ro parts and water 90 parts and then remounted in chloral hydrate. This clears up very refractory subjects. Sce also page 293 .

When the sections are in condition to show all of the cells clearly make camera lucida drawings (see page 280) from both cross and longitudinal sections, showing groups of cells from each tissue to compare with similar drawings from the powder under investigation. This method of comparison is much more reliable than one in which the drawings are not made. If the full length of the bast fibers cannot be seen in the sections the fibers can be isolated by the methods for maceration given in Chapter XVI under Maceration.

Employment of Microchemistry.-Having thus become acquainted with the different tissues mount a section in chloral hydrate jodine (see page 292) to bring out clearly any starch that may be present. This reagent dissolves proteids and swells the starch-grains and colors them blue so that they can easily be seen even when very minute and previously obscured by the cellcontents. Drawings had better be made of the starch grains, but since they are swollen in the chloral hydrate other sections mounted in potassium iodide-iodine (see page 3II) should be used for the drawings. Other sections should be tested for aleurone (page 330), gums (page 348), mucilage (page 352), resins (page 360 ), and tannins (page 364 ).

The nature of the cell-walls is next to be tested. Mount sections in chloroiodide of zinc (page 292), and stone cells, bast fibers, and cork cells should be colored yellow; and the walls of other tissues should be purple, indicating cellulose. Mount sections in phloroglucin (page 324 ), and bast fibers and stone cells only will be colored pink; while other sections mounted in aniline sulphate (page 287) will have yellow bast fibers and stone cells and all other tissues unstained. Phloroglucin and aniline sulphate, since they stain only lignified walls, are of especial value in sharply differentiating stone cells, bast fibers, and wood fibers and the tracheal tissues from all other tissues.

Finally the sections are to be studied with a polariscope (page 
282) to bring out minute crystals that would otherwise escape detection.

Having studied sections of cinnamon bark in this manner one is prepared to recognize the different tissues in the state of powder. Grind the bark in a perfectly clean mill or with a pestle and pass it by shaking, and not pressure, through the series of fine sieves $20,40,50,60$, 80, of the U. S. Pharmacopœia. The bark should be ground to the degree of fineness that results in the same amount of residuum on each sieve as results from an equal weight of the powder whose purity is under investigation. Any fragments too large to pass through sieve 50 will need further pulverization before their cell-elements can well be made out under the microscope.

The authentic and questionable powders are now to be compared under the microscope. Take equal amounts of each powder of the same degree of fineness and shake them up in equal small quantities of water 2 parts and glycerine I part; and while still in agitation mount a drop of each of these mixtures under coverglasses of equal sizes. The object is to compare the two powders under as like conditions as possible.

From both preparations make camera lucida drawings of the different cells and cell-contents as they lie in the field, so that by a comparison of the sizes, shapes, frequencies, etc., of the elements of the two preparations it may be determined whether foreign substances are present in the powder under investigation.

If it proves that the tissue fragments of the powders are too opaque to allow the shapes and sizes of the cells and the thickness and markings of the walls to be made out with certainty the powders should be first bleached by the hydrochloric acid and chloral hydrate treatment recommended above for the sections.

By the abore method, while the forms of the cells and the characteristics of their walls are plainly revealed, there may be certain cell-contents, such as some classes of proteids, that will have gone into solution, and the powders should be further compared by stirring them up and mounting them in a mixture of 
castor oil I part and 95 per cent. alcohol 2 parts that has been slightly colored with eosin. This will preserve the form of proteid cell-contents and stain them pink.

Various adulterants have been detected in ground cinnamon: wood and leaves from the cinnamon tree, sawdust from darkcolored woods, ground nutshells, and foreign barks, oil cakes, various cereal products browned to the color of cinnamon, such as bread or biscuit, and ground millet. The presence of cereals will be apparent from the foreign starch, and nutshells will be revealed by the large percentage of stone cells; and any adulterant will cause a marked difference in the camera lucida drawings of the two preparations.

Sometimes ground cinnamon contains cinnamon bark from which the essential oil has been extracted, and then the powder may have the same appearance under the microscope as that made from the unextracted bark, except that the starch-grains will have become swollen and broken in the process of distillation.

If it is found desirable the powders may be treated with any or all of the reagents recommended for cinnamon bark, and in doing so it would be advisable to make a fresh mount directly into each reagent employed.

Determining the Source of the Adulterant.-Of course the possible sources of adulteration are innumerable, but it may be taken for granted that those things will be chosen which are the cheapest and most available, and which at the same time afford the least opportunity for detection. Of all adulterants the hardest to detect are those which have no well-pronounced anatomical characteristics, or those that can be considered adulterants only because some of their useful substances have been extracted from them, as when ground cinnamon from which the oil has been extracted is mixed with the ground unextracted bark. And adulterants easiest to detect are those that contain an abundance of characteristic starch-grains, such as that from potato and corn, or a large amount of stone cells, as when cocoanut and other nutshells are employed. 
Kinds of Adulterants Commonly Employed.-In seeking out the fact and source of adulteration under the microscope it will be of great assistance to know what kinds of adulterants have already been found most commonly in use. A list of these will now be given.

Adulterants of Ground Coffee.-Roasted rye, barley, and barley malt, ground peas, beans, and other legumes, pea hulls, and cereals made into pulp with molasses; ground grape seeds, dried, roasted, and ground figs, ground date stones, and coffee already used in making coffee extract.

Adulterants of Ground Spices. - The list of adulterants here is a long one. Both inorganic and organic substances a re employed. The inorganic adulterants are: brick dust, coal ashes, calcium sulphate and carbonate, sand and clay, chrome yellow, and Venetian red. And the organic adulterants are: hulls and bran of buckwheat, bran and chaff of cereals, flour, mill screenings, peas, beans, and other legumes, cottonseed and linseed meal, ground cocoanut cake, and other oil cakes, ground shells of the cocoanut, almond, and other nuts, ground olive stones. sawdust of red sandalwood and of other woods, and dyestuffs.

Black pepper has been adulterated more than any other spice. In it has been found almost any variety of waste material capable of being reduced to powder. Sometimes when the amount of adulteration has been so great as to remove the natural pungency very perceptibly cayenne pepper has been added.

The study of adulteration in spices should be undertaken as suggested above for ground cinnamon. When the source of the spice is in seeds, as in the case of mustard and black pepper, sections of seeds can be obtained by soaking the seeds in water and embedding them in glycerine gum, as described on page 306 . The seeds can then be sectioned free-hand or in a sliding microtome.

Adulterants of Wheat Flour.-Corn flour and gypsum. The starch of the corn flour is quickly detected by the angular shape of the grains and the central cracks which are seen with especial clearness in alcohol. For the detection of gypsum 
see under Calcium Sulphate on page 338. The presence of an inorganic adulterant would be apparent in flour treated with a solution of iodine where the starch and proteids would be stained and the inorganic matter would be left uncolored.

Adulterants of Buckwheat Flour.-Wheat flour and corn flour. The characteristic starch-grains in each would reveal the presence of the adulterant.

Adulterants of Jams, Marmalades, and Preserves.-Pulp of turnip, beet, apple, figs, pumpkin, and watermelon; starch paste, gelatine, agar-agar, grass seeds to imitate seeds of berries. Adulterants in this class are sometimes very hard to detect, partly because of the materials having been macerated by cooking, and partly because of the scarcity of characteristic elements. Pure fruits raw and cooked, of which the jams, etc., are claimed to be made, should be studied under the microscope, and the probable adulterants should be studied in the same way. Employ aniline sulphate and phloroglucin to bring out lignified walls. Dilute some of the suspected product with water, allow it to settle and study the residue under high powers, when the presence of silicious diatom skeletons would indicate the presence of the seaweed agar-agar.

Adulterants of Canned Tomatoes.-Pulp of carrots, turnip, sugar beet, coal tar dyes.

Adulterants of Sweet Chocolate.-Wheat flour, cornstarch, peanut meal, peas, acorns, arrowroot, and cocoa shells.

Adulterants of Tea.--Tea is sometimes colored with Prussian blue, indigo, turmeric, soapstone and gypsum. Black tea is sometimes coated with plumbago. Under the microscope plumbago can be made out by its shining, glossy appearance, Prussian blue by its transparent, light blue particles, and indigo by its greenish-blue particles. The color of Prussian blue is removed by sodium hydroxide while that of indigo is not.

The leaves of the following plants have been used as tea adulterants: Lithospermum officinale, Epilobium angustifolium, E. hirsutum, Salix sp., Fraxinus sp., Sorbus aucuparia, Morus alba and nigra, Coffea Arabica, Camellia Japonica. Prunus 
spinosa and avium, Rosa canina, Fragaria vesca, Spiræa ulmaria, Wistaria Sinensis.

It will be seen that in most of these cases the fact of adulteration would be casily detected by the skilled microscopist, but the source of adulteration could not be told without a preliminary knowledge of the histology of the adulterant, and a knowledge more intimate than could be obtained from pictures and descriptions. It is clearly necessary for the investigator to get a first-hand acquaintance with the possible adulterants.

Estimating the Percentage of Adulteration.-In some instances it is possible to make a very close approximation of the percentage of adulteration. Having determined the fact and the source of adulteration, make preparation of different and definite percentages of adulteration and compare them with the sample under investigation for the relative frequencies of some of the characteristic elements of the adulterant, such as starch-grains, bast fibers, stone cells, hairs, etc. If these elements are few the total number in the field of view may be counted; but if their frequency makes this impossible the count may be made in a definite portion of the eyepiece micrometer. It is very important in doing this that the material in all cases be evenly distributed under the coverglass, and that a medium power objective be used, in fact as low a power as will serve in identifying the different elements, in order that the reliability of the results may be increased by a comparison of the larger areas which the lower powers embrace. An equal distribution of the material under the coverglass can be approximated by giving the coverglass a gyrating motion under gentle pressure of the forefinger covered with a clean cloth. 


\section{INDEX}

Absorption, 17

affect of temperature, etc., on, 95

by aerophytes, 96

of water and minerals, 90

of water, different methods of 9 s

Adulterations of foods and drugs, 308

Adulterant, determining source of, $37 \mathrm{I}$

estimating percentage of, $37+$

Adulterants of buckwheat flour. 373

of canned tomatoes, 373

of ground coffee, 372

of ground spices, 372

of jams, marmalades and preserves, 373

of sweet chocolate, 373

of tea, 373

of wheat flower, 372

Aerating system, reason for, 124

Aerial root, cross section of, Fig. 45

Aerophytes, absorption by, 95

Albumins, I 82

Albumoses, i 82

Aleurone grains, I 8 I

Allium, cross section of root of, $3+$

Amides, I 82

Amygdalin, I 80

Amyloid, 179

Amylose, varieties of, 177

Aniline oil, $28_{7}$ sulphate, 287

Annual growth, ring of, 51, Fig. 25

Antheridium, 2 I 8

Anthocyanin, 10

Antipodal cells, 229

Apposition, growth by, I 6

Archegonium, 2 I 8

Aristolochia, secondary growth in, Fig. 24

stem of, Fig: 23

tissues of, Fig. 23

Ascent of water, power concerned, I $\mathbf{I}$
Ascomycetes, I 2

nuclear division in, I 2

Asparagin, I\& 2

Assinuilation, 193

Balsain, $28_{7}$

Bast fibers, $32,75,77$

development of, diagram, 33

how adapted to their function, 78

in corn stalk, Fig. 39

in palm sten, Fig. to

in monocotyledons, 78

length of, 78

Benzol, 287

Bicollateral bundle, 43

Bleeding, I 68

Borke, 55

Border parenchyma, I +5

Bordered pits, position of in pine wood, 108, Fig. 52

Cambirum, 24

cork, 27

fascicular, $2 \mathrm{~s}$

interfascicular, 28

origin of, 4 I

Camera lucida, drawing from, 280

Carbon dioxide, necessity of, I 23.

Carbohydrates, relation of to ni-

Carotin, 10 trogenous foods. 154

Cell-division, Io

Cell, application of, I discovery of, I origin of term, 1

Cellulose, reserve, 170

Chloroplasta, $8, I_{4} 0$

Chromoplasts, 8

Chromosomes, io paternal and maternal, $23+$

Collenchyma, 75,76 development of, diagranl, 33

Companion cells, 36 , I 58

Coniferin, I 8 I 
Cork, 60

as protective tissue, 70

as waterproof covering, 70

cambium, 27,54

in healing wounds, $7 \mathrm{I}$

Cornstalk, growth in thickness of, 57

cross section of stem of, 57

Cortex, growth in thickness of, 54

primary, $2+30$

various applications of name, 30

secondary, 55

Crystalloids, I 82

Cuticle, 29

Cutting sections, $25 \mathrm{I}$

with microtome, 25.3

Cystolith, 30, 207

Cytase, I 02

Cytological methods, 257

Cytoplasm, 5

Dextrine, 78

Diastase, 192

Differentiation of tissues, $2+$

Digitalin, I 8 I

Digestion of stored food, I $9 \mathrm{I}$

Digestive ferments, 191 glands, I 93

Dionæa, r9o

Diosmosis, I 33

Diplotaxis Harra, Fig. +8

Dominant characters, 23 I

Dracæna, growth in thickness of, 58 cross section of stem of, 58

Drawing to scale, 278

Drosera, i 90

Ectoplasm, 2

Egg apparatus, 229

$$
\text { cell, } 229
$$

fertilization of, 2 I 8

Elaioplasts, I 85

Emulsin, I 92

Endodermis, 34

Endosperm, 230 nucleus, 229

Energy from the sun, $4_{4} 2$ sources of, 155 supply, I 94

Engelmann's method, $\mathrm{I}+2$

Enzyme-secreting cells, 205

Enzymes, I 9 I

Epidermis, 24. 28

as protective tissue, 62

as waterproof covering, $6+$

cell contents of, 66

chloroplasts in, 20)
Epidermis, cutinization of outer walls of, 65

different forms of cells of, 29

efficiency of, 64

excretions from, 67

under different environments, 65

frequency of radial walls of, 63 multiple, 26,28

outgrowths from, 67

radial and inner walls of, 66

Equisetum, incrustations of silica

Euglena,

$$
\text { on, } 63
$$

Excretion, is

Excretions, nature of, I 99

Fascicular cambium, 28

Fats, I 78 , as reserve food, 179

Fatty oils, 178

Ferns, spore-formation in, 2 I 5

Ficus elastica, leaf of, $1+7$ cystoliths in, 30 multiple epidermis of, 30

Fixatives, 259

Fixing process, 258

Fleshy roots, tubers, etc., growth in thickness of, 59

Food, assimilation of, 193

carried by phloem, i 59

character of, in transport, $I_{7} 2$

course of, from leaf, i 60 , ing

distribution, course of, I 63

kinds used for storage, 170

relation of, to energy supply, 194

sources and uses of, I 38

storage, need of, I 75

synthesis of, without light, I 52 transport, propelling power in, I 72

Food-building apparatus, I 40

Food-conducting tissues, annual additions to, 170

Fundamental meristem, 24, 2;

Gametophyte, 2 i 8

Gases, motive power in distribution of, $13+$

Girdling, significance of, In I

Glands, 200

Glands, digestive, I 03

Gliadin, I 82

Globoids, I 82

Globulins, I 82

Glucosides, i 80

Glutamin, Is 2 
Glutenin, I $_{2} 2$

Glycerine and glycerine jelly, mounting sections in, 209

Grapevine, bleeding of, $\mathrm{I}$ os

Ground meristem, 24, 26, 27 substance, I $\mathrm{S}_{2}$

Growth, zo

in diameter of Monocotyledons, in thickness, Fig. 22

unusual, 57

primary and secondary, $t^{6}$

time of cessation of, 107

Hairs, different forms of, Fig. 33 stinging, 07

Hardening process, 260

Hereditary characters, bearers of, 235

Heterozygote organisms, 230

Homozygote organis nis, 239

Hybrids, 23 I

inosaic offspring of, 24 I

Hydatodes, 209

Ids, 230

Imbedding in paraffin, $20 \mathrm{I}$, in celloiclin, 260

Indian corn, homozygote strains of, $2+7$

method of improvement of, $2+7$

structure of leaf of, $I_{4} 8$

Indican, I S I

Intercellular spaces, distribution of, I 3 I

formation of $13 \mathrm{I}$

kinds of, 132

purposes served by, 124

Interfascicular cambium, 28

Inulase, I 92

Inulin, 179

Invertase, I 92

Lævulose, I 78

Laticiferous ressels, 203

Leaf, architecture of, $1+6$ relation of, to photosynthesis, $\mathrm{I}+\mathrm{t}$

Leaves, relation of, to annual growth, 52

vascular bundles in, +4

Lenticel, 55, I 30

Leucin, 182

Leucoplasts, 8

Lipases, 192

Lysigenous intercellular spaces,
Male nuclei, 220

Maltase, I $)_{2}$

Mangrove, epidermis of. os

Medulla, $2+$ development of, + I

Medullary rays, frequency of, 102 , I 88

primary, 24

secondary, to

Megaspores, formation of, 227

Mendel's Laws, $2+2$

apparent exceptions to, $24+$ practical application of, $2+2$ results, interpretation of, 233

Meristems, 25,26, 27 primary, 24 secondary, $2 \mathrm{~S}$

Mesophyll, I +5

Micellæ, I 6

Microchemistry, employment of, 369

Microscope, use of, $27 \mathrm{I}$

Mills tubes, 203

Minerals, secretion and excretion of, 207

Mistletoe, thickness of epidermis of, 62

Nonocotyledons, bast fibers in, 78 growth in thickness of, 50 procambium in, 26

Nounting paraffin sections, 203

Mucilage, is I

Multiple epidermis, $20,30,68$

Myrosin, 102

Myxomycete, I 9

Nepenthes, ro6

Nägeli's micellar hypothesis, It

Nuclear division, details of, 223 interpretation of, 2 I 8

Nucleins, I 82

Nucleus, 0

Nymphæa odorata, epidermis of, Fig. $3 \mathrm{I}$

Oak wood, cross section of, Fig. 36

Osmosis, o+

Oxygen, necessity of, to plants, I 2.3

Palisade cell, work of, $1+3$ parenchyma, $I+5$

Palm stem, cross section of, Fig. to skeleton in, 80

Pangeneic interchange, theory of, 230

Pangenes, 236

Parenchyma, 32

Paraffin sections, mounting, 263 
Pectase, I 92

Pedigree cultures, necessity of, 2 to hybrids, behavior of, $23 \mathrm{r}$

Perception, 19

Pericycle, 24 in roots, 35 topography of. 35

Periderm, 5t

Phelloderm, 54

Phellogen, 27,54 in roots, 50

Phloem, 24 as food carrier, 159 constitution of, 36 parenchyma, 30, I 58 relation of, to other tissues, i 02 relation of one vear's elements to those of the next, $17 \mathrm{I}$ secondary, + I

Photosynthesis, I $t^{\circ}$ conditions affecting, I 48 in lower plants, I 50

Pine wood, cellular structure of, Fig. 52

course of water in, Figs. 53. 54.

Pith, 24

$$
55,50
$$

development of, 4 I

Plasma, I membrane, description of, 3 selective action of, 92

\section{Plastids,}

Polariscope, use of, 282

Polar nuclei, 220

Poplar, cross section of mood of, $8 \mathrm{I}$

Potassium myronate, 18 I

Primary cortex, 24,30 endosperm nucleus, 229

Primordial meristem, 24, 26

Primary permanent tissues, 27,28 vascular bundle, 30

Procambium, 24, 20

Protection by bast fibers, stone cells and collenchyma, 72

from injuries and loss of water, $6 \mathrm{I}$

Protective tissues, diagram of, Fig. 35

Proteolytic ferments, 192

Protoderm, 24,26

Proteids, I 8 I

Protoplasm, I

Protoplast, I

description of, 2

etymology of, I

powers of, I 7

Pyrus Japonica, epidermis of, Fig. 3 I
Reagents, use of, $28_{3}$

Recessive characters, 23 I

Reproduction, 2 I 3

Reserve cellulose, I 79

Respiration, aerobic, I 23 anaerobic, 123

Ring of annual growth, 5 I, I I O relation of, to growth in length, I 12

to the leaves, I 13

Root, cross section of, 34 hairs, 90, 9 I

diagram of, Fig. +2

excretions from, 93

parts of, Fig. 44

Roots, growth in thickness of, 53 in the soil, 90

vascular bundles in, 53

Russian olive, epidermis of, Fig. 31

Saccharose, i 78

Schizogenous intercellular spaces, 202

Sclerenchyma, 32

Secondary cortex, 55

increase in thickness, to

meristems, 28

permanent tissues, 28

xylem and phloem, $4 \mathrm{I}$

Secreting cells and glands, 200

Secretions, nature of, 199

Secretion, rocess of, 208

Section cutting, $25 \mathrm{I}$ with microtome, 253

knife, care of, 255

Sections, kinds of, 253

Sexuality, significance of, 246

Sieve parenchyma, 37

tubes, 36,158

contents of, 37

length of time active, I 72

Silica, incrustations of, 63

Skeleton, making of, 76

frogressive development of, Fig. 4 I

in leaves, 86

topographV of, $8_{3}$

Soil particles, Fig. 43

Solanin, I 8 I

Solutes, distribution of through leaf, int

method of intake of, 94

Spermatophytes, spore-formation in, $22 \mathrm{I}$

Sperm nuclei, 229

Spongy parenchyma, 145

Spore-formation, 2 I 6

Spores, germination of, 2 I 7 
Sporophyte, 2 I 8

Staining sections, 264,268

Starch, I 76 grains, forms of, I $S_{5}$

sheath, 34

Steapsins, I 92

Stele, 25

Stinging hairs, 67

Stomata, action of, I 27

function of, I 26

relation of, to environment, I 29

structure and frequency of, I 25

use of, in transpiration, I 28

Stone cells, $32,75,8 \mathbf{I}$

develowment of, diagram, 33

different forms of, $\mathrm{S}_{2}, \mathrm{Fig} .{ }_{3} \mathrm{~S}$

Storage, I 75

of water, 195

process of, $\mathrm{I}_{2}$

tissues, characteristics of, 187

location and extent of, 187

Stored food, fluctuations in physical character of, 190

Suberin, 68

Suberization, 69

Synergids, 220

Tannin cells, 205

Tillandsia usneoides, 97, Fig. 47

Tissues, differentiation of, 24,25

primary, diagram of, 3 I

topouraphy of, 3 I

Tracheal tube, development of, 38

tissues as food carriers, 160 duration of activity of, I I I relation of, to medullary rays and wood larenchyma, I IO

tubes, 102

course of, through stem, 103 in mono- and dicotyledons, Figs. 49, $5^{\circ}$

Tracheid, development of, 39

Tracheids, ion

bordered pits in, development of, Fig. 5 I

Transporting system, IOI

tissues, 157

Triple-fusion nucleus, 230

Turpentine, 109
Tubercle bacilli, I 54

Tyrosin, 182

Ulothrix, io

Unit characters, $2+$ I

dominance of, $2 .+2$

recombinations of, $24^{2}$

segregation of, $2+2$

Urtica, sting hairs of, 67

Vascular bundle, 24

primary, 36 , types of, 43

bundles, anastomosis of, 42

growth of, to

in leaves, +4 constitution of, 164

in roots, 53

Vegetative nucleus, 229

Veins, frequency of, I $4+$

Velamen 96, Figs. 45,40

Water absorption, different methods of, 98

ascent of, I 16

distribution of, through leaf, I 14

method of intake of, 94

path of ascent of, I 8

storage of, I 95

Water-conducting tissues, influence of enviromment on, I I 8

Water-storage tissues, $I_{4} 8, I_{4} 9$

characteristics of, I 96

Wood fibers, 79

development of, 39

length of, 79

Xanthin, Io

Xylem, 24

constitution of, 38

figure showing stages in development of, 40

parenchyma, development of, 3)

secondary, $4 \mathrm{I}$

Yeast, culture of, 23 


1 



